Routledge Studies in Contemporary Pbilosopby

\title{
TOWARDS A PHILOSOPHICAL ANTHROPOLOGY OF CULTURE
} NATURALISM, RELATIVISM, AND SKEPTICISM

\section{Kevin M. Cahill}
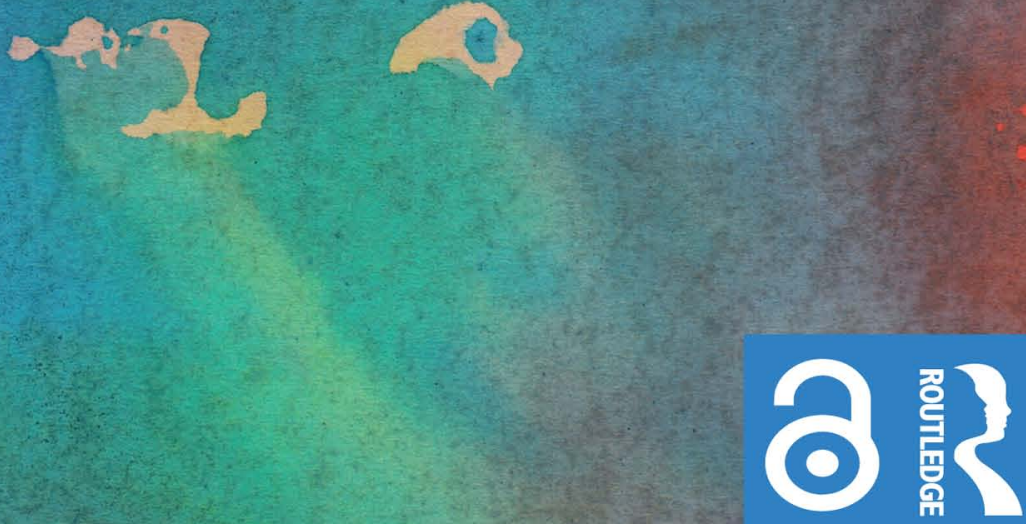


\title{
Towards a Philosophical Anthropology of Culture
}

\begin{abstract}
"Anyone interested in the relationship between naturalism and relativism in the philosophy of social science or the philosophy of culture should read this insightful and original book."
\end{abstract}

- David G. Stern, University of Iowa

This book explores the question of what it means to be a human being through sustained and original analyses of three important philosophical topics: relativism, skepticism, and naturalism in the social sciences.

Kevin M. Cahill's approach involves an original employment of historical and ethnographic material that is both conceptual and empirical in order to address relevant philosophical issues. Specifically, while Cahill avoids interpretative debates, he develops an approach to philosophical critique based on Cora Diamond's and James Conant's work on the early Wittgenstein. This makes possible the use of a concept of culture that avoids the dogmatism that not only typifies traditional metaphysics but also frequently mars arguments from ordinary language or phenomenology. This is especially crucial for the third part of the book, which involves a cultural-historical critique of the ontology of the self in Stanley Cavell's work on skepticism. In pursuing this strategy, the book also mounts a novel and timely defense of the interpretivist tradition in the philosophy of the social sciences.

Towards a Philosophical Anthropology of Culture will be of interest to researchers working on the philosophy of the social sciences, Wittgenstein, and philosophical anthropology.

Kevin M. Cahill is Professor of Philosophy at the University of Bergen, Norway. He works mainly on Wittgenstein's philosophy and philosophy of the social sciences. His publications include The Fate of Wonder: Wittgenstein's Critique of Metaphysics and Modernity (2011) and Wittgenstein and Naturalism (Routledge, 2018). 


\section{Routledge Studies in Contemporary Philosophy}

Toleration and Challenges to Liberalism

Edited by Johannes Drerup and Gottfried Schweiger

The Philosophy of Reenchantment

Edited by Michael Meijer and Herbert De Vriese

Caring for Liberalism

Dependency and Liberal Political Theory

Edited by Asha Bhandary and Amy R. Baehr

Language and Phenomenology

Edited by Chad Engelland

The Philosophy and Psychology of Ambivalence

Being of Two Minds

Edited by Berit Brogaard and Dimitria Electra Gatzia

Concepts in Thought, Action, and Emotion

New Essays

Edited by Christoph Demmerling and Dirk Schröder

Towards a Philosophical Anthropology of Culture

Naturalism, Relativism, and Skepticism

Kevin M. Cahill

Examples and Their Role in Our Thinking

Ondřej Beran

Extimate Technology

Self-Formation in a Technological World

Ciano Aydin

For more information about this series, please visit: www.routledge.com/ Routledge-Studies-in-Contemporary-Philosophy/book-series/SE0720 


\title{
Towards a Philosophical Anthropology of Culture \\ Naturalism, Relativism, and Skepticism
}

\author{
Kevin M. Cahill
}


First published 2021

by Routledge

52 Vanderbilt Avenue, New York, NY 10017

and by Routledge

2 Park Square, Milton Park, Abingdon, Oxon, OX14 4RN

Routledge is an imprint of the Taylor \& Francis Group, an informa business

(C) 2021 Kevin M. Cahill

The right of Kevin M. Cahill to be identified as author of this work has been asserted by him in accordance with sections 77 and 78 of the Copyright, Designs and Patents Act 1988.

The Open Access version of this book, available at www. taylorfrancis.com, has been made available under a Creative Commons Attribution-Non Commercial-No Derivatives 4.0 license.

Trademark notice: Product or corporate names may be trademarks or registered trademarks, and are used only for identification and explanation without intent to infringe.

Library of Congress Cataloging-in-Publication Data

Names: Cahill, Kevin M. (Professor of Philosophy), author.

Title: Towards a philosophical anthropology of culture : naturalism, relativism, and skepticism / Kevin M. Cahill.

Description: New York, NY : Routledge, 2021. I Series: Routledge studies in contemporary philosophy I Includes bibliographical references and index.

Identifiers: LCCN 2020045005 (print) I LCCN 2020045006 (ebook) I ISBN 9780367637156 (hardback) I ISBN 9781003120841 (ebook)

Subjects: LCSH: Philosophical anthropology. I Wittgenstein, Ludwig, 1889-1951. I Naturalism. I Skepticism. I Relativity. I Social sciences-Philosophy. I Culture-Philosophy.

Classification: LCC BD450 .C2236 2021 (print) I LCC BD450 (ebook) I DDC 128-dc23

LC record available at https://lccn.loc.gov/2020045005

LC ebook record available at https://lccn.loc.gov/2020045006

ISBN: 978-0-367-63715-6 (hbk)

ISBN: 978-1-003-12084-1 (ebk)

Typeset in Sabon

by Apex CoVantage, LLC 
To philosophy's forgotten somewheres 
$\because$ Taylor \& Francis

Taylor \& Francis Group

http://taylorandfrancis.com 


\section{Contents}

Preface and Acknowledgements viii

$\begin{array}{ll}\text { Introduction } & 1\end{array}$

1 Lost in the Ancient City: Pluralist Naturalism and the Philosophy of the Social Sciences

2 The Grammar of Conflict 53

3 Skepticism and the Human Condition 73

Appendix: Wittgenstein's Paganism 163

Bibliography 177

Index 183 


\section{Preface and Acknowledgements}

In the preface to The Fate of Wonder: Wittgenstein's Critique of Metaphysics and Modernity, I singled out Hubert Dreyfus and Cora Diamond for special thanks for much of the philosophical inspiration behind that book. The present work will make evident that I am still much indebted to them, whatever distances there may be between their views and mine. Some of my institutional debts remain unchanged since the time of the publication of the earlier monograph. This is not surprising since, as the Introduction makes clear, much of the work for the two publications overlapped. Thus, thanks once again to the Department of Philosophy at the University of California, Berkeley, where I was a Visiting Scholar for the 2005-2006 academic year; Professor Carla Frecerro, Director of the Center for Cultural Studies at U.C. Santa Cruz, for her hospitality during my stay as Resident Scholar for Winter and Spring Quarters, 2009. I would also like to express my gratitude to Professor Paul Roth, then chair at the Department of Philosophy at U.C. Santa Cruz for being a welcoming host for my research stay as a Visiting Scholar during the Winter and Spring Quarters, 2011. Finally, I owe a special thanks to Professor Mark Risjord at the Department of Philosophy, Emory University, for hosting my stint as a Visiting Scholar for the 2019-2020 academic year. Risjord was generous in the extreme with the time he set aside for philosophical discussions, which I hugely enjoyed and profited from. Finally, I would like to thank my colleague Dr. Rolf Scott of the Department of Social Anthropology at the University of Bergen. In addition to years of lively discussions, there is one incident that deserves special mention. My earliest conception of the third essay in this volume was that it would primarily be an exploration of Cavell's views on skepticism in terms of comparative epistemology. During a presentation of my main ideas for the essay many years ago, Scott pointed out to me that the project would be better framed in terms of the comparative ontology of the subject. This suggestion ended up being a turning point for that work. Much of the Appendix has already appeared as in Mark Bevir and Andrius Galisanka, eds. Wittgenstein and Normative Inquiry (Leiden: Brill, 2016) 174-191. I am grateful to the publisher for permission to reprint this material. 


\title{
Introduction
}

\author{
Kevin M. Cabill
}

\section{An Uneven Start}

The impetus for this book comes from the last chapter of my dissertation, The Moral Dimension of Wittgenstein's Thought, defended at the University of Virginia in August of 2001. In the fourth and final chapter, called "The Disengaged View and 'The Darkness of this Time" ", I argued, based on both textual and extra-textual support, that the remarks on rulefollowing in Philosophical Investigations constituted a kind of cultural critique of modernity qua critique of what Charles Taylor has termed "the disengaged view" of human practice. ${ }^{1}$ Part of my aim there was to make plausible that Wittgenstein saw the problems of Western metaphysics in a substantially historical light. Accordingly, my discussion involved a critique of Stanley Cavell's view that for Wittgenstein, the impulse to skepticism (for Cavell synonymous with metaphysics) is part of the human condition. Especially relevant for the chapter was Cavell's essay "Declining Decline: Wittgenstein as a Philosopher of Culture", where he in effect claimed that by concluding that Wittgenstein saw philosophical problems as primarily rooted in our way of life, historicist oriented commentators such as G.H. von Wright had given short shrift to universalist strains in Wittgenstein's anthropology. Von Wright had claimed that for Wittgenstein,

Because of the interlocking of language and ways of life, a disorder in the former reflects a disorder in the latter. If philosophical problems are symptomatic of language producing malignant outgrowths which obscure our thinking, then there must be a cancer in the Lebensweise, the way of life itself. ${ }^{2}$

In reasserting his signature humanist interpretation of Wittgenstein, Cavell distinguished between what he called an "ethnological" or "horizontal" sense of Lebensform in Wittgenstein's work and what he termed a "vertical" or "biological" sense of that expression. ${ }^{3}$ Responding specifically to the previous passage, Cavell writes,

Given my sense of two directions in the idea of a form of life, von Wright's appeal here to "a cancer in the way of life" makes me 


\section{Introduction}

uneasy. "Way of Life" again to me sounds too exclusively social, horizontal, to be allied so directly with human language as such, the life form of talkers. ${ }^{4}$

Without going into detail, in the final chapter from my dissertation I defended a view close to von Wright's by arguing that Cavell had (characteristically, I now think) given short shrift to the "ethnological" or cultural, both in regards to his reading of Wittgenstein and as a philosophical matter more generally.

Unfortunately, soon after handing in the dissertation the embarrassing fact dawned on me that my arguments against Cavell had more or less failed to distinguish between two clearly different questions: 1) Is Cavell's view of Wittgenstein correct? and 2) Is Cavell's view about the relation between metaphysics and human nature correct? (I am probably not the first interpreter of Wittgenstein who has failed to see that questions like these are in fact different.) I have addressed the former question elsewhere. ${ }^{5}$ The years it has taken me to address the latter question are no doubt partly attributable to the special obligations I incurred by moving to Norway immediately after my dissertation defense, but also to the usual pressures to publish. The latter exigency in particular inclined me to stick to writing about what I knew best, i.e. Wittgenstein, rather than taking up new projects. But these externalities only really account for part of the story of why this book has been so long in the making. The truth is, I had also vastly underestimated what was involved in approaching the second question, both as a matter of intellectual difficulty and as a function of anthropological and philosophical trends.

\section{II. “Cultural” Anthropology?}

The original hunch that motivated "Skepticism and the Human Condition" was that there was something implausible with Cavell's claim for the universality of skepticism, both in its everyday and philosophical modes. Even before I had begun my investigation, my untutored intellectual instincts (which admittedly have always inclined towards relativism and anti-realism), inclined me away from such universalism. Once I had liberated my criticisms of Cavell from exegetical questions in Wittgenstein scholarship, the road forward seemed fairly straight: all that remained for me to do was to gather some data by reading some relevant cultural anthropology and then to throw them at Cavell in a way that would undercut his essentialist claim. Naturally, it wasn't that simple.

I had naively assumed that the occasional sympathetic references to concepts such as "thick description" or the "hermeneutic circle" in the writings of some of my early philosophical heroes such as Hubert Dreyfus or Charles Taylor reflected the stature enjoyed by these ideas and their associated thinkers in anthropology generally. Unfortunately, my 
first tentative discussions with colleagues in my university's own Department of Social Anthropology promptly revealed that the state of that discipline was nothing like what I had assumed. For one thing, I quickly learned that the word "culture" was, if not exactly taboo, certainly passé. My initial references in these conversations to interpretivism in general, and to the work of Clifford Geertz in particular, were met with polite frowns and wrinkled noses. ${ }^{6}$ In some cases, it became apparent that this was as much due to politics as to methodology. I recall for instance, being abruptly confronted by a graduate student with the assertion that the interpretivist approach in anthropology was wrong because, and I'm quoting from memory here, thick description "does nothing to help empower marginalized groups". ${ }^{7}$ This early exposure to the activist turn in anthropology turned out to be a harbinger of more to come. The particular episode was also especially off-putting, as I was already familiar with the accusation that Wittgenstein's widely misunderstood declaration that "philosophy can only describe the actual use of language, and leaves everything as it is" was some kind of expression of political reaction. ${ }^{8}$ As things turned out, the activist turn taken by many in ethnography was not the only development of which I was ignorant. There was an apparent rejection of most things German (Critical Theory perhaps excepted) and the embracing of many things French. At one point someone even referred me to Badiou as someone from whom I could learn about the "real" Wittgenstein. My colleagues were gracious and patient with me, but traversing this road took time. I plodded away.

\section{Naturalism}

Shortly after my stumbling start with the anthropologists, I made a hopeful foray into the philosophy of the social sciences. Surely, these philosophers hadn't succumbed to French obsessions. While this was mostly true, here again my philosophical starting point proved to be like relying on an outdated edition of "Let's Go Europe". Once more, my sheltered life in Wittgenstein scholarship had left me unprepared for the real world, such as it was. In particular, after my earliest exposure to the American philosophy of social science community I had the distinct impression that the field had been colonized by a tight-knit cadre of reformed and not so reformed Quineans. The self-assertive scientific naturalism I encountered there, even in its pluralist guises, seemed (almost) as alien to me as references to Deleuze. I was a bit shaken when arguments that invoked the concept of "meaning" were liable to be met with accusations of apriorism or provoke incredulous questions about the role "meaning entities" were supposed to play in the causal structure of nature. ${ }^{9}$ I was also wholly ignorant of the fact that, as a matter of philosophical sociology, naturalism's debate with the Verstehen tradition had long ago 


\section{Introduction}

been relegated to side-show status. It was more unsettling still to discover how culture was routinely depicted in mainstream philosophy of social science textbooks, as though it were a mysterious membrane fabricated by romantic nationalists to envelope imagined islands of history that most likely never existed. It sometimes felt as though the very concept of culture was regarded by mainstream naturalists as an obscurantists' postulate that explained nothing and excused everything. It did no "work".

A further point of frustration for me in this milieu was that any reference to Wittgenstein's thought seemed only to provoke a knee-jerk reaction to Peter Winch, as though nothing of relevance had happened in Wittgenstein scholarship since the appearance of The Idea of Social Science and its Relation to Philosophy in 1958. Further, to the extent that Winch's work was mentioned independently of Wittgenstein, it seemed to serve mainly as a poster boy for what was wrongminded with the interpretivist tradition. Despite finding many problems both with Winch's Wittgenstein interpretation and with some of his own arguments, I had always believed that he had initiated a worthwhile conversation about the relationship between science and the critique of culture. So, it was dispiriting when my former advisor Cora Diamond published several papers roundly attacking some of Winch's most famous conclusions as incoherent. ${ }^{10}$ Worse still, I realized that the substance of her attacks was fundamentally sound.

\section{IV. "Back" to "Wittgenstein"}

Like many narratives, the one I am giving here about the genesis of the three essays in this volume falsifies matters to a certain extent. To understand why Diamond's criticisms of Winch were so decisive not only for my view of Winch but more importantly for how I would go on to use ethnographic material, it will help if I turn "back" to Wittgenstein. The scare quotes are due to the fact that my reading and thinking about anthropology, philosophy of the social sciences, Wittgenstein, and Cavell, far from constituting a continuous progression, instead substantially overlapped in irregular ways. At any rate, in the years immediately after I handed in my dissertation, much of my philosophical attention was taken up by the debates over the so-called "New Wittgenstein", in particular over the merits of the resolute reading of the Tractatus fronted originally by Diamond and James Conant and subsequently elaborated by several other philosophers. ${ }^{11}$ This is not the place to explicate, let alone adjudicate, the many facets of that debate. But one idea that I drew from those discussions is central for each of the three essays included here, and so is worth making explicit. The idea is that we don't know what an a priori criterion of meaning would be. ${ }^{12}$ 
In order to fill in some historical background for this strange sounding claim, consider what Wittgenstein writes at TLP 5.473:

Logic must take care of itself.

A possible sign must also be able to signify. Everything which is possible in logic is also permitted. ("Socrates is identical" means nothing because there is no property which is called "identical". The proposition is senseless because we have not made some arbitrary determination, not because the symbol is in itself unpermissible.) In a certain sense we cannot make mistakes in logic. ${ }^{13}$

\section{At TLP 5.4733 we read further,}

Frege says: Every legitimately constructed proposition must have a sense; and I say: Every possible proposition is legitimately constructed, and if it has no sense this can only be because we have given no meaning to some of its constituent parts. (Even if we believe that we have done so.) Thus "Socrates is identical" says nothing, because we have given no meaning to the word "identical" as adjective. For when it occurs as the sign of equality it symbolizes in an entirely different way - the symbolizing relation is another - therefore the symbol is in the two cases entirely different; the two symbols have the sign in common with one another only by accident. ${ }^{14}$

I take the upshot of these remarks to be that attempting to identify an utterance or string of signs as meaningless or nonsensical out of all context, lands us in a dead end. If we have yet to indicate that the sign "identical" has an adjectival use, then the reason "Socrates is identical" says nothing is not that the already-grasped meaning of the individual word "identical" doesn't fit in the schema "Socrates is x". Rather, things don't even get that far, because outside of any context of use in a proposition, there is as of yet no symbol at all, and so no symbol that fails to fit into anything. There is only an isolated sign, "identical". Lacking any such symbolic adjectival use, the occurrence of "identical" in "Socrates is identical" means that the sign there, in fact the whole string, could mean anything, and so in fact means nothing. Imagining that we have some grasp of what the symbolic use of "identical" might have meant in the schema, even if it couldn't mean anything, in effect requires us to imagine the sense that such a string or utterance made, while simultaneously ruling out that sense as unthinkable. This sort of trick is precisely what Wittgenstein warns against in an oft-cited passage from the book's preface.

The book will, therefore, draw a limit to thinking, or rather - not to thinking, but to the expression of thoughts; for, in order to draw 
a limit to thinking we should have to be able to think both sides of this limit (we should therefore have to be able to think what cannot be thought). The limit can, therefore, only be drawn in language and what lies on the other side of the limit will be simply nonsense. ${ }^{15}$

Much of Diamond's criticism is focused on Winch's 1964 article "Understanding a Primitive Society". Winch argued in that article that practices and forms of discourse are immune to criticism from "outside" of the logically closed world of possibilities that are circumscribed and underwritten by those very same practices. ${ }^{16}$ In particular, he claimed that the person who, from within the confines of his or her own form of life, attempts to criticize the concept of reality internal to an alien grammar, is liable to have committed a category mistake, and thus to have spoken nonsense. This is precisely because, as being different, the grammars are incommensurable. ${ }^{17}$ Such a critic is therefore trying to say something that cannot logically be said. Hopefully, my brief foray into the resolute reading of the Tractatus makes evident that in order to argue that certain kinds of criticism, that is to say certain forms of language use, are logically out of bounds, Winch must take himself to have some grasp of just what is being forbidden, long enough at least for him to see that this impossible something cannot in fact be said. Put in the Tractarian terms just sketched, Winch's argument attempts the equivalent of ruling out a priori an adjectival use of "identical". Now the context of his paper, following as it did his 1958 book, makes it clear that for Winch, it is the later Wittgenstein's thought on grammar that he takes to provide the basis for his argument. Nevertheless, while Diamond's criticisms of Winch do not draw explicitly from her own work on Wittgenstein, and while I believe those criticisms can rather easily be formulated in terms drawn from ways of reading Philosophical Investigations, I think the considerations from Wittgenstein's early work that I have been discussing here not only form the philosophical heart of her critique of Winch, they also bring out clearly why his arguments for the limits of intelligible criticism are unconvincing. Those arguments rely on imagining ourselves as occupying a position where we can discern the limits of a domain of discourse or system of thought based on our taking our current grasp of a system's logical expressiveness for an unspecified notion of logical limit per se. Diamond's point is that Winch in effect tries to rule out an unexplored use of "reality" and that this doesn't work.

This section of my genealogy has two main points. The first is to make clear that the philosophical considerations behind Diamond's criticisms of Winch are an essential part of the framework for each essay in this volume. In other words, I want to ward off and reject any impression that I am trying to do something akin to what Diamond, rightly I believe, takes Winch to be attempting. This is why none of my conclusions, if that's the right thing to call them, take the form that " $\mathrm{x}$ cannot be said" 
or " $\mathrm{x}$ is meaningless". Abandoning the illusory idea of an a priori criterion of meaning, however, should not by any means be taken as a surrender of my ordinary language orientation to scientific naturalism; as will be made evident, "meaning" remains a critical term for me. This shows itself in key moments of each essay, particularly where I describe some (metaphysical) thesis as incomprehensible or deeply unclear. My making this sort of declaration is, moreover, accompanied by a strong suspicion, based on prior experience with relevantly similar word forms, that this incomprehension is not due to any lack on my part, intellectual or otherwise. It expresses instead the belief that efforts made to reshuffle our current conceptual deck in search of a meaningful articulation of an unintelligible formulation will be futile. This is because I also suspect, even while insisting that I cannot prove, that behind the thesis is the false imagination characteristic of the metaphysical impulse: the aspiration to a "view from nowhere".

Accordingly, my conclusion in each essay is negative. In the first essay, "Lost in the Ancient City: Pluralist Naturalism in the Philosophy of the Social Sciences", I claim that while there is no conclusive argument showing that the normativity of ordinary language and social life cannot be treated in natural scientific terms, no criterion for what would count as such a successful treatment has been so much as gestured at in the work I discuss. In the second essay, "The Grammar of Conflict", I claim that while there is no conclusive argument showing that distinct systems of thought cannot converge into one mutual logical space in which their differences might be adjudicated, I see no conclusive argument for thinking that they must find such convergence. In the third essay, "Skepticism and the Human Condition", I claim that while there is no conclusive argument showing that skepticism as Cavell understands it cannot be formulated within the systems of thought that I canvas, it is nevertheless entirely unclear to me what insisting on skepticism's universality would amount to in such cases.

The second main point connects with the story with which I began this introduction, the story about Cavell's dual claims about skepticism and Wittgenstein on the one hand, and skepticism and the human condition on the other, and how it took time for me to distinguish those claims after having conflated them in my dissertation. The point is that in the current volume, philosophical exegesis and philosophy have once more come apart. I certainly put to use the things I take myself to have learned in reading Wittgenstein and several contemporary commentators whose work I hold in high esteem. Moreover, it is also true that the topics dealt with in these essays, naturalism, relativism, and skepticism, were of central concern to Wittgenstein and have also received much attention in the secondary literature on Wittgenstein. But the essays here do not in any way depend on any particular interpretation of Wittgenstein being the correct one. (The appendix is a different story, but what I present there 


\section{Introduction}

should be taken as supplementary to one essay only and by no means as its primary focus. ${ }^{18}$ Even if all of the interpretations that have influenced these essays were based on bad readings of Wittgenstein, the philosophical outlook that I have extracted from them would still have to be reckoned with. The arguments themselves stand or fall independently of any genetic reliance they may have on Wittgenstein exegesis. So, these essays are not works of Wittgenstein scholarship.

\section{The Ambit of Culture}

Already by 1966, Clifford Geertz could record that

The term "culture" has by now acquired a certain aura of ill-repute in social anthropological circles because of the multiplicity of its referents and the studied vagueness with which it has all too often been invoked. (Though why it should suffer more for these reasons than "social structure" or "personality" is something I do not entirely understand.) In any case, the culture concept to which I adhere has neither multiple referents nor, so far as I can see, an unusual ambiguity: it denotes an historically transmitted pattern of meanings embodied in symbols, a system of inherited conceptions expressed in symbolic forms by means of which men communicate, perpetuate, and develop their knowledge about and attitudes toward life. ${ }^{19}$

I remain agnostic about the validity of the contextual definition of culture that Geertz offers in the second half of this passage. It certainly has not prevented the concept from falling under ever greater critical suspicion during the more than 50 years since he suggested it. More interesting is how the parenthetical remark expresses a sense of unfairness in the treatment of the concept of culture, namely the practice of many writers who eschew "culture" (and so "cultural anthropology") as exuding an "aura of ill repute", but go on to rely on terms such as "peoples", "societies", "regions", and "ethnic groups", which are neither more nor less well defined than "culture" itself. This seems rather typical of the phenomenon wherein precisely which undefined terms go unchallenged is largely, even if not exclusively, a function of academic fashion. If then, someone wishes to play the game of definition mongering by attacking my use of "culture", or while we're at it, my uses of "modernity", "the West", or "modern Western culture", as lacking defined essences, they should be aware that this tactic cuts both ways. Most likely, the terms in which they cast their own criticisms could suffer the same fate. Naturally, they could avoid the problem altogether by merely making the demand that all concepts be defined for all eventualities. But without making their own entry in the discussion, this demand from the sidelines seems empty. Not even particle physics can meet the sophomoric demand 
to "define everything"; and no less a nominalist than Quine saw fit to employ the term "culture". ${ }^{20}$

Geertz's characteristic use of textual imagery in the previous quotation could partly explain why the culture concept came to be so widely distrusted, especially in his hands. It seems to blur the distinction between the ethnographer and the "mere" reader, and so perhaps between the human sciences and the humanities. A famous passage from the classic essay "Thick Description" makes this even more vivid:

Believing, with Max Weber, that man is an animal suspended in webs of significance he himself has spun, I take culture to be those webs, and the analysis of it to be therefore not an experimental science in search of law but an interpretive one in search of meaning. ${ }^{21}$

The imagery invoked here must have been off-putting to many, because being caught up in something like a web of symbols naturally calls for a hermeneutic approach, with its unending "circle". This makes our finitude manifest in a way that is not only deeply at odds with a modern sensibility, it may also have led to the charge that understanding a foreign system of thought and life surely can't be as easy as reading a text. Societies, so one line of criticism goes, operate primarily in terms of causal concepts, and these cannot be "read off" of anything. They may have to be teased out of the false consciousness of one's informants, perhaps tallied up if one goes in for that sort of thing, and, depending on one's ambitions for truth or fame, perhaps even set back into the explanatory framework that motivated one's data collection in the first place.

But as a preliminary response, take an example that will reappear in the first essay: familiarity with what it is to go to church. I was a regular churchgoer for much of my early life. When I see people out of my living room window "on their way to church on Sunday morning" (while I may well be settling into my favorite chair with my waffles and coffee to watch a football game), I have a pretty good idea of what is going on with them. I can read that much from the situation, less so, perhaps, the further away from Catholicism their denomination(s) might be (and there are such distances). Anyway, if I decide I want to understand these more distant ones better, I might have to get up off the couch, go out and talk to them, and even observe and participate in their lives. Possibly for years. And yes, perhaps this may involve my forming hypotheses that involve causal notions like power, repression, and education. But if I want to apply the notion of "church goer" at all, or apply any concept meant to catch some aspect of human agency, those causal concepts will eventually have to be subsumed, or at the very least equilibrated, within a broader context of these people qua human agents who are caught up in webs of meaning that I must learn to read. And if my "account" is to be an account, and not just a series of chirps and marks about some other 


\section{0}

set of chirps and marks, I must bring to bear in my account-giving activity my own webs. For if I think I can so much as say anything about the churchgoers through so much as talking with them without bringing my own webs of significance into play, then I will have betrayed my own false consciousness, my having confused (empiricist) gawking for genuine learning.

This section has been largely taken up with defending the very legitimacy of the concept of a certain concept of culture. I now want to close by distinguishing between two levels at which this and related terms should be understood as operating in the three essays. (Perhaps this means that I am proposing yet two more "referents".) The fundamental level is conceptual or logical. While the second level retains this conceptual role, it also has the kind of identifiable empirical content one normally associates with the word "culture", both in its everyday uses and in its social scientific contexts. To the extent we wish to describe the actions of an individual language animal at all, culture plays the logical or conceptual role as a holistic taken-for-granted background, both for our own work of description and in those whom we wish to describe. This is a point made by Hubert Dreyfus with his term "practical holism", of which I make extensive use in the first essay. It goes by other names: Bildung (Gadamer, McDowell) Second Nature (Aristotle, McDowell), Weltbild and Lebensform (Wittgenstein): choose your metaphor. If there is a "proof" that such a background is "necessary", it is the incoherence we fall into when we seek to talk of human action without it. Where, on the other hand, we have not only the form but also the content of this phenomenon more or less uniformly filled out and predictably distributed over some population of humans, we have culture both in the conceptual sense and in the sense that makes ethnography possible. Where such roughly regular distribution is lacking, the conceptual sense of practical holism will still be in play, to the degree we are dealing with human agents at all. ${ }^{22}$ Not surprisingly the more empirical level comes out most visibly in my use of relevant ethnographic literature. In either case, culture is not some kind of logically impenetrable meaning miasma surrounding certain populations. Nor, as a critical concept, does it play an explanatory role here. Rather, as the home of the concept of meaning, the two-level concept of culture is rather a thread tying together the concept of the human in the three essays of this volume.

Geertz writes "that culture, rather than being added on, so to speak, to a finished or virtually finished animal, was ingredient, and centrally ingredient, in the production of that animal itself. ${ }^{23}$ Geertz's speaking here of the production of an animal brings to light that thus far I have said a good deal about the concept of culture, but nothing about why the essays in this volume are contributions to philosophical anthropology. For one thing, it should be obvious that I am not using the term "philosophical 
anthropology" in a manner restricted to the thought of classical German philosophical anthropology in such figures as Scheler, Ghelen, or Plessner. For another, despite the clear anti-scientistic thrust of these essays, they are not the expression of just one more disgruntled anti-naturalist. I mean, rather, the term "philosophical anthropology" to indicate a kind of philosophical criticism that initiates its reflections on philosophical problems from an unapologetically humanist perspective, a perspective that is kept alive in the very structure of any inquiry into the human, most notably and fruitfully from within the discipline of anthropology itself. Finally, Towards a Philosophical Anthropology of Culture aims to rejuvenate the interpretivist-hermeneutic tradition in the philosophy of the social sciences on a firmer critical footing, without any relativist or metaphysical baggage. That tradition has faced more than a generation of misrepresentation, whether by post-structuralists or naturalists, which it is high time to call out.

\section{Notes}

1. See for example, Charles Taylor, "Understanding and Explanation in the 'Geisteswissenschaften'," in Wittgenstein: To Follow a Rule, ed. S. H. Holtzman and C. M. Leich (London: Routledge and Kegan Paul, 1981), 191-210.

2. G. H. von Wright, "Wittgenstein in Relation to His Times," in Wittgenstein (Oxford: Blackwell, 1982), 216.

3. See Stanley Cavell, "Declining Decline," in This New Yet Unapproachable America: Lectures After Emerson After Wittgenstein (Albuquerque: Living Batch Press, 1989), 41.

4. Ibid., 52-53.

5. See Chapter 6 of my The Fate of Wonder: Wittgenstein's Critique of Metaphysics and Modernity (New York: Columbia University Press, 2011).

6. While "interpretivism" is frequently identified with Clifford Geertz, whose work I cite especially in the essay on skepticism, I am not restricting my use of the term to Geertz's ideas. In addition to Geertz, I mean to include here also such symbolic thinkers as Marshall Sahlins, Victor Turner, E. E. EvansPritchard, Paul Ricoeur, Peter Winch, Heidegger, Wittgenstein, and of course Taylor and Dreyfus. Despite differences, I believe these thinkers can all be treated under the interpretivist rubric.

7. Other more senior practitioners were similarly hostile. A few years ago, I attended a seminar by a world-renowned anthropologist, where he claimed that according to Geertz, the Balinese cockfight merely unfolded according to a self-enclosed and predetermined cultural logic supposedly immune to social factors (read "power"). When I raised my hand and tried to say something about the relevance of the hermeneutic circle in anthropology, the speaker interrupted me and proclaimed loudly that "Anthropology is an empirical discipline!" No point in arguing, I thought (even though his response appeared to presuppose that a hermeneutic approach was somehow a priori). Much more recently, I was present at a workshop when the very same anthropologist pronounced, much to my surprise, that "social anthropology has no data".

8. Ludwig Wittgenstein, Philosophical Investigations, trans. G. E. M. Anscombe (Oxford: Blackwell, 1997), \$124. 


\section{Introduction}

9. On this, see my "Naturalism and the Friends of Understanding," Philosophy of the Social Sciences 44, no. 4 (2014): 460-77.

10. See Cora Diamond, "Criticising from 'Outside'," Philosophical Investigations 36 (2013): 114-32; Cora Diamond, "Putnam and Wittgensteinian BabyThrowing: Variations on a Theme," in The Philosophy of Hilary Putnam, ed. R. E. Auxier, D. R. Anderson, and L. E. Hahn (LaSalle: Open Court, 2015), 603-39; Cora Diamond, "The Skies of Dante and Our Skies: A Response to Ilham Dilman,” Philosophical Investigations 35 (2012): 187-204.

11. Chapter One of my The Fate of Wonder contains a summary of how I understood the status of that debate as it stood around 2010. Chapters Two and Three are my own contributions to the development of the resolute reading of the Tractatus as it pertains to ethics. For a concise presentation of my views on those questions, see my "Tractarian Ethics," in The Cambridge Companion to Wittgenstein, ed. Hans Sluga and David Stern, 2nd ed. (Cambridge: Cambridge, 2018), 96-125.

12. The sketch draws on numerous works by Diamond and Conant. See Chapter One, note 65 for references.

13. Ludwig Wittgenstein, Tractatus Logico-Philosophicus, trans. G. K. Ogden (London: Routledge \& Kegan Paul, 1983). Henceforth TLP.

14. Ibid.

15. Ibid., 27. At Philosophical Investigations $\$ 374$ Wittgenstein writes, “The great difficulty here is not to represent the matter as if there were something one couldn't do". And at PI $\$ 500$, we read "When a sentence is called senseless, it is not as it were its sense that is senseless. But a combination of words is being excluded from the language, withdrawn from circulation". There has been a recent discussion as to whether such remarks warrant the use of "resolute" reading to the Investigations. See James Conant and Silver Bronzo, "Resolute Readings of the Tractatus," in A Companion to Wittgenstein, ed. Hans-Johann Glock and John Hyman (Chichester: John Wiley and Sons, 2017), 175-94.

16. See Peter Winch, "Understanding a Primitive Society," American Philosophical Quarterly 1 (1964): 307-24.

17. Ibid., 315. I am unsure whether Winch would have thought that every grammatical difference led to some degree of incommensurability and to what degree incommensurability might be localized or be global.

18. As for the occasional references in footnotes to passages in Wittgensteinian texts, these are intended for readers who might be interested in knowing where I take myself to have found inspiration in his writings. They play no logical role in my arguments.

19. "Religion as a Cultural System". Reprinted in Clifford Geertz, The Interpretation of Cultures (New York: Basic Books, 1973), 89.

20. W. V. O. Quine and J. S. Ullian, The Web of Belief (New York: Random House, 1978), 81.

21. Geertz, The Interpretation of Cultures, 5.

22. This raises difficult questions about just how much regularity is required for the ethnographer to get a foothold. I doubt this question has a clear answer. It also begs the question about what to say about the humanity of so-called "feral children". If such cases really do exist, then beyond relaying that I would of course regard them as human, I don't really know what else to say. My only comfort there is that I don't believe anyone else has any idea about what to say about such cases.

23. Clifford Geertz, "The Impact of the Concept of Culture on the Concept of Man," in The Interpretation of Cultures (New York: Basic Books, 1973), 47. 


\title{
1 Lost in the Ancient City \\ Pluralist Naturalism and \\ the Philosophy of the Social \\ Sciences
}

\author{
Kevin M. Cabill
}

This essay deals with questions concerning naturalism and its relation to the idea of philosophical anthropology. My way into these questions will be to take up the threads of an old debate in the philosophy of the social sciences, a debate many today would likely describe as quaint, and probably mostly settled: this is the debate about the possible "demarcation" between the Geisteswissenschaften and the Naturwissenschaften. My half-ironic use of the antiquated terminology here signals my awareness of how passé this discussion may appear to be, especially in light of the confident ascendancy of various naturalisms that, to me at least, now hardly seem to recognize that there was ever a time when their credentials were respectably questioned. My route will be a bit circuitous and, not surprisingly for an unreconstructed interpretivist and hermeneuticist such as myself, begins with the question of language. Although many of the pieces of my story have been shaped by the thinkers whose work I rely on here, I have tried to rework and assemble them in a way that I hope casts some new light on an old question.

My starting point is some recent claims by John Dupré that concern the relationship between ordinary language and the language(s) of the social sciences. ${ }^{1}$ For many years, Dupré has offered powerful arguments for an anti-reductionist, pluralist naturalism in the Philosophy of Science. ${ }^{2} \mathrm{He}$ has supported his position by arguing that reductionist dogmas, most notably physicalism, are simply unsupported by scientific practice and findings. Dupré's anti-reductionism runs deep indeed: he is not merely a methodological pluralist, a now widespread view in the philosophy of science, he is also an ontological pluralist. He thinks, rightly I believe, that the sciences not only exhibit the legitimacy of different ways of studying nature, but that they also show that nature itself contains genuinely different kinds of things to be studied. ${ }^{3}$

Dupré has recently taken his pluralist naturalism to cast doubt on an apparent suggestion by Wittgenstein in Philosophical Investigations to the effect that there is a philosophically relevant difference between the 
languages of the sciences and ordinary language. Dupré argues against this idea that not only is there no discernible sharp difference between the natural and the social sciences, but relatedly, there is no in-principle difference between the languages of the natural and social sciences on the one hand, and ordinary language on the other. Dupré has stated previously that, " $[\mathrm{O}]$ ne point I share with all contemporary philosophers who describe themselves as naturalists is that I assume that the best ways of interrogating nature can be found by looking at the empirical sciences" ${ }^{4}$ I understand him here merely to be making the point that the work of coming to know whatever it is we can know about nature should involve our best tools, and those tools happen to be the empirical sciences. There is nothing, or at least not much, to object to there. ${ }^{5}$ Yet a key element of what I will say in response to Dupré's position rests on the point that intractable philosophical problems intrude if we fail to recognize that human language users occupy one end of a relation to the world not well described as "knowing", but one that in some sense can be said to undergird the knowing relation. ${ }^{6}$ By drawing on important aspects of ordinary language that Dupré overlooks or mischaracterizes, I will argue here that he misses a philosophically crucial, even if not metaphysical, distinction between the natural and social sciences, a distinction that goes directly to the issues of naturalism and philosophical anthropology. ${ }^{7}$

After sketching Dupré's discussion of the relationship between ordinary language and the languages of the sciences in Part II, I criticize his account in Part III by calling on a distinction between "theoretical holism" and "practical holism" that was introduced by and argued for many years ago by Hubert Dreyfus. Working with this distinction, which Dreyfus articulates by relying mainly on ideas taken from the early Heidegger but also from the later Wittgenstein and others, I try to show that despite his frequent avowals of pluralist anti-reductionism, Dupré's treatment of the relevant passage by Wittgenstein, as well as some of his remarks on Peter Winch's work, betrays a subtle but deeply troublesome form of reductionism. In short, while Dupré certainly recognizes differences between ordinary language, the languages of the social sciences, and those of the natural sciences, I will argue that those acknowledged differences don't go deep enough. As I'll make evident, in his discussion of Wittgenstein and Winch, Dupré implicitly depicts, or at least allows the image to stand of, ordinary language as a kind theory. As a result, essential normative facets of the kinds of agents that human language users are, become obscured and the twin results are a distorted view of the social sciences and meaning skepticism. In Part IV, I go on to show that despite their importance of bringing out a troubling aspect in the kind of naturalism Dupré stands for, Drefyus' own arguments are marred by a dubious apriorism. In order to bring this point out, I refer briefly to a tradition of reading Wittgenstein which can be traced back to 
Stanley Cavell, but has been brought into sharper focus by other writers over roughly the last 30 years by writers like Cora Diamond and John McDowell. ${ }^{8}$ While Dupré's tacit treatment of ordinary language as a theory blocks our view of the normativity of human conceptual life in one way, in Part V, I look at the issue from a different vantage point, namely, how or whether the kind of agents that human language users are can be accommodated within a scientific naturalist worldview. I show that the usual attempts to "naturalize" the normativity that characterizes us as language users, what John McDowell has called our second nature, faces a new version of the same problem that arose when from collapsing the distinction between theoretical and practical holism. In Part VI, I try to bring these considerations together in a way that folds the sort of naturalism McDowell has defended into the overall theme of Philosophical Anthropology.

\section{II}

Dupré states that "[t]he central thesis of this paper ... [is] that social science is not that different from much in the natural sciences." In the event that the point of arguing for such a thesis has become so obscure in today's philosophical climate that it might need pointing out, Dupré is referring to an old question in the philosophy of the social sciences, namely whether there is a philosophically interesting demarcation between the natural and the social sciences. In former times this was frequently cast as a debate between the supporters of Erklären (explanation) and Verstehen (understanding) with those in the first camp maintaining that the methods (or perhaps, "the method") of the natural sciences were entirely appropriate for gaining knowledge about human social life, while those in the latter camp countering that the social sciences required a distinctly humanistic, more literary approach appropriate to their objects of study. ${ }^{10}$

Let's start with a well-known remark from The Blue and the Brown Books, cited by Dupré, where Wittgenstein suggests something like the idea that assimilating philosophical to scientific contexts is centrally implicated in generating metaphysical confusions:

Our craving for generality has another main source: our preoccupation with the method of science. I mean the method of reducing the explanation of natural phenomena to the smallest possible number of primitive natural laws; and, in mathematics, of unifying the treatment of different topics by using a generalization. Philosophers constantly see the method of science before their eyes, and are irresistibly tempted to ask and answer questions in the way science does. This tendency is the real source of metaphysics, and leads the philosopher into complete darkness. ${ }^{11}$ 
Dupré sympathizes with the main thrust of this remark, which points to the lamentable consequences of philosophers' tendency to treat different kinds of problem in a one-size-fits-all manner, but at the same time he strongly disagrees with what he takes to be Wittgenstein's own simplistic depiction of science here, something like a covering law view, perhaps supplemented by the idea that chemistry and physics provide paradigmatic examples of the sciences. As an avowed pluralist naturalist, Dupré resists the idea that there is such a thing as "the method" of natural science, and so only distortion can arise by contrasting philosophy, or anything else, with a false monolith. Rather, Dupré rightly maintains that there are different sciences with distinct but overlapping methodologies, and so, not surprisingly, one finds distinct but overlapping languages of science.

With Dupré's view of the languages of the sciences in mind, we can turn to his treatment of the following passage by Wittgenstein's Philosophical Investigations:

[A]sk yourself whether our language is complete;-whether it was so before the symbolism of chemistry and the notation of the infinitesimal calculus were incorporated in it; for these are, so to speak, suburbs of our language. (And how many houses or streets does it take before a town begins to be a town?) Our language can be seen as an ancient city: a maze of little streets and squares, of old and new houses, and of houses with additions from various periods; and this surrounded by a multitude of new boroughs with straight regular streets and uniform houses. ${ }^{12}$

Given Wittgenstein's anti-scientism, his hostility to philosophical theorizing, and the evident significance that ordinary language plays in his later thought, it is entirely reasonable to read this remark as expressing suspicion of conflating two importantly different kinds of things: ordinary language and the theoretical languages of science (or the sciences, if you will). ${ }^{13}$ But this idea runs afoul of an important feature of Dupré's pluralist naturalism, since it seems to postulate a clear break between ordinary language and what is only a mere caricature of science. Indeed, Wittgenstein's examples of chemistry and calculus, each one a discipline with a fair amount of formal structure, might seem to both screen out the general linguistic messiness of various scientific enterprises and ignore the ways in which the languages of the natural sciences, social sciences, and ordinary language penetrate one another. Resisting Wittgenstein's contrast of an ancient city (presumably ordinary language) and new boroughs with straight regular streets (presumably "science"), Dupré remarks,

This charming metaphor suggests some kind of radical disjunction between so-called "ordinary language" and the language of science, 
and while such a disjunction may seem plausible enough when science is represented by these particular examples, in general, it is, I think, a serious mistake. ${ }^{14}$

And a bit further on we read,

I now want to argue, the complexity and diversity of both language and phenomena provide no more objection in principle to a successful social science than they do to biological science. We need only avoid unrealistic and unattainable aspirations as to what any science can be expected to achieve. ${ }^{15}$

Thus far we have seen three critical terms, "ordinary language", "natural science", and "social science". Yet the remark by Wittgenstein that Dupré wants to criticize only seems to invoke the first two. But Dupré's main thesis is that the natural sciences and social sciences are not substantially different from one another and so it may not be clear what is going on and where the questions lie. In a nutshell, one might say that Dupré wants to criticize the following idea: since the social sciences aim to study entities who happen to be ordinary language users, and since ordinary language has some special characteristics, the languages and methods of the social sciences will (of necessity?) be different from those of the natural sciences. That is, at least, the idea that Dupré takes Wittgenstein's remark to support. And a bit later still, Dupré frames the main issue by pointing to one of the special characteristics of human social life that Wittgenstein is famous for foregrounding in his later writings on language:

The question before us is whether there is anything peculiar to the social sciences that makes a parallel scientific pursuit of the relevant questions impossible. ... One answer does suggest itself as a quite general way in which deeper understanding of social facts, scientific or otherwise, should be provided. Wittgenstein emphasized the centrality of rules in the structure of social life, and thus the idea that there is something normative about the social. ${ }^{16}$

Judging from the general drift of his discussion and from his expressed overall sympathy with Wittgenstein's thought, Dupré seems to accept as basically correct the view he ascribes to Wittgenstein, namely that rules and norms are a central feature of ordinary language and therefore of much in human social life. ${ }^{17}$ At any rate, he offers two examples of what he thinks of as misguided arguments that purport to show that the study of social phenomena is different in kind from the natural sciences. The first comes from "normative linguistics" and involves the simple fact that 
some descriptions of English language sentence construction are true, while others are false.

It is a fact, in English, that plural nouns take plural verb forms. If I want to inform you that cows are herbivorous, I ought to say "cows are herbivorous" and I ought not to say "cows is herbivorous." And that's a fact. Not a very high-level fact, or a very important one, no doubt. As more descriptive linguists have insisted, correctly in my view, there may well be dialects in which "cows is herbivorous" is correct, and it may come to pass that "cows is herbivorous" becomes generally correct English. But not yet. Are these scientific facts? I really do not understand this question. . . . Might one rather say that this is nonscientific? The only sense I can make of this is that the statement in question is not one that should or could play any part in a science of linguistics. And I simply have no idea what basis there might be for such a claim. ${ }^{18}$

For his second example, Dupré discusses an idea he finds in Winch's The Idea of a Social Science, namely that while the natural scientist need only heed the rules of her home discipline, the sociologist must in some sense participate in two sets of rules, those of her home discipline and those of her subjects. The passage that Dupré quotes from Winch reads as follows:

If the judgments of identity - and hence the generalisations - of the sociologist of religion rest on criteria taken from religion, then his relation to religion cannot be just that of the observer to the observed. It must rather be analogous to the participation of the natural scientist with his fellow workers in the activities of scientific investigation ... [A] historian or sociologist of religion must have some religious feeling if he is to make sense of the religious movement he is studying. ${ }^{19}$

In speaking of judgements of identity, Winch is referring to the question of the sociologist's ability to make correct identifications of the things she aims to be studying. His point is that there is no hope of fulfilling this necessary condition by mere presuppositionless observation, staring, so to speak, and his proposal is that therefore one must have some sort of "religious feeling" at the outset of one's study so as to make possible fruitful observation. Dupré responds,

The sociologist of religion, it appears, will face the difficult task of engaging simultaneously in two rule-governed social worlds, the world of sociology and the world of religion.

I have to confess I find this strange. Of course, if the sociologist is investigating a system of rules, then he is engaged with two 
systems of rules: the rules of sociological discourse and the rules he is investigating. But why must he participate in the latter? I mean no disrespect to the tradition of cultural anthropology that does pursue a certain kind of participation with the societies it aims to investigate, and there may be a particular kind of knowledge that requires this kind of methodology. But surely it is not the only kind of knowledge possible of an unfamiliar culture? As an atheist, I can perfectly well understand why everyone in a village goes into a large building on Sunday morning and recites various narratives together about what I take to be an imaginary being. I might sympathize less with this practice than could a religious person, but I can understand it fairly well. And even if participatory anthropology gains a certain depth of understanding that is not available to other methods of study, it surely pays a price for this in breadth, or generality? ${ }^{20}$

Though insisting on the continuity between the natural and social sciences, Dupré makes clear that he is not asserting that there is no important difference between them at all. That would belie his anti-reductionism. He thus reassures us that he is "not, of course, suggesting that molecules obey rules, or have meanings." ${ }^{21}$ However, for Dupré, the recognition of such a difference is best thought of as a result of a kind of empirical finding, as though we discover through mere observation, say, normativity or meaning when we observe human subjects; these are not understood as constitutive features of social scientific investigation itself. Thus, the social sciences don't need to employ a special method or rely on any special presuppositions different in kind from the natural sciences.

Both of Dupré's examples, the one about English grammar and the one about the churchgoers, would suffice for my purposes here. But since Winch's work has had so much historical importance for the philosophy of the social sciences (not to mention for the reception of Wittgenstein's thought in this field of study), it seems more natural for me to follow up the example concerning religion for pursuing my argument. Despite his finding Winch's argument "strange", Dupré does think there is value in an idea he finds in Winch, namely, that the findings of social science should be rendered in ordinary language if they are to be of any use. And this, in turn, requires that the sociologist's descriptions of his subjects' activities must be given in a thick language "in which central terms have both descriptive and evaluative content". ${ }^{22}$ Dupré then asks,

How deep a divide does this show between the natural and the social sciences? I suggest that it shows a deep and familiar difference between the subject matters, but no obvious systematic difference between the epistemological standards that constitute these diverse investigations as scientific. ${ }^{23}$ 
Against this, I will argue in the next section that the thick description that rightly characterizes much social science is already a mark of a significant "epistemological" difference from the natural sciences, and that this is so because of the distinct nature of the entities under investigation. In other words, the epistemological difference belies an ontological, though not metaphysical, one.

\section{III}

\section{$A$}

As a declared pluralist naturalist, Dupré is always careful to resist any dogmatic insistence on the methodological or metaphysical unity of science, since he wants to give proper due to the distinctness of various scientific disciplines. Still, something in his confident declarations of knowledge of the facts of normative linguistics and of his understanding of churchgoing suggest to me that something is seriously wrong with his overall argument that the social and natural sciences are fundamentally on a continuum. In this section, I'll try to bring out what I think the main problem is by first imagining a case that touches on the churchgoers.

Imagine a little boy growing up in an English village in the 1950s. His own family is secular, but many, or perhaps even most of the villagers still participate in the rituals that regularly go on inside of the village church or churches. (Which denomination they are doesn't seem to be very important for the example.) When he is very young, a particular building in the village grabs his attention and he asks his parents "What's that house?" Perhaps they merely respond, "That's a church". Things are likely to get more complicated rather quickly later when he asks what people are doing on Sunday morning trudging up the hill to the church. Perhaps the little boy's parents, siblings, or neighbors will tell him things like "those people are going to church because it's Sunday". Because his family is secular, he may also hear things like "We don't go to church, it's all hocus pocus". When he is in kindergarten or grade school, he is likely to hear things like "We have to go Christmas shopping soon", "You'll soon have Christmas vacation", "Shall we go to the Christmas fair?", "There is an Easter Egg hunt this Saturday", "You get out of school early on Good Friday this week". Now all of this "knowledge" about the goings-on inside and around a church might be imparted to him without his ever having set foot inside of one. More to the point, it seems he will have acquired this "knowledge" without having to form any hypotheses or conduct any empirical testing in order to get a basic handle on an impressive amount of church-related terminology and behavior. That is, long before his secondary education has begun, a whole lot of what is meant by words such as "God" and "worship" and other church-related vocabulary will be "known" by the boy. Yet this "knowledge" will not really amount to anything more than having acquired and mastered the terms 
that go into the language he speaks and the life he shares with many of his co-villagers. Consequently, unless one believes it clarifies matters by, for instance, introducing something like a distinction between knowinghow and knowing-that, it seems like a mischaracterization simply to call the little boy's familiarity "knowledge" and to leave things at that.

Naturally, someone could object to my use of pejorative scare quotes and point out that "knowledge" is an entirely appropriate expression for the boy's effortless ability to make "judgements of identity" regarding what goes on in connection to the church, despite his never having been inside one. This might be fine in an ordinary context, but in a philosophical context I would want to ask what, if any, evidence the little boy is imagined to possess in having arrived at this supposed knowledge of the various church words employed in the example. (How quickly one gets back to Descartes' predicament in the First Meditation: the "evidence" is really pretty poor.) In fact, I think it's difficult to conceive of the supposed evidence as amounting to much more than the boy's elders and others having told him what a church is, what the Bible is, what worship is, etc. And this hardly seems to count as evidence supporting any hypothesis at all. In particular, just staying at the phenomenological level for now, it seems, at the very least, rather far-fetched to assume that a child would treat the utterances of those around him as evidence in support of his "theory" of village religious life. Whether as part of his observing their casual conversation or as part of their explicit teaching him English, the boy would have had little reason to believe one way or the other that his elders were or were not speaking truthfully or correctly when they uttered words such as "church", "Bible", "worship", etc. What can we imagine the young boy doing when his elders point at a gray stone building and state "That's a church, some people worship God there but it's all rubbish"? Do we imagine him processing this evidence, with the possibility this entails of his concluding they were perhaps mistaken about the name of the structure or what goes on inside? What would evaluation of evidence actually look like when the boy was learning to speak? I want to say that such considerations of weighing evidence don't even get into the game at these early stages of learning language, and through it, the social world, and that this is the main reason why Duprés claim to know lots of things about the church-goers without participating much in their practices strikes me as utterly misleading. The mere enculturation of the child in my example will have involved him in a massive amount of participant practices connected to their religion, even if he himself is taught to, or comes to regard, religion as delusional. Dupré rightly notes that the degree to which one's participation in the actual practices of the religion is rather thin, as in his own case, one likely lacks an intimate understanding of some of the finer details of what the churchgoers are up to. But the fact is that the boy in my example, budding atheist or no, already participates rather massively in the way of life of the churchgoers. And the same almost assuredly holds true of Dupré. 


\section{2}

\section{Lost in the Ancient City}

I should stress that there is no inherent problem with Dupré's use of the word "knowledge" to describe his ability to understand what goes on at church (or to understand elementary English grammar). My thought example was meant to make such a use seem less compulsory or attractive by showing that there need not be the slightest reason to regard such an ability as the result of an activity involving the forming of hypotheses and the collecting of data into a theory of church-going. Using "knowledge" to describe what is learned in acquiring the basic concepts of churchgoing provides no reason to see it as on any obvious sort of continuum with the sorts of knowledge one hopes to acquire when one engages in any form of scientific research. On the contrary, it seems to be significantly discontinuous at precisely this point.

Still, even if such common sense considerations make it implausible to conceive of the boy in my example as a kind of mini-epistemologist, a philosopher could dig in his heels on this point because he may see no alternative to casting his description of the boy's relation to early facts of language learning and social life in a substantially epistemological light. But as I'll argue later, doing so puts one on a very short path to skepticism, not just about the existence of the "external world", but about the very intelligibility of both scientific and non-scientific discourses. Now the insistence on a fundamentally epistemological relation might take different forms. Although it seems like a bizarre possibility, one could insist on a kind of direct and infallible knowledge of linguistic and social facts, on analogy with G.E. Moore's claim to know of the existence of his two hands as proof of an external world. ${ }^{24}$ I think that it is hugely unlikely that Dupré would postulate this sociolinguistic variety of "Moorean propositions" merely in order to salvage the use of "know" in the context of his discussion. There seems something philosophically desperate in characterizing our earliest relation to an unlimited number of obvious linguistic and social facts in terms of epistemological success as Moore understood this..$^{25}$ I won't pursue this particular avenue further.

Even if his paper is not explicit on this question, Dupré's talk of continuity between ordinary language and the social sciences (and ultimately the natural sciences) suggests an idea already contained in germ in my discussion of the example of the little boy: that our primary relation to culture and language is one of semantic interpretation, even if this is not necessarily assumed to be the result of our conscious handling of data and hypotheses. As we just saw, this second idea seemed implausibly overly intellectualist, in large part I suspect, because of the way in which it breaks so radically with common sense phenomenology. Instead, the alternative, apparently more plausible, idea of interpretation here is that, perhaps as a result of sub-personal psychological (or neurological, it doesn't really matter) processes, the child fits various uninterpreted (that is to say meaningless) linguistic data into his overall theory of meaning and truth. ${ }^{26}$ This idea, then, might provide the support for the sort 
of continuity between ordinary language, social scientific theories, and natural scientific theories envisioned by Dupré.

\section{$B$}

In the precious section, I said that casting our description of the boy's relation to early facts of language learning and social life in a substantially epistemological manner put us on a very short path to meaning skepticism. To develop this idea in a direction that will make clearer what I take to be misleading in Dupré's discussion, I want to (re)introduce a distinction made many years ago by Hubert Dreyfus between "theoretical holism" and "practical holism". ${ }^{27}$ As Dreyfus explains it, theoretical holism, made familiar by Quine, Davidson, and Føllesdal, among others involves the idea that meaning is something we arrive at by translating or interpreting otherwise preliminarily meaningless linguistic items, so as to fit them into a semantic theory. The holism of our theory is one consequence of the failure of various forms of linguistic reductionism or meaning atomism traditionally favored by empiricists. As Quine explains in his classic "Two Dogmas of Empiricism",

The dogma of reductionism survives in the supposition that each statement, taken in isolation from its fellows, can admit of confirmation or information at all. My counter suggestion, issuing essentially from Carnap's doctrine of the physical world in the Aufbau, is that our statements about the external world face the tribunal of sense experience not individually but only as a corporate body. ${ }^{28}$

The corporate body is construed as our overall theory of the world and it is only our placing them into such a system that sentences or utterances acquire meaning, gain their life, as it were. In The Web of Belief, Quine writes in this vein,

Of course hypotheses in various fields of inquiry may tend to receive their confirmation from different kinds of investigation, but this should in no way conflict with our seeing them all as hypotheses. We talk of framing hypotheses. Actually we inherit the main ones, growing up as we do in a going culture. The continuity of belief is due to the retention, at each particular time of most beliefs. ${ }^{29}$

Elsewhere, Quine takes this view of language to argue for an erasure of any significant distinction between scientific theories and everyday language:

If, as suggested earlier, the terms 'reality and 'evidence' owe their intelligibility to their applications in archaic common sense, why 


\section{Lost in the Ancient City}

may we not then brush aside the presumptions of science? The reason we may not is that science is itself a continuation of common sense. The scientist is indistinguishable from the common man in his sense of evidence, except that the scientist is more careful. ${ }^{30}$

Dreyfus comments on this perspective as follows:

This view thus treats all understanding as an epistemological problem, as a question of theoretical knowledge, so, on this view, there is no important difference between the knowledge sought in the social and the natural sciences. ${ }^{31}$

We are in essence asked to imagine ourselves from birth as gathering and evaluating evidence pertaining to our various hypotheses in a ceaseless and bottom up attempt to see how all the aspects of the world hang together. The idea of continuity between ordinary language and the social sciences, and between these and the natural sciences, seems to follow naturally, as does a certain understanding of what comes to "revise" ordinary language, embodying as it does the crude scientific theory of practical common sense.

Against the primarily epistemological thrust of theoretical holism, Dreyfus counterpoises the idea of "practical holism", a theme he finds running through the work of Heidegger, Wittgenstein, and MerleauPonty. A central feature of practical holism is the way in which both practical and theoretical activities rest for their intelligibility on a mostly unarticulated, pre-theoretical, substantially (though perhaps not exclusively) acquired background understanding of how the world hangs together. ${ }^{32}$ For example, in order to conduct her research, the experimental scientist must share with her colleagues a vast amount of understanding of social, linguistic, technical, and institutional norms and facts. ${ }^{33}$ The point is not merely that the task of making this background understanding explicit on par with a theory would be a herculean and largely pointless task. Nor is it that these difficulties point in turn to some underlying logical impossibility. ${ }^{34}$ The point is, rather, that it is deeply unclear how any theoretical scientific work could get off the ground at all without some common unquestioned understanding about what is relevant and what is not; and this pertains first and foremost to the facts of everyday life with language. This non-theoretical understanding exhibits, moreover, a kind of holistic, narrative unity wholly alien to the thoroughgoing contingent unity characteristic of theoretical holism. As Dreyfus describes it,

Practical understanding is holistic in an entirely different way from theoretical understanding. Although practical understanding and everyday coping with things and people involves explicit beliefs and 
hypotheses, these can only be meaningful in specific contexts and against a background of shared practices. And just as we can learn to swim without consciously or unconsciously acquiring a theory of swimming, we acquire these social background practices by being brought up in them, not by forming beliefs and learning rules. A specific example of such a social skill is the conversational competence involved in standing the correct distance from another member of the culture depending on whether the other person is male or female, old or young, and whether the conversation involves business, courtship, friendship, etc. More generally, and more importantly, such skills embody a whole cultural interpretation of what it means to be a human being, what a material object is, and, in general, what counts as real. ${ }^{35}$

The example here of conversational distance-standing nicely illustrates the holism of background understanding: even holding a competent mundane conversation might only work given a positioning of the participants' bodies that appropriately takes account of age, gender, social position, etc. While Dupré notes that the holism which characterizes biological theory is structurally similar to that exhibited by the language we use to describe the actions of the churchgoers, the holistic understanding at issue for Dreyfus is one that affords our language, actions, and perceptions not merely conceptual coherence, but a kind of immediate or prima facie sense, without which we would neither understand what to do nor what to say in the shifting contexts of our lives. ${ }^{36}$

How, then, should we think about the relationship between the understanding characteristic of practical and theoretical holism generally, or between the different uses of languages that imbue them specifically? One upshot of these considerations is that there is an important sense in which ordinary language and the know-how which infuses it is fundamental (even if not foundational) to the epistemological perspective characteristic of scientific theorizing. Dreyfus thus writes in this vein,

We can ... use Heidegger's distinctions to highlight the difference between theoretical and practical holism's view of the interpretive circle. The Quinean theoretical circle results ... from the fact that all verification takes place within a theory, and that there is no way out of the circle of holistic hypotheses and evidence. The Heideggerian hermeneutic circle, on the other hand, says that this whole theoretical activity of framing and confirming hypotheses takes place not only on the background of explicit or implicit assumptions but also on a background of practices ... which need not and indeed cannot be included as specific presuppositions of the theory, yet already define what could count as a confirmation. ${ }^{37}$ 


\section{Lost in the Ancient City}

In other words, the epistemological dependency relation of ordinary language practices and those of the sciences is not reciprocal or symmetrical.

Someone could try to mitigate this fact by noting that the languages of both the natural and social sciences penetrate everyday language: "relativity", "quantum leaps", "chaos", "genes", "evolution”, "unconscious", "cultural capital", "class", are all examples we commonly encounter (even if such terms of art are rarely used in everyday discourse with the same grammar with which they are employed in their original theoretical contexts). Dupré could thus correctly argue both that not only do ordinary language practices surround and even penetrate theoretical disciplines but also that theoretical languages have in some sense become part of ordinary language and its practices. He may also be correct in his claim that, for example, "[b]iology . . . is actually a maze of little streets and squares just as intricate as ordinary language". ${ }^{38}$

Although each of these points are valid and worth making note of, they fail to negate the difference in the direction of logical significance. The simple fact is that ordinary language permeates the intelligibility of every form of scientific activity much more pervasively than the other way around. Now it is undoubtedly true that lives led without any of the advantages afforded by modern scientific theories would be far nastier, more brutish, and shorter than is currently the case. Still, we can pretty well conceive of people carrying on their lives with little or no natural or social science, as we currently understand these. On the other hand, it's doubtful we could conduct any science at all minus the orientation provided by natural language. Moreover, while it may be next to impossible to imagine the members of any human society speaking a language completely lacking the conceptual resources for engaging in any kind of hypothetical thinking (apart from whether this thinking amounted to positing explanations in terms of theoretical entities, as is often the case with the sciences), the fact remains that practical holism cum ordinary language can get along much longer and better without any theoretical stance, scientific or otherwise, than theorizing can get along without ordinary language. That does not demonstrate the dependence of a priori necessity (assuming we knew what that was supposed to mean anyway), but it does strongly suggest an epistemological dependence whose absence we would, to put it mildly, have a very hard time fathoming. ${ }^{39}$

I have been employing Dreyfus' term of art "practical holism" both in order to elaborate on my example of the boy in the village and in order to suggest that basing our relation to the coherence of ordinary language and the social world primarily on the model provided by the idea of fitting data into a theory is a kind of philosophical fantasy. Philosophers are of course fond of promoting these sorts of images, but I think that if one tries to think it through, the idea can't really be made out. So far, however, these considerations haven't really been brought to bear on the 
issue of fleshing out the alleged essential difference between the natural and the human sciences, supposedly one of my main goals in this essay.

To move things along requires that I make explicit that the practical holism embedded in ordinary language is fundamental to the natural sciences and social sciences in crucially different ways. To put things a bit crudely, with very few exceptions there is no need for the natural scientist to reflect on her immersion in ordinary language or the social world at all. ${ }^{40}$ These will naturally become relevant when the time comes to disseminate her results, especially in popular scientific channels. They may also come into play should there arise the kinds of conflicts that are inevitable in any human social endeavor. Nevertheless, a sensitivity to practical holism's background understanding itself is conspicuously absent in the field of her study. ${ }^{41}$ She is free to put her scientific training and education to use and let her background understanding work by remaining invisible. Dreyfus puts it this way:

[T] he important point for the natural sciences is that natural science is successful precisely to the extent that these background practices which make science possible can be taken for granted and ignored by the science. ${ }^{42}$

In the study of human societies, on the other hand, taking practices for granted is self-confounding:

[S] uch skills and the context of everyday practices they presuppose are internal to the human sciences, just as the laboratory skills of scientists are internal to the history and sociology of science, for if the human sciences claim to study human activities, then the human sciences, unlike the natural sciences, must take account of those human activities which make possible their own disciplines. ${ }^{43}$

At one point in his discussion of Winch, Dupré seems to come tantalizingly close to seeing this point. Just before he cites a passage where Winch speaks of the requirements for the sociologist of religion to make judgements of identity (see p. 18), Dupré glosses Winch's view as one in which the distinct nature of the social sciences can be seen in the way the social scientist must participate simultaneously in two sets of rules, those guiding appropriate action in his home discipline and those guiding the action of the subjects of his study.

Winch, at any rate, argued that a crucial difference between the social and the natural sciences is that in the former, rules come in twice. The natural scientist must learn the rules that concern the practice of her science. She must learn, for example, when it is appropriate to say, "there is an electron" or "that is a kinase". More generally, scientists 
need to know when two situations are to be counted as belonging to the same kind. But, according to Winch, the social scientist must also have some kind of knowledge of the rules that govern the practice she is investigating. ${ }^{44}$

Setting aside the question of whether it is correct to frame the issue in terms of rules as Winch does, it is apparent that the difficulty Dupré recognizes Winch to be raising is the very same problem just described by Dreyfus. But Dupré misses the significance of the point because he seems to make the implausible assumption that his knowledge that "cows is herbivorous" is grammatically incorrect or that his knowledge of what generally goes on inside a church are products of empirical observation and testing. At any rate, Dreyfus concludes,

We have argued that in the human sciences the background is internal to the science while in the natural sciences it is external. ... But the importance of this difference depends on a further ontological question, whether the background can itself be treated as a belief system or a set of rules, i.e., whether there can be a theory of practice. That there can be such a theory is the unargued assumption of the view that theoretical holism is the only kind of holism..$^{45}$

\section{C}

I have tried to flesh out Dreyfus' idea of practical holism in order to clarify why a doctrine like theoretical holism obscures an important difference, or discontinuity if you will, between the natural and the human sciences. At the same time, I briefly alluded to the idea that failing to recognize this difference by adopting theoretical holism is of a piece with succumbing to a kind of meaning nihilism. When what is at stake is not just the nature of the human sciences, but the intelligibility of language itself, the result of treating ordinary language as just one more revisable theory represents not merely a distorted view of science, but a fall into incoherence. What accounts for both sides of this ruinous coin is a largely unquestioned dogma in philosophy, namely that language consists primarily of, indeed could only be, a set of normatively inert signs that require interpretation to give them meaning: chirps and marks if you will that only receive the breath of life through a theoretically sophisticated act of interpretation. ${ }^{46}$

It is in the scientific spirit of theoretical holism that my very act of placing, say, an "acoustic blast” emanating from someone's mouth into a theory is always revisable in light of future evidence and so subject to doubt. ${ }^{47}$ But in fact the doubtfulness here is of a much more radical nature than might be assumed. This is so because doubt would have to apply not only to justifying the semantic result of placing this or that lexical item into my theory, but to something like the very (admittedly 
ungainly) concept: "evidence for placing an utterance into a semantic theory". Consequently, things would never get as far as weighing the result of applying the theory of theoretical holism, since radical uncertainty already creeps into the very idea of evidence itself, and so into the very formulation of what it means for the theory to explain anything. If, in other words, one already has to have some unquestioned concepts in order to articulate what theoretical holism amounts to, which is a theory supposedly accounting for how we acquire all of our concepts, it is entirely unclear how theoretical holism as a general theory accounts for very much at all. ${ }^{48}$ It may help to make this point even clearer by referring to Sellars' term of art "The Myth of the Given". Sellars coined this expression to denote the traditional empiricist assumption that the senses passively take in information from the environment that arrives, mythically as it were, already suitable for entering into rational relations. ${ }^{49}$ In the context of theoretical holism one can say the following: if, in order to treat some kinds (which kinds?) of acoustical blasts as evidence for possible interpretations or some kinds (which kinds?) of ink marks on paper as evidence for possible interpretations, it seems that I must treat these "inputs" as already suitably packaged as evidence, even if only of a fairly indeterminate kind. Although distinct in some respects from what Sellars so devastatingly critiqued, one could well describe what I am drawing attention to as theoretical holism's own version of the myth. As Cavell once remarked in responding to a similar case of empiricist excess, "What these remarks come to is this: it is not clear what such an activity as my-finding-out-what-I-mean-by-a-word would be". ${ }^{50}$ In the current context, this is a polite way of saying that theoretical holism is, so far as I can see, useless (and, can one say with a clean conscience in our current philosophical environment: "meaningless"?) as a general theory. One could, I suppose, try to avoid this outcome by stipulating that whatever one does fits this concept of "evidence for placing an utterance" This saves theoretical holism by rendering it vacuous, and so again, useless.

I cannot emphasize strongly enough how important it is that my tentative rehabilitation of terms such as "meaningless" and "vacuous" in my analysis not be read in the wrong light. I am not drawing support from an antecedently held a priori principle, something like a verificationist theory of meaning, and then on this basis concluding that theoretical holism makes no sense. When I stated that theoretical holism is, so far as I can tell "meaningless", that should only be taken as a provisional declaration of, first, my own inability to make any sense of the theory (for the reasons just given) and, second, my frank suspicion that no clearer articulation is forthcoming from the usual philosophical suspects. ${ }^{51}$ At any rate, on the view of our relation to language at the core of theoretical holism, there can be no genuine questions, let alone correct answers to real questions about what oneself means or what others mean with a sentence or an utterance. The theory builds a pernicious sort of general 
meaning skepticism or meaning nihilism into the very nature of language use and social interaction. ${ }^{52}$

It bears noting that however different in context and motivation, the unquestioned assumption at the bottom of theoretical holism, namely that language users must first deal with meaningless signs, is in effect identical with a key assumption that produces Saul Kripke's famous (or infamous) reading of Wittgenstein as acquiescing in a form of meaning skepticism in the remarks on rule-following in Philosophical Investigations. ${ }^{53}$ Kripke takes Wittgenstein's remarks concerning the "wayward child" to entail that because any sign such as " +2 " can always be variously interpreted, it can never genuinely guide our writing out the series. ${ }^{54}$ We then appear to be faced with a paradox that forces on us one of two choices: the first, commonly referred to as "Platonism" in the literature, requires a super intellectualist feat whereby one "grasps in a flash" the potentially infinite extendibility of the rule, thus arriving at an interpretation of the rule that itself cannot be interpreted. ${ }^{55}$ But, because we have "no model" for such a superlative fact, it can appear as though we are forced to look elsewhere for a solution to the question of how a lifeless sign such as " +2 " can genuinely guide our actions at all. ${ }^{56}$ Kripke takes Wittgenstein in turn to maintain that the sheer regularity of outcome we observe with pupils is generated by our early arithmetic training, while the community provides a sort of faux normativity by keeping individual deviation in check. We are thus led to the view that "correctly" developing a simple arithmetic rule, and more generally correctly applying other concepts, amounts to no more than our regular responses to the presentation of otherwise normatively inert signs, accompanied we may imagine, by something like a crowd barking out its "agreement".

The problem here, which Wittgenstein's text eventually makes tolerably clear, yet which Kripke fails to notice, is that a) within the Krikpensteinian paradox of interpretation the very terms "accord" and "conflict" would admit of any application and hence have no application, b) the paradox described previously itself rests on a misunderstanding, or perhaps better an oversight that, c) there is a way of understanding the expression for a rule that does not require the interpretation of otherwise lifeless signs. ${ }^{57}$ Having no model of the superlative act of interpretation we took as a requirement for understanding the meaning of a rule should not imply that there was ever a genuine requirement that we failed to fulfill. It implied rather that both the imagined requirement and the sense of failure that precipitated Kripke's skeptical solution were illusory.

The previous paragraph was intended to make vivid that, whatever their differences, the strategic deployment that Wittgenstein makes of "rule", "sign", and related terms through the voice of his interlocutor in the service of developing the dialectic of his remarks on rule-following on the one hand, and various full-throated iterations of theoretical holism made by other writers on the other, actually exhibit a common 
assumption, namely that meaning and understanding require an incredible feat of mental prowess, whether of the mind or the brain seems not to matter much. When subjected to a theoretical gaze in the hunt for the "primary quality" through which we hope to explain our capacity for meaning and understanding, meaning itself only recedes from view and we are left with mere "signs". ${ }^{88}$ We end up instead with the strange idea that we never really knew what we meant, said, or intended. Understanding the meaning of an utterance or of a written sign thus comes to be regarded as analogous to the dominant understanding of perception since the dawn of modern philosophy: the subjective projection of a secondary quality on to the world, not as an activity involving a capacity to take in something genuine from the world or from those around us.

I have on several occasions used the term "ordinary language" in tandem with terms like "social world" or "every-day world". The conjunction was always superfluous. If there is no good reason to regard ordinary language as a theory, then there is equally no good reason to regard the everyday world as a world represented by that theory. The two may be notionally separable, but in fact always come as one. We learn one as we learn the other. This was stated beautifully over 60 years ago by Cavell in a passage I quote at length:

But what is troubling about this? If you feel that finding out what something is must entail investigation of the world rather than of language, perhaps you are imagining a situation like finding out what somebody's name and address are, or what the contents of a will or a bottle are, or whether frogs eat butterflies. But now imagine that you are in your armchair reading a book of reminiscences and come across the word "umiak". You reach for your dictionary and look it up. Now what did you do? Find out what "umiak" means, or find out what an umiak is? But how could we have discovered something about the world by hunting in the dictionary? If this seems surprising, perhaps it is because we forget that we learn language and learn the world together, that they become elaborated and distorted together, and in the same places. We may also be forgetting how elaborate a process the learning is. We tend to take what a native speaker does when he looks up a noun in a dictionary as the characteristic process of learning language. (As, in what has become a less forgivable tendency, we take naming as the fundamental source of meaning.) But it is merely the end point in the process of learning the word. When we turned to the dictionary for "umiak" we already knew everything about the word, as it were, but its combination: we knew what a noun is and how to name an object and how to look up a word and what boats are and what an Eskimo is. We were all prepared for that umiak. What seemed like finding the world in a dictionary was really a case of bringing the world to the dictionary. 
We had the world with us all the time, in that armchair; but we felt the weight of it only when we felt a lack in it. Sometimes we will need to bring the dictionary to the world. That will happen when (say) we run across a small boat in Alaska of a sort we have never seen and wonder - what? What it is, or what it is called? In either case, the learning is a question of aligning language and the world..$^{59}$

If therefore it seems inescapable that we always start science in the everyday world opened up by ordinary language, then my interpolation of Dreyfus' paired notions of theoretical and practical holism into my reading of Wittgenstein's metaphor shows that the metaphor itself may be not only charming, but telling. It may well be the case, as Dupré wants to stress in the case of biology, that some of the suburbs share a structural messiness with the small streets of the old city. But since those suburbs of scientific theories and the objects they represent were constructed by city-planners, they fundamentally remain epistemological accretions to the world of everyday language.

\section{IV}

In the last section, I devoted considerable effort to putting Dreyfus' concept of practical holism to work in arguing both why theoretical holism, as a view of our primary relation to language and social life, is profoundly unclear, and second, by implication, why Dupré's claim of the continuity between ordinary language, the social sciences, and the natural sciences, resting as it does on theoretical holism, is equally unclear. On a few occasions in the midst of that discussion, I also signaled that I was not, or at least should not be taken as trying to, rely on something like a general principle of meaning for the basis of my imputation of emptiness to theoretical holism. In this section, I want to go further in warding off such suspicions by briefly distinguishing my own intended use of practical holism from that of Dreyfus himself, whose use of this idea tends to be marred by an apriorism, similar in kind to other recognizable attempts to delineate the bounds of the sayable or thinkable.

What I mean by "apriorism" in Dreyfus' thought can be detected in a passage that I used previously in my explication of his account of practical holism (see p. 25). The relevant part of the passage runs as follows:

The Quinean theoretical circle results ... from the fact that all verification takes place within a theory, and that there is no way out of the circle of holistic hypotheses and evidence. The Heideggerian hermeneutic circle, on the other hand, says that this whole theoretical activity of framing and confirming hypotheses takes place not only 
on the background of explicit or implicit assumptions but also on a background of practices ... which need not and indeed cannot be included as specific presuppositions of the theory, yet already define what could count as confirmation. ${ }^{60}$

My concern is how we are to take Dreyfus' use of "cannot" in this passage. One use might be in something like a purely psychological sense, where what he means to be pointing out is the fact that as an empirical matter, humans are simply not able to list off all of the things they presuppose for the purposes of carrying on with scientific activities. While this is almost certainly the case, it is also almost certainly true that Dreyfus does not merely wish to call attention to such a fact about our limited psychological capacities. In fact, the way I think Dreyfus intends to use "cannot" here is in something much closer to a logical sense of "cannot", where this word is meant to point to a limit or bound of sense, the transgression of which is a logical or conceptual impossibility. Something of the same "Kantian" spirit comes out later in his paper when he writes "the important point for the natural sciences is that natural science is successful precisely to the extent that these background practices which make science possible can be taken for granted and ignored by the science" (italics original) ${ }^{61}$ and "if the human sciences claim to study human activities, then the human sciences, unlike the natural sciences, must take account of those human activities which make possible their own disciplines". ${ }^{62}$

Indeed, this way of thinking about the logical significance of background practices runs at least as far back in Dreyfus' work to "Holism and Hermeneutics" published in 1980, and all the way up to his dispute 25 years later with John McDowell concerning the relation of practices and conceptuality. In the opening salvo of that debate, his 2005 APA Pacific Division Presidential Address, Dreyfus asserts,

[a]s Heidegger and Merleau-Ponty (as well as Wittgenstein) have argued, we can only relate to objects and make judgements about them insofar as they show up on the background of the world - and the world is not a belief system but is opened to us only through our unthinking and unthinkable engaged perception and coping. ${ }^{63}$

In a subsequent contribution to the same dispute, when discussing a difference between performing a skilled activity like fielding and throwing a baseball and making an assertion about that activity, Dreyfus quotes approvingly from Merleau-Ponty:

[I]n order to be able to assert a truth, the actual subject [i.e. the embodied coper] must in the first place have a world or be in the world, that is, sustain round about it a system of meanings whose 
reciprocities, relationships and involvements do not require to be made explicit in order to be exploited. ${ }^{64}$

Yet, in seeming admonishment of Merleau-Ponty for merely making a factual claim about explicitness rather than a logical claim about the limits of conceptuality, Dreyfus immediately adds,

Merleau-Ponty should have said "can't be made explicit if they are to be exploited".

Dreyfus is apparently operating here with the assumption that whatever is open to concepts, whether in language or thought, must rest on a ground floor of something fundamentally non-conceptual, in this case practices, which necessarily escape the sayable or thinkable.

The problem, however, with taking practices, or anything else, to be the general conditions of the possibility of language, thought, or intelligibility is that it is very questionable whether such a thing is necessary and very difficult to make out what the idea of such a condition is supposed to come to. ${ }^{65}$ Following a traditional reading of Immanuel Kant's idea of transcendental limits beyond which we cannot know anything, we have perhaps a natural tendency to think of such logical limits as constituting an "outer" boundary of the sayable. But positing such a bounds of sense, whether an "outer" limit of transcendental conditions beyond which we cannot think or say anything, or a lower substrate of background practices that ground what we can think or say, seems inevitably to demand the correlative notion of there being a "something" beyond or beneath the limit that we manage to grasp just long enough to say we can't think "it": this seems to require us precisely to think or talk about that which we are said to be unable to think or talk about. And this seems to me to be simply an unstable idea. ${ }^{66}$

Previously, I claimed that treating ordinary language and social practices as proto-theories, as is characteristic of theoretical holism, leads to a quick descent into incoherence. While the fact, if that's the right thing to call it, that I am pointing to here, namely that these practices are not logically sacrosanct, entails that they are subject to criticism and so are revisable, we should expect both criticism and revision to look different here than they do in the case of the sciences. ${ }^{67}$ Perhaps in some cases, criticism and revision are actually simpler; I suspect more often than not that they are more complicated. At any rate, there is no good reason to believe that Wittgenstein's "ancient city" is one that we learn to navigate in virtue of, or as, a theory. Rather, we learn the thoroughfares of theories, whether straight boulevards or windy roads, subsequent to our mastery of our first language, not, I should reemphasize, as a matter of logical necessity, but as a matter of deeply intransigent fact. Of course this could be taken as an admission on my part that I have failed to show a metaphysical or 
a priori difference between the social and natural sciences, a difference, that is, whose conceivability takes nothing for granted about us. I think instead that getting over the habit of insisting that only distinctions graspable from a non-existent epistemological position can be philosophically significant distinctions is a mark of intellectual progress.

\section{V}

A

Where does this leave us with the question of naturalism, pluralist or otherwise, in the social sciences? Dupré's reflections on Wittgenstein were my starting point and so my discussion has up to now accordingly preoccupied itself with the relations between ordinary language, the languages of the social sciences, and the languages of the natural sciences. In resisting Dupré's continuity claim, I have been putting considerable pressure on a particular idea of ordinary language as well as on other related ideas. Specifically, I have argued that we overlook an important difference between the social and natural sciences if we fail to appreciate the nature of ordinary language and the everyday world that it brings in tow. Yet, my focus on language and theory thus far may seem to reflect an excessive concern with mainly epistemological or methodological issues, and so leave unaddressed the more ontological side of things. That is, to some it might seem that we are left with questions as to whether the very existence of normativity immanent in ordinary language practices is itself something that ought to be explained by the sciences, natural or social. Does the fact of norm-carrying creatures like us call for such an explanation?

In recent times, John McDowell's Mind and World has offered the most significant, even if not completely unproblematic, negative rejoinder to the explanatory impulse embodied in this question. McDowell worked to preserve the idea that thought and belief must be rationally responsive to nature, and so to avoid the kind of coherentism he finds for instance in Donald Davidson, a view from which McDowell sees our rational capacities remaining permanent aliens in the world. McDowell's way of attempting to find this balance is to argue that conceptual capacities are drawn into action in sensual perception. ${ }^{68}$ McDowell writes in his introduction,

The mistake here is to forget that nature includes second nature. Human beings acquire a second nature in part by being initiated into conceptual capacities, whose interrelations belong in the logical space of reasons. Once we remember second nature, we see that operations of nature can include circumstances whose descriptions place them in the logical space of reasons, sui generis though that logical space 
is. ... Conceptual capacities, whose interrelations belong in the sui generis logical space of reasons, can be operative not only in judgements . . . but already in the transactions in nature that are constituted by the world's impacts on the receptive capacities of a suitable subject; that is, one who possesses the relevant concepts. Impressions can be cases of its perceptually appearing - being apparent - to a subject that things are thus and so. ${ }^{69}$

McDowell's reference to "second nature" here signals that he regards himself as a naturalist, albeit of an unorthodox variety: he refers at one point to his view as "naturalized Platonism" as opposed to "Rampant Platonism". ${ }^{70}$ In speaking of our acquiring a "second nature", McDowell is referring to the ubiquitous phenomenon of the initiation of human beings into a set of practices most closely associated with learning their mother tongue(s) and home culture(s), a process of enculturation McDowell refers to as Bildung. ${ }^{71}$ It is precisely Bildung that McDowell believes obviates the felt need for accounts of our conceptual capacities that would take what he calls a "sideways on" view that is typical of mainstream scientific naturalist approaches. "Sideways on" is McDowell's metaphor for the self-understanding of traditional philosophy, including its iterations in modern naturalism, from which the philosopher imagines that, while taking nothing for granted about the practices and concepts actually involved in making rational assessments, we can nevertheless somehow manage to investigate whether those same practices and concepts yield independently intelligible results. What McDowell sometimes calls "bald" naturalism is the view that the natural sciences can be of assistance in such a sideways on task by "building up" the normativity found in our ordinary language activities bit by non-normative bit from resources provided by various sciences. Because the bald naturalist's attempt to explain that normativity must imagine itself as relying on the illusion of a sideways on view, McDowell thinks bald naturalism itself is fundamentally incoherent. Bildung is his own naturalist counterpoise.

McDowell's views in Mind and World have of course been subject to much debate and criticism, even by those who are best described as broadly sympathetic to his outlook. ${ }^{72}$ More important here, many philosophers still hold that so-called "sideways on" projects are worthy of pursuit, under the rubric of fields such as social psychology, cognitive science, evolutionary psychology, evolutionary game theory, and comparative psychology. Some naturalists have raised specific objections to McDowell's claims for the special nature of human conceptual capacities and the particular form of normativity they embody. Another complaint concerns McDowell's relative silence on the relevance of investigating the evolution of human culture, and thus of creatures capable of gaining a second nature. ${ }^{73}$ In a related vein, others are skeptical of McDowell's claims for the sui generis character of human conceptual capacities. ${ }^{74}$ 
Still others have proceeded as though Mind and World had never been written. ${ }^{75}$

Certainly, some criticisms of McDowell or McDowell-like positions can have merit. I don't dispute, moreover, that various scientific disciplines, in particular those like social or comparative psychology that are, as it were, close to the surface of our lived experience, can provide interesting insights into what we might think of as the underlying necessary conditions for our being the kinds of creatures we are. ${ }^{76}$ To put it modestly, however, no one has the slightest idea what it looks like for an explanatory account in psychological or neuroscientific terms (however intricate and detailed), to explain, as in make intelligible, the normativity in our various linguistic and scientific practices. ${ }^{77}$ It is entirely unclear how fields such as social psychology, comparative psychology, or infant psychology are supposed to provide us with any criteria for what is to count as a truer "match" between our concepts and practices and reality, conceived independently (of what? those concepts and practices?) or what it would mean for such fields to provide any non-question-begging criteria for deciding that some concepts allow us to cope "better" with our environment than others. However much more humanized such fields may seem when compared to physics, we are still involved here with a pretty traditional, now just more complicated, idea of a "sideways on" bridging project between non-normative building blocks and our everyday activities. Nor is it to the point to suggest that my remarks here conceal a crypto a priorist agenda and that these are really "empirical" questions. In fact, if one is suspicious of traditional notions of the a priori, this has repercussions too for what we can call an "empirical question" with a straight face. Without a traditional notion of the $a$ priori to push off against, claims that every idle speculation is empirical, however unmoored it might be from even the thinnest sketch of an actual explanatory schema, are themselves completely empty. Trying to fill in the massive gaps in Quine's story of surface irritations to torrential output with theories from psychology, while perhaps appealing, will not alter this situation. (Modules or speech centers may be activated by signals describable in terms with no semantic content. Speakers, so far as we can imagine, respond to meaningful words.)

\section{$B$}

I have been portraying second-philosophical, "sideways on" ideas about using the natural sciences to explain or assess the normativity immanent in ordinary language(s) as rife with confusion. If, however, one is looking for a discipline that might show promise for critiquing our set of conceptual commitments, that discipline does not come from the natural sciences, but from the social sciences, in particular, from certain approaches within social anthropology and sociology. At least as these used to be 
commonly practiced up until fairly recently, these have the potential to provide us with a comparative view, all the while remaining clearly within the space of normativity. If we imagine a form of human life as an orientation of sense in the world that is always and inextricably a biological and cultural hylomorphism, then it seems to be the case that given our common biology, there can be the promise of investigating how these different orientations are expressed that respects both their diversity and commonality. (This used to be called the "psychic unity of mankind".) Of course, empirical findings can lead us to revise the specific conceptual structures and norms we find to be most constitutive of whatever conceptual capacities are required for knowledge and rationality. But, on pain of incoherence, such revision will be the result of starting from the current critical faculties we already have confidence in. These findings, moreover, will not speak for themselves. Finally, I should stress that seeing through the illusion of the demand for a "sideways on" perspective or for second philosophy in no way entails a kind of conservatism whereby we are forced to just settle for whatever conceptual commitments we find manifested in our ordinary language activities. These commitments can themselves be material for critical reflection on both everyday life and on the findings of science in a way that doesn't require us to imagine anything like an extra-logical space.

Next, while my reference earlier to "lived experience" should certainly be taken to mark the importance I attach to a first-person perspective when thinking about normativity and the social sciences, it should not be taken to suggest any affinity for subjectivism. Everything I have said about our inculcation into the norms of ordinary language makes clear that I regard the agent's perspective as only notionally separate from the public everyday world. The conception of world in which we begin to philosophize is thus crucial for clarifying certain key confusions in debates about naturalism in the social sciences. If this world is the ordinary social world that we learn to navigate when we learn to speak and act, there is no reason to think that it can be understood either through the logical equivalent of chemical decomposition or in terms of formal structures. ${ }^{78}$ In fact, it is precisely the kind of reductionism pervading much naturalist thinking in the philosophy of mind that, for all of its pretensions to modern materialism, is no less "Cartesian" than was the master himself. Building up normativity bit by non-normative psychologistic bit seems fated to trying to understand the normative entirely on the side of the subject, leaving the context of the world out of the picture. Yet there is simply no good reason for believing that approaches which try to make sense of normativity by ignoring context would have any chance of working, when the only examples we have of understanding when actions are correctly performed or expressions are correctly used are shaped by the context of their performance or the occasions of their use. Conversely, the idea of treating worldly context itself as a subject 
for the natural sciences, however pluralistically one conceives of them, strikes me as downright oxymoronic.

In my earlier discussion of theoretical holism, I suggested that treating ordinary language and its practices as a kind of theory distorts their nature and so blocks from view, from the top down as it were, the immediacy of the normativity these instantiate. Theoretical holism over intellectualizes background practices and ordinary language by viewing them through theoretical lenses and the result is that their immanent normativity becomes too remote to recognize. Naturalizing projects, on the other hand, when taken as providing anything like a full story, blot out the very idea of normativity, including the rationality found in scientific enterprises themselves. Such "bottom-up" strategies that attempt to explain the very existence of such normative features of our lives in nonnormative natural-scientific terms make any notion we might have of normativity, either theoretical or practical, equally unavailable to understanding by failing to accommodate the very idea of such a thing. ${ }^{79}$ If theoretical holism starts with uninterpreted chirps, bald naturalism starts and ends with brute chirping. Both invite the emptiness that comes with a refusal to acknowledge "the natural phenomenon that is normal human life is itself already shaped by meaning and understanding". ${ }^{80}$

\section{VI}

In a recent introduction to the philosophy of the social sciences, we find the following passage in the chapter devoted to the hotly contested issue of norms:

For many philosophers, norms represent the last bastion in the defense of human uniqueness. The irreducibility of "ought" to "is" marks a gap between the human and natural world. Social scientific attempts to appeal to norms must fail if they take norms to be anything but a sui generis feature of the social world. ${ }^{81}$

I am not acquainted with the author's specific views on the subject broached in the quotation. Nevertheless, despite its surface neutrality, the passage does seem to me to embody a central strain of modern naturalism's self-understanding, namely as having excised one excrescence after another from our image of what was supposed to be distinctively human. For many who have internalized it as second nature, this confidence might lend the current essay a sense of a last, desperate stand or rearguard action - a view of normativity close in spirit to a "God of the gaps" view of religion, already common after Newton and in many quarters plain common sense after Darwin. But this appearance notwithstanding, I am claiming that the debate about normativity is where the fight between modern naturalism and the kind of (naturalist) 
view that I am defending should have been fought 350 years ago. On behalf of those sympathetic to what I have said here, I confess it has taken us a while to get over the routine drubbings we have taken since the 17th century. Some of those beatings were no doubt well deserved. Still, this "last bastion" should always have been our first frontline of counterattack.

With some qualifications, much of the view that I have defended in this paper was already contained in spirit in this passage from Alasdair MacIntyre:

Quine's conclusion is that ... any genuine science of human behavior must eliminate such intentional expressions; but it is perhaps necessary to do to Quine what Marx did to Hegel, that is, to stand his argument on its head. For it follows from Quine's position that if it proved impossible to eliminate references to such items as beliefs and enjoyments and fears from our understanding of human behavior, that understanding could not take the form which Quine considers the form of human science, namely embodiment in law-like generalizations. An Aristotelian account of what is involved in understanding human behavior involves an in-eliminable reference to such items; and hence it is not surprising that any attempt to understand human behavior in terms of mechanical explanation must conflict with Aristotelianism. ${ }^{82}$

MacIntyre's recourse to the expression "in-eliminable reference", with its gesture at impossibility arguments, should perhaps make us somewhat suspicious, given what I've said previously about the apriorism in Dreyfus' Heideggerian account of practical holism. MacIntyre's reference to "law-like generalizations", moreover, suggests that, at least when he wrote After Virtue, he may have been in thrall to an outdated positivist view of science which no contemporary naturalist holds. Still, even if Dupré's version of pluralist naturalism is certainly free from many of positivism's well-documented sins, there is a sort of residual scientism (I believe it is actually an unacknowledged holdover from positivism) running through his thought and through the thought of many contemporary naturalists in the philosophy of the social sciences. Consequently, I find the instinct to which MacIntyre is giving expression in the previous passage to be fundamentally sound. To put it starkly: for all of the unquestionable explanatory power unleashed by 17 th century science and its many offspring, there never really was a genuine question as to whether scientific naturalism gave us a believable story about human language and social relations. Neither, therefore, was there ever any need to stand arguments like Quine's on their heads. There was merely a need for exposing the gross inadequacies in their very formulations. 
In a memorable passage from his classic essay "Thick Description: Toward an Interpretive Theory of Culture”, Clifford Geertz writes,

Believing, with Max Weber, that man is an animal suspended in webs of significance he himself has spun, I take culture to be those webs, and the analysis of it to be therefore not an experimental science in search of law but an interpretive one in search of meaning. ${ }^{83}$

One of the main problems for those in thrall to scientific naturalism in philosophy, it seems to me, is accommodating themselves to the idea that such a creature as Geertz describes here could be a starting point for serious work. And so, for example, in "Beyond Understanding: The Career of the Concept of Understanding in the Human Sciences", Paul Roth writes that interpretivists think "cultural artifacts are evidence of meaning, of inner life reified" and that "[n]onnatural states - how things stand in the minds of those studied - account for objects in the world" ${ }^{84} \mathrm{I}$ am unsure to whom these remarks are addressed. It certainly seems odd to imagine them pertaining to the arch-interpretivist Geertz, at least based on anything he ever wrote. In any case, there is no reason for holding up a caricature of "inner objects" that the interpretive social scientist must per impossible "get at". ${ }^{85}$ Meaning does not find its "expression" in cultural artifacts any more than thought finds its "expression" in language. It is the artifacts themselves that must be understood, be they paintings, poems, novels, roadways, utterances, rituals, or ruins. There is no harm in retaining certain mundane uses of "meaning" and "understanding" where, for example, we say we understand the meaning of the painter through understanding the meaning of what he or she produced. It may be both the painting and the painter that we want to understand. But this gives no call to take these ordinary uses in any inflammatory senses, ones that invoke a mystical inner object that must be, but cannot quite be, gotten at. Thus, there is no reason to take Geertz's unabashed interpretivist use of the term "web of meaning" as an invitation to accuse him of hypostasizing "meanings" as some kind of ethereal entity. The substantive "meaning" can be read as a useful, albeit frequently misunderstood, shortcut for indicating what a speaker of a language does, for example, when asked to explain an utterance, which is to substitute for it other words in their explanation. ${ }^{86}$ Even if the manner in which interpretivists and hermeneuticists sometimes speak can encourage misunderstandings, the idea that when they talk of "meaning" they intend to refer to some unobservable entity "outside the causal order" (the "idea" idea as it were) is just one more tired philosophical dogma. ${ }^{87}$ Speaking, and so explaining your speech, are observable actions; there is nothing hidden about them. Qua actions, they are already normatively shaped. The alternative is to regard speaking as the emitting of normatively inert signals that require interpretation by placing them into a semantic theory. This brings us full 
circle back to theoretical holism, which as I have tried to argue, is nothing more than a collection of statements in search of a sense.

Few writers have been more convincing than Dupré in arguing for pluralism in the philosophy of the natural sciences. Displacing physics as the paradigm to which the natural sciences must aspire has been entirely healthy. And yet, although the idea of pluralist naturalism in the social sciences may sound correct, my discussion has followed the tendency of many other writers sympathetic to interpretivism and hermeneutics by giving a certain pride of place to philosophical issues connected to cultural/social anthropology. In this tradition, the anthropologist is seen as trying to make sense of other societies in an on-going comparison between its background understanding and her own; there is no thought in this of imagining either from a normatively inert "sideways on" perspective. ${ }^{8}{ }^{8}$ Astonishing (or perplexing) as this may sound, I am trying to articulate a perspective from which the ongoing critical project of Philosophical Anthropology, informed by and informing anthropology, can be regarded as the "queen of the sciences". ${ }^{89}$

It is worth emphasizing that this is importantly distinct from, but not inconsistent with, a perspective that acknowledges the usefulness of "middle-range" theories in sociology or political science, for example. In such cases, a social scientist might make a conscious choice to screen off philosophically loaded questions about normativity, and on this basis, employ objectifying methods that resemble or draw on those of the natural sciences. There is nothing inherently wrong with such approaches. Studies that investigate causal relations between everyday non-theoretical macro variables (such as "church-goer" and "philosopher", for example) might be suitable for studying limited aspects of human behavior, whether these come from one's own society, a different society, or both. They can have explanatory power, sometimes even providing long-term predictive ability, and thus produce much useful knowledge. It is, however, important to be clear about why they are only suitable for "adducing external facts" about their subjects: naturalist methods prescind from fully enculturated human beings, and do so always at the risk of obscuring this inconvenient truth. They do not add up to an overall theory of the human language user, i.e., the human being. As I have argued in my analysis of theoretical holism, failing to recognize this risk is a recipe for incoherence. From this perspective, the thick description recommended by interpretivists and like-minded social scientists is, in an important sense, more fundamental than the thin descriptions provided by naturalist methods..$^{90}$ To take one example, the various iterations of rational choice (even though not paradigmatic of a naturalist theory per se) are most properly understood as investigating a set of skills for comporting oneself that, while perhaps all cultures have achieved in some measure, others have refined to a much higher degree (approaching idolatry in some cases). Barring a descent into a view of detached means-ends rationality bordering on Platonism 
in mathematics, the historical, cultural context for making sense of such an achievement calls for thick description; a sufficiently different cultural context, or a radical enough historical change of context-dependent circumstances, would escape the purview of rational choice theory, thus making its reliance on thin description much less relevant for understanding what is going on. ${ }^{91}$ None of this is a plea for anti-naturalism, but for a widening of the scope of what we accept as natural, so as to include the nature of human life as already shaped by meaning and understanding. Otherwise, naturalism is far too restricted.

Galileo's shattering of Aristotle, and with it a naïve trust of our experience of ourselves and of nature, the rupture with which modern naturalism began, has no doubt been mostly good for science (certainly for physics, chemistry, and their progeny). In many other practical respects, probably too many to count, it has been decisively beneficial for most of us. For philosophy, and perhaps other very countable but sadly not counted ways of understanding ourselves, not so much. It goes without saying that for all the wisdom I find in MacIntyre's work, and in the work of others such as McDowell, G.E.M. Anscombe, and Charles Taylor, Heidegger, and of course Wittgenstein, there is simply no question of a wholesale re-adoption of an Aristotelian worldview. We simply know too much, about the history of the universe and of our galaxy, and about the evolution of life and human culture, to fit this into any sort of static framework, whether ancient or medieval. Trying to force our knowledge into the confines of an entirely pre-modern worldview would do unimaginable intellectual violence to our thinking. Among other things, we know that there was an awfully long time when there simply were no "self-interpreting animals" around. Yet, once we get into view what interpretivists and hermeneuticists, broadly understood, have been trying to say about "meaning", at least in their more lucid moments, I hope it is clear that language, properly understood, is, and always has been, the issue separating them from mainstream naturalists, particularly in philosophy and the social sciences. And why shouldn't language be the great divider? I think, for better or worse, there is only so much that can be done to normalize this very strange fact, if "fact" is indeed the right word here. Perhaps we are stuck with ourselves, sui generis. Explanations come to an end (and start) from somewhere.

\section{Notes}

1. See John Dupré, “Social Science: City Center or Leafy Suburb,” Philosophy of the Social Sciences 46, no. 6 (2016): 548-64.

2. An early expression of John Dupré's pluralism can be found in The Disorder of Things: Metaphysical Foundations of the Disunity of Science (Cambridge: Harvard University Press, 1993). More recently, see John Dupré, Processes of Life: Essays in the Philosophy of Biology (Oxford: Oxford University Press, 2012). 
3. See for example John Dupré, "It Is Not Possible to Reduce Biological Explanations to Explanations in Chemistry and/or Physics," in Contemporary Debates in Philosophy of Biology, ed. Francisco J. Ayala and Robert Arp (Oxford: Wiley Blackwell, 2010), 32-47. See also with A. Powell, "From Molecules to Sytems: The Importance of Looking Both Ways," Studies in History and Philosophy of Biological and Biomedical Sciences 40, no. 1 (March 2009): 54-64.

4. John Dupré, "How to Be Naturalistic Without Being Simplistic in the Study of Human Nature," in Naturalism and Normativity, ed. Mario de Caro and David Macarthur (New York: Columbia University Press, 2010), 289.

5. My hedging language is due to there being unobjectionable uses of "know" that fall "in between" more dubious cases that philosophers are prone to mischaracterize on the one hand, and less controversial cases on the other. The dubious cases include, famously, "I know I have a hand", where it requires an effort to imagine a context in which such an utterance could be seriously made. The uncontroversial cases include examples more evidently connected to a theory, such as "I know that Carbon can form 4 SP3 bonding orbitals". As an intermediate case I have in mind a particular example of Dupré's to which I will return later.

6. What I mean by "undergird" will become clearer later in the paper. It does not mean "provide a foundation for".

7. Another recent paper that I think also goes wrong, in large measure because it fails to appreciate the significance of ordinary language, is Julie Zahle's, "Methodological Anti-Naturalism, Norms, and Participant Observation," in Normativity and Naturalism in the Philosophy of the Social Sciences, ed. Mark Risjord (New York: Routledge, 2016), 78-95. Among Zahle's arguments against the idea that the social sciences make use of a unique and ineliminable method, and so are relevantly distinct from the natural sciences, is that ethological studies of higher mammals such as great apes may well require forms of participant observation strikingly similar to those of the social anthropologist. The example Zahle uses here is a fascinating one, but she neglects to mention that a) there are many things we simply wouldn't say of a gorilla that we would routinely say of a human being, and b) there is no possibility of learning the language of a gorilla, let alone interviewing one. Ethnography and ethology are different.

8. Although Wittgenstein is clearly a key figure in the background for much of my essay (hardly surprising since Dupré takes his own starting point from a remark in the Philosophical Investigations), my main aim in referring to his thought in Part IV and throughout the essay is not exegetical, but rather to make more visible a way of reading his later work that, even if it has received some attention in discussions of naturalism in philosophy more generally, has not in my view been adequately brought to bear in disputes concerning naturalism pertinent to the philosophy of the social sciences.

9. Dupré, "Social Science," 557-58.

10. Even if I strongly disagree with his substantive conclusions, a nice discussion to the background of this question can be found in Paul A. Roth, "The Philosophy of Social Science in the Twentieth Century: Analytic Traditions: Reflections on the Rationalitätstreit," in The Sage Handbook of the Philosophy of Social Sciences, ed. Ian Jarvie and Jesus Zamora-Bonilla, 103-18 (London: Sage, 2011). See also 2013 of Cahill, where I lay out some of my disagreements with Roth.

11. Ludwig Wittgenstein, The Blue and Brown Books, 2nd ed. (Oxford: Blackwell, 1969), 18. Note that Wittgenstein does not claim that "our preoccupation with the method of science" is the only source of our craving for generality. 
12. Ludwig Wittgenstein, Philosophical Investigations, ed. and trans. G. E. M. Anscombe, 2nd ed. (Oxford: Blackwell, 1997), \$18. Henceforth PI. Quoted by Dupré, "Social Science," 1.

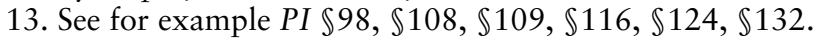

14. Dupré, "Social Science," 549. Despite Dupré's use of the pejorative sounding "charming metaphor" to describe Wittgenstein's remark, the tone of his paper makes it evident that he is no anti-Wittgensteinian naturalist. Indeed, Dupré has relied explicitly on insights taken from Wittgenstein to critique a kind of Cartesianism that runs through much evolutionary psychology. See his Human Nature and the Limits of Science (Oxford: Oxford University Press, 2001), 31-36.

15. Dupré, "Social Science," 553.

16. Ibid., 554.

17. Dupré doesn't discuss practices in his paper. Depending on how one understands the notion of rules in later Wittgenstein's writing, this might already suggest trouble. Contrary what seems to be a popularized view, Wittgenstein never claims in Philosophical Investigations that rule-following is what is fundamental to language use, let alone social life. If anything, he says that many of our concepts are unbounded by rules (see PI $\$ 68$ ). And at PI $\$ 202$ he writes that " 'obeying a rule' is a practice". This suggests that participating in a practice, not rule-following per se, is the more important notion at work in the remarks on rule-following.

18. Dupré, "Social Science," 555-56.

19. Peter Winch, The Idea of a Social Science and Its Relation to Philosophy (London: Routledge, 1958), 86-88. Cited in Dupré, “Social Science," 557.

20. Dupré, "Social Science," 557. Winch doesn't use the notion of participation in the quotation cited by Dupré. Instead he speaks of the need for the sociologist to have some kind of “religious feeling”. I won't explore here the possible significance of this discrepancy.

21. Dupré, "Social Science," 558. This suggests a serious distance on Dupré's part from other naturalist pluralists such as Paul Roth, who, following Quine, finds the very idea of meaning anathema. See Roth, "The Philosophy of Social Science in the Twentieth Century."

22. Dupré, "Social Science," 558.

23. Ibid., 559.

24. See G. E. Moore, "Proof of an External World," Proceedings of the British Academy XXV (1939).

25. We read at On Certainty $\$ 32$ : It's not a matter of Moore's knowing that there's a hand there, but rather we should not understand him if he were to say "Of course I may be wrong about this". We should ask "What is it like to make such a mistake as that?" - e.g. what's it like to discover that it was a mistake? Moore's own example does not of course deal with the epistemic status of our earliest enculturation, but there are in any case serious conceptual confusions in his approach to knowledge. See also Ludwig Wittgenstein, On Certainty, ed. G. E. M. Anscombe and G. H. von Wright, trans. Denis Paul and G. E. M. Anscombe (New York: Harper, 1972), $\$ 93, \mathbb{\$ 3 6 9 - 7 0 . ~}$

26. Or, if it makes little sense to speak of the child "fitting" data at the beginning of his interpretive exercise, one might use the passive and speak of the data "getting" fit into an overall theory.

27. Hubert Dreyfus, "Holism and Hermeneutics," The Review of Metaphysics 34, no. 1 (September 1980): 3-23. My choice of Dreyfus' work in this area is not only due to what I find profoundly right about it, but as will become clear in the next section, also due to what I find instructively wrong with it.

28. See W. V. O. Quine, “Two Dogmas of Empiricism," in From a Logical Point of View (Cambridge: Harvard University Press, 1953), 41; See also Donald 
Davidson, "Radical Interpretation," in Inquiries into Truth and Interpretation (Oxford: Oxford University Press, 2001), 125-40. Of course, not all semantic or theoretical holists are created equal. Quine thinks it's intelligible to begin our epistemological enterprise with mere "surface irritations", while Davidson somewhat more plausibly maintains that our truth-theory has to start with more readily observable objects, since he believes the notion of "evidence" available to us on Quine's understanding of the "Humean condition" is simply too thin to support any robust conceptions of meaning and truth. See W. V. O. Quine, "Epistemology Naturalized," in Ontological Relativity and Other Essays (New York: Columbia University Press, 1969), 69-90; Donald Davidson, "Meaning, Truth, and Evidence," in Truth, Language, and History (New York: Oxford University Press, 1990), 47-62.

29. W. V. O. Quine and J. S. Ullian, The Web of Belief (New York: Random House, 1970), 52-53. Quoted in Dreyfus, "Holism and Hermeneutics," 6.

30. W. V. O. Quine, The Ways of Paradox and Other Essays (Cambridge: Harvard University Press, 1976), 233. Quoted in part in Dreyfus, "Holism and Hermeneutics," 6.

31. Dreyfus, "Holism and Hermeneutics," 6.

32. My qualification comes from my wanting leave space for something like a pre-cultural, biological dimension.

33. Thus, we see that practical holism pertains not only to practical activities such as carpentry or dancing.

34. I am not claiming that "theoretical" = "sharply defined", or that background understanding is always semantically messy, so to speak. Dupré makes clear for his part, moreover, that he thinks there is plenty of fuzziness even in the more explicitly theoretical parts of scientific activity. See Dupré, "Social Science," 561.

35. Dreyfus, "Holism and Hermeneutics," 7. Cf. Wittgenstein, On Certainty,

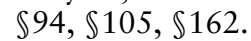

36. See Dupré, "Social Science," 557-58. See also Wittgenstein, On Certainty, $\$ 341, \$ 344$. This includes contexts in which we wish to engage our background understanding in order to critique it. I will say more about this later. Dagfinn Føllesdal's paper "Hermeneutics and Hypothetical-Deductive Method" exhibits to my mind one of the starkest misunderstandings imaginable of the difference between the sense of "interpretation" in the hermeneutic tradition and that in the Quine-Davidson tradition, that is, between practical and theoretical holism as Dreyfus describes these. In effect, Føllesdal assumes that the features of our background relevant for understanding a historically distant text (and so presumably a foreign culture) can be straightforwardly treated as hypotheses and so subjected to a method of falsification. Føllesdal thus not only conflates theoretical and practical holism, he almost seems to take a perverse pride in erasing what is distinctive of the hermeneutic tradition in his treatment of historical pre-judgements (our background understanding) as a set of theoretical hypotheses. See Dagfinn Føllesdal, "Hermeneutics and the Hypothetical-Deductive Method," in Readings in the Philosophy of Social Science, ed. Michael Martin and Lee McIntyre (Cambridge: MIT Press, 1994), 233-45.

37. Dreyfus, "Holism and Hermeneutics," 9-10. There are two ideas contained in this passage from which I would want to distance myself. One is the undue prominence it seems to give to confirmation or verification for the understanding of science. This often goes with an uncritical willingness on the part of interpretivists like Dreyfus, Winch, and Charles Taylor to accept something like a covering model view of science, prevalent among positivists. Dupré 
suggests (see "Social Science," 563) that Wittgenstein himself may have held some such view. At any rate, this question is not directly relevant for my purposes here and so I will not pursue it. Roth, "The Philosophy of Social Science in the Twentieth Century" has a nice discussion of this question. The second idea concerns Dreyfus' apparently logical use of “cannot". I will say more about this later.

38. Dupré, "Social Science," 549.

39. See Wittgenstein, On Certainty, $\mathbb{2} 204-5$. Insisting on the intelligibility of science apart from ordinary practice in effect amounts to a form of metaphysical realism, or, what amounts in my view to the same thing, a reintroduction of a sharp dichotomy between the contexts of discovery and justification. Whatever else other philosophers of science may think about such a step, I have my doubts that Dupré has any interest in taking it.

40. This will presumably not be the case, however, for the philosopher or historian of natural science.

41. My way of putting things here is likely to encounter resistance from either philosophers or ethologists who regard gorillas, for example, as exhibiting behavior that calls for participant observation in order to understand them. A point of enormous importance here, manifest in my frequent practice of including "social world" along with "ordinary language", is first that these two are only notionally distinct ideas, and second that on my understanding of what a social world is, a gorilla doesn't have a language, and ipso facto any background understanding.

42. Dreyfus, "Holism and Hermeneutics," 16.

43. Ibid., 17.

44. Dupré, "Social Science," 557.

45. Dreyfus, "Holism and Hermeneutics," 20.

46. See PI $\$ 432$.

47. The apt term "acoustic blast" is from John Searle, even though I am not claiming that Searle is a theoretical holist. See John Searle, Speech Acts: An Essay in the Philosophy of Language (Cambridge: Cambridge University Press, 1969), 3.

48. See Wittgenstein, On Certainty, $\$ 114-15, \$ 126$.

49. Wilfrid Sellars, "Empiricism and the Philosophy of Mind," in The Foundations of Science and the Concepts of Psychoanalysis, Minnesota Studies in the Philosophy of Science, ed. H. Feigl and M. Scriven (Minneapolis: University of Minnesota Press, 1956), 127-96.

50. Stanley Cavell, Must We Mean What We Say? A Book of Essays (New York: Scribner, 1969), 39.

51. See Cora Diamond, "Criss-Cross Philosophy," in Wittgenstein at Work: Method in the Philosophical Investigations, ed. Erich Ammereller and Eugen Fischer (London: Routledge, 2004), 201-20. Elsewhere, Diamond describes this manner of philosophizing as "invitational" in the sense that any conclusion one reaches regarding the emptiness of a philosophical thesis is always provisional and only always following an invitation for one's opponent to clarify the meaning of the thesis. See Cora Diamond, "The Hardness of the Soft: Wittgenstein's Early Thought About Skepticism," in Varieties of Skepticism: Essays After Kant, Wittgenstein, and Cavell, ed. Andrea Kern and James Conant (Berlin: De Gruyter, 2014), 145-82.

52. In Philosophical Foundations of the Social Sciences, Harold Kincaid raises the question whether the theoretical holistic naturalized epistemology he advocates in the social sciences rules out skepticism by "fiat", but only to drop the issue on the grounds that skepticism poses no greater problem for 
the social sciences than it does for the natural sciences. By "skepticism”, Kincaid clearly means at least "external world" skepticism; whether he would also include other minds skepticism is less certain. At any rate, Kincaid refers in passing to Barry Stroud's paper "The Significance of Naturalized Epistemology," Midwest Studies in Philosophy 6, no. 1 (1981). In a few footnotes to that very illuminating paper, Barry Stroud comes tantalizingly close to hitting on the same problem with theoretical holism that I am pressing here. Stroud's discussion does not touch on meaning, however, but on the status of any notion of an external world that we might be able to make sense of on Quine's views. Stroud casts the issue in terms of two ways that Quine might understand the "Humean predicament" in which each of us supposedly finds himself. The first way, which is presumably Quine's actual view, is that the data of the senses gives us no deductively sufficient justification for our beliefs about the external world. Scientific investigation remains fragile, but intelligible on this view. The second way to understand the "Humean predicament", what Stroud argues Hume believed himself to have actually shown, is that the senses provide us with no evidence at all, deductive or inductive, for believing in so much as the very idea of an external world. Had Stroud made more of this question, it would, I think, have rightly pushed his discussion of Quine's project towards what James Conant has recently termed a "Kantian" version of skepticism rather than a mere "Cartesian" version associated with the first understanding of the "Humean predicament". Read this way, Kant's analysis brings us to the brink of attributing meaning skepticism to Hume (and of course to Quine as well). See Harold Kincaid, Philosophical Foundations of the Social Sciences (Cambridge: Cambridge University Press, 1996), 22; Barry Stroud, "The Significance of Naturalized Epistemology," Midwest Studies in Philosophy 6, no. 1 (1981): 455-72, especially footnotes 20, 31, 34. See also James Conant, "Two Varieties of Skepticism," in Rethinking Epistemology, ed. Guenter Abel and James Conant, vol. 2 (Berlin: Walter De Gruyter, 2012), $1-73$.

53. Saul A. Kripke, Wittgenstein on Rules and Private Language: An Elementary Exposition (Oxford: Blackwell, 1982).

54. See Warren Goldfarb, "Kripke on Wittgenstein on Rules," Journal of Philosophy, 82 (September 1985): 485.

55. See John McDowell, "Wittgenstein on Following a Rule," in Essays on Wittgenstein's Later Philosophy, ed. Crispin Wright (Dordrecht: Reidel, 1984), 325-63.

56. PI $\$ 192$.

57. Ibid., $\$ 201-2$.

58. In fact, it's not even obvious that we are left with mere signs. If a sign is really only intelligible as what we are left with after we prescind from a full-blown symbol of meaningful language, then the idea that we can make intelligible the notion of sign without first having some grasp of meaning is itself dubious.

59. Cavell, Must We Mean What We Say?, 19-20.

60. Dreyfus, "Holism and Hermeneutics," 9-10 (emphasis added).

61. Dreyfus, "Holism and Hermeneutics," 16.

62. Ibid., 17. David Stern seems to follow Dreyfus here in two papers that explain the significance of practical holism for the social sciences. See his "Practices, Practical Holism, and Background Practices," in Heidegger, Coping, and Cognitive Science: Essays in Honor of Hubert L. Dreyfus, ed. Mark Wrathall and Jeff Malpas (Cambridge: MIT Press, 2000), 66 and "The Practical Turn," in The Blackwell Guide to the Philosophy of the Social Sciences, ed. Stephen 
P. Turner and Paul Roth (Oxford: Blackwell, 2003), 185-206. For a critique of attempts to use practice theory as an a priori limit to thought and language in Dreyfus, Pierre Bourdieu and Theodore Schatzki, see my "The Habitus, Coping Practices and the Search for the Ground of Action," Philosophy of the Social Sciences 46, no. 5 (2016): 498-524.

63. Hubert Dreyfus, "Overcoming the Myth of the Mental: How Philosophers Can Profit from the Phenomenology of Everyday Expertise (APA Pacific Division Presidential Address 2005)," Proceedings and Addresses of the American Philosophical Association 79, no. 2 (November 2005): 14 (emphasis added).

64. Hubert Dreyfus, "Return of the Myth of the Mental," Inquiry 50, no. 4 (August 2007): 357 (brackets in original).

65. In his debate with Dreyfus, McDowell argued primarily for what he termed the "situated specific" nature of concepts and rationality and, based on this, claimed there was no need for a ground floor such as Dreyfus maintained. He did not focus there on the very intelligibility of such a notion, but has done so elsewhere. This exchange originally appeared in Inquiry 50, no. 4 (August 2007) as 'What Myth?' (McDowell), 'Return of the Myth of the Mental' (Dreyfus), 'Response to Dreyfus' (McDowell), and 'Response to McDowell' (Dreyfus).

66. The considerations I am rehearsing here draw openly on what I take to be some of the most seminal writings on Wittgenstein from the last 30 years, writing that constitutes much of what have come to be known alternately as "resolute" approaches to the Tractatus or "quietist" approaches to his later work. (I realize that these terms and their relations are themselves subjects of dispute.) These writings include Cora Diamond, The Realistic Spirit: Wittgenstein, Philosophy, and the Mind (Cambridge: MIT Press, 1991); Cora Diamond, "Ethics, Imagination and the Method of Wittgenstein's Tractatus," in The New Wittgenstein, ed. Alice and Rupert Read (London: Routledge, 2000), 149-73; Cora Diamond, "Rules: Looking in the Right Place," in Attention to Particulars: Essays in Honor of Rush Rhees, ed. D. Z. Phillips and Peter Winch (New York: St. Martin's Press, 1989), 12-34; Diamond, "Criss-Cross Philosophy" (see note 51 for reference); James Conant, "The Method of the Tractatus," in From Frege to Wittgenstein: Perspectives on Early Analytic Philosophy, ed. Erich Reck (Oxford: Oxford University Press, 2002), 374-462; James Conant, "The Search for Logically Alien Thought: Descartes, Kant, Frege, and the Tractatus," Philosophical Topics 20, no. 1 (Fall 1991): 115-80; John McDowell, "Meaning and Intentionality in Wittgenstein's Later Philosophy," in The Wittgenstein Legacy, ed. Peter A. French, Theodore E. Uehling, and Howard K. Wettstein (Notre Dame: University of Notre Dame Press, 1992), 40-52; John McDowell, Mind and World (Cambridge: Harvard University Press, 1994); John McDowell, "Wittgensteinian Quietism," in Common Knowledge 15:3 (Durham: Duke University Press, 2009), 365-72. There is a large literature pertaining to the resolute reading of the Tractatus. For a fairly recent overview, see Silver Bronzo, "The Resolute Reading and Its Critics: An Introduction to the Literature," WittgensteinStudien 3 (2012): 45-80.

67. See Wittgenstein, On Certainty $\$ 99$.

68. "The view I am recommending is that even though experience is passive, it draws into operation capacities that genuinely belong to spontaneity". John McDowell, Mind and World (Cambridge: Harvard University Press, 1994), 13. Henceforth $M W$.

69. $M W, \mathrm{XX}$ (emphasis in original). 
70. See Ibid., 77-78, 83-84, 88, 91-95, 109-10, 123-24, 176-78. "Rampant Platonism" is McDowell's expression for the idea that such normativity as we typically find in humans must be regarded as non-natural, perhaps even as other-worldly. Such a dualistic idea may no longer find many explicit adherents, but the vision of rationality it embodies remains implicit in good deal of mainstream philosophy nevertheless.

71. See $M W, 84,87-88,95,123-25,183$. By employing "Bildung”, McDowell flags an affiliation of his thought not only with that of Hans Georg Gadamer, but by extension with that of Martin Heidegger. In broader historical terms, this also connects McDowell's strand of Analytic philosophy with the German Romantic tradition, in particular with that tradition as represented by Herder. Probably no one has written more eloquently on that tradition in philosophy than Charles Taylor. Most recently, see his The Language Animal (Cambridge: Belknap Press, 2016).

72. Some who agree with McDowell that both bald naturalism and the Myth of the Given are to be rejected are nevertheless deeply critical of his account of human perceptual capacities. Charles Travis is perhaps the most prominent example of this type of critic. Others have pointed to an uncritical willingness on McDowell's part, at least in Mind and World, to take on more traditional philosophical baggage than is warranted. For a critique of Mind and World in this vein from the perspective of ordinary language philosophy, see Avner Baz, "On When Words Are Called For - Cavell, McDowell, and the Wording of Our World'," Inquiry 46, no. 4 (December 2003): 473-500.

73. On these two criticisms, see Peter Godfrey-Smith, "Dewey, Continuity, and McDowell," in Naturalism and Normativity, ed. Mario de Caro and David Macarthur (New York: Columbia University Press, 2010), 304-21.

74. See for example Dorit Bar-On, "Minding the Gap: In Defense of MindMind Continuity," in Wittgenstein and Naturalism, ed. Kevin M. Cahill and Thomas Raleigh (New York: Routledge, 2018), 177-2018. Bar-on's paper is primarily directed against Davidson, although she makes it clear that she regards Brandom and McDowell as targets as well.

75. See for example Penelope Maddy, Second Philosophy: A Naturalistic Method (Oxford University Press, 2007). Perhaps more surprising is that McDowell's work is also passed over in Maddy's more recent book on Wittgenstein, Penelope Maddy, The Logical Must: Wittgenstein on Logic (Oxford: Oxford University Press, 2014). There isn't space here to enter into the lengthy discussion that the point deserves, so I will only say that given my reading of McDowell and Wittgenstein as in substantive agreement on the prospects for constructive philosophy, the violence that Maddy's book does to Wittgenstein's thought on precisely this issue makes it evident that she would not be amenable to McDowell's (or my) standpoint in the least.

76. On pp. 123-24 of Mind and World, McDowell makes it clear that he is aware of the issue of emergence, understood as nature making possible creatures with our cognitive equipment. But as he notes there, this is a long way from calling for a "constructive philosophical account of meaning."

77. Here it might be apt to repeat that the same reasoning applies mutatis mutandis to practice theorists who try to ground normativity and meaning in practices. Practices and linguistic use may be carriers of normativity, as in where we might look to see the meaning of an action or of an utterance (which is a subspecies of action), but as soon as we look to practices as somehow providing an ontological ground for meaning, we are asking for trouble. On this see Denis McManus, "Rules, Regression and the 'Background': Dreyfus, 
Heidegger and McDowell," European Journal of Philosophy 16, no. 3 (December 2008): 432-58.

78. Which is not to say that we ought to adopt some kind of metaphysical organicism or functionalism.

79. Since this essay is devoted to the subject of naturalism in the social sciences, I don't have space to discuss the strikingly parallel sense in which similar issues crop up in post-structuralist accounts of human life. On this see Mark Bevir, "Situated Agency: A Post-Foundational Alternative to Autonomy," in Finite but Unbounded: New Approaches in Philosophical Anthropology, ed. Kevin M. Cahill, Martin Gustafsson, and Thomas Schwarz-Wenzer, Berlin Studies in Knowledge Research 12 (Berlin: de Gruyter, 2017), 47-66.

80. McDowell, "Meaning and Intentionality in Wittgenstein's Later Philosophy," 50-51. In Mind and World, McDowell is more apt to call second-philosophical bridging operations unnecessary. But in some of his treatments of Wittgenstein on rule-following, where the deconstructive aspect of his thinking is much more visible, he is more likely to call them empty or incoherent, which of course also makes them unnecessary. See "Meaning and Intentionality" (reference note 65) and "Wittgenstein on Following a Rule" (reference note 55). See also Stanley Cavell, "The Argument of the Ordinary," in Conditions Handsome and Unhandsome: The Constitution of Emersonian Perfectionism (Chicago: University of Chicago Press, 1990), esp. 67-68.

81. Mark Risjord, Philosophy of Social Science: A Contemporary Introduction (New York: Routledge, 2014), 176.

82. Alasdair MacIntyre, After Virtue: A Study in Moral Theory (London: Duckworth, 1985), 83-84. In my earlier discussion of theoretical holism (see Part III), the more overtly linguistic aspects of Quinean-inspired thought were relevant, in particular, ideas such as evidence and meaning. In this passage, MacIntyre is focusing on Quine's ontology, in particular that which comes out in his views about extensionality, and thus on intentional expressions that purport to refer to things like beliefs and desires, entities that are anathema to Quine's metaphysics. Because Quine's understanding of language is so selfconsciously austere, however, the two sides of his thought, what we might ordinarily think of as semantic unit versus brute signal, are only notionally separate.

83. Clifford Geertz, The Interpretation of Cultures (New York: Basic Books, 1973), 5.

84. Paul Roth, "Beyond Understanding: The Career of the Concept of Understanding in the Human Sciences," in The Blackwell Guide to the Philosophy of the Social Sciences, ed. Stephen P. Turner and Paul A. Roth (Oxford: Blackwell, 2003), 315.

85. Ibid.

86. Cora Diamond, "How Long Is the Standard Metre in Paris?," in Wittgenstein in America, ed. Timothy G. McCarthy and Sean C. Stidd (Oxford: Clarendon Press, 2001), 104-39, is a brilliant treatment of this kind of confusion. While her paper is primarily concerned with Kripke's view that units of measurement refer to "chunks" of space or time in ways completely cut off from our practices of measurement, her distinction between "transitive" and "intransitive" employments of words also seems appropriate for deflating criticism of "meaning" in Roth's Quinean attacks on interpretivism and hermeneutics. See "How Long Is the Standard Metre in Paris?" 104-39.

87. It is important not to confuse the emphasis that writers such as Taylor or Geertz for example place on the need for interpretation in the social sciences, with the role "interpretation" plays in the dialectic of Wittgenstein's 


\section{Lost in the Ancient City}

rule-following remarks. Paul Roth seems to equate the two when he labels Taylor an "interpretivist" and then argues that Wittgenstein, as read by Kripke, has shown the interpretivsit position to involve an impossible task, finding the final interpretation that cannot itself be interpreted. But there is nothing in Taylor's use of "interpretation" that licenses the equating of their use of this term with Wittgenstein's ridicule of the same token. On the contrary, Wittgenstein explicitly makes space for an everyday use of "interpretation" of a rule at $P I \$ 201$ : "But we ought to restrict the term 'interpretation' to the substitution of one expression of the rule for another". This is precisely what the hermeneuticist does when she offers an interpretation of a text, albeit in a much more complicated context. See Roth, "The Philosophy of Social Science in the Twentieth Century: Analytic Traditions: Reflections on the Rationalitätstreit," 103-18.

88. This is of course a mainly descriptive enterprise. I have nothing to say here about the various types of political activism that have come to dominate much of the field. That would be a whole different essay.

89. This may sound like an echo of Heidegger's call for fundamental ontology in Being and Time, but it is not. Despite my sympathy with much of that book (and for Heidegger's work generally), much of his rejection of the significance of anthropology in Being and Time is simply dogmatic. Worse, his later claim that only the West had an evolving "understanding of Being" (Seinsverständnis), even if the claim was shaped by his specific understanding of Europe's inheritance from the ancient Greeks, was silly, if not appalling.

90. In addition to works by Geertz, I am thinking of some of the classic work in anthropology produced by Victor Turner, Mary Douglas, and Marshall Sahlins as well as those in cultural psychology by Jerome Bruner and Richard Schweder. More recently, Mark Bevir and Jason Blakely have taken up this mantle in political science. See their Interpretive Social Science: An AntiNaturalist Approach (Oxford: Oxford University Press, 2018).

91. Given the repeated and crashing failures of the micro-foundations program in economics, as well as the results of U.S. foreign policy when it has relied heavily on formal methods, it is depressing that this still needs saying. 


\title{
2 The Grammar of Conflict
}

\author{
Kevin M. Cabill
}

"I am afraid we are not rid of God because we still have faith in grammar."1

In what follows, I discuss some questions raised by recent work of Cora Diamond in which she has criticized arguments made by Peter Winch that try to show the logical limitations of what can be said about alien systems of thought and practice. ${ }^{2}$ In Part II, I provide some brief historical background to my discussion. In Part III, I summarize Diamond's main criticisms against the Winchian sort of view. In Part IV, I examine Diamond's view and its implications for the kinds of questions we can ask about the possibility of criticism between systems of thought with different grammars. In particular, I look briefly at an intersection between her views and those of Hilary Putnam's on the question of realism. In Part V, I address some issues and possible criticisms arising from my way of setting things out in Part IV. In Part VI, I discuss two consequences of what I take to be Diamond's views, one pragmatic and the other historical.

\section{II}

In his now classic paper from 1964, "Understanding a Primitive Society", Peter Winch attacked E.E. Evans-Pritchard's (by then already classic) ethnographic work Witchcraft, Oracles, and Magic Among the Azande. ${ }^{3}$ Evans-Pritchard had claimed to find a contradiction at the heart of the Zande system of magic, a contradiction that arises from the Zande view that witchcraft is an inherited substance. ${ }^{4}$ This view entails that all members of a clan with one witch are themselves witches, since the Zande clan is a group related biologically through the male line. ${ }^{5}$ This would mean that the whole system of witchcraft either was pointless, since asserting that someone was a witch would in effect assert nothing more than clan membership. Or it would mean that the thought that some people in the clan are witches while others are not contradicts the underlying premise about witchcraft substance 
transmission. It is worth underlining that Evans-Pritchard is not at all dismissive of Zande magical practices. He writes with great sensitivity in helping the reader come to appreciate the role these practices played in Zande life: "We have to see", he says, "how the drive behind all acts of witchcraft is to be looked for in emotions and sentiments common to all men - malice, jealousy, greed, envy, backbiting, slander, and so on" ${ }^{6}$ In the concluding chapter, moreover, we read

Throughout I have emphasized the coherency of Zande beliefs when they are considered together and are interpreted in terms of situations and social relationships. I have tried to show also the plasticity of beliefs as functions of situations. They are not indivisible ideational structures but are loose associations of notions. When a writer brings them together in a book and presents them as a conceptual system their insufficiencies and contradictions are at once apparent. In real life they do not function as a whole but in bits. A man in one situation utilizes what in the beliefs are convenient to him and pays no attention to other elements which he might use in different situations. Hence a single event may evoke a number of different and contradictory beliefs among different persons. I hope that I have persuaded the reader of one thing, namely, the intellectual consistency of Zande notions. They only appear inconsistent when ranged like lifeless museum objects. ${ }^{7}$

Nevertheless, for all of the context he supplies, on a couple of occasions early in the book, and not long after having pointed out the discovery of contradiction in the system of Zande magic, Evans-Pritchard seems to betray his true view of his subject matter when he asserts, "Witches, as the Azande conceive them, clearly cannot exist". ${ }^{8}$ As if to remind us, or perhaps himself, of this consequence of the contradictory nature of Zande beliefs, we read a bit further on, "We must remember that since witchcraft has no real existence a man does not know that he has bewitched another, even if he is aware that he bears him ill will".?

Where Evans-Pritchard writes of a "conceptual system", Winch quite naturally takes him to mean something like a modern scientific theoretical structure. Winch also takes for granted that freedom from contradiction is one of the hallmarks of such a structure and that Evans-Pritchard, qualifications about "lifeless museum objects" notwithstanding, is relying on something like this conception of a scientific theory in particular as a gold standard for judging whether or not any given system corresponds with reality. Winch criticizes Evans Pritchard's occasional remarks to the effect that while Zande magic was to a certain extent coherent in its own terms, it failed to describe an independently existing reality as judged by the more rigorous canons of Western science. Specifically, Winch objected 
that, in effect, Western science and Zande magic were incommensurable discourses, different grammars as it were, and that Evans Pritchard was attempting the impossible in relying on the one grammar to criticize the other grammar's relation to a supposedly discourse-neutral term, "reality". He writes,

We can imagine a language with no concept of, say, wetness, but hardly one in which there is no way of distinguishing the real from the unreal. Nevertheless we could not in fact distinguish the real from the unreal without understanding the way this distinction operates in the language. If then we wish to understand the significance of these concepts, we must examine the use they actually do have - in the language.

Evans-Pritchard, on the contrary, is trying to work with a conception of reality which is not determined by its actual use in language. He wants something against which that use can itself be appraised. But this is not possible. ${ }^{10}$

Winch concludes that Evans-Pritchard, in trying to import the standards for speaking about reality from one language in order to criticize the use of the same word in another, has made a serious logical blunder.

It is noteworthy . . that the Azande, when the possibility of this contradiction about the inheritance of witchcraft is pointed out to them, do not then come to regard their old beliefs about witchcraft as obsolete. "They have no theoretical interest in the subject." This suggests strongly that the context from which the suggestion about the contradiction is made, the context of our scientific culture, is not on the same level as the context in which the beliefs about witchcraft operate. Zande notions of witchcraft do not constitute a theoretical system in terms of which Azande try to gain a quasi-scientific understanding of the world. This in its turn suggests that it is the European, obsessed with pressing Zande thought where it would not naturally go - to a contradiction - who is guilty of misunderstanding, not the Zande. The European is in fact committing a category mistake. ${ }^{11}$

\section{III}

Before I turn to discussing the upshot of Diamond's arguments, there are two points that I want to make about her interpretation of Winch. The first point is that she does not take his position to be merely an expression of anti-scientism. Given the way Winch formulates his objection to Evans-Pritchard in the previous section, that would be an easy conclusion to draw. Winch was anti-scientistic, and famously so, but as 
Diamond makes clear, his main point is also meant to cut a good deal deeper. She writes,

I am suggesting that the issue for Winch was not specifically a matter of using scientific standards to criticise the Zande but of what he takes to be the failure to recognise that there are two different concepts of reality involved, in two different "languages." What Winch regards as illegitimate is taking one such concept to be the correct one. And this is what he takes to be at stake if one says, after noting the parallel position of the Europeans and the Zande, that the Europeans are right and the Zande wrong. ${ }^{12}$

In other words, Diamond is pointing out how Winch thought it was incoherent to privilege in any absolute sense the idea of "reality" at work in any discourse over the idea of "reality" at work in another discourse, regardless of whether one of them was scientific. That is, Winch thought in order to criticize a particular conceptual scheme, cultural system, or domain of discourse, one must already be "moving within the system". ${ }^{13}$ This is because he thought it was a logical requirement of such debates that all parties are in agreement as to the meaning of (perhaps a weighted portion of) their terms. Presumably, for example, Winch would have found it as logically suspicious for someone to make pronouncements on the reality of Zande magic from a Christian standpoint, as he found the sort of assertions that Evans-Pritchard made. This is because, as the previous passages make clear, Winch found the idea of a discourse-neutral conception of the meaning of the sign "reality" to be confused. This view involves the idea that criticizing certain elements of social and intellectual systems of thought and practice from the "outside" deprives these elements of the very identity and content they have only within the "inside" of a particular social context. Because such criticism would violate the purported boundaries of intelligible speech, someone who engaged in it could be met with the response "you can't say that", i.e. criticism from "outside" literally makes no sense.

The second preliminary point concerns the fact that it is Diamond's interpretation of Winch that is my primary focus in this chapter. This accounts for why I move fairly quickly in the last section through the details of Winch's attack on Evans-Pritchard on to Diamond's criticisms of Winch's position in this section. I am aware that there is a very large and still growing literature both on Winch's 1958 book on the social sciences and his 1964 paper criticizing Evans-Pritchard; that literature merits a substantially longer treatment than I can provide here. But my interest is not in providing anything like a scholarly synopsis and analysis of this material. My purpose, rather, is to investigate what I see as some of the consequences of Diamond's reading of Winch. I happen to believe, as a matter of fact, that her interpretation and analysis rely on a faithful 
understanding of his actual arguments. But if that somehow turns out not to be the case, that should not have much or any bearing on what I write next when I examine the consequences of her views.

Diamond attacks Winch's position on the grounds that it imposes a dubious logical or metaphysical requirement on the conceptual resources available to language users, and so unnecessarily restricts the possibility of criticizing a system of thought such as an alien world view in which one does not participate. The dubious requirement is, of course, the idea that the content of terms like "reality" (and relatedly, "true") must be articulated only within the pre-given logical spaces provided by existing discourses. At the time he wrote his paper, this may have seemed to Winch like a bit of philosophical obviousness, made so by his way of reading later Wittgenstein at the time. But quite apart from questions concerning Wittgenstein interpretation, Diamond finds this view anything but obvious. She asks, "[W]hy should there have to be an 'established universe of discourse?' Why can one not be making, giving articulation to, a kind of thought about reality in thinking about the conflict?" ${ }^{14}$ She elaborates the thought behind these questions in the following passages:

[W]e can take the situation here to be one in which what is real is contested; and this idea of reality as contested is a different notion of reality from that which is involved in either of the two forms of thought themselves. If the conflict is understood in this way, the space for the dispute between the two forms of thought is not given in advance; it is not provided by either of the two modes of thought that are in conflict. ... There is thus an important sort of contrast between the way the notion of real and unreal works in the dispute and the way that notions of real and unreal work in the two systems of thought that are at odds.... [I]n such systems of thought, there are standards that operate independently of any particular move that someone makes; but in the kind of conflict with which we are concerned. .. , giving what one takes to be rational grounds for one's judgement is itself part of the articulation of the logical space here, the space of reasons in this conflict. ${ }^{15}$

Further on we read,

What is questionable about Winch's arguments is that he repeatedly emphasises there being understandings of real and unreal internal to the modes of thought that may be in conflict, as if that implied that any understanding of real and unreal at work in judging that Zande thought about their oracle (say) is deeply wrong must involve illegitimately misapplying one of the prior understandings of real and unreal. Whereas one can say instead: in bringing out the irreconcilability of the principles involved in two modes of thought, and in 
reasoning about such cases, we may be developing an understanding of real and unreal. ${ }^{16}$

Thus, against Winch, Diamond holds that making new conceptual and linguistic moves, including new modes of evaluating other discourses, can emerge as part of a conflict, so that indeed in many cases one can intelligibly criticize another system. This means that one can, for example, criticize another culture's practices as confused or false, or in some cases even delusional without invoking a traditional "view from sideways on" metaphysics of rationality that is unconnected to any linguistic practice at all. This is not an invitation to linguistic imperialism. Our criticism may be hasty, sloppy, or based on sheer ignorance or prejudice; coming to understand the meaning of what people do and say may take enormous effort. What Diamond is questioning, however, is that there is a ready-made, a priori condition on meaning that rules out the very idea of making new conceptual and linguistic moves, especially new modes of evaluating other discourses with regard to questions of reality and truth. Indeed, her view seems to be that the intelligibility of such an evaluative practice is already internal to our grammar, just as we find it, so that one can say "that", except that "saying that" in such a case may have some new, perhaps unpredictable features that no a priori argument about meaning can preclude.

I should just briefly note here that exploring Wittgenstein's relation to the idea of what is supposedly logically out of bounds to thought and thus to criticism has been utterly central to Diamond's interpretative work on Wittgenstein for the last 30 years. Much of this writing has been devoted to developing the details of the so-called "resolute reading" of the Tractatus. Greatly simplified, this way of reading that book involves an attempt to draw out what Diamond takes to be the implications of the thought expressed in this passage from the preface:

[T] he aim of the book is to set a limit to thought, or rather - not to thought, but to the expression of thoughts: for in order to be able to set a limit to thought, we should have to find both sides of the limit thinkable (i.e. we should have to be able to think what cannot be thought). It will therefore only be in language that the limit can be drawn, and what lies on the other side of the limit will simply be nonsense. ${ }^{17}$

As Diamond reads it, a major aim of the Tractatus is to deconstruct the very idea that one could employ special kinds of language, more specifically special kinds of nonsense, to convey otherwise ineffable thoughts that lie on the other side of the limit of the ordinarily sayable, and so thinkable. In the present context the more relevant text is of course Philosophical Investigations, as it is largely from that and other later writings 
that most philosophers have drawn inspiration for their views about the logical-grammatical (im)possibility of criticizing, or even understanding at all, from "outside". Yet Diamond is no less adamant that Wittgenstein's later work not be read as lending support to any arguments purporting to establish the "bounds of sense". And with good reason, for such a reading would land the later Wittgenstein in precisely the confusion against which he warned of in his earlier book.

\section{IV}

I agree with Diamond's main criticisms of the kind of view put forth by Winch. ${ }^{18}$ In what follows, I discuss what I take to be some of the implications of her analysis, even though I am very unsure whether she would regard them as genuine implications. I take Diamond at any rate to be committed to something close to the following two claims: 1) systems of thought may contain logical resources for making various types of criticisms that go beyond what is clearly visible to their current participants and 2) these conceptual resources can be developed, brought out, made manifest, by, among perhaps other things, conflicts with other systems of thought. I think that Diamond is certainly correct in claiming 1 ), while I think 2) raises some complicated issues. In particular, it is unclear to me whether Diamond thinks that the logical space that may be articulated in the course of a conflict must be understood as a result of mutual features of each conflicting system's logical resources, or if it is enough for coherent criticism that only one of those grammars has this potential openness in its self-understanding of "reality". As I will try to show, it is difficult to argue that only the first possibility is permissible and allowing for the second possibility reveals some interesting complications.

The main issue between Winch and Diamond here runs both deep and broad in the history of 20th century philosophy. Its depth is a function of its importance, which I believe is great. By "broad", I mean that despite substantial philosophical differences among them, the list of those who have held positions with strong affinities to the one Diamond finds in Winch is a venerable one. Indeed, on the list of eminent thinkers targeted in his "On the Very Idea of a Conceptual Scheme", Donald Davidson includes, in addition to Winch, Quine, Kuhn, Feyerabend, Sapir/Whorf, and Strawson. ${ }^{19}$ Surprisingly absent from this list, however, is the Rudolf Carnap, whose thought as much as anyone's proved a source for many of the central ideas in various iterations of 20th century linguistic relativism. In particular, Carnap's distinction between questions that are "internal" and those that are "external" to a linguistic framework, with his rejection of the latter as lacking cognitive significance, bears more than a little resemblance to Winch's insistence that we can only ask questions about the meaning of words, "reality" for example, in the language. ${ }^{20}$ 


\section{0}

The kind of realist views Diamond defends in her dispute with Winch are quite close to those represented by Hilary Putnam during the last 35 years or so of his philosophical life. During that span, Putnam pushed back hard against the kind of anti-realism inherent in the Carnapian view and what he sometimes referred to as the "tired pseudo-Wittgensteinian philosophy of language" he found typical of many verificationist interpreters of Wittgenstein, especially Norman Malcolm..$^{21}$ In light of these connections, I want to begin my examination of Diamond's arguments against Winch with a passage from a paper by Warren Goldfarb, where he is discussing Putnam's attack on ideas that were central to the work of Carnap in the early 1930s, in particular Carnap's defense of a principle of tolerance and its sanctioning of linguistic pluralism in The Logical Syntax of Language. ${ }^{22}$

As Goldfarb has described it, the issue here concerns Putnam's assertion that the principle of tolerance already presupposes the (to Putnam, at any rate, dubious) verification principle. If a prior commitment to verificationism (in Winch's context this would be a use-theory of meaning) cannot be justified, then Carnap cannot easily deflect "external" questions about how "the world truly is" merely by appealing to tolerance. ${ }^{23}$ While not endorsing Carnap's verificationism per se, Goldfarb seems to think that Putnam's dismissal of it is a bit too quick. Goldfarb asks,

How would Carnap react to Putnam's argument? In the argument, Putnam assumes that the notion of "The world as it truly is" is antecedently understood, so that Carnap needs to adduce powerful enough considerations to undercut it. In my view, though, Carnap would simply point out that the notion should not be assumed as understood, and is in fact rather unclear, so it would be best to start by clarifying it. There seems little way for Putnam to clarify it except by telling us what the world, as it truly is, is. That is, he will wind up giving us his theory of what the world is. Putnam's argument then dwindles to an assertion (or a proposal) that a linguistic framework be deemed correct only if its rules include Putnam's theory of the world. This is hardly an argument at all; it is just the outright rejection of Carnap's pluralism. ${ }^{24}$

Assuming for the moment that Putnam was correct in rejecting Carnap's verificationism, then his rejection of the principle of tolerance and his commensurate suspicions of Carnap's rejection of "external" questions concerning the meaning of terms outside of any linguistic framework may seem well motivated and natural. But, as I take Goldfarb to be bringing out, if we broaden our perspective from the narrow issue of verificationism per se to a much more ecumenical and non-theoretical understanding of linguistic practice, so that our view of meaning is informed by the close conceptual relation (even if not identification) between meaning and use, 
then the sort of dogmatic tone that Goldfarb is bringing out in Putnam's position vis-à-vis Carnap becomes far less attractive as a general view.

With Goldfarb's point against Putnam in mind, we can return to Diamond's criticisms of Winch by posing an issue in the following way: While it is unclear how Winch (or Carnap) can insist that no language can have the grammatical resources for engaging questions about "reality" (or "the world as it truly is") in a manner not already given internally by the grammar of the language itself, it seems equally unclear to me whether such questions are always appropriate, and so whether there is any nondogmatic basis for insisting that every language must have such resources for asking them. Previously, we saw Diamond ask, "why should there have to be an 'established universe of discourse'? Why can one not be making, giving articulation to, a kind of thought about reality in thinking about the conflict?" I am asking a different, perhaps symmetrical, question: what if one of those conflicting systems has no such resources for envisaging a conflict about reality outside its already established universe of discourse? In other words, what if there were cases where the logical space or spaces for resolving the conflict only came from one of the two conflicting systems (for example, ours)? Is that something we can rule out a priori? I think the idea that every discourse must be open to the sort of conflict under discussion here is just as murky as Winch's insistence that no discourse can be. Is it legitimate, that is, simply to rule out the possibility of a grammar in which "reality" (and perhaps other terms like "truth") only has meaning within the domain of the grammar itself? What if, in other words, there were "natural born Carnapians", or better still, "natural born Winchians"? Judging by their indifferent reaction as described by Evans-Pritchard when he pointed out a contradiction in their system of magic, perhaps this is even an apt way to describe the Azande.

\section{V}

A

There are three points relating to the last section that I want to address before moving on. First, I have not made any specific demand that the reader imagine a group of language users who cannot extend their sense of reality based on the development of their own conceptual resources or through their encounters with other forms of life. My point has not been that any language, as a matter of logic, cannot so develop, but that it is dubious business to insist, as a matter of logic, that each one must be able to develop this way. How the anthropological and linguistic facts play out is of course another matter. In making this point, moreover, I am merely drawing some implications from what Diamond herself writes. As we have seen, she asks why there should have to be an 'established 
universe of discourse' for the deployment of a concept like reality. This question seems to leave completely in place the coherence of the idea that while there might be such a practice, contra Winch and others, there doesn't have to be. I have not felt particularly obligated so far to give a background story that describes what this might be like, precisely because my point here relies on an argument based on symmetry: if it is dogmatic to insist with Winch, that talk of reality always must be confined to an established domain of discourse, then it is equally dogmatic to insist that it never can be thus confined. If Diamond had wanted to argue that she found it impossible to imagine such a language, she could have written something very different from what she actually wrote.

\section{$B$}

Second, a critic might nevertheless object that the real point Diamond could or should have made is that the idea of grammar that my symmetry argument relies on, a grammar in which unlike our grammar there simply is no talk of reality and related concepts without an established universe of discourse, is absent more concrete detail or special explanation, not something we can really imagine. This objection might draw inspiration from a point made long ago by Stanley Cavell that projectability of words into new contexts is something internal to language, because the criteria by which we apply our concepts just have, qua criteria, this kind of openness to them. Another way to put this point would be to note with Cavell that criteria aren't just self-applying in some general mechanical sense. There must be a specific context for the employment of a concept, and this requires a language user in the context who sees to it, and so must take responsibility, that the criteria connected to certain words are applied in that given context. Cavell's wonderful example of the natural extension of the word "feed" from "feed the kitty" to "feed the parking meter" illustrates the point well. ${ }^{25}$ In short, someone could argue against my story thus far that the projectability of grammatical criteria is essential to language, and that my symmetry argument requires that we imagine language users for whom precisely such projectability is lacking. ${ }^{26}$

In responding to this Cavellian criticism from ordinary language, I want first to note that if projectability of criteria is internal to a language, then insisting that the concepts of any language must have this feature makes as much sense as insisting that a triangle have three sides. If we are talking about a language at all, then the criteria governing the use of its concepts are projectable. More to the point, there is something potentially misleading in the critic's use here of Cavell's original example. The example of feeding the meter nicely shows what it means to say that criteria are not closed by showing how they can be projected into a novel context. But of course it is also true, for otherwise much of Cavell's diagnosis of external world skepticism in the Claim of Reason falls away, 
that everyday application of criteria governing everyday concepts also requires relevant projection; even in the most mundane of circumstances they are not self-applying. ${ }^{27}$ Even pointing at my cat and telling my son to "feed the kitty" requires such projection of criteria and uptake on both of our parts. Cavell's diagnosis of skepticism relies on the idea that the skeptic's claim to know the existence of a generic object lacks any specific context to make it coherent. There is no suggestion by him that providing such a context would require Descartes to describe unusual contextual features of his sitting in front of the fire. He just has to say something that would make it relevant for him to remark that he is holding a piece of wax. In effect, language users are condemned to projecting criteria in context all the time; some examples like "feeding the meter" just make this activity more apparent.

This makes it evident that the objection of my imagined critic is not really about projectability per se. It is about the actual projection of particular concepts by actual language users into particular kinds of new contexts. (One could equally characterize the dispute as being about certain facts being taken to stand in as representatives, schemata if you will, of the legitimate projection of certain concepts into these new contexts.) At any rate, projectability in a language per se and the actual projection of particular concepts into new situations are not the same. In the cases we are looking at here, not only will the ordinary language philosopher's appeal to the question "what do we say when?" not be of much use, what "we" say and "when" is just what is at issue, in particular in light of there not being an obvious "we". If therefore, there is no disagreement about the pertinence of the very notion of projectability for grammar, but only about its extent, we seem to have a dispute about the grammar of "grammar". As we will see, symmetry considerations will come into play here as well. ${ }^{28}$

As we have seen, there may be certain "new" contexts such as the logical spaces between two already existing grammars of which Diamond speaks, where one side finds itself ready to explore the projection or extension of its concepts pertaining to the nature of reality, but where members from the other group of language users do not accommodate such an investigation. Of course, it's obvious that we ourselves don't cotton on to just any projection of concepts; no one is claiming that criteria can be extended willy-nilly. How then should we describe cases where our own concepts are not extended? On some occasions, an attempt at a new use may be almost universally perceived as so wrongheaded that it just falls silently flat. Other times, perhaps in the case of "feeding the meter", the new use immediately catches on. Still, in other cases, we end up in conflicts, where one side sees the point or correctness of the new use, while another side does not. (Such cases seem to be everywhere at the moment.) I think there is a strong temptation to describe such cases, especially but not only those concerning morals and politics, as 
characterizable as cases in which the side for whom the new use does not seem natural is "withholding" its assent, where "withholding" is taken to refer to some sort of semi-conscious repression of something that, were it not for some inculcated shame, resentment, or bigotry, the extension might be gladly granted. Yet if, as Cavell made so forcefully clear many years ago, "voluntary" and "involuntary" present us with a misleading and inadequate set of options for thinking about action, so perhaps do "assenting" understood as projecting and "withholding" understood as "repressing" for thinking about extending grammar. ${ }^{29}$

A number of years ago Sabina Lovibond coined the term "transcendental parochialism" to denote an ideal state of affairs where a society's critical resources for reform were fully extended, at their limits so to speak, yet where the language or discourse so arrived at would still be a recognizably human one. She contrasted this with what she called "empirical parochialism", which she characterized in effect as the parochialism of repressive conservatism. ${ }^{30}$ One might wish that this pair of concepts could be of some help in the context of our current discussion about the nature of a possible extension of each of our two imagined group's grammars into uncharted logical space. The idea could be that the side willing to explore the extension of its grammar into new logical spaces would be overcoming empirical parochialism and striving towards a more enlightened transcendental parochialism, while the other side would be seen as failing in such a task. Unless, however, one wants to take on what I regard as some fairly substantial metaphysical baggage about the nature of rationality, I don't think this terminology gets us any further. If we are not just dealing here with a self-righteous and logically unmotivated call for permanent linguistic revolution, where the aim seems to be change for the sake of change, we might wonder how one ever knows whether one is being transcendentally parochial or merely empirically parochial. How, relatedly, does one determine that the other side is being empirically parochial? More to the present point, where comes the certainty in the kind of conflict we are envisaging, that either group is guilty of empirical parochialism, should the conflict about whether to explore the new logical space go unresolved? Maybe there could be any number of concrete conceptual logjams, stable configurations of unresolved conflicts consistent with neither side's being guilty of "empirical parochialism".

Is it always reasonable to suspect bigotry or ignorance if a group of speakers simply does not respond to a particular "invitation" to extend or change its practices? Does this always call for some special explanation or justification in terms of something like repression that accounts for their withholding an extension of their concepts? There is a difference between, on the one hand, making the merely abstract grammatical point that any given parochial view could, at least in theory, be extended at a particular point, and on the other hand, saying that people must always 
push the limit at that point on pain of being an irrational reactionaries. Prima facie, someone or some peoples not projecting some of their concepts into new logical spaces no more needs a special explanation than does our willingness (or is it now an insistence?) on doing so. If this is true, then it may not always be clear whether lack of assent must be regarded as a failure or refusal to project one's concepts into new logical spaces, so much as being regarded as something that just never seemed apt to some people. Naturally, language users may sometimes actively resist changes. And in such cases, there may well be some background story which explains what happens: some ethical or social sensitivity or hope or worry. But we don't have to look at everything through the lenses of a Weltanschauung that seduces us into regarding every such case as a result of what some imagined clan of old, conservative elders forbids. Allowing the projection of criteria implicates us no less than preventing such projection implicates others. Both are equally signs of a value commitment. We may call the new space a result of an appropriate extension of the same grammar. They may not even have so much of an idea of this space. To insist on attributing bad faith to those who resist exploring new logical spaces, not to mention those to whom doing so doesn't show up as a live option, is just political metaphysics.

Grammar is embedded in practice, and without a practice, talking about what grammar per se calls for or doesn't call for is useless. Others may not have our same practice(s) of extending particular concepts beyond certain uses. If someone were to ask whether, as a matter of logic, a group of language users must have this or that practice, how might one answer? It is very unclear that we have anything like a pre-given notion of what constellation of practices and concepts are necessary for a grammar to be “complete". Wittgenstein writes at On Certainty $\$ 611$ and $\$ 612$,

Where two principles really do meet which cannot be reconciled with one another, then each man declares the other a fool and heretic.

I said I would 'combat' the other man, - but wouldn't I give him reasons? Certainly; but how far do they go? At the end of reasons comes persuasion. (Think what happens when missionaries convert natives. $)^{31}$

These passages can be, and most likely have been, read as expressing a kind of relativist cum incommensurability thesis. As I made clear earlier in her discussion of Winch, I agree with Diamond that there are deep confusions with this type of view. Nor do I see any convincing reason for attributing such a view to Wittgenstein, based on these or any other passages. But more to the present point, these passages do not suggest that there is any kind of guarantee in the nature of things such that all empirical parochial views, or, even all transcendental parochial views, are 
harmonizable, either into one big overarching transcendental parochial view or even into some more modest, transitional harmony. If anything, Wittgenstein's mention of "persuasion" and his subsequent reference to what missionaries do does not strike me as though he was particularly sanguine about the idea that, whatever eventual harmony might arise between conflicting grammars or colliding forms of life, it must be necessarily describable as a transcendental parochial view arrived at through the mutual exploration and articulation of conceptual resources. The symmetry idea comes in here again with the following consideration: someone can indeed ask "why can't there be a merging of empirical parochial views into a larger empirical parochial view and finally into something like Lovibond's idea of a transcendental parochial view?" The answer is that there is nothing like a knock-down philosophical argument showing why this question is out of bounds. But someone may ask a different, symmetrical question: "Why must there be a harmonization of empirical parochial views, tending to a harmonized transcendental parochial view?" The answer here too is that there is nothing like a conclusive philosophical argument ruling this out as somehow illegitimate. In effect, we are back to my symmetry-based question about Diamond's question about the nature of grammar and the contours of logical spaces between conflicting grammars. We seem to be at an impasse.

\section{C}

Third and finally, before I turn to some of the consequences of Diamond's view, it is worth emphasizing that I don't believe that her idea has to be read as entailing that grammars containing the resources for a logical space of conflict outside of themselves also contain the actual correctness of some particular view or set of views held in spe by those who speak a language with such a resourceful grammar. Rather, the grammars with such resources may be understood to contain the bare concept that some as yet unspecified view is correct. This is the idea of the sheer possibility of getting things right in a way not yet fully intelligible from within any of the discourses of the parties to a conflict. To arrive at some contentful view of what is in fact right, much more in the way of various sorts of practical and scientific resources from one (or both) of the conflicting discourses will have to be brought into the picture. So, in an important sense, I believe this concept of reality as being something to be worked out is basically formal and empty of content (or at least empty of any clear content). Individual claimants in a dispute might gain some solace from the logical possibility that their currently held view may resemble what turns out to be the right one at a later stage. In many cases, especially where something like their views have prevailed in a given conflict, it may even be reasonable for them to describe those views and their attendant concepts as always having been the right ones all along and thus to share a kind of organic lineage with prior established truths. But by itself the 
grammatical feature whose possibility Diamond and Putnam are pointing to, while I believe intelligible, won't support anything else in the way of specific concrete or empirical claims. The grammatical possibility may be important for maintaining a certain self-critical attitude towards epistemic practices, making clear that we can always do better, but the grammar doesn't really add any empirical content to the view we arrive at in any given case. Once it is evident that the realism we are concerned with here amounts to a kind of regulative idea, in effect a formal feature of our grammar and perhaps the grammar of others, the insistence that "somewhere out there, there must be a way things really are" sounds more like the making manifest one's commitment to a historico-grammatical artifact, however important this may be legally, ethically, or scientifically.

I thus take Diamond to have argued convincingly that such a grammatical artifact shows how criticism from "outside" can be entirely in logical order. But the considerations I have brought out in the last two paragraphs do, I believe, mean that such criticism may sometimes have a quite particular, even peculiar shape and will depend on some rather precarious facts. In what follows, I want to discuss two issues in particular that may arise when two sorts of grammars, one with the more "Putnamian" view of the "world as it truly is", conflicts with the more "Winchian" or "Carnapian" view where that phrase only has a use within a framework. ${ }^{32}$ The first issue is mainly pragmatic, while the second involves some deep philosophical questions concerning the nature of intercultural conflict.

\section{VI}

In this section, I want to look briefly at two important consequences of Diamond's arguments. The first is pragmatic, the second is ethical and historical. Diamond is correct to oppose the claim that the nature of reality can in all cases only be debated from within a given system of thought. Nevertheless, her argument leaves me uneasy in a certain pragmatic sense. I can sum up my sense of what I find unsatisfying by merely pointing out that her argument about what our grammar allows us to do in the way of criticism licenses a conflation of the observer and participant points of view in certain debates, making "us" as it were both judge and party to the same dispute. For many people, these are roles that other important practices that we hold strongly incline us to keep separate. Consider, in this light, the following scheme for visualizing the two situations:

Case 1

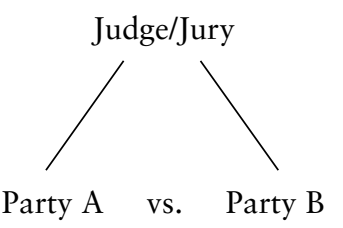


Case 2

Party A (Also Judge/Jury) vs. Party B

Case 1 is supposed to represent something like a normal trial or formal dispute in our culture, where judge/jury, Party A, and Party B are three different individuals or groups belonging to that culture. Case 2 is supposed to represent the sort of cross-cultural or trans-historical judgements with which Diamond and Winch are concerned. While my diagrams may strike one as vastly oversimplified in relation to our real world experience of conflict, I don't believe that their formal structure fatally misrepresents how conflict can look in other contexts, especially ones concerning certain intercultural conflicts. In fact, given the relevance for cultural and social anthropology of the very recent colonial past, where colonial rulers routinely collapsed the observer and participant standpoints, Case 2 seems especially pertinent to the issues under discussion here.

I agree with Diamond that there is not some logical requirement that Party A in Case 2 fails to fulfill (though there could be an institutional one). And so, I think she is correct that we can't just exclude the possibility of practices for making precisely these kinds of judgements. So, Party A's judgements in Case 2 can be completely in order, which is to say, in Case 2, Party A can make judgements überhaupt about Party B's view. But it is not surprising either, if people feel there is something fishy or unsatisfying with Case 2, precisely because there is something deeply embedded in our practices, even if not our logico-grammatical practices, that suggests the two roles that Case 2 collapses ought rather to be kept separate as an ideal of objectivity. I feel sure Diamond is aware of this, but I believe nevertheless that it is worth underlining that while Case 2 is coherent, it also is different from Case 1, and its logical coherence does not erase that difference. Consequently, regardless of how Party A comports himself or herself in relation to Party B, there is an implicit paternalism in Case 2 that is somehow less than satisfying, even though not incoherent.

The second issue concerns what I believe to be a more philosophically interesting and to some degree neglected point, both in Diamond's discussion and in the literature generally. It seems to follow that if we cannot rule out grammars of both types, one grammar that allows for the bare notion of "reality" having a use outside of its own already articulated conception, and another type without such a notion, or at least with a much more restricted notion, then we are led to the idea that the feature of the grammar of Party A that makes criticism from outside intelligible is not a given, but rather has a contingent dimension to it. Such a grammar can be regarded as a sort of historical achievement. This fact, in turn, would suggest that there is not likely to be any stand-alone argument showing that the grammar with the feature that makes criticism from 
outside or exploration of new logical spaces intelligible is, or ought to be, immune to change. This does not imply of course that once we realize the historical contingency of our grammar's containing things like the "concept of an object as independent of that concept", we could simply shake ourselves loose of this concept through an act of will, even if for some reason we found ourselves wishing to do so. To say that a feature of our grammar is historical or conventional is not to say that it is arbitrary or easily dropped. Things are much more complicated than that. But like any other concept or feature of a grammar, this one must be articulated and thus supported in practices if it is to remain available to us. And this fact about the historical embeddedness of grammar can raise, in turn, the normative question as to whether this feature is worthy of that continued support. That is to say, the very fact of the existence of a feature of a grammar can't by itself be used in any non-circular way to justify our continued reliance on that very same feature. In our present context, this does not imply, however, that no defense at all can be articulated of the value of the idea of reality conceived as independent of any discourse. Our practices make this kind of internal argument available to us as well. For example, Diamond makes clear that in the case of witchcraft and witches, more is at stake than questions of reality and possibility. How we think about those questions may have serious ethical consequences, which, while not exactly providing our ontology with an "external" justification, do suggest the difficulties involved with the view that a choice of what to take as real is somehow arbitrary. She writes,

When we are confronted by contemporary systems of thought and practice involving the identification and punishment of supposed witches in Africa, Saudi Arabia and elsewhere, we may indeed reject these systems as appalling, but we may also take it that they involve hideous injustice to vulnerable people who are punished for doing occult harm, where the accusations and punishment depend on a system of false beliefs about what human agents can do and what can constitute good evidence of what they have done. Our thought about our own and other people's systems of thought and practice, and our rejections of such systems, are not isolated from judgements of injustice; and our judgements of what is just and what is unjust may be connected with judgements about whether people are capable of having done what they are accused of doing and with judgements about the methods of supposedly establishing that they have done what they are accused of doing. ${ }^{33}$

Anyone appalled at the injustice involved in these practices of punishing innocent individuals, who nevertheless claimed that these powerful considerations had no bearing on what to think about reality, would likely be engaged in a form of self-deception. The question is whether these 
considerations having to do with reality, truth, and justice settle the matter. Is there anything profound remaining for philosophy to say? ${ }^{34}$

\section{Notes}

1. Walter Kaufmann, ed., "Twilight of the Idols," in The Portable Nietzsche (New York: Viking, 1976), 483.

2. See Cora Diamond, "The Skies of Dante and Our Skies: A Response to Ilham Dilman," Philosophical Investigations 35 (2012); Cora Diamond, "Criticising from 'Outside'," Criticising from 'Outside'," Philosophical Investigations 36 (2013); Cora Diamond, "Putnam and Wittgensteinian Baby-Throwing: Variations on a Theme," in The Philosophy of Hilary Putnam, ed. R. E. Auxier, D. R. Anderson, and L. E. Hahn (LaSalle: Open Court, 2015). (see Introduction for references.) I do not address Diamond's criticisms of Dilman's, Wittgenstein's Copernican Revolution: The Question of Linguistic Idealism (Basingstoke: Palgrave, 2002) or her brief discussions of some later work by Winch (see Cora Diamond, "Unfolding Truth and Reading Wittgenstein," Sats - Nordic Journal of Philosophy 4, no. 1 (2003), as these do not really concern my main points. See also Cora Diamond, "How Old Are These Bones? Wittgenstein, Putnam and Verification," Proceedings of the Aristotelian Society 73 (1999): 99-134, where she criticizes a related, verificationist style argument in Richard Rorty. Clearly, issues about how to read the later Wittgenstein are in the background of my paper, but I do not directly address those.

3. Peter Winch, "Understanding a Primitive Society."American Philosophical Quarterly 1 (1964), (see Introduction, note 15 for reference). Winch's The Idea of a Social Science and Its Relation to Philosophy (see Chapter 1, note 19 for reference) is of course also in the background for Diamond's work and for my discussion, although I do not refer to it here. See also E. E. EvansPritchard, Witchcraft, Oracles, and Magic Among the Azande (Oxford: Oxford University Press, 1937).

4. Although for the purposes of my discussion I do not distinguish magic, witchcraft, and the use of oracles, I don't believe that this has any serious philosophical consequences.

5. Evans-Pritchard, Witchcraft, 3. In fact, Evans-Pritchard claims to have found a second contradiction, or near contradiction, in the following Zande ideas. Since all death is due to witchcraft, and therefore not by vengeance magic, knowing the names of victims of vengeance magic would make the latter activity futile, because it would mean that such victims were both the victims of magic and witchcraft. Most people are of course not privy to the names of victims of vengeance, so for them the contradiction is not apparent. However, princes are thought to know such details. When Evans-Pritchard pointed this out to a prince, "he smiled and admitted that all was not well with the present-day witchcraft system". Ibid., 5-7.

6. Evans-Pritchard, Witchcraft, 82.

7. Ibid., 221-22. What Evans-Pritchard describes in this passage anticipates a central part of Pierre Bourdieu's critique of structuralism. See Pierre Bourdieu, Outline of a Theory of Practice (Cambridge: Cambridge University Press, 1977) 9, 37, 171.

8. Evans-Pritchard, Witchcraft, 18.

9. Ibid., 43.

10. Winch, "Understanding," 309 (emphasis in original). 
11. Ibid., 314-15. See Evans-Pritchard, Witchcraft, 4 for the passage quoted by Winch here.

12. Diamond, "Criticising from 'Outside'," 118 (emphasis in original).

13. See G. E. M. Anscombe, "The Question of Linguistic Idealism," in From Parmenides to Wittgenstein (Oxford: Blackwell, 1981), 131. Quoted in Diamond, "Baby-Throwing: Variations on a Theme," 629.

14. Diamond, "Criticising from 'Outside'," 119 (emphasis in original).

15. Ibid. (emphasis in original). Diamond's and Elizabeth Anscombe's ways of reading Wittgenstein, especially some of his remarks in On Certainty, are very much in the background of her discussion, and so I will leave them mostly in the background for my own discussion. The remarks from $\mathrm{On}$ Certainty she refers to in particular are $\$ 147$ and $\mathbb{6 0 8 - 1 2}$. She gives them a more realist inflection than I think they bear in context.

16. Diamond, "Criticising from 'Outside'," 121.

17. Ludwig Wittgenstein, Tractatus Logico-philosophicus, ed. D. F. Pears and B. F. McGuinness (London: Routledge \& Kegan Paul, 1974), 3. See Chapter 1, note 65 for references.

18. Because it is not a given that everyone agrees with Diamond's reading of Winch's work, I should make it clear that for the purpose of my argument here I am simply assuming the correctness of her interpretation.

19. Donald Davidson, "On the Very Idea of a Conceptual Scheme," Proceedings and Addresses of the American Philosophical Association 47 (1973-1974): 5-20. Whether Davidson's way of taking each of the mentioned authors is fair is an open question, as is of course Davidson's own position.

20. See Rudolf Carnap, "Replies and Systematic Expositions," in The Philosophy of Rudolf Carnap, ed. Paul Schilpp (La Salle: Open Court, 1963), 859-1013. Of course, this should not be taken to minimalize the enormous differences between Winch and Carnap.

21. Much of Putnam's explicit ire was directed at verificationist and anti-realist strains in the work of Richard Rorty. On this, see Cora Diamond, "How Old Are These Bones? Wittgenstein, Putnam and Verification." See note 2 for reference. James Conant argues that, in fact, some well-known commentators ascribe views about language to Wittgenstein that are more accurately attributable to the Carnap of the early 1930s. See "Two Conceptions of Die Überwindung der Metaphysik," in Wittgenstein in America, ed. Timothy McCarthy and Sean C. Stidd (Oxford: Oxford University Press, 2001), 13-61.

22. Rudolf Carnap, The Logical Syntax of Language (London: Routledge and Kegan Paul, 1937).

23. Warren Goldfarb, "Semantics in Carnap: A Rejoinder to Alberto Coffa," Philosophical Topics 25, no. 3 (1997): 60. Goldfarb cites Hilary Putnam, "Philosophers and Human Understanding," in Realism and Reason: Philosophical Papers, 3 (Cambridge: Cambridge University Press, 1983), 191.

24. Goldfarb, "Semantics in Carnap," 60.

25. Stanley Cavell, The Claim of Reason: Wittgenstein, Skepticism, Morality and Tragedy (Oxford: Clarendon Press, 1979), 181. Henceforth CR.

26. I am grateful to Reshef Agam-Segal for raising the question addressed here.

27. See CR, 216-20.

28. My use of "symmetry" here borrows from and is meant to allude to Diamond's discussion of a dispute between David Wiggins and Bernard Williams about the conditions for ethical judgement, in particular in making judgements concerning slavery. See "Truth in Ethics: Williams and Wiggins," in her Reading Wittgenstein with Anscombe, Going on to Ethics (Cambridge: 
Harvard University Press, 2019). I make so presumption, however, that Diamond would sanction my use of the idea of symmetry here.

29. See the title essay in Stanley Cavell, Must We Mean What We Say? A Book of Essays (New York: Scribner, 1969).

30. Sabina Lovibond, Realism and Imagination in Ethics (Oxford: Basil Blackwell, 1983), 214.

31. Ludwig Wittgenstein, On Certainty, ed. G. E. M. Anscombe and G. H. von Wright, trans. Denis Paul and G. E. M. Anscombe (New York: Harper, 1972), $\$ 611 \& \$ 612$ (emphasis original).

32. In "Criticising from 'Outside"” Diamond's arguments against Winch and Dilman are made from a position she describes as "Anscombian". I believe Diamond's Anscombian position is very close to what here I am referring to as "Putnamian" and that this is borne out by the way Putnam's and Anscombes views intertwine in "Putnam and Wittgensteinian Baby-Throwing". See Introduction, note 10 for reference.

33. "Criticising from 'Outside'," 124. In “Truth: Defenders, Debunkers, Despisers”, Diamond argues against Richard Rorty's epistemological behaviorism by recounting the way in which Primo Levi's training as a pharmaceutical chemist, and his believing in the objective truth of the periodic table of the elements, was crucial for his spiritual and psychological survival in Nazi concentration camps. Diamond brings out well the significance which this knowledge of an independent objective truth had for Levi during his experience with the worst consequences of Nazi lies. See "Truth: Defenders, Debunkers, Despisers," in Commitment in Reflection, ed. Leona Toker (New York: Garland, 1994), 195-222. In defense of Rorty, it's worth pointing out that, to my knowledge at least, he never suggests that our best epistemic practices amount to accepting whatever the political authorities say, and in any case the Nazis were a long way from adhering to these practices. And of course, we should recall that this historical example of the value of what I have called a grammatical artifact, in this case concerning "truth" instead of "reality", does not by itself provide any empirical content. What we call "truth" in any given case is closely connected to what we are going to agree upon after taking account of our (hopefully) best epistemic practices, and this will surely capture, extensionally at least, Levi's periodic table. Unless we believe in the idea of a finished science and that chemistry was already one of them during the Second World War, we will have to agree that Levi's belief in the truth of the periodic table was at most in line with the best epistemic practices of his time.

34. On the question of religious truth, see the Appendix. 


\title{
3 Skepticism and the Human Condition
}

\author{
Kevin M. Cahill
}

"The data of ethnology prove that not only our knowledge but also our emotions are the result of the form of our social life and of the history of the people to whom we belong."1

I take it that one of the most significant characteristics of the conceptual and ideological revolutions that ushered in the modern period in the West is the way the new theological, scientific, and economic regimes portrayed themselves as representing a kind of genuine natural order over what they saw as the social and theological institutions of the Middle Ages (which, I don't doubt, understood themselves as embodying a natural order too). ${ }^{2}$ This exemplifies a general moral: during periods of great change, it will often be useful for furthering one's agenda to frame the debate so that it will seem as though one's new conceptions of science, commerce, religion, or the subject of epistemology, are not just new and better, but were already latent in the older and dominant regimes, and that this fact would have been clearly seen by earlier generations if only they had managed to cast off the artificial social barriers, traditions, and superstitions of precisely those older systems. That is to say, the new order will usually find it advantageous to present itself as having made a set of discoveries about certain fundamental factors, the nature, say, of human beings, and not as having reorganized our interpretations of those factors. With regard to Western modernity's more or less uncritical acceptance of its own accepted individualistic notions of political, moral, and epistemological agency, both in its relation both to medieval Europe and to other cultures, Charles Taylor refers to such an interpretation as a "subtraction story". ${ }^{3}$ At the broadest level, this essay addresses questions connected to conceptual and/or cultural difference and change, specifically the intersection of certain questions that concern modernity, human nature, and the concept of the self. ${ }^{4}$ More specifically, I want to look at a nest of connected questions in philosophical anthropology or perhaps better yet, the anthropology of the self in the Western epistemological 
tradition after Descartes as that tradition is represented in the work of Stanley Cavell.

In his insightful treatment of skepticism about the external world, Unnatural Doubts: Epistemological Realism and the Basis of Skepticism, Michael Williams was principally concerned to establish the credentials of a contextualist approach to epistemology. ${ }^{5}$ According to the position which Williams defends there, external world skepticism arises out of the traditional epistemologist's demand for a context invariant account of the conditions of knowledge in general. ${ }^{6}$ Williams' term for the guiding belief that such an account is available is "epistemological realism". He describes this view as the assumption there is a kind of thing called "knowledge of the external world", which the epistemologist tends to assimilate to natural kinds talk among realists in metaphysics and the philosophy of science.

Williams believes that once we have accepted the demand for an entirely general, context invariant account of knowledge, our canvassing of the various sources of knowledge will almost invariably land us with something close to a sense-data theory, what Williams terms the "priority of experiential knowledge". Williams holds further that the thesis of the priority of experiential knowledge is essential to epistemological realism qua foundationalism. ${ }^{7}$ Yet the epistemologist's acquiescing in the demand for absolute generality not only leads to the priority of experiential knowledge, it has immediate and familiar skeptical consequences since, while perhaps context invariant (assuming for the moment we allow such talk to go unchallenged), sense data are notoriously unsuitable for establishing any secure epistemological foothold in the world outside of the mind.

Williams describes his approach as providing a "theoretical diagnosis" of external world skepticism, which aims to show that epistemological realism is a false doctrine, or at least a poorly supported one, based on the dubious assumption that knowledge exhibits the kind of essential structural unity supposedly characteristic of natural kind concepts. ${ }^{8}$ Williams argues in turn for the truth of his own contextualist epistemology, which rejects the foundationalist idea that the supposedly context invariant deliverances of the senses are the only source of knowledge. In rejecting epistemological realism as a dubious doctrine, Williams believes he can also show that there are good reasons for regarding his own contextualist account as convincing, and so for regarding skepticism as false.

Although most of his energy is devoted to the diagnosis and critique of epistemological realism, Williams also has much to say about so-called "therapeutic diagnoses" of skepticism. As Williams understands it, a therapeutic diagnosis of skepticism seeks to locate and display something that is fundamentally amiss with the meaning of one or more of the skeptic's premises, so that the skeptic's conclusions are not so much shown to be false, as they are revealed to be confused or incoherent. ${ }^{9}$ Although 
in some places Williams appears sympathetic to the main representatives of this approach, whom he uncontroversially takes to be Austin, Wittgenstein, and Cavell, he finds their assessments often based on an under appreciation or misunderstanding of the strength of the skeptic's arguments. ${ }^{10}$ Yet, setting aside Williams' treatment of Austin and Wittgenstein, there is something very misleading in Williams' presentation of Cavell's thought about the nature of external world skepticism. In particular, Williams' claim that Cavell regards himself as having provided a therapeutic diagnosis that yields a definitive refutation of skepticism flies directly in the face of Cavell's own stated views that not only is skepticism irrefutable, but that trying to refute it is itself an expression of skepticism. ${ }^{11}$ How Williams might have missed this feature of Cavell's thought, or as is perhaps more likely, why he chose to disregard it, is difficult to say. This point may become clearer once Cavell's account has been laid out.

Cavell has claimed that attempts to give a philosophical refutation of skepticism are misguided because they tend to obscure or suppress what he terms the "truth of skepticism". ${ }^{12}$ By this, Cavell does not mean to suggest that it is the coherence of the philosophical thesis of skepticism itself that dooms such attempts to failure, but rather something such attempts at refutation cover up, namely the fact that "Our relations to the world as a whole, or to others in general, is not one of knowing, where knowing construes itself as being certain". ${ }^{13}$ Cavell does not endorse the philosophical thesis of skepticism. Indeed, he thinks there is something wrong with the skeptic's conclusions. But he thinks that because the skeptic is on to something, the philosopher who tries to refute skepticism is, in an important sense, as misguided as the skeptic himself. He thus suggests that we might think of both parties as subject to what Kant calls a "dialectical illusion" in the Antinomies of Pure Reason:

I hope it will not seem perverse that I lump views in such a way, taking the very raising of the question of knowledge in a certain form, or spirit, to constitute skepticism, regardless of whether a philosophy takes itself to have answered the question affirmatively or negatively. It is a perspective from which skepticism and (what Kant calls) dogmatism are made in one another's image, leaving nothing for choice. ${ }^{14}$

For Cavell, the force of these considerations is that, while we cannot fulfil the skeptic's requirements for knowledge, neither do we fail to fulfil them. As he notes, however, this only raises a further question: "Why does the skeptic - how can he - take what he has discovered to be some extraordinary, and hitherto unnoticed, fact? Or perhaps we could ask: Why does he take his discovery to be a thesis?" 15

This brief description of Cavell's attitude towards skepticism may sound reminiscent of a well-known remark by Heidegger in Being and 
Time concerning something Kant says in the preface to the second edition of the Critique of Pure Reason. Kant had complained there that it was a "scandal of philosophy" that no one had yet succeeded in proving the existence of the external world. ${ }^{16}$ Heidegger's response to Kant's complaint was to suggest that the real scandal is "not that this proof has yet to be given, but that such proofs are expected and attempted again and again" ${ }^{17}$ Yet while some of Heidegger's thoughts on skepticism dovetail with Cavell's analysis, in particular around the relevance of human finitude, there is an important sense in which Cavell and Heidegger differ crucially on the underlying significance of the "truth of scepticism". I shall return to this point presently.

Philosophy is of course not the only venue where Cavell has examined the issue of skepticism. He has also written eloquently on the importance of this question for areas such as literature and film. But the reason it is essential to consult Cavell's prodigious writings in areas often regarded as peripheral to philosophy if one wants to understand his thought about skepticism is not just that he so often explicitly raises the topic in his interpretations of art. That would risk mistaking his discussions of the arts as mere window dressing for his more "strictly philosophical" work, such as that devoted to Wittgenstein. There are no "strictly philosophical" works in Cavell's corpus; or better, all of his works are strictly philosophical because while not wishing to conflate philosophy and art, Cavell rejects the intellectual priority of one over the other. He writes, for example, that "I have more than once said or implied that the problem of the other was no less a literary than a philosophical problem". ${ }^{18}$ And so accordingly, we find the following in the introduction to his collection of essays on Shakespeare:

My intuition is that the advent of skepticism as manifested in Descartes' Meditations is already in full existence in Shakespeare, from the time of the great tragedies in the first years of the seventeenth century, in the generation preceding that of Descartes. ${ }^{19}$

Cavell treats film with equal philosophical seriousness, as we can see when he claims that Clark Gable's difficulties in understanding Claudette Colbert in the 1934 comedy It Happened One Night "is a framing of the problem of other minds". ${ }^{20}$

Indeed, one of the most prominent themes running through all of Cavell's work is the idea that an engagement with skepticism forms an essential part of the human condition. In particular in Cavell's view, skepticism is an expression of our inability to be at peace with the inherent contingency involved in our application to the world and to each other of the criteria that inform the everyday intelligibility of language. We find this theme articulated, for example, in "Declining Decline", an essay in which Cavell discusses the possibility of reading Wittgenstein as 
a philosopher of culture. Cavell writes there, "the griefs to which language repeatedly comes in the Investigations should be seen as normal to it, as natural to human natural language as skepticism is". ${ }^{21}$ Not only does Cavell believe that the possibility of skepticism forms a natural part of our life with language, he repeatedly claims that he sees the impulse to eradicate skeptical doubt (prevalent within, but not limited to, philosophy) as also somehow basic to our humanity. In the same essay he describes this impulse as "the desire for thought, running out of control. That has become an inescapable fate for us, apparently accompanying the fate of having human language." 22 This point is put even more forcefully a few pages later: "I mean to say that it is human, it is the human drive to transcend itself, make itself inhuman, which should not end until, as in Nietzsche, the human is over". ${ }^{23}$ Such remarks as these lend further weight to Cavell's thought that his diagnosis of the origins of skepticism is close in spirit to Kant. In particular they seem in harmony with Kant's assertion in the preface of the Critique of Pure Reason that

Human reason has this peculiar fate that in one species of its knowledge it is burdened by questions which, as prescribed by the very nature of reason itself, it is not able to ignore, but which, as transcending all its powers, it is also not able to answer. ${ }^{24}$

Nevertheless, while for thinkers like Kant, Barry Stroud, and Thomas Nagel, the problems of metaphysics are intuitive intellectual problems, for Cavell, the sources of skepticism lie not only or even primarily in our intellect but first and foremost in our affective nature.

At any rate, we can begin to see where Cavell's interpretation of skepticism diverges substantially from Heidegger. For although Heidegger does not offer a theoretical response to skepticism, it would nevertheless make little sense for him to term a "scandal" what we have seen Cavell characterize as our "inescapable fate" (unless Heidegger thought there was something inherently scandalous about being human, something Cavell might well have thought, but I doubt Heidegger would ever put things this way). Cavell is right in thinking that there is something profoundly dubious about the attempt to give a philosophical refutation of skepticism. I also have much sympathy for the importance he attaches to what he terms "the truth of skepticism". Nevertheless, I will show how his failure to consider significant alternatives undermine his claim that some kind of engagement with skepticism is itself part of what it is to be human.

Can we think of the "truth of skepticism" as merely one way of presenting what I take to be the facts to which it refers, that is, certain facts of human finitude? To put it another way: must an engagement with these facts be mediated by epistemological concerns to the degree Cavell assumes is compulsory? Or are there other ways of being in touch with 
the concrete reality of this truth, ways which are not mediated by the concerns with knowledge that we find in the exclusively modern works of philosophy, literature, and film that Cavell discusses? I believe there are and I will argue that Cavell's conception of the human arises from the inadequate consideration he gives to the possibility that humans within different historical cultures may have sufficiently different conceptions of the self than the one he takes for granted. Attention to the possibility of such differences makes it unrealistic to assume that the problems that Cavell locates in the sphere of the human must inevitably arise (or inevitably be repressed, which is in effect the same). To put this another way by borrowing a phrase from William James, Cavell does not account for the very real possibility that there can be people for whom skepticism is not a "live option".

This essay will involve an investigation of precisely this last aspect of Cavell's understanding of skepticism. In particular, as opposed to Williams' theoretical diagnosis and Cavell's version of a therapeutic diagnosis, I will argue for a historical or cultural-anthropological diagnosis of skepticism. My approach is rooted in the suspicion that largely motivating much of what Cavell says about skepticism, not so much about its irrefutability, but about its chronic recurrence, is a picture of what it means to be a human being, specifically what a human self is. And I further suspect that it is a picture that fundamentally fails to appreciate the depth or logical significance of historical practices for our intelligibly talking about the self in the ways Cavell wants to do.

Two reasons why I believe Cavell's work is worthy of serious attention is my belief that he has provided us with the "best case" for thinking that skepticism is a natural part of human life and because this claim is intimately connected to his taking for granted a more or less modern conception of the self. ${ }^{25}$ Overturning these ideas, then, is likely to have important and interesting consequences. I will show that at the root of Cavell's portrait of the human lies an ahistorical dogmatic ontology of the self that suffers from its assumption that certain features characteristic of the modern individual are universal. Therefore, whereas Cavell has primarily intended to provide a kind of ethology of the human animal, he has instead succeeded in providing an ethnography: a compelling ethnography, but an ethnography nonetheless.

In Part II, I clarify how I intend to deal with three features of Cavell's thought on skepticism that might be thought to present obstacles for my way of laying out and criticizing his work. These are first, the asymmetry of Cavell's understanding between external world (or material object) skepticism and other-minds skepticism, second, the occasional exploration of the relationship between skepticism and sex or gender in Cavell's writing, and third, the relationship between history, especially the history of modernity, and skepticism as Cavell understands it. ${ }^{26}$ In Part III, I give a brief synopsis of Cavell's analysis of external world skepticism, 
with emphasis on why Cavell thinks the skeptic's procedures lead to a kind of incoherence. In Part IV, I discuss why Cavell nevertheless insists that the argument laid out in Part III does not constitute a refutation of skepticism, and, more importantly, why he believes that for human language users skepticism is in a certain sense natural and unavoidable. The key idea in this section is that a particular interpretation of the self is utterly central to Cavell's claim that a relation to skepticism is inevitable for creatures with language and thought. In Part V, I provide an overview of work by Charles Taylor where he presents a portrait or the modern Western self that is substantially more historical and stands in fairly stark contrast to what I regard as Cavell's mainly ahistorical picture. In Part VI, I turn to some anthropological literature that further challenges the picture of selfhood that lies at the heart of Cavell's understanding of skepticism. In Part VII, I draw out some of the philosophical consequences of my analysis. I argue that Cavell's claim that skepticism is an inevitable expression of the human condition is at best underdetermined; seen less charitably, it is hard even to make sense of the claim. In Part VIII, I address questions connected to my use of historical and ethnographic material in my analysis of skepticism. In Part IX, I show that there is no reason to believe that the self as Cavell understands it is somehow necessary to linguistic agency. Part X addresses some remaining issues concerning modernity and the modern self. I argue that even when taking into account what signs there are of hermeneutic, historical understanding in Cavell's account, these are not enough to avoid the conclusion that a kind of essentializing (even to the point of fetishizing) of the modern conception of the self pervades his thought and that this seriously undermines his claim about the universality of the human relation to skepticism. Finally, In Part XI, I briefly address a few of the practical, ethical, and political dimensions of the contingency of skepticism in light of the contingency of the correlative modern notion of selfhood.

\section{II}

In this Part, I deal with issues that some might feel pose important challenges for my own presentation and analysis. These issues concern my way of handling three features of Cavell's thought about skepticism: the asymmetry between his treatment of external world (or "material object") skepticism and other-minds skepticism, the relation between skepticism and gender, and lastly the question of the role that history plays in his account of skepticism. My reason for dealing with these issues in a preliminary way here, rather than in a systematic way later, is that the second option would, I think, unnecessarily complicate my story. It would draw me off in all sorts of directions without in the end adding anything substantial to my discussion. Someone might think that if these issues are worth mentioning at all, then they are surely worth handling 
in the body of this essay. I disagree and my reasons for disagreeing will hopefully emerge and be convincing by the end of this essay. Yet I feel I should say something about these issues, if only to ward off possible unwarranted attacks to the effect that I have ignored or distorted crucial aspects of Cavell's thought altogether. Whether or not this is actually the case can only be evaluated for each issue individually, and then only after my narrative is completed.

\section{A}

In Part III, I will sketch the salient features of Cavell's understanding of skepticism including the part of his view that I go on to examine in the remaining sections of this essay, namely, the anthropology of the self that I believe runs through his authorship. Yet my sketch of Cavell's diagnosis of the skeptic's procedures in philosophy, and my conjoining it to my own description of his portrait of the human in Part IV that relies on this sketch, might seem to be incongruous in one troubling respect. For while the sketch of Cavell's account of philosophical skepticism draws mainly from Part II of The Claim of Reason, which deals primarily with external world (material object) skepticism, my description draws not only from some of Cavell's works where that variant of skepticism is at stake, for example from those works devoted to Romanticism or to American Transcendentalism. ${ }^{27}$ It also draws from his numerous discussions in which other-minds skepticism is in focus, for example from some of his works that address themselves to film and to Shakespeare. ${ }^{28}$ The possible problem with my presentation stems from the fact that while there is a crucial asymmetry in Cavell's diagnoses of external world and other-minds skepticism respectively, this asymmetry of his analyses plays no role in my critique of his anthropology of the self.

The asymmetry itself is rooted in Cavell's view that external world skepticism and other- minds skepticism have somewhat different logics and etiologies, and thus that their diagnoses call for somewhat different concepts and responses. With external world skepticism, Cavell believes that my failure to have knowledge of a generic object in a best possible case threatens to ramify to my knowledge as a whole, thus generating a global skepticism about material objects. ${ }^{29}$ But he also believes that to try to live this kind of skepticism would be next to impossible as it would involve renouncing my ability to lead a normal human life. Fortunately, as with Hume's famous description of the change that came over him upon leaving his study for the billiard parlor, this version of skepticism dissipates when we return to the world of our practical engagement with things. Cavell says,

To say that I cannot "live" material object skepticism is to say that there is an alternative to its conclusion that I am bound, as a normal human being, to take. Accordingly, to say I (can) live skepticism with 
respect to others is to say that there is no such alternative, or no such conclusion. ${ }^{30}$

This is what Cavell means, that with material object skepticism, I have to (and usually can) "forget my skepticism", that is, I can forget the lesson of my failed best case of knowledge of a generic object and become reabsorbed with objects in the everyday world. ${ }^{31}$

But Cavell also thinks that the role of the key terms in which he frames external world skepticism, in particular the idea of a best case of knowledge of a generic object, become more obscure when it comes to otherminds skepticism. In particular, with other-minds skepticism it is far less clear that I need or can have a best case for knowing a generic object. (I took you to be content with me when in fact you were angry and only feigning contentment.) The nature of the "objects" we want to know, so to speak, are the individual "mind-states" (love, fidelity, hatred, envy) of individual humans. Because there are no relevantly generic minds, failure in the one case need not ramify. ${ }^{32}$ We read in a late essay,

In the case of other minds I find that instances of the other do not generalize; or rather, where objects are singled out on the model of the Cartesian format of supplying a basis for a claim to know and grounds for doubting the basis, the format does not express my interest. At the place with material objects where I object to your claim to know by saying, for example, that "you don't see the back half of the object," I say in the case of other minds that you don't know what's going on in the other, who might, say, be feigning what you say she feels, or feeling something quite different. The difference is that the case of the material object is argumentative; I am apt to feel bullied by it and if I accept it confess a shock or realization. Whereas the case of the other is too trivial to mention. Who doesn't know that what I go on in knowing others is their outward behavior - or is it their conduct, or the subtler movements of the body, especially the face, and, as documentary filmmakers insist upon, the hands? In any event, what is inside the other is not transparent to me. This is no news, and accordingly it suggests that the problem of the other is not discovered the way the problem of the knowledge of objects is discovered. ${ }^{33}$

Furthermore, this feature of our relations to this or that person on this or that occasion means that for Cavell, a kind of piecemeal other-minds skepticism is not only possible for us, avoiding it calls for effort and attention. He writes,

With respect to material objects we have to "forget" the possibility of skepticism, e.g. that the best case will fail us. With respect to other 
minds we might say that we have to "remember" the possibility of skepticism, e.g. that we have not permitted ourselves a best case, that we do not know but that we may, at any place, be singled out; hence that, so far as we know, we now are not. ${ }^{34}$

I take that his saying that with other-minds skepticism I have to remember the possibility of skepticism means that acknowledgement of others requires a specific form of attention, that I have to be more active in applying criteria, that I have perhaps to remember to resist my own temptations to overlook or deny others. Cavell sums up the asymmetry between the two variants of skepticism this way:

[T] here is no everyday alternative to skepticism concerning other minds. There is no competing common sense of the matter; there is nothing about other minds that satisfies me for all (practical) purposes; I already know everything skepticism concludes, that my ignorance of the existence of others is not the fate of my natural condition as a human knower, but my way of inhabiting that condition: that I cannot close my eyes to my doubts of others and to their doubts and denials of me, that my relations with others are restricted, that I cannot trust them blindly. ${ }^{35}$

Therefore, unlike external world skepticism, which Cavell thinks has a provisionally satisfactory everyday alternative, viz. my absorption in my everyday life with objects, and which thereby cannot be lived except perhaps on pain of something close to insanity, other-minds skepticism has no obvious everyday alternative. Absorbing myself in what I suspect to be fakers may be possible, but it would require some serious mental gymnastics. I can, however, easily and coherently not care whether I know or understand you: "I said there is no general, everyday alternative to skepticism concerning other minds. Now I will say: I live my skepticism".36

While the livability of other-minds skepticism is precisely why Cavell finds drama and film such rich resources for philosophical reflection, this fact also suggests that his treatment of other-minds skepticism is likely to be less perspicuous than his dealings with material object skepticism. And indeed, not only do I find his treatment of the former substantially more drawn out and complex (not to mention sometimes downright incomprehensible) than his analysis of the latter, I am frankly unsure whether his prolific dealings with other-minds skepticism add up to a coherent account at all. (It is also unclear to me whether they are supposed to do so. I am further unsure whether his acolytes perceive this as a problem or a virtue.) At any rate, in the present case it would be good if I could skirt a comprehensive handling of this issue. 
Fortunately, Cavell himself provides the clue to the resolution of this issue. He writes in the preface to the Claim of Reason,

One of my first expressions of my contrary intuitions about these cases was to say that at the conclusion of the material object case I was left sealed inside the circle, whereas at the end of the other minds case I was left sealed outside the circle of the other's experiences. ${ }^{37}$

Cavell describes here his "contrary intuitions" about the positionality of the self in relation to its object. Yet while his expression of a sense of reversed relationality is no doubt interesting, given my interests here, it makes sense to ignore it. This is because my focus on the anthropology of the self in Cavell's work is concerned with the unquestioned status of the modern self's image of itself as thus "sealable" in the first place. Whether sealed in as with material object skepticism or sealed out as with other-minds skepticism, we are surely dealing here with the same "punctual" self. ${ }^{38}$

\section{B}

This section concerns the way in which I handle a possible different asymmetry in Cavell's understanding of skepticism, an asymmetry that, though he clearly came to believe it to be significant, never received a worked out articulation in his thought, and thus in my view can't really be said to have anything like Cavell's imprimatur. This is the asymmetry in the way skepticism may be inflected by sex and/or gender.

The category pairs of male/female and feminine/masculine seem to play minimal, or at least very subterranean, roles in Cavell's thinking about skepticism from the time of Must We Mean What We Say, through the Claim of Reason, and on into the mid-1980s. In his analysis of remarriage comedies, Pursuits of Happiness, Cavell does begin to broach gender-related issues such as the way the creation of what he calls the "new woman" made these comedies possible, but there is as of yet no suggestion that skepticism itself may be more intimately connected to sex and/or gender. ${ }^{39}$

The possibly deeper connections that Cavell was to explore only a few years later in his analysis of Shakespeare's The Winter's Tale might thus be read as marking a significant shift in the position that he had by then already been advocating for nearly two decades, namely, that a relation to skepticism was something inherently human that each of us bore simply in virtue of being language users. In the introduction to his collection of essays on Shakespeare, however, Cavell writes that while he had harbored a suspicion for some time that the impulse to skepticism was somehow deeply connected to sex and gender,

I resisted saying it. ... Because the premonition or suggestion threatens the insight I had found and refound so guiding for two decades in 
pondering human finitude, that human language is inherently open to the repudiation of itself. The premonition or suggestion or tuition of the play of Leontes' opposition to his wife is that skepticism is a male business; and accordingly that the passion for knowledge as such, so far as it is motivated in skepticism (hence in a certain strain of modern philosophy as such, since Descartes, Hume, and Kant), is inflected by gender difference, that the economy of knowing is different for men and for women (Is this news?). ${ }^{40}$

The specific explanation proposed for this suggested asymmetry in the play is that

Because The Winter's Tale represents skepticism as the question whether I can know that my children are mine, the question of a father and distinctly not that of a mother, the implication now seems to me irresistible that the issue of skepticism in this text ... is inflected by the question of gender. ${ }^{41}$

Cavell is of course not suggesting that the fall into skepticism is a singularly masculine temptation. In fact, it is precisely the lack of any clear-cut correspondence to sex that leads him to introduce gender concepts into his account. He thus notes, "I know some women for whom I do not doubt that the skeptical issue does arise. One might here speak not of men and women but of masculine and feminine aspects of human character generally" ${ }^{22}$ As to what might prompt a corresponding feminine flight from finitude, he speculates a bit later,

Then a feminine passion toward the unconditioned, construed as a drive toward the given, may be representable not as doubt but instead as love. And what masculine philosophy knows as skepticism feminine philosophy knows as fanaticism. Fanaticism is explicitly one of Kant's names for a distorted expectation of reason, one form taken by the desire to refuse human limitations, the limitation of finitude; hence it is exactly measurable with skepticism. ${ }^{43}$

Yet, despite what may be a fruitful line of exploration, there are several reasons for why I opt not to examine the question of how issues of gender may, as Cavell puts it, "inflect" the issue of skepticism.

My first reason for not making Cavell's speculations about skepticism's relation to sex and gender central to my essay concerns what I hope to accomplish by the historicist and cultural anthropological thrust of my argument. I will argue that a fundamentally essentialist, because ahistorical, conception of the self permeates Cavell's work on skepticism. If it should turn out that by Cavell's own lights much of his authorship pertains primarily to men instead of to all of humanity, that still leaves him 
by my lights making questionable claims about an awful lot of humanity. Second, even if it is plausible that, as Cavell speculates, the feminine existential issue is not a catastrophic doubt pertaining to knowledge but a catastrophic fanaticism pertaining to love, it could well be that my approach applies just as well to the self of such fanaticism as it does to the self of skepticism. Both ideas seem to take for granted a radicalized sense of the punctual sealed off/sealed in self that I find equally noncompulsory. Finally, however, my third and main reason for not dealing with the issues of how sex and gender play out in Cavell's work is simply that this provisional asymmetry in his analysis of skepticism receives so much less attention than do his much broader claims about the relation of skepticism to humanity as a whole. Indeed, only a few pages after suggesting that feminine fanaticism about love is exactly measurable with masculine skepticism about knowledge, we find Cavell back to making the more typical sort of universalist claim I find suspect:

What skepticism threatens is precisely irretrievable outsidedness, an uncrossable line, a position from which it is obvious (without argument) that the world is unknowable. What does "threaten" mean? Not that skepticism has in its possession a given place in which to confine and isolate us, but that it is a power that all who possess language possess and may desire: to dissociate oneself, excommunicate oneself from the community in whose agreement, mutual attunement, words exist. ${ }^{44}$

In fact, given my approach, both the degree and nature of Cavell's ambivalence around this issue expressed in this passage from "Macbeth Appalled" in the same collection bear out my decision not to make it central to my essay.

There is in me ... a standing possibility that I use the more general, or less historical ... species anxiety to cover a wish to avoid thinking through the anxiety of gender. If there is a good reason to run this risk it is that the reverse covering is also a risk, since knowing what is to be thought about the human is part of knowing what is to be thought about gender. ${ }^{45}$

C

In the case of the asymmetry Cavell finds between other-minds skepticism and external world skepticism, and in the case of the question he raises of the relation between sex/gender and skepticism, my previous discussions will have to suffice: for the reasons given, I won't revisit either of those issues later in the essay. In the case of the third issue I deal with in the present section, that of the history of modernity and its relation 
to skepticism, the situation is more complicated. After my presentation in the next section of Cavell's diagnosis of skepticism, my critique of his views of the self that are internal to that diagnosis will be fundamentally historical and anthropological in its orientation. I will argue that Cavell in effect relies on an ahistorical essentialist picture of the modern self. What makes things complicated for my mode of presentation, however, is that it could give the reader the false impression that history is entirely absent from Cavell's writings. Understandably, this could give rise to some head shaking on the part of impatient readers, especially those sympathetic to Cavell, because historical context is in fact not absent from Cavell's numerous discussions. On the contrary, references to the historical context of the advent of both skepticism and the modern notion of the self are abundant in his writings. A few examples make this clear.

While noting his previous neglect of Macbeth in the preface to his collection of essays on Shakespeare, Cavell states that,

Macbeth was the remaining great tragedy of Shakespeare's I had not been moved, or was otherwise not able, to test against the thought that this mode of tragedy is a response to the crisis of knowledge inspired by the crisis of the unfolding of the New Science in the late 16 th and early 17 th centuries, especially as articulated so decisively for philosophy in the next generation following those tragedies by Descartes' articulation of modern skepticism. ${ }^{46}$

Later in "Macbeth Appalled" in the same collection, Cavell says that

I proposed thinking through the play [Antony and Cleopatra] as a representation of the catastrophe of the modern advent of skepticism (hence also of the advent of the new science, a new form of knowing), taken as an individual and a historical process. ${ }^{47}$

In "Being Odd, Getting Even (Descartes, Emerson, Poe)", among speculations that Cartesian skepticism may be the alternative to affirming the conditions of one's finitude we find a parenthetical remark indicating the significance of historical context for the emergence of Descartes' cogito:

I imagine that the appearance of the cogito at its historical moment is a sign that some conditions were becoming ones for which getting even, or anyway overcoming, was coming to seem in order: for example, the belief in God and the rule of kings. ${ }^{48}$

Again, in "Night and Day: Heidegger and Thoreau" from 2000 Cavell refers to the historical situation in which modern skepticism broke through as "the cultural cataclysm represented by the advent and installation of the new science in the sixteenth and seventeenth centuries". ${ }^{49}$ 
Finally, in 2004, Cavell expresses his wish "to leave open the idea that a Cartesian 'privacy' bears on what is felt as Shakespeare's marking of a new stage in human - Western? - Subjectivity". ${ }^{50}$

Rather than arguing, then, that Cavell simply ignores history in his account of modern skepticism, my complaint will be that the lack of philosophical weight that he attributes to historical context is troubling. It is, moreover, this fact that I think justifies the way I will present Cavell's account of the self. I will ascribe to Cavell a largely ahistorical view of the nature of the self that lies at the basis of his account of modern skepticism. After this ahistorical and essentialist view is on the table, I will explicitly take into account the kinds of considerations that Cavell raises about historical context in order to see if these contradict or ameliorate this criticism. Not only will I show that they do not, citing Cavell's own remarks about historical context actually allows me to bring out even more clearly how his consistently strong claims about skepticism and human nature reveal that he must either adhere to something like a metaphysical developmental story about the modern conception of the self, or, as I suspect is more likely, land him in some sort of subtraction story. ${ }^{51}$ Neither option will turn out to be tenable. Both exhibit a disregard for what I believe to be a more compelling hermeneutic approach to historical-cultural considerations.

\section{III}

In the previous section, we saw Williams wrongly attribute to Cavell the ambition of providing a therapeutic diagnosis of skepticism that would amount to a definitive refutation. Yet more important than citing authorial disclaimers by Cavell that undermine William's claim is getting into a position to see precisely why Cavell thinks any project of definitive refutation of skepticism misses its mark so widely. This is what my brief sketch of Cavell's analysis of material object (external world) skepticism aims to do. ${ }^{52}$

Cavell argues against Austin that criteria, the marks by which we correctly apply our concepts, do not provide the materials for a convincing rejection of the skeptic. ${ }^{53}$ To see why, consider Austin's anti-skeptical arguments that make use of knowledge of specialized criteria. Suppose for example I call out, "Look at that gorgeous '65 Mustang right there!” A friend might challenge me with the question, "How do you know that's a '65?" If we assume for a moment that the challenge is directed to the specific claims implicit in my call, then it could well be taken as asking how I know that there is a 1965 Mustang as opposed to a 1966 Mustang, given that the two editions are very close in appearance and are easily mistaken for one another. Austin's use of specific criteria was supposed to show how I could meet this type of challenge by using my special knowledge of Mustangs to give a response such as "Because of the grille". (To 
someone familiar with these editions, the grille on the two different years' models can be distinguished, even from a considerable distance, and was one of two main differences in outer appearance (the other being the quarter ornaments)). By Austin's lights, if my friend persisted by asking how I really know the year of the car, this could reveal him to be either ignorant or confused about just what it would be to know the difference between a 1965 and 1966 Mustang based on their outer appearance. ${ }^{54}$

If my companion were simply interested in challenging things like my ability to distinguish between two early editions of a popular 1960s American car, then my response might satisfy him. But as Cavell makes clear, the Cartesian skeptic's doubt is intended to have a much wider and more destructive scope; it is meant to force me to admit that, my feeling of certainty notwithstanding, the "car" parked on the street might for all I know be a fiberglass replica (my "stuffed goldfinch", as it were), and no amount of complaining about common sense and "what is true for present intents and purposes" can make this possibility just disappear. This point shows how, as Cavell argues, Austin's kind of anti-skeptical argument is useless if, instead of relying on examples that make use of special knowledge of concepts and of one's abilities to discriminate specific objects, the skeptic actually makes his point with reference to grammatical criteria that govern our use of words, referring to what Cavell calls a "generic object", i.e. a car, a tomato, a bird, a piece of wax, a tree. ${ }^{55}$

Once we take into account that not only does the skeptical challenge operate with a generic object (a car) and not a specific object (a '65 Mustang), but a generic object perceived under ideal conditions (right there in the street under bright sunshine), his line of questioning can be fatal to our claims to perceptual knowledge. If I am wrong about the Mustang being a ' 65 , either because I didn't know the difference between its grille and that of a '66, or perhaps because I was careless in my reporting, I may see no great threat to knowledge in admitting, that, after all, it was a '66 Mustang and not a ' $65 .{ }^{56}$ My error is localized and need not have any broader epistemic reverberations. But if, however, I am standing five feet away with ample light and normal eyesight, the potential effects of mistaking a fake car for a real one are not so easily contained. This is why in Cavell view, Austin's examples are unsuited to refute skepticism: the skeptic operates with criteria for generic objects that describe the best possible occasions of our correct our use of general concept words under ideal circumstances. ${ }^{57}$ The depressing conclusion to these reflections on the attempt to refute skepticism by the notion of criteria is that

Criteria are "criteria for something's being so", not in the sense that they tell us of a thing's existence, but of something like its identity, not of its being so, but of its being so. Criteria do not determine the certainty of statements, but the application of the concepts employed in statements. ${ }^{58}$ 
Criteria pertain to those occasions when it is appropriate or justified to claim something about the world, but not necessarily to when one is correct in doing so.

Cavell thus thinks that refutations of skepticism that rely on criteria fail. But he does not worry that this failure makes the truth of the skeptical thesis more likely. In fact, he thinks that considerations from criteria do play a key role in showing what is fundamentally amiss with the skeptic's procedure; it is just not the role sometimes assigned to them. To see what Cavell finds suspect in the skeptic's apparently impeccable line of reasoning, consider the following schematized exchange: ${ }^{59}$

1. Claim: Here is a car. (Made under ideal circumstances)

2. Request for Basis: How do you know?

3. Basis: I know because I see it. ("By means of the senses")

4. Grounds for Doubt: How do you know you're not dreaming or hallucinating?

Cavell notes that as far as he is aware, the usual efforts to stanch the skeptical movement of this recital concentrate on either the Request for a Basis (2) or the Ground for Doubt (3). ${ }^{60}$ His own unorthodox line of inquiry, on the other hand, will focus on the Claim itself.

As the schema illustrates, the skeptic's procedure requires that a claim be made about a generic object such as a car, a piece of wax, or a hand when presented under ideal perceptual circumstances. Further, because the case is a best case, if doubt can be raised about my claim to knowledge here, it can be generalized so as to call into question all of my knowledge of material objects. This then seems to threaten to yield a skeptical conclusion. Yet at this point Cavell thinks he can bring to bear a crucial point that he has argued for earlier, namely, that the criteria governing words are not self-applying. The words I utter may have a general semantic meaning, but in a particular context unless I mean something by them, they may mean anything at all, which is really to say nothing at all: without my input, "criteria are dead" ${ }^{61}$ This allows Cavell to broach the surprising idea that "what can comprehensibly be said is what is found to be worth saying". ${ }^{62}$ Because criteria are not self-applying, we have to apply them with some purpose or other when we speak. So if the initial Claim (1) is to provide the skeptic the platform he needs to launch his attack, the Claim itself must be uttered for some specific reason, given an actual use, that makes it worth saying in that context. In the case of the skeptical recital of traditional epistemology, this possibility prompts Cavell to ask, "Is the example the philosopher produces imaginable as an example of a particular claim to knowledge? What are his examples examples of?" 63 
Now the epistemologist may naturally assume that it is sufficient for him to have made a genuine knowledge claim even if the only unusual thing about his utterance is that in ordinary circumstances its truth would be so "flamingly obvious". ${ }^{64}$ Yet just proclaiming out of the blue "Here is a hand", with no context for saying so (and as Cavell provocatively underscores "because it's true" does not on its own provide such a context), could mean anything, and consequently nothing. ${ }^{65}$ There are certainly contexts in which words such as these can be sensibly uttered; it's just that the epistemological non-context isn't one of them. Saying something, even something flamingly obvious, has its conditions, but the epistemologist, "wants to speak without the commitments speech exacts". ${ }^{66}$ As there is no claim context, no context in which we understand why the skeptic says what he says and so for our understanding what he says in saying it, no concrete claim is made. ${ }^{67}$

With these considerations in the background, Cavell maintains that in so far as there is an incoherence at the very beginning of the skeptic's procedure, the very knowledge claim that is supposed to generate the generalized doubt in the first place cannot not be coherently entered. Cavell sums up his reading of the skeptic's predicament as a dilemma:

The "dilemma" the traditional investigation of knowledge is involved in may now be formulated this way: It must be the investigation of a concrete claim if its procedure is to be coherent: it cannot be the investigation of a concrete claim if its conclusion is to be general. Without that coherence it would not have the obviousness it has seemed to have: without that generality its conclusion would not be skeptical. ${ }^{68}$

The skeptic relies on a baseless claim that provokes a baseless question and thus a baseless attempt to answer it.

But if Cavell has in fact revealed something incoherent in the skeptic's procedure, why should we not read him as having at least tried, and perhaps even succeeded, in giving a conclusive refutation of skepticism? The answer is that pointing out, as Cavell seeks to do, that the skeptic's particular opening move is incoherent, because his basis claim lacks a context for meaning anything at all, is not equivalent to showing that the skeptical thesis that we can never know the truth of that basis claim has been shown to be false. To show the falsity of the skeptical thesis, to refute it, one would have to show that, contrary to that thesis, one knows, or can know, the truth of utterances like "Here is a hand" that the epistemologist is inclined to make. To show that, one would have to hold that one had managed to understand what the epistemologist really meant with his (empty) basis claim, while at the same time maintaining that the skeptical conclusion, that knowing this (empty) claim to be true was impossible, was itself false. But this requires that the truth of the 
basis claim could in fact be known, even if the claim itself can't actually be understood in the first place. As Cavell puts it,

The reason we cannot say what the thing is in itself is not that there is something we do not in fact know, but that we have deprived ourselves of the conditions for saying anything in particular. There is nothing we cannot say. That doesn't mean that we can say everything, there is no "everything" to be said. There is nothing we cannot know. That does not mean we can know everything: there is no everything, no totality of facts or things to be known. To say we do not (cannot) know things-in-themselves is as much a Transcendental Illusion as to say we do. ${ }^{69}$

All that Cavell's argument amounts to thus far is the idea that we don't understand what the skeptic says, along with the implied suspicion that neither does the skeptic. Arriving at a place where a purported claim turns up as empty is not a refutation of anything. Nor is it a demonstration that, as a matter of general philosophical principle, one can't say what the skeptic is trying to say. This is enough to make clear that there is something seriously wrong with the idea that Cavell believes he has given a conclusive therapeutic refutation of skepticism.

\section{IV}

We see, then, that Cavell thinks one reason why material object (external world) skepticism "cannot" be refuted is quite simply that it doesn't really provide anything to refute. One could, I suppose, construe this as a kind of logical or philosophical sense in which he imagines anti-skeptical arguments as missing their targets. Yet according to Cavell, this is hardly the only or even the deepest sense in which such arguments are unsatisfactory. To see this, consider that one could well wonder why it is that skepticism arises in the first place. Or better, once having been exposed as incoherent by a diagnosis of the type Cavell offers, one could well ask why skepticism doesn't merely evaporate or disappear, as certain illusions or bad ideas sometimes do, never to return. Cavell holds, on the other hand, that skepticism is a pervasive problem in everyday life and an accordingly a recurring theme in philosophy, film, and drama. What, in his view, accounts for this phenomenon?

We first need to note that since skepticism as Cavell understands it is inherently tied to the constant vulnerability of our criteria to failure and rejection, it would never arise for a creature without language. Without meaning to imply that he would ever suggest that a creaturewith-language could be intelligibly factored into parts in anything but a nominal sense, Cavell would I believe allow for one or the other aspect of this unified whole to be emphasized in a given case, especially if 
doing so permitted one to make a salient point. In the present case we can say that for Cavell, skepticism is not only part and parcel of our being creatures-with-language (and minds), but perhaps more pertinently creatures-with-language and minds. ${ }^{70}$ This makes clearer why he regards theoretical attacks intended to refute skepticism as even more profoundly mis-calibrated than we have seen thus far; they fail to take into account how deeply skepticism pertains to our affective nature as language users, however much it can appear in philosophy to be a primarily if not wholly speculative problem. At the most basic level in his thinking, therefore, Cavell holds that attempts to refute skepticism misfire because the impulse to skepticism is, qua impulse, not at root an intellectual position and so not a "suitable object of refutation". Skepticism's manifestation as a philosophical problem is more aptly seen for him as a kind of (as we'll see in a moment, motivated) distortion or sublimation of the genuine vulnerabilities of an animal with language into an inflated intellectual problem. In The Claim of Reason, Cavell is referring precisely to such covering up of the affective roots of philosophical skepticism when he recalls "what I have throughout kept arriving at as the cause of skepticism - the attempt to convert the human condition, the condition of humanity, into an intellectual difficulty, a riddle." 71

The idea that human speakers face a permanent susceptibility to skepticism traces out a remarkably consistent Leitfaden running through Cavell's authorship over more than 40 years. Consider first this famous passage from his ground-breaking essay on Wittgenstein from 1962:

For Wittgenstein, philosophy comes to grief not in denying what we all know to be true, but in its effort to escape those human forms of life which alone provide the coherence of our expression. He wishes acknowledgement of human limitation which does not leave us chafed by our own skin, by a sense of powerlessness to penetrate beyond the human conditions of knowledge. ${ }^{72}$

In his magnum opus from 1979 we read,

If the fact that we share, or have established, criteria is the condition under which we can think and communicate in language, then skepticism is a natural possibility of that condition; it reveals most perfectly the standing threat to thought and communication, that they are only human, nothing more than natural to us. ${ }^{73}$

Some years later, in an essay from the mid-1980s, Cavell describes the possibilities of skepticism as "natural to the human being; parts of the nature or fate of a creature complex enough for, or fated to, language. ${ }^{74}$ 
In works from the mid and late 1990s, Cavell asserts for example that the ordinary language philosopher's

sense of returning words from their metaphysical to their everyday use is driven by a sense of a human dissatisfaction with words (not as it were solely a philosophical dissatisfaction) in which an effort to transcend or to purify speech ends by depriving the human speaker of a voice in what becomes his (or, differently, her) fantasy of knowledge, a characterization I have given of what happens in skepticism. ${ }^{75}$

He makes substantially the same claim in an essay published a couple of years later:

Reading tragedy back into philosophical skepticism I would variously, in various connections, characterize the skeptic as craving the emptiness of language, as ridding himself of the responsibilities of meaning, and as being drawn to annihilate externality or otherness, projects I occasionally summarize as seeking to escape the conditions of humanity, which I call the chronic human desire to achieve the inhuman, the monstrous, from above or from below. ${ }^{76}$

Finally, in a late essay from the 2000s, Cavell is still articulating this perspective, for instance in maintaining that

the question of what I might call skepticism's necessity and its possibility, to its paradoxical presence within our very possession of language, glimpsed when Descartes asserts that we are misled by the ordinary word "see" into supposing that we really as it were see things of the world. ${ }^{77}$

Indeed, Cavell consistently holds in addition that this tendency to deny the human by attempting to evade the burdens of human speech and thought is an essential possibility that goes into the very makeup of the concept of the human being itself. Passages such as these, written over many years, illustrate this point:

(T)he denial of the human, the wish to escape the conditions of humanity, call them conditions of finitude, is itself only human. ${ }^{78}$

Nothing is more human than the wish to deny one's humanity, or to assert it at the expense of others. ${ }^{79}$

... the denial of the human is the human; thinking to escape human nature from above, and from below ... to interpret a metaphysical finitude as an intellectual lack. ${ }^{80}$ 
... skepticism's negation of the human, its denial of satisfaction in the human (here in human conditions of knowing), is an essential feature of the human, as it were its birthright. ${ }^{81}$

... a final philosophical victory over (the temptation) to skepticism, which would mean a victory over the human $\ldots{ }^{82}$

... I persist in thinking that to lose knowledge of the human possibility of skepticism means to lose knowledge of the human $\ldots .^{83}$

Further, the relation to skepticism that Cavell regards as endemic to the life of language users does not in his eyes remain a bare, even if constant, unactualized possibility. As I have already pointed out in the introduction, on occasion Cavell makes the even stronger claim that we are fated to full-blown outbreaks of skeptical madness. Here are two passages cited previously:

What turns it upon us is philosophy, the desire for thought, running out of control. That has become an inescapable fate for us, apparently accompanying the fate of having human language. ${ }^{84}$

I mean to say that it is human, it is the human drive to transcend itself, make itself inhuman, which should not end until, as in Nietzsche, the human is over. ${ }^{85}$

These sorts of remarks are not isolated or idiosyncratic; other passages make it clear that Cavell views skepticism as not merely a perhaps unfortunate, but ultimately manageable impulse. His use of terms like "drive" and related terms warrants a reading in which he thinks it is simply part of our nature that we will in fact find ourselves overcome by unbridled fits of irrational intellectual aggression:

I take skepticism not as the moral of a cautious science laboring to bring light into a superstitious, fanatical world, but as the recoil of demonic reason, irrationally thinking to dominate the earth. I take it to begin as a wish not to reject the world but rather to establish it. ${ }^{86}$

The human capacity - and the drive - both to affirm and to deny our criteria constitutes the argument of the ordinary. And to trace the disappointment with criteria is to trace the aspiration to the sublime - the image of the skeptic's progress. ${ }^{87}$

As we have already seen, on Cavell's analysis the skeptic's argument requires a non-claim context. In so far as the traditional anti-skeptic tries to defeat the skeptic, he acquiesces in this initial yet "decisive conjuring trick". Both the skeptic and the anti-skeptic accept the intelligibility of a picture of language where the criteria that guide our words and concepts are self-applying, operating in a vacuum, isolated from the contextual factors that make it understandable why someone some place at some 
time might be concerned to say what she says at all. Moreover, Cavell thinks that such denial of the conditions for how language, mind, and world might come together is not surprising. On the contrary, such blind ambition is bound to break out. It is Cavell's fascination with our inability to live with the all of the contingency, complicity and complexity that comes with our application of our criteria to the world and to each other, that motivates his work on philosophy, literature, and film. ${ }^{88}$

But all of this only begs the question as to what kind of view of the human being underlies Cavell's view of skepticism's inevitability. Why, in fact, is he so confident that skeptical worries will return to haunt us? This is a central question for this essay. In order to begin our approach to it, we can take another rightfully celebrated quotation from Cavell's early essay on the later Wittgenstein.

We learn and we teach certain words in certain contexts, and then we are expected, and expect others, to be able to project them into further contexts. Nothing insures that this projection will take place (in particular, not the grasping of universals nor the grasping of books of rules), just as nothing insures that we will make, and understand, the same projections. That on the whole we do is a matter of our sharing routes of interest and feeling, modes of response, senses of humor and of significance and of fulfillment, of what is outrageous, of what is similar to what else, what a rebuke, what forgiveness, of when an utterance is an assertion, when an appeal, when an explanation all the whirl of organism Wittgenstein calls 'forms of life.' Human speech and activity, sanity and community, rest upon nothing more, but nothing less, than this. It is a vision as simple as it is difficult, and as difficult as it is (and because it is) terrifying. ${ }^{89}$

Because criteria don't just apply themselves on their own, but require our involvement, nothing guarantees that we will make the effort to apply them, let alone that we will apply them correctly and successfully. As we shall see shortly, moreover, Cavell believes there is much that militates against our willingness to own up to precisely these possibilities. In fact, after The Claim of Reason, it was the investigation of this theme in philosophy and various art forms that came to dominate Cavell's energy even more than it had before that watershed publication.

Now we saw earlier that Cavell wants to say that there is a "truth of skepticism" to which the skeptic has latched on, even if not always in a very perspicuous manner. As Cavell puts it, this truth was that "Our relations to the world as a whole, or to others in general, is not one of knowing, where knowing construes itself as being certain"..$^{90}$ The basis for what I think of as Cavell's "anthropology" resides precisely in what he finds to be our human inability, both in our relations to the world and to each other, to live with the conditions that underlie this truth. ${ }^{91}$ 
In Cavell's various numerous elaborations of skepticism, it is clear that he believes that we find living with this truth to be an almost unbearable task. Hence, his repeated claims that it is human to deny the human condition. But why do we find facing this condition so hard? Why is the contingency internal to criteria so terrifying that Cavell finds we are driven almost of necessity to deny their very existence?

Consider in this vein two long quotations taken from the same stretch of The Claim of Reason that vividly portray the core of a Cavellian response to these questions.

My major claim about the philosopher's originating question - e.g., "(How) do (can) we know anything about the world?" or "What is knowledge; what does my knowledge of the world consist in?" - is that it ... is a response to, or expression of, a real experience which takes hold of human beings. It is not "natural" in the sense I have already found in the claim to "reasonableness": it is not a response to questions raised in ordinary practical contexts, framed in language which any master of a language will accept as ordinary. But it is, as I might put it, a response which expresses a natural experience of a creature complicated or burdened enough to possess language at all. What experience? Well, of course, an experience or sense that one may know nothing about the real world. But what kind of experience is that? How or when does it emerge? ${ }^{92}$

The experience of knowing nothing about the real world at all is of course the experience of the total failure of our criteria to make actual contact with it. A bit further on we find the following:

I can here only attest to my having had such experiences and, though struggling against them intellectually, have had to wait for them to dissipate in their own time. It seems to me that I relive such experiences when I ask my students, as habitually at the beginning of a course in which epistemology is discussed, whether they have ever had such thoughts as, for example, that they might, when for all the world awake, be dreaming; or that if our senses, for example our eyes, had differently evolved, we would sense, i.e., see, things other than as we see them now, so that the way we see them now is almost accidental, anyway at least as dependent on our constitution as on the constitution of the world itself; or that the things of the world would seem just as they now do to us if there were nothing in it but some power large enough either to keep us in a sort of hypnotic spell, or to arrange the world for our actions as a kind of endless stage-set, whose workings we can never get behind, for after all consider how little of anything, or any situation, we really see. I know well enough, intellectually as it were, that these suppositions 
may be nonsense, seem absurd, when raised as scruples about particular claims to knowledge. But if these experiences have worked in the initial motivation of particular claims, then the attempt to prove intellectually that they have no sense is apt to weaken one's faith in intellectuality. ... [W] hen the experience created by such thoughts is there, it is something that presents itself to me as one, as I have wished to express it, of being sealed off from the world, enclosed within my own endless succession of experiences. It is an experience for which there must be a psychological explanation; but no such explanation would or should prove its epistemological insignificance. And I know of no philosophical criticism which proves that either. ${ }^{93}$

There is a lot one could say about these passages. ${ }^{94}$ Here I want to focus on how the experience of the possible failure of our criteria described in the first passage gets elaborated by Cavell in the second as an experience whose content, though admittedly bordering on the absurd, is nevertheless impervious to rational criticism: the experience reveals something "true", even if not exactly the truth of a thesis. First, recall that irrefutability, even in the face of nonsensicality, is one of the hallmarks of skepticism according to Cavell. But second, and more significant, note that even if the language that Cavell uses to describe this experience may strike some as "poetic" or "non-philosophical" (and anything like a sharp distinction between the force of poetry and philosophy is likely to be a distinction Cavell would question anyway), when he writes that this experience presents itself to him as a sense of "being sealed off from the world" in his own "endless succession of experiences", Cavell takes the experience to reveal something genuine, let's say true, about his condition: that in some sense he really is separate, cut off from the world.

The very presentiment, however much lacking in rational grounds, that the criteria on which our lives and sanity as speakers depend may completely fail us, exacerbates the underlying "metaphysical fact" that we are utterly alone with this real or potential failure. Variations on this threat of isolation are pervasive in Cavell's work. Nearly all of his writing, both prior and subsequent to The Claim of Reason, and whether in philosophy, film, or literature, is dedicated to showing that the "best case" of himself as revealed in the previous passages is representative of the universal human struggle to live with the horror of our separateness. Indeed, the persistent motif of chronic horror at our separateness and the resulting flight from this fact is as consistently sounded in Cavell's writings as is the correlative theme of the connection between our being criteriological creatures and skepticism itself: " $[\mathrm{T}]$ ragedy is the working out of a response to skepticism - as I now like to put the matter, that tragedy is an interpretation of what skepticism itself is an interpretation of. ..." ${ }^{95}$ What they are both an interpretation of is our separateness. If anything, it is the repressed fact that each of us is our "own haecceity" 
that is the real truth of skepticism, a truth we flee and that underlies the essential connection between language and skepticism. ${ }^{96}$ We see, then, that Cavell's account of skepticism has several strands, which though in any given work can seem more or less related, in fact make up one philosophical fabric. The following, from 1988's In Quest of the Ordinary: Lines of Skepticism and Romanticism, weaves them together in one stretch.

Here my thought was that skepticism is a place, perhaps the central secular place, in which the human wish to deny the condition of human existence is expressed: and so long as the denial is essential to what we think of as the human, skepticism cannot, or must not, be denied. This makes skepticism an argument internal to the individual, or separate, human creature, as it were an argument of the self with itself (over finitude). That this is expressed as a kind of argument of language with itself (over its essence) is how it came to look to me as I worked out the thought that Wittgenstein's Investigations is not written - as it had in my experience uniformly been taken as a refutation of skepticism (as if the problem of skepticism were expressed by a thesis) but as a response to what I have come to call the truth of skepticism (as if the problem of skepticism is expressed by its threat, or temptation, by our sense of groundlessness). ${ }^{97}$

Cavell's interpretation of skepticism is brilliant, original, and often compelling in a way that none of its contemporary rivals approaches. Having said that, I also believe, however, that his philosophy is badly marred by an ahistorical and uncritical assumption that certain features characteristic of modern Western individualism are universally valid. In the Claim of Reason he asserts that,

The truth here is that we are separate, but not necessarily separated (by something); that we are, each of us, bodies, i.e. embodied; each is this one and not that, each here and not there, each now and not then. If something separates us, comes between us, that can only be a particular aspect or stance of the mind itself, a particular way in which we relate, or are related (by birth, by law, by force, in love) to one another - our positions, our attitudes, with reference to one another. Call this our history. It is our present. ${ }^{98}$

It may be true that on Cavell's interpretation of skepticism, especially other-minds skepticism, we are not completely at the mercy of our separateness. We can be honest and ever vigilant about the requirements our criteria and the world make on us. It may even be the case, as this passage may seem to suggest, that Cavell thinks our proclivities towards flight and denial are more inflamed by some historical settings than by others. 
Nevertheless, whatever significance he might on occasion be prepared to ascribe to cultural context, the upshot of the ontology of separateness underpinning Cavell's anthropology is that we are at bottom creatures who simply can't stand being the kind of creatures we are. The foundation for Cavell's thought, and the foundation from which he believes all of us are always fated to begin as animals burdened with language is that "[w]e are endlessly separate, for no reason." "Y9 Yet what if there is no convincing reason for thinking that assertions like this one correspond to a "brute metaphysical fact" about our predicament? What if on the other hand there are good reasons for interpreting such assertions as revelatory of a state of mind characteristic of a particular grammar, of a certain historical horizon?

\section{V}

By referring in the previous section to Cavell's "anthropology”, I did not intend anything unusual by this use of the term, even if Cavell is not an anthropologist, or at least not one of the usual sort. I merely meant to flag my view that a fairly definite picture of the human being runs through his authorship. Of course, "anthropology" is more typically used to denote a social scientific discipline with its own institutional moorings in universities. Fronting this more usual sense of the word makes it natural to ask about the sources of Cavell's data. A short answer is that I suppose Cavell takes his observations about the human mainly from philosophy, everyday life, and not the least art forms such as film, drama (especially Shakespearean tragedy), poetry, etc. If I am roughly correct, however, that there is an ontology of the human running through Cavell's thought, then this short answer might seem to set this ontology up for easy ridicule, since surely (he, and I, must both know that) ethnographies are one thing, films or plays quite another. Yet while Cavell surely realizes that, for example, reading Descartes' Meditations or watching Cary Grant and Katherine Hepburn's banter on the big screen are importantly different activities from observing Berber cooking rituals, he would, I believe, reject any strong conclusion that only the second observational setting can provide genuine facts about the goings on of a human culture. Elaborating this point sufficiently would require an explanation and perhaps defense of an essential feature of Cavell's views that, for example, art can teach us something about the "real world". Bringing Cavell's work into closer contact with the fields of history and anthropology as I do next also requires that I make a point explicit: the narratives that histories and ethnographies provide do not rely on or consist of "direct observational data". Thus, while historical and ethnographic accounts are certainly different from works of art, they are not incommensurable as sources of evidence. Because I think these points should be obvious at this time point in intellectual history, I take them for granted in what follows. 
Having just defended Cavell's bona fides for speaking about the human without having conducted field work, my discussions in this part and the next nevertheless take a more empirical (though certainly not empiricist) turn. Having shown previously how Cavell believes that skepticism is an ineradicable feature of human life with language, it may seem natural for me to pursue a project of comparative epistemology and to ask whether in fact disciplines such as social or cultural anthropology or history provided any good reasons for thinking that skepticism is actually a universally observed phenomenon. I can imagine that such a project has its own intrinsic interest and that it could well be complementary to my work here. Since, however, I have also claimed that underlying Cavell's sense of the essential connection between language and skepticism is our often repressed sense of ourselves as separate, what I described as the real "truth of skepticism" we flee, I will pursue a different avenue here.

Recall Cavell's claim that the experience of feeling sealed off from the world in his own endless succession of experience is a major motivation for the skeptic's originating question. This connects to his taking the experience to reveal something about his genuine predicament, a predicament the honest awareness of which we are driven to flee. Yet if a tendency to flee this kind of experience is one of the ways in which Cavell understands our shared humanity, then presumably something like the experience that sets us fleeing is also shared. Now Cavell says he realizes that the suppositions of the experience may seem nonsensical or absurd; perhaps we could say the same of the thoughts and reactions of Lear, Othello, and other figures who serve to illustrate skepticism's insanity throughout Cavell's authorship. Still, there is no suggestion on his part that the descriptions he offers of his own experiences or those descriptions of these other representatives of humanity are unintelligible gibberish. If, on the other hand, these descriptions had been offered outside of any imaginative or projective context, then we would be hard pressed to do anything with them at all. Yet many of us in fact are able to connect our understanding to Cavell's words, or to Lear's words, or to Othello's words, etc. What I am driving at is that descriptions such as Cavell's don't just perform their figurative work out of the blue. ${ }^{100}$ Rather, they give expression to experiences of hyperbolic separateness capable of seizing the intellect for beings who already can interpret themselves as isolated and cut-off. For me this raises two related questions: 1) What if the having of such experiences not only makes skepticism seem inevitable, but if their very description already in some way goes with, or arises out of, a prior background ontology of the person? 2) What would it be like to imagine the descriptions of these experiences doing the work Cavell requires them to do without some prior context for imagining that ontology? 
I begin my critique of Cavell's anthropology of the self with a remark from anthropologist Clifford Geertz's "From the Natives' Point of View":

The concept of person is, in fact, an excellent vehicle by which to examine this whole question of how to go about poking into another people's turn of mind. In the first place, some sort of concept of this kind, one feels reasonably safe in saying, exists in recognizable form within all social groups. Various notions of what persons are may be, from our point of view, more than a little odd. People may be conceived to dart about nervously at night, shaped like fireflies. Essential elements of their psyche, like hatred, may be thought to be lodged in granular black bodies within their livers, discoverable upon autopsy. They may share their fates with doppelgänger beasts, so that when the beast sickens or dies they sicken or die too. But at least some conception of what a human individual is, as opposed to a rock, an animal, a rainstorm, or a god, is, so far as I can see, universal. Yet, at the same time, as these offhand examples suggest, the actual conceptions involved vary, often quite sharply, from one group to the next. The Western conception of the person as a bounded, unique, more or less integrated motivational and cognitive universe; a dynamic center of awareness, emotion, judgment, and action organized into a distinctive whole and set contrastively both against other such wholes and against a social and natural background is, however incorrigible it may seem to us, a rather peculiar idea within the context of the world's cultures. Rather than attempt to place the experience of others within the framework of such a conception . . . we must, if we are to achieve understanding, set that conception aside and view their experiences within the framework of their own idea of what selfhood is. ${ }^{101}$

I will consider this passage more fully in Part VIII. For now I want to note that although, as usual, Geertz is mostly right on the money, he moves too hastily here from briefly referencing various cultures' conceptions of the person to an elucidation of the "the Western conception of the person". In this present context, the other cultural interpretations to which he refers are, I think, more properly contrasted with the "modern Western conception of the person" than they are with the mere "Western conception". This is because the "modern Western conception of the person" can also be relevantly contrasted with the "premodern Western conception of the person", or as I will from now on put it, the "pre-modern Western conception of the self". ${ }^{102}$ Writing in 1974, Geertz can perhaps be forgiven for not having made much of this, as much of the intellectual heavy lifting in this area had yet to be 


\section{2}

done. That all changed with Charles Taylor's monumental Sources of the Self: The Making of the Modern Identity published in 1989. While Taylor's book by no means appeared on the scene de novo, its synthesis of historical and philosophical analysis constituted an enormous and original intellectual achievement. ${ }^{103}$ Its themes also came to define Taylor's intellectual agenda for the next 20 years, exploring the significance of the central interweaving strands of European modernity, culminating in the magisterial A Secular Age from 2007. ${ }^{104}$ Much of this work, especially as it traces the interplay of historical and intellectual changes that produced modern understandings of selfhood are directly relevant for evaluating the ontological underpinnings of Cavell's interpretation of skepticism. In what follows, I give a brief sketch of Taylor's description of the contrast between what he calls the dominant understanding of the self in the modern West and a very different understanding characteristic of pre-modern Europe.

According to Taylor, the understanding of the nature of what a self is that is taken for granted by most modern Westerners (and probably also by many people living in cultures or sub-cultures that have been deeply shaped by the by the dominant culture of modern Europe and North America) is the idea of a center of consciousness and motivation that is bounded or "buffered". By "buffered", Taylor means a sharp distinction between on the one hand what is taken to be "inside" the mind, characterized as subjective feeling, thought, evaluations, secondary sense qualities, etc. and on the other hand what is regarded as the world "outside" the mind, interpreted as non-mental, spatial, and value neutral. ${ }^{105}$ A key argument in Taylor's account is that the modern understanding of such a sharp boundary has a history, and that this history is tied to the emergence of certain historical practices of what he calls "disengagement". He writes, "For the modern, buffered self, the possibility exists of taking a distance from, disengaging from everything outside the mind". ${ }^{106}$ By "disengagement" Taylor means among other things, certain spiritual and moral forms of self-understanding achieved through discipline, especially pertaining to salvation, that became prevalent around the time of the Protestant Reformation. Somewhat later, these ideas morphed into conceptions of political autonomy, rights, and obligations internal to early iterations of liberalism. Taylor also frequently speaks of practices of "disengaged rationality". This term signifies an agent's ability to adopt a stance of theoretical reflection, in which she "disengages" from her immediate practical, instinctual, or emotional engagement with the environment as she experiences and interacts with it. Disengaged rationality thus denotes an objectivizing stance toward the world often paradigmatically associated with the explanatory power of natural sciences such as physics and chemistry, but also with instrumental forms of reasoning connected to economic behavior and to developing technology. Although I list them separately here, in fact all of these aspects of disengagement 
are only so many threads in the ongoing creation of one historical tapestry that comprise Taylor's account of modernity.

Now we clearly don't spend all or even most of our time in the various kinds of stances made possible through the disciplines of disengagement. Yet for a myriad of reasons, some of them connected to the status accorded to the activities that disengagement makes possible, the "buffered" understanding of ourselves has, as Geertz writes, become so "incorrigible" for us that it is an "an outlook which has to some extent colonized the common sense of our civilization". ${ }^{107}$ Taylor's reference to common sense here underscores a crucial point: as with any conception at or near the "bottom" of our worldview, the buffered self is not a theoretical entity. ${ }^{108}$ Moderns (especially perhaps educated ones) just tend to assume that the sense of a sharp boundary or buffer between the self and world that disengagement both creates and reinforces merely reflects a gulf that is there anyway, and that consequently thought, reason, meaning, emotion, everything mental, must obviously be inside our heads or souls. Nevertheless, against this ahistorical common-sense view Taylor argues that

The localization is not a universal one. . . Rather it is a function of a historically limited mode of self-interpretation, one which has become dominant in the modern West and which may indeed spread to other parts of the globe, but which had a beginning in time and space and may have an end. ${ }^{109}$

In striking contrast to the modern buffered self of modernity, Taylor paints a vivid portrait of a prevalent understanding in the Middle Ages, up to and including much of the Renaissance. His term for this understanding is the "porous self".

By definition for the porous self, the source of its most powerful and important emotions are outside the "mind": or better put, the very notion that there is a clear boundary allowing us to define an inner base area, grounded in which we can disengage from the rest, makes no sense. ${ }^{110}$

As in the case of the self as buffered, Taylor's point is not that the sense of the self as porous was a well-supported theory based on evidence. Its place in the pre-modern "conceptual scheme" was more basic and "has to be seen as a fact of experience, not a matter of 'theory', or 'belief' ". ${ }^{111}$ We should instead imagine this as

how we sense things to be; and thus how we seem to experience them. Then the inside is no longer just inside: it is also outside. That is, emotions which are in the very depths of human life exist in a 
space which takes us beyond ourselves, which is porous to some outside power, a person-like power. ${ }^{112}$

To illustrate this idea, Taylor refers to the historical example of how melancholy was once imagined. Today, we would of course normally describe melancholy (or perhaps better depression) as a state pertaining solely to an individual consciousness. Someone might object to my way of putting this so bluntly because we do naturally also speak of a group of people (or even mammals) as being melancholy. We even describe the atmosphere of, say, a dive bar as melancholy. Despite this, if we're being honest, most of us will admit that for us now such uses have become secondary or metaphorical. They are dependent on, even if not reducible to, the more primary case consisting of an individual state of consciousness. Philosophers such as Heidegger may want to dispute this, but even they know they are fighting an uphill battle against modern "common sense". Taylor's point, however, is that there was a time in Europe when certain objects or substances "outside" the mind did not just represent certain emotional states or have as a matter of fact tendency to provoke them in people. The connection was immeasurably closer:

Consider melancholy: black bile is not the cause of melancholy, it embodies, it is melancholy. The emotional life is porous here again; it doesn't simply exist in an inner, mental space. ${ }^{113}$

Perhaps more important still, this fuzziness or porosity between inside and outside did not of course merely affect the way in which the assumed boundary between me and objects in the world was experienced, but also between me and my fellow humans. Taylor even goes so far as to state that under such circumstances, the very notion of a "self" is a bit misleading. ${ }^{114}$ In other words, the self was experienced as a social being through and through:

The point I am trying to make here is that in earlier societies, this inability to imagine the self outside of a particular context extended to membership of that society in its essential order. ${ }^{115}$

I introduced Taylor's notion of a buffered self by reference to modern disciplined practices of disengagement and by noting the way things tend to be characterized on each side of the inside-the-mind/outsidethe-mind dichotomy once these practices become the primary carriers of our understanding. The outside half of that divide I described as "non-mental, spatial, and value neutral". This description is one of a "disenchanted" world, to use Weber's famous term. Not surprisingly, this stands in radical contrast, if not outright opposition, to how Taylor 
describes pre-moderns as experiencing the world as enchanted, containing not only meaning and moods, but real forces of good and evil. Eventually as modernity progressed, our relation to the "external world" changed fundamentally:

The buffered self is the agent who no longer fears demons, spirits, magic forces. More radically, these no longer impinge: they don't exist for him: whatever threat or other meaning they proffer doesn't "get to" him. ${ }^{116}$

Taylor is also not the first to point out that what he calls the "Great Disembedding", the change from an enchanted to a disenchanted outlook, has had far-reaching implications for how we live our relations not only to the world but to ourselves and to one another as well. ${ }^{117}$

The disciplined stance helps to build a second facet of what I've been calling the buffered self. I discussed above how disenchantment involves a drawing of boundaries, an end to porousness in relation to the world of spirits. Now the disengaged stance also leads to the drawing of boundaries, and a withdrawal from certain modes of intimacy, as well as taking a distance from certain bodily functions. ${ }^{118}$

In fact, Taylor believes that the change has been so profound, that most moderns must "find the idea of spirits, moral forces, causal powers with a purposive bent, close to incomprehensible". ${ }^{119}$

At this point we seem to be left with a discontinuous story, according to which in the space of a few hundred years major populations of Europe underwent profound conceptual and cultural changes, in particular in the way they came to understand the very notion of the human self. Yet while there will presumably never be a final story of the changes wrought by modernity, this does not imply that just any old narrative will do. While no doubt many people today realize that we are very different from those strange medievals, what we actually know firsthand may not amount to much more than a familiarity with a few hysterical caricatures in a Monty Python sketch. Taylor glosses this somewhat lamentable state of affairs: "In this sense, modern self-consciousness has a historical dimension, even for those - who are, alas, many today - who know next to nothing about history". ${ }^{120}$ In addition, while he thinks we can all agree that one of "the central features of Western modernity ... is the progress of disenchantment, the eclipse of the world of magic forces and spirits", ${ }^{121}$ he also believes we are too easily led into accepting a "drastically overly simplified Entstehungsgeschichte of exclusive humanism", ${ }^{122}$ one that distorts our understanding of our relations to the past as well as to the present. On Taylor's view, one of the most widespread of such accounts of the genesis of the modern self is what he calls "subtraction" 
stories. ${ }^{123}$ Resisting such metanarratives is a key goal of Taylor's overall project, which he explains this way:

Concisely put, I mean by this stories of modernity in general, and secularity in particular, which explain them by human beings having lost, or sloughed off, or liberated themselves from certain earlier, confining horizons, or illusions, or limitations of knowledge. What emerges from this process - modernity or secularity - is to be understood in terms of underlying features of human nature which were there all along, but had been impeded by what is now set aside. Against this kind of story, I will steadily be arguing that Western modernity, including its secularity, is the fruit of new inventions, newly constructed self-understandings and related practices, and can't be explained in terms of perennial features of human life. ${ }^{124}$

As a result of their having absorbed such subtraction stories by a kind of cultural osmosis, many if not most moderns uncritically accept a dogma of the self as something like a natural kind. They thus "tend to think that we have selves the way we have hearts and livers, as an interpretationfree given". 125

We ought to view the essentialism and determinism that a subtraction story requires us to accept ought with great suspicion. Such a story also requires that we view human history as lacking any genuinely creative force, that it, in effect, be regarded as a mere unravelling of a story already told. What, on the surface, appears to be the self-interpretations, evaluations, and actions of human agents, made within limited historical horizons and in immensely complicated contexts, comes instead to be seen as the mere unfolding of factors working out their inevitable effects behind our backs, just so as to bring us to our present state of affairs and understanding. Naturally, there is little or no detailed evidence for this grand structural story. It works more like an article of faith. The epistemological and metaphysical problems that attach to anything like a subtraction story of the self are so immense that I think one is well within one's rights to be skeptical about the very intelligibility of this metanarrative.

Rather than present his own grand explanatory history of the self, Taylor prefers instead a more historical and hermeneutic approach. He avoids the pretense of a "value-free" explanation, instead treating the changes between the porous and buffered self as having involved subtle, contextual, and tentative shifts in moral perspective. In the introduction to Sources of the Self he writes that "Selfhood and the good, or in another way selfhood and morality, turn out to be inextricably intertwined themes". ${ }^{126}$ Later in the same work, we read that "Radically different senses of what the good is go along with quite different conceptions 
of what a human agent is, different notions of the self". ${ }^{127}$ Nearly twenty years later we find him voicing the same view in A Secular World:

In short, the buffered identity, capable of disciplined control and benevolence, generated its own sense of dignity and power, its own inner satisfactions, and these could tilt in favour of exclusive humanism. ${ }^{128}$

By eschewing a metaphysical "view from nowhere" account, Taylor can instead offer us an historically extended "perspicuous representation" consisting of historical Zwischenglieder, with human beings experiencing gains and losses each step of the way. ${ }^{129}$

I should stress that Taylor does not think that the dominant modern Western conception of the self as buffered is intrinsically confused, even if he may hold that, for example, the Cartesian and Lockean accounts of the self are philosophically suspect. We can, and apparently do, interpret ourselves as being "buffered" selves in a disenchanted world. Cartesianism and its innumerable descendants may simply be metaphysically perverse inflections of this otherwise logically innocuous, if not altogether happy, interpretation of our condition. However, even this everyday common sense understanding of a self is by no means an understanding that would have been obvious to Europeans several centuries ago. It is, furthermore, still far from common sense in many parts of the world today. ${ }^{130}$

\section{VI}

As we just saw, Taylor contrasts the modern "buffered" self with a more "porous" understanding, which he suggests went hand in hand with a more enchanted European world before the Reformation, and especially before the intellectual upheavals in science, politics, and commerce of the 17 th century. In this part, I want to turn to some ethnographic material that covers much of the same conceptual ground. In addition to allowing me to bring to bear perspectives from disciplines different from intellectual history and philosophy, this will broaden my focus before I turn back to interrogating Cavell's views of the self of modern skepticism in the next part of this essay.

Note first, however, that while the various understandings of the self on view in the material discussed next would certainly seem to fall outside of what Taylor includes under the concept of a "buffered" self, it is not obvious that they satisfy Taylor's concept of a "porous" self. This suggests that there is more conceptual space outside of "buffered" than is covered by "porous". As we have seen, "porous self" denotes something like a psycho-spiritual entity that is more or less locatable in the body but is nevertheless in contact with the "outside" world both 


\section{8}

causally and semantically. This is what I take Taylor to mean when he writes that black bile did not symbolize melancholia, and did not just, as a contingent matter of fact, cause melancholia, it was itself melancholia. So that, odd as it sounds to us, for the mind to be in contact with this substance was to be in direct contact with the state of mind of melancholia itself, not merely with a brute cause of an internal mental state. Presumably, similar considerations would apply to other states of mind and other discreet states of affairs. If Taylor is right, this seems to have been internal to what living in the "enchanted world" of medieval Europe came to, at least for many. Yet, it is unclear to me that, whichever similarities with other societies this particular fact about medieval Europe may indicate, this particular conception of porosity is manifest in the understandings summarized next. And of course, particulars matter. Accordingly, the reader should not infer that I believe that these understandings necessarily fall under the term "porous" self in Taylor's sense. Instead, it is preferable for now to take them as simply falling under the contradictory of "buffered", i.e. "non-buffered". I will say a bit more about this later.

The initial focus of my discussion is Rane Willerslev's Soul Hunters: Hunting, Animism, and Personhood among the Siberian Yukaghirs from 2007. ${ }^{131}$ The Yukaghirs are a people of the Upper Kolyma River in northeastern Siberia, and Willerslev's book is an exploration of aspects of the hunting practices of Yukaghir culture, in particular of the Yukaghir understanding of the nature and role of the self in these practices. Willerslev's book is a richly illustrative work on a perplexing topic in its own right. Moreover, its discussion of the Yukaghir understanding of personhood suggests fruitful comparisons with other ethnographic material that I will mention, if only cursorily.

There are several key ideas that make up Willerslev's portrait of the Yukaghirs. The first is animism, which he introduces into his discussion with some caution. As Willerslev makes clear, ideas such as animism have fallen out of favor among contemporary anthropologists as analytical concepts because they are frequently associated with the colonial period when the field was taking shape. During this time, there was a tendency to assume either that indigenous declarations of animist practices and beliefs were either a sign of "primitive mentality" or of "the natives" " propensity to deceive Westerners about what they were really up to. ${ }^{132}$ I will return later to this tendency, not restricted to Victorian anthropologists, whereby beliefs and practices such as animism are dismissed out of hand on the grounds that it is simply not possible for anyone to hold such views. For now, it is enough to note that Willerslev quite sensibly maintains against this kind of dogmatism that one cannot even get so far so as a critique of a people's practices and concepts unless one takes the time to understand what those practices and concepts entail. Naturally, this begins, at the very least, with taking 
seriously their self-interpretations when it comes to their own lives. ${ }^{133}$ As Willerslev puts it,

For us in the West, it is customary to assume that attributes of personhood, with all this entails in terms of language, intentionality, reasoning, and moral awareness, belong exclusively to human beings. Animals are understood to be wholly natural beings, and their behavior is typically explained as automatic and instinctive. Among the Yukaghirs, however, a different assumption prevails. In their world, persons can take a variety of forms, of which a human being is only one.... Moreover, humans and animals can move in and out of different species' perspectives by temporarily taking on each other's bodies. Indeed, among the Yukaghirs, as we shall see later, this capacity to take on the appearance and viewpoint of another being is one of the key aspects of being a person. ${ }^{134}$

However, grasping the content of these ideas still may not be adequate. Any meaningful comparison between systems of thought further requires that one correctly see, even if one does not accept, the role that these ideational structures play in the lives one wishes to understand. And, as Willerslev underscores in this regard, animism among the Yukaghirs is not an explicitly articulated doctrinal system. ${ }^{135}$ Instead, "[t]he personhood of animals and things is, as we shall see, something that emerges in particular contexts of close practical involvement, such as during hunting”. ${ }^{136}$ Consequently, for the Yukaghirs,

animals and other nonhumans are conceived as persons, not because personhood has been bestowed upon them by some kind of cognitive processing, but because they reveal themselves as such within relational contexts of real-life activities, such as during hunting. ${ }^{137}$

Complementing animism is another key notion for Willerslev's account of the Yukaghirs, namely mimesis. He describes the Yukaghir cosmos as "in effect a hall of mirrors, as various dimensions of reality are conceived as replicas or reflections of others" and adds that

In sum, the world of the Yukaghirs is by and large a "mimeticized" world: everything is paired with an almost endless number of mimetic doubles of itself, which extend in all directions and continually mirror and echo one another. ${ }^{138}$

Mimesis becomes especially prominent when it comes to hunting:

Animals and their associated spiritual beings are ... said to take on human shapes and live lives analogous to those of humans when in their 
own lands and households. Likewise, when the hunter seeks to bring an elk out into the open by mimicking its bodily movements, he is inevitably put into a paradoxical situation of mutual mimicry. As a result, the bodies of the two blend to a point that makes them of the same kind. ${ }^{139}$

The Yukaghir hunter not only understands himself as taking on the perspective of the person who is his prey, but also as a reincarnation of a deceased relative:

The Yukaghir hunter assumes the viewpoint, senses, and sensibilities of his prey while still remaining aware of himself as a human hunter with the intention of killing it. Likewise, the Yukaghir person is intertwined with the deceased relative of whom he is considered a reincarnation sharing the same name, personality and knowledge. Yet he also retains a personhood of his own and is capable of individual agency and intention. ${ }^{140}$

More generally, according to the Yukaghirs' notion of reincarnation,

each living person is seen as a kind of new embodiment of a particular dead relative. In fact, everyone in Nelemnoye would always insist that the living person is the dead relative of whom he or she is a reincarnation. "The two are one and the same person," they assured me. Yet some people would add, "but a person's body is also him or herself," thereby illustrating that it is an aspect of the person, his ayibii or soul, rather than the person in toto that is reincarnated. An individual's body is, in principle, himself or herself, but, as we shall see below, it can at times be "colonized" by the ayibii, which might divide itself into its various parts and take control. ${ }^{141}$

In fact, the relation between the "empirical person" or embodied individual and the reincarnated ayibii is such that "the perspective of the dead person he claims to be can sometimes penetrate his own perspective" 142 This means that at a basic level the empirical individual "is neither himself nor his dead relative in any absolute sense, but is something in between or both at once. The implication of this, however, involves not only perceptual experience, but the very structures of embodiment as well". ${ }^{143}$

These brief considerations on animism, mimesis, and reincarnation naturally raise questions about how the Yukaghirs understand the just mentioned concept of the soul, or ayibii. The word "ayibii" is translated as "shadow" in Yukaghir, something that might suggest a dualism of body and spirit. ${ }^{144}$ Willerslev points out, however that

Among the Yukaghirs, however, souls do not have this disembodied existence but are vested with a good deal of physicality. We need 
only point out that the hunter occasionally sees his ayibii in dreams as a freely operating being, and in waking life he sees his own soul or that of his fellows in the shape of an animal. ${ }^{145}$

Willerslev also cites work suggesting that, despite conflicting testimony, many Yukaghir believe each individual has three ayibii, the "head soul" representing the intellect, the "heart soul" controlling motion, and a third soul pervading the body and controlling physiological functions. ${ }^{146}$

The heart, head, and shadow are among its favorite locations, which is why people tend to talk about three souls, the head-ayibii, the heart-ayibii, and the shadow. However, the ayibii can, in principle, reside in all body parts and organs. Diffused throughout the body in this way, the ayibii becomes individualized into different agents or "persons" (Rus, lyudi), as he [Nikolai Likhachev] called them, each of which takes its specific character from the body part or organ it inhabits. ... Thus, each of these animated body parts or organs is understood to be a kind of person within the person. However, as he emphasized, the ayibii is originally only one, and it can therefore gather itself into wholeness and act as a single person. ${ }^{147}$

As with animism, Willerslev notes how there is a lack of an explicit theoretical account of how these various aspects hang together: "In general, Yukaghirs showed little interest in my questions about the number of souls and where in the person's body they might possibly dwell. ${ }^{148}$ As with animism, Willerslev underscores how the Yukaghir understanding of ayibii comes out best in the practical contexts where it is relevant; there is little effort given to reconciling what is said in these practical contexts in abstraction from them. ${ }^{149}$

Willerslev emphasizes, however, that none of this should be taken to imply that the Yukaghirs subscribe to some version of monism in which everything is understood as simply a part or aspect of an all-encompassing "over-self". On the contrary, he makes it clear for the Yukaghir,

everyday practical life demands a kind of "depth reflexivity" as a form of defense mechanism against the dissolution of the self, which faces a real risk that identification with the world of other bodies, things, and people will become so complete that all the differences will appear to vanish and an irreversible metamorphosis will occur. ${ }^{150}$

The risk of such self-dissolution is nowhere more manifest than in the context of hunting:

We must bear in mind that in the world of the Yukaghirs, where the various boundaries between self and other, such as the ones 


\section{2}

\section{Skepticism and the Human Condition}

between living and dead or human and animal, are permeable and easily crossed, the ability not to confuse analogy with identity is of paramount importance. This is probably most clearly revealed with regard to the Yukaghir hunter and his prey. ... (H) unters consider it necessary to assume the identity of their prey in order to kill it. However, if the hunter loses sight of his own human self in this process and surrenders to the single perspective of the animal, he will undergo an irreversible metamorphosis and transform into the animal imitated. In this case, then, confusion between analogy and identity does not lead to madness as such, but instead to something just as dreadful, namely "othering" beyond recovery. ${ }^{151}$

I now want to touch briefly on some interesting resonances that Willerslev notes between his account of the Yukaghirs' understanding of personhood and other descriptions in the literature. First, Willerslev suggests a connection between the Yukaghir understanding and the Amerindian in the work of Eduardo Viveiros de Castro. Recall that we read previously that according to Willerslev, "Animals and their associated spiritual beings are . . . said to take on human shapes and live lives analogous to those of humans when in their own lands and households". Later he adds that, "This is what Viveiros de Castro . . . calls 'perspectivism" ", namely, the conception "according to which the world is inhabited by different kinds of persons, human and non-human, which perceive reality from distinct points of view". ${ }^{152}$ Like Willerslev, Viveiros de Castro does not shy away from using the term "animism" in his ethnographic work:

What I am defining here is what anthropologists of yore used to call animism, an attitude that is far more than an idle metaphysical tenet, for the attribution of souls to animals and other so-called natural beings entails a specific way of dealing with them. ${ }^{153}$

As Viveiros de Castro glosses it, Amerindian animism has some profound consequences:

Personification or subjectification implies that the "intentional stance" adopted with respect to the world has been in some way universalized. Instead of reducing intentionality to obtain a perfectly objective picture of the world, animism makes the inverse epistemological bet. ${ }^{154}$

Elsewhere he claims that this view entails a "cultural universalism" and correlative "multinaturalism". Humans share a commonly structured person-shaped understanding with other species, and each species lives in an equally real natural world shaped by its specific perceptual needs. ${ }^{155}$ 
More striking still is the similarity in Willerslev's and Viveiros de Castro's respective descriptions of the dangers which such animism present for the Yukaghirs and Amerindians. Willerslev writes,

If . . . mimesis becomes totalizing, and the imitator loses himself in what he imitates, we are no longer talking about mimesis but metamorphosis: nothing is left to imitate when the difference between the copy and the original is totally gone. Mimesis, therefore, is situated and defined through difference as much as through similarity. ${ }^{156}$

Consider in this vein this passage from Viveiros de Castro in which he compares the threat of solipsism implicit with Western objectivism with an opposite and perhaps even more terrifying possibility inherent in Amerindian views:

Solipsism and metamorphosis are related in the same way. Solipsism is the phantom that threatens our cosmology, raising the fear that we will not recognize ourselves in our "own kind" because, given the potentially absolute singularity of minds, our "own kind" are actually not like us. The possibility of metamorphosis expresses the fear the opposite fear - of no longer being able to differentiate between human and animal, and above all the fear of seeing the human who lurks within the body of the animal that one eats. Our traditional problem in the West is how to connect and universalize: individual substances are given, while relations have to be made. The Amerindian problem is how to separate and particularize: relations are given, while substances must be defined. ${ }^{157}$

Willerslev also indicates affinities between his depiction of personhood among the Yukaghir and Marilyn Strathern's work in Melanesia, where she developed the idea of a "dividual". ${ }^{158}$ Strathern writes,

Melanesian persons are as dividually as they are individually conceived. They contain a generalized sociality within. Indeed, persons are frequently constructed as the plural and composite site of the relationships that produced them. The singular person can be imagined as a social microcosm. ${ }^{159}$

When writing later that one "of the best known Melansian axioms must be that appearances deceive", she adds that "the unitary identity sets the stage for the revelation that it covers or contains within itself other identities". 160

Strathern goes on to show how this Melanesian imagining of the person as a social microcosm breaks profoundly with a dominant Western understanding of each person's relations to her body, her actions, her 


\section{Skepticism and the Human Condition}

property, and others. According to Strathern, on the latter conception, these relations are construed on the model of ownership. She thus writes,

Western proprietism inheres in the way relations between persons and things are conceived through the metaphor of the commodity. Persons are assumed to be the proprietors of their persons (including their own will, their energies, and work in the general sense of directed activity). ${ }^{161}$

Naturally, such a view entails that other persons, let alone external objects, are conceptually extraneous to one's identity. While this may be common sense for many of us, Strathern counters that

the Western notion that people own what they do to the exclusion of others seems hardly borne out by the evidence on how claims and ceremonial duties in such non-Western societies are often structured. . . . To assume that one can take as an analytical base a condition in which people control themselves and their labor, without reference to social others, is to introduce a neoclassical economism when one least expects it. ${ }^{162}$

In sharp contrast with this "proprietary" paradigm, Strathern maintains that the

Melanesian cases delineate the impact which interaction has on the inner person. The body's features are a register, a site of that interaction. Consequently, what is drawn out of the person are the social relationships of which it is composed: it is a microcosm of relations. ${ }^{163}$

Consequently, there "is no presumption of an innate unity: such an identity is only created to special, transient effect". ${ }^{164}$ The situation in which a transient unitary identity is created, or drawn out, is one in which a specific action is called for by someone else or something else to which a person bears the appropriate kind of relation. Action here is therefore not regarded as an effect of a unitary willing spiritual entity. Rather, it is a temporal manifestation of just one of many relations harbored within each dividual person. Strathern thus distinguishes between a person, a nest of relations as it were, and an agent, a single actor activated on a given occasion by an external entity, be that another person or object. ${ }^{165}$ She writes,

The person is constituted from the vantage points of the relations that constitute him or her; she or he objectifies and is thus revealed in those relations. The agent is construed as the one who acts because of those relationships and is revealed in his or her actions. ${ }^{166}$ 
An agent's action is thus instigated by another person or object; it is the presence of these that calls for some particular response because of the way in which they too are understood as sets of social relations. There are no clear nodal points of subjects acting on objects (whether those objects are understood as other persons or ordinary objects such as food stuffs). Instead,

The whole burden of analyzing the objectifications of a gift economy has been that, if we use the shorthand at all, it is persons (relations) who replace persons (relations). These may appear as bodies, but then the body is an objectified form: the self so to speak from another's point of view. ${ }^{167}$

Strathern sums up this radically different way in which persons, agents, their objects, and their relations are understood in the Melanesian context as she finds it.

The center is where the twentieth-century Western imagination puts the self, the personality, the ego. For the 'person' in this latter day Western view is an agent, a subject, the author of thought and action and thus 'at the center or relationships. ... It has shaped our cultural obsession with the extent to which human subjects are actors who create relationships or act rather as the precipitation of relationships; this obsession fuels the individual/society dichotomy with which I began. ${ }^{168}$

Despite these notable similarities, however, there also seem to be some interesting differences between the Hagen and Yukaghir. So far as I can tell from Willerslev's account, personhood among the Yukaghir can involve a transitory multiple identity of the hunter, his prey, and a deceased relative. This involves not only cross-species relations, but also both synchronic and diachronic human relations. The main focus in Strathern's description of the Hagen, on the other hand, seems to me to be on synchronic social relations alone. ${ }^{169}$ It's thus unclear to me whether it would be apt to say of them, as Willerslev does of the Yukaghirs (and perhaps would say of the Amerindian in Viveiros de Castro's work) that they live in a "hall of mirrors".

Finally, I should repeat that the understandings of personhood in the ethnographic material described previously certainly seems to be rather different from Taylor's account of the medieval porous self. In these ethnographic descriptions of non-buffered selves, rather than a porous, yet mostly discreet, individual mind or soul existing in both direct causal and semantic contact with entities in the world, we find something more like the attainment of wholesale multiple identities in one and the same embodied being. So far as I can see, then, even if a person is not exactly 


\section{Skepticism and the Human Condition}

understood as bound at the skin, as in the modern Western picture, the specific notion of porosity seems either to be absent in the summarized descriptions, or at least not to be in the forefront of them. ${ }^{170}$

\section{VII}

There is no getting around the fact that the descriptions of the people recounted in the previous section are puzzling (even though they are often the very stuff of which much history and ethnography is made). One perhaps all too human response to this perplexity is to try to explain it away. Willerslev notes for instance an aversion in some quarters to ascribing even self-proclaimed animist views to peoples on the grounds that it smacks of "primitivism". Some writers have actually preferred to treat certain paradoxical statements made by informants as deceptions offered up in order to conceal the real nature of their activities from overly inquisitive Western investigators. ${ }^{171}$ I completely agree with Marshall Sahlin's assessment that this option fails miserably as an attempt to show respect to indigenous cultures. Rather, it does "symbolic violence" to them and sacrifices huge portions of ethnography to a "moral shakedown" imposed by a misguided political agenda. ${ }^{172}$ It simply strains credulity to believe that the Yukaghir hunters with whom Willerslev lived, and the informants of countless other ethnographers who have similarly investigated other cultures, were putting on an elaborate show to satisfy his need to project a Eurocentric fantasy onto an exotic "other". This is just political humbug. At any rate, my main conclusion is that there is no good reason for attributing to these people an essential relation to skepticism as Cavell conceives of it. In fact I find it difficult, to put it mildly, to accommodate Cavell's vision of skepticism, tied as it is to the experience of the locked-in/locked-out self, within the contexts of these other cultures. On the contrary, in the cultural-historical worldviews we have been looking at, there seems to be little or no place for the very experience of a fundamental predicament of separateness. Indeed, the ideas of "acknowledging the other" or "accepting the world" seem forced in these contexts, since the others and the world are already very much woven into the fabric of the self.

Of course it's important to keep in mind that on Cavell's view, that each of us is his "own haecceity" is not a conclusion we arrive at through philosophical argumentation, in the manner in which, for example, Descartes seeks to establish this kind of proposition after his First Meditation. Even if he seems to think that Descartes was on to something significant, for Cavell the philosophical doctrine of our isolation only seems to result if we follow the misguided assumption that our fundamental relation to the world might have been one of knowing with certainty. If, as I think Cavell rightly argues, there is something fundamentally illusory with this assumption anyway, then this fact or proposition, if those are the right 
words, is not something we could ever really know. Instead, the "experience" leading to the "philosopher's originating question", an experience Cavell thinks we usually respond to by fleeing into various obsessions, including various epistemological projects, is supposed to be a revealing mood that uncovers our true predicament of separateness, even if that revelation is not construed by Cavell as a cognitive operation and that separateness is at least temporarily remediable in a way that philosophical solipsism never could be. Our condition of separateness has to be lived with and faced up to, not just cognized, if we are to attain the only genuine relations to others and the world of which we are capable, the relations of acknowledgement and acceptance.

Still, even during those brief respites when the dust of our panic settles and we are perhaps able, however fleetingly, to accept the world and to acknowledge others before we once again succumb to our mania for domination through knowledge, Cavell's view is that our fundamental existential condition must remain that of separateness. In the context of these other systems of thought, however, the for us apparently redeeming concepts of acknowledgement and acceptance seem frankly redundant and out of place. In fact, not only does it become difficult to talk about any possible edifying lesson to be had through having the experiences of separateness described so vividly by Cavell, I think it is completely opaque how, for instance, we can realistically entertain the question as to what it would be like for the Yukaghir to undergo such an experience. Yet according to Cavell, it was the essence of our very humanity to be vulnerable precisely to the feeling of the world's withdrawal, if only long enough to repress it. I don't buy it.

It could be argued that I am defending an extremely implausible form of psychological relativism, to be denying the "psychic unity of mankind", by implying that all emotional experience is determined by language, and, where there seem to be different grammars of such experience, concluding that there we have logically incompatible emotional possibilities. Nothing is further from the case. I take it as given that joy, fear, grief, anger, and expectation are part of our common natural inheritance and are found universally in all cultures. But experiences such as that of "being sealed off from the world, enclosed within my own endless succession of experiences" 173 or of oneself being under threat of metamorphosing into a moose seem to me only possible for a creature burdened with a language. And it seems further to me to be not only the case that certain things are simply not given expression in the context of certain forms of life, but entirely unclear how to conceive of their sensibly being given such expression.

At this point, I might be accused of trying to get away with a logical sleight of hand. That is, one might try to show that my argument against Cavell's claim for the universality of the human condition of separateness relies on nothing more than a shopworn and now generally rejected 


\section{Skepticism and the Human Condition}

argument from incommensurability of the kind commonly associated with figures such as Thomas Kuhn, Peter Winch, and others. ${ }^{174}$ In the examples from history and ethnography I have discussed, so this counterargument could go, certain words such as "self", "person", "agent", "soul", "mind", "individual", "I", "body", and "world" appear in very different linguistic contexts and seem to be employed in very different ways than those ways to which most of us in the modern West are familiar. If, moreover, these lexical items, these signs, have whatever particular meaning they have in those very different contexts, how, it can be asked, can I pretend to locate in these other contexts of use what Cavell means by the same expressions in the contexts of use in which he employs these terms? This would require that I understand what Cavell means by them in his context, and then, when turning my attention to the appearance of these expressions in ethnographic contexts, I am somehow able to recognize that Cavell's meaning can't be meant or said in these other systems of thought: that his meaning won't "fit" those contexts as a matter of logic. The sleight of hand amounts to imagining that after one has extracted a sign out of one context of use, that the sign somehow magically retains its meaning, and then discovering that, lo and behold, it can't retain this original meaning in a substantially different context of use. Such a maneuver could tempt us to conclude something like "the Yukaghir understanding of self is incommensurable with the Western understanding”. But that would involve overlooking that as soon as a lexical item is removed from the original context of use and left in limbo as a bare sign, there was no more "meaning" remaining for to fit or not to fit into the new and supposedly incommensurable context. The same signs in the new context may mean whatever they mean, and this may indeed be different from what those signs mean in the first context. But this is not the same as the first meaning not fitting into the slot occupied by the second meaning. All I am doing, so this potential criticism goes, is identifying some superficial syntactical or lexical similarities, the occurrences of the same signs in different contexts, and drawing tendentious philosophical conclusions about what can and cannot be thought in those contexts. To claim therefore that Cavell can't articulate his skepticism within the logical parameters provided by the logic of affect that each of these other cultures exhibit, is not just a bold metaphysical claim, it is downright incoherent. Claiming that "Cavell can't say that" logically only works if I can provide some story about what "that" is supposed to be. And, as we have just seen, it is in the very nature of this trick as I've described it that no such story is being told. My attempt to show that Cavellian skepticism cannot be formulated by drawing the limits around what can be said in these other thought systems, so this line of criticism might go, is simply unintelligible. ${ }^{175}$

But in fact, I am not relying on anything like an incommensurability thesis and I am not claiming that Cavellian skepticism cannot, as a 
matter of logic, be formulated within these other "conceptual schemes" or systems of thought. I am only claiming that I, for one, cannot make sense of what it would mean for the Yukaghirs to sense (or repress) the "brute metaphysical fact" of their separateness given what Willerslev reports. But I am also claiming that I doubt anyone else can make sense of this either. ${ }^{176}$ There is nothing logically amiss here. More importantly, it is essential to reject an assumption on which the accusation of my relying on an incommensurability thesis may rest in the first place. This assumption is that I am treating these accounts as though they consisted of uninterpreted strings of signs and then drawing my conclusion. This is false. On the contrary, I take the ethnographies and histories in which these accounts appear to contain careful translations, not merely unusual strings of signs. I take it that historians and ethnographers (and hopefully their attentive readers) actually have some measure of comprehension of these strange pronouncements, even if they do not sit easily with our ordinary understanding. Addressing this issue, Strathern writes,

It is important to show that inapplicability is not just a result of poor translation. Our own metaphors reflect a deeply rooted metaphysics with manifestations that surface in all kinds of analyses. ${ }^{177}$

At the same time we may not be justified in assuming that such translations are based on scant evidence, on mere individual occurrences of expressions taken out of context, so that a more extensive comparison would surely remove for us any oddity. Strathern writes in this vein, "Comparative analysis does not in the end turn on the applicability of single concepts but on the comparison of whole systems". ${ }^{178}$

Consider in this light the following passage from J. Prytz Johansen's work in New Zealand:

According to our knowledge the reason why the Ngatiwhatuwa came to Kaipara was a murder committed by the Ngatikahumateika. This tribe murdered my ancestor Taureka. The tribe lived in Hokianga. This country was theirs, the tribe's. My home was Muriwhenua, it was my permanent residence because my ancestor lived there. Later I left Muriwhenua because of this murder. Then I tried to revenge myself, and Hokianga's people were defeated and I took possession of the old country. Because of this battle the whole of Hokianga was finally taken by me right to Maunganui, and I lived in the country because all the people had been killed. ${ }^{179}$

Johansen adds almost laconically, "All the events described . . . took place long before the narrator was born". ${ }^{180}$ If after having learned their informant's language and conducted extensive field work, investigators found that, given the perplexity they cause, such statements could be 


\section{0}

rendered with more tame translations, they would have no good reason for not providing those instead of the translations one so frequently encounters in their works. That is, unless we are to accuse a hefty portion of ethnographers of rank sensationalism, we will have to regard passages like the previous one as real attempts to give meaningful interpretations that express some understanding. (I hesitate to write "express at least partial understanding" because that implies that we have some working notion of what complete understanding looks like, which, unless we aren't concerned about being dogmatic, we should admit we do not). If we were to look askance at ethnographies and histories for containing paradoxical descriptions, then the only occurrences of sentences like, "unlike people in X, the people in Y, think Z", would be the ones we could easily domesticate. Having little or no knowledge of German beer or religious geography would not present much of an obstacle to assimilating a sentence such as "unlike Düsseldorfers who like Alt Bier best, the people in Køln think Kölsch is best" to "unlike the people in St. Louis who think Budweiser is the best beer, the people in Milwaukee think Miller is the best beer". If these were the only cases, there wouldn't be much call for ethnographies at all (and maybe not much call for imported beer).

I am not, therefore, arguing that we cannot as a matter of logic harmonize what certain peoples are reported as saying about their lives and how Cavell has construed our predicament. I am arguing rather that, as a matter of fact, I (we) don't know how to reconcile the Cavellian picture with these (and I suspect countless other) cases of what other peoples say or have said about themselves. One could of course find oneself driven (or tempted?) to conclude that rather than regarding certain other societies as having a vastly different concept of the self, we should say that it is simply not clear how they can be regarded as having such a concept of self at all. I think there are reasons for resisting such a move, but in any case, it offers no help to the Cavellian picture, resting as that does on Cavell's essentialist claim about the ubiquity of skepticism and its originating experience. ${ }^{181}$

\section{VIII}

Even if my arguments in the previous section should allay certain logical suspicions about my historicist-oriented critique of Cavellian skepticism, there are further concerns that I need to address. These pertain to my use of historical and anthropological texts in my critique of Cavell.

First, it might be argued that I have framed the issue wrong and have distorted the nature of Cavell's main claim about what works such as Othello are meant to reveal about the human condition. At the beginning of Part V, I provided a defense of my attributing to Cavell a kind of anthropology. This was directed in the first instance at those with an 
empirical bent of mind who might resist or even resent this word being used to describe a thinker whose conclusions were primarily drawn from the arts. I can imagine, however, howls of protest coming from other quarters to the effect that my critique of Cavell, drawing as it does on history and anthropology, completely misses its mark precisely because it construes him as making something like a universal empirical claim. The complaint might run like this: What you are in effect accusing Cavell of doing is making a hasty generalization. You are, that is, saying that he draws a false empirical generalization about the human condition from an inadequate data set. But that is not at all the kind of reasoning in which Cavell is engaged. He is taking himself and characters such as Lear and Othello as representatives of humanity, in the way in which an ethologist might say "the Canada lynx has long ear tufts, flared facial ruff, and short, bobbed tail with a completely black tip. It has unusually large paws that act like snowshoes in very deep snow, thick fur and long legs and feeds primarily on the snowshoe hare". It would hardly be to the point, this line of counter-argument would continue, for you to assert that this statement was false because I had found a Canada lynx who didn't eat meat. That would misunderstand the nature of the statement, which describes what is typical or representative of the Canada lynx. My attempt to refute the statement by pointing to our supposed vegetarian would merely reveal that I did not understand the grammar of such statements in the first place. ${ }^{182}$ If this were so, then I would be in full agreement with this argument. In fact, Geertz makes this very same point:

The notion that unless a cultural phenomenon is empirically universal it cannot reflect anything about the nature of man is about as logical as the notion that because sickle-cell anemia if, fortunately, not universal, it cannot tell us anything about human genetic processes. ${ }^{183}$

Well and good. I am not, however, accusing Cavell of making a hasty generalization, but rather of confusing a figure as representative for humanity who is rather better thought of as representative of one culture. If lots of our vegetarian lynxes start showing up in peoples' vegetable patches in Alberta, we would have ample reason to rethink the worth of the ethologist's original claim about lynx diet, however we wish to regard its grammatical status. Claims of what is typical of this or that kind of living creature are, to be sure, not the same as universal generalizations. But neither are they immune against observable facts.

More seriously, I might be accused of selectively choosing my sources and so stacking the deck against Cavell's views. More specifically, someone might accuse me of presuming that Taylor can be employed against Cavell as "the voice of intellectual history" on the one hand, while Willerslev and others are called into service as the "voices of anthropology" on the other. Whereas in truth, no one could responsibly pretend 


\section{2}

that a single or small subset of thinkers can simply be taken as speaking finally and authoritatively for their respective fields on a subject as vast as the nature of the self. This criticism could even be extended if someone wished to accuse me of taking myself to be the authoritative voice of these voices, thereby making a blunt instrument even blunter. And it is true that historical and anthropological data should not be cherry picked and hurled at one's opponents, as much as that image appeals to me, and despite the fact that I believe philosophers sometimes deserve such treatment. But I am not assuming in any way that Taylor and Willserslev et al. are the only important voices here or that I am their only reliable reporter. They are all merely individual (albeit very pertinent) voices and my take on their takes is just that. It remains the case, however, that these works are part of the record, and granting for the moment that they have been competently researched and written and that my renderings are fair and balanced, they present a significant challenge to Cavell's viewpoint. After all, since Cavell is the one making gestures at typicality, the burden of argument is on him. I merely have to play defense.

But not only do I not presume to be the sole legitimate voice for the anthropological and historical material sketched previously, I should also make clear that despite my reliance on his work, Willerslev and I may be in substantial disagreement about an important aspect of his findings. Recall that in Part V I quoted a passage from a well-known paper in which Clifford Geertz asserted the peculiarity of the Western conception of the self. Willerslev appears to take deep exception to the sort of view he sees Geertz as representing. He writes,

My point is not that we should distinguish between two different notions of the person, a Western one and a Yukaghir one. The anthropological literature is crammed with typologies of this kind that crudely contrast the firm self-other boundary of the Western person with the fluid self-other boundary of the non-Western one. In my view, however, such bipolar types of personhood, even if conceived as ideal types, are widely overdrawn $\ldots{ }^{184}$

This passage contains a footnote with a reference to an article by Melford Spiro that explicitly attacks what is taken as the Geertzian view, an attack which I thus take Willerslev to endorse. ${ }^{185}$ Taking a brief look at Spiro's paper provides me with an additional opportunity for bringing out what I see as at stake in philosophical discussions of the self. (It will also make it more probable that Geertz is more philosophically sophisticated than most of his critics would have it.)

Spiro reveals that he was first stimulated to write in opposition to Geertz's view not by Geertz's original paper itself, but by two social psychologists, Markus and Kitayama (1991), who follow him. ${ }^{186}$ Remarking 
on their agreement with Geertz's contention that the Western conception of the person is a "rather peculiar idea within the context of the world's cultures", Spiro asserts,

This statement, and their approval of it, struck me as strange, for, seeing that the person (which Markus and Kitayama, like Geertz, conflate with the self) has hardly been a focus of anthropological inquiry, it is not inaccurate to say that the person or self has been studied in only a small fraction of human societies. ${ }^{187}$

He soon adds,

To claim, however, that the Western conception of the self is different from that of the Indian or the Japanese or the Balinese conception is one thing, but to claim that in the context of the world cultures, the Western conception is "peculiar" is another, for the latter claim implies that typologically there are two conceptions of the self-a Western type, on the one hand, and a second type that is instantiated in all other societies. ${ }^{188}$

There seem to be several complaints here, which it will be useful to disentangle. First, there is Spiro's point that Geertz and his followers have failed to distinguish between the concept of the person and the concept of the self. Second, there is the claim that the concept of the person has simply received too little attention in the literature for the Geertzian view to have been validated. Third, there is an objection that the researchers whom Spiro criticizes have taken on an either/or typology of Western/ non-Western as the only legitimate axis of comparison for understanding various cultural conceptions of the self (and/or person). And fourth, although Spiro doesn't mention it explicitly in the passages just cited but does devote a fair amount of attention to it in his paper, he argues that as an empirical matter, Geertz's talk of a "Western conception of the person as a bounded, unique, more or less integrated motivational and cognitive universe" just isn't that peculiar after all. Next, I will try to address all but the second objection. ${ }^{189}$

To begin with, I will take up Spiro's and Willerslev's third complaint, that the very talk of a Western/non-Western typology, or what for my purposes here I am taking to be the same, a buffered/non-buffered typology, is somehow illegitimate. Spiro asserts that,

in my view a typology of the self and/or its cultural conception which consists of only two types, a Western and a non-Western, even if conceived as ideal types, is much too restrictive. Surely, some nonWestern selves, at least, are as different from one another as each, in turn, is different from any Western self. ${ }^{190}$ 


\section{Skepticism and the Human Condition}

"Ideal type" is of course Max Weber's term of art. We will revisit it later when I discuss Spiro's use of "cultural conception", which I take to be more or less equivalent. For now, I merely want to point out that I believe that Willerslev and Spiro are at the very least uncharitable and quite likely just wrong in their complaint on this point. Let's assume for a moment that there were good reasons for believing that "the Western, buffered" self really was in some sense unique, or at least atypical, so that a social scientist could with a relatively clean conscience assert that "Westerners are pretty much like this (buffered), while (most of) 'the rest' are not". And let's assume, moreover, that it is true as Willerslev asserts that much attention in the literature had been devoted to making the case that this is so. While it might lead us to ask why such a finding (if it is one) bared repeated pointing out, this alone would not necessarily make it irrelevant to emphasize it in any particular case. In fact, if this purported difference has received so much attention, this may be because it is considered by many researchers to be hugely important that one understand its history, contingency, and significance. But my main point here in responding to this objection is that the buffered/non-buffered dichotomy is of course only one axis of comparison and no one (and not Geertz) has so far as I can tell claimed that it is the sole legitimate characteristic to investigate. There are likely countless comparisons that can and have been employed by researchers, which lend support to diverse sorts of groupings. Some comparisons may rely on the same kind of either/or conceptual bifurcated structure as the buffered/non-buffered distinction does. Others may wish to avoid such sharp dichotomies and see fit to use a much more graded conceptual scale for the purposes of the comparison one wants to make. The upshot is that so long as no pernicious dogmas lie at their basis, there is no call for the writings of Geertz et al. to raise any unsavory suspicions about methodological framework.

In order to address the first and fourth objections, it will help if I give a short outline of Spiro's own conceptual scheme for thinking about the questions at hand. Spiro's arguments rest in large part on his reliance on three ideas and his claims that the work of the social scientists he criticizes fails to respect the important distinctions between them. The three ideas are that of "cultural conception of the person", "self-presentation", and "self-representation". According to Spiro, the cultural conception of the person is an ideal type of understanding of what a self is based on such generally shared public, cultural factors such as morals, religion, familiar artistic works, knowledge of social structure, ideology, etc. He notes first that,

some investigators ascertain the characteristics of the "self" and/ or its cultural conception as an inference from classical texts, some from cultural symbols, some from behavioral observations, some by means of eliciting procedures, and so on. ${ }^{191}$ 
Subsequently he remarks that

typically, anthropologists (and comparative social psychologists) do not investigate the self or the individual's conception of his self (the self-representation), but the cultural conception of the person. They mostly arrive at this conception by investigating some set of cultural symbols of a social group, from which they infer its cultural conception of the person, although in a few instances they do so by means of various experimental tasks. ${ }^{192}$

While Spiro does not accuse those social scientists whom he thinks traffic merely in cultural conceptions of the person as conducting their research entirely from the comfort of their libraries, and while he does not imply that the cultural conception of the person (or any other ideal type) is without some social scientific value, he thinks that to settle for such a generality for one's understanding of the self is to settle far too cheaply.

It is difficult to clarify the next idea, self-presentation, without already drawing on ideas from the cultural conception, because through language self-presentation already interfaces with the cultural conception. In a rough sense, we can say that according to Spiro, self-presentation is something like an individual's conscious, conceptual take on herself as well as the self-articulation that she more or less consciously presents to others. If the social scientist bothers at all to conduct one on one interviews, then Spiro would likely say that it is the self-presentation she is likely to encounter, a kind of presentation that is usually deceptively shot through with the expected cultural generalities characteristic of the cultural conception. The true self, in such cases, is obscured.

Spiro doesn't provide much independent description in his paper about the level he terms "self-representation" (naturally), but it is clear that it is at this fundamentally individual bio-psychological, affective, and largely unconscious level where the real investigative work ought to focus. Suffice to say, he thinks this all-important level escapes the likes of Geertz and his co-interpretivists, stuck as they are at the levels of the purely symbolic. He complains that

most of these studies assume that cultural conceptions of the person are isomorphic with the actors' conceptions of the self, and some also assume that they are isomorphic with the actors' mental representations of their self, and with their self itself. ${ }^{193}$

His explanation for such negligence is that many anthropologists remain unfortunately

committed to the regnant theory of wholesale cultural determinism, they take it as self-evident ... that cultural conceptions of the self are 


\section{Skepticism and the Human Condition}

isomorphic not only with the actors' conception of the self, but with their mental representation of their own self as well. ${ }^{194}$

Presumably what Spiro means by "wholesale cultural determinism" is something like a quasi-mechanical top-down determination not only of the ways in which actors present themselves to the public (including themselves) but also a cultural colonizing of their deepest private somatic sense of themselves. On this basis Spiro concludes that

[h] aving learned the hard way that one cannot validly infer actors' conception of the self, let alone their mental representations of their own self, from the normative cultural conception, it is not surprising that I was rather skeptical of Geertz's claim that from a study of symbolic cultural forms alone, one can validly infer the manner in which people "actually represent themselves to themselves." 195

Based on the distinctions between the cultural conception of the self (more or less identical with the concept of a person for Spiro), self-presentation, and self-representation, Spiro is able to lay out some specific objections against "wholesale cultural determinism". With regard to Markus and Kitayama, Spiro maintains that their

statement that in non-Western societies "others are included within the boundaries of the self" would mean that an individual's otherrepresentations are located within his self-representation, and such a condition (according to modern psychiatry) is a sign of rather severe psychopathology. ${ }^{196}$

Spiro elaborates a bit further on:

[I]f for Markus and Kitayama the term "self" denotes (as I think is most likely the case) some psychological entity (an ego, a soul, an "I") within the person, and "others" denotes such an entity within other persons, then non-Western peoples, for whom "others" are allegedly included within the boundaries of the self, would be characterized by little, if any, self-other differentiation, and like William James and A. I. Hallowell, I find such a notion very difficult to comprehend. Thus, both James and Hallowell, respectively the preeminent psychological and anthropological (cross-cultural) theorists of the self (in my view at any rate), construe self-other differentiation-the sense that one's self, or one's own person, is bounded, or separate from all other persons-as a distinguishing feature of the very notion of human nature. ${ }^{197}$ 
On this point, Spiro thus concludes as follows:

Although Geertz contends that in his studies of Bali, Java, and Morocco he has employed "symbolic forms" to describe the actors' own "sense of self" ..., in my judgment he has employed them to describe the ways in which actors are often designated and identified by others, and in which they often present themselves to others. In other words, although he has described the actors' selfpresentation, he has not described their "sense of self," or their self-representation. ${ }^{198}$

In addition to the previous arguments based mainly on purportedly neglected conceptual distinctions, Spiro also makes recourse to research conducted in Bali by Unni Wikan that he believes empirically refutes Geertz's views, in particular by showing up his more dramatic claims such as that in Balinese social life "It is dramatis personae, not actors, that endure; indeed, it is dramatis personae, not actors, that in the proper sense really exist". ${ }^{199}$ A few of the offending passages from Geertz's earlier writings on Balinese culture provide some vivid examples of the ideas that Spiro sees Wikan's research as refuting. In one passage, Geertz claims that

The various "village chiefs" and "folk priests" on the Sudra level, and, on the Triwangas, the hosts of "kings," "princes," "lords," and "high priests" do not merely occupy a role. They become, in the eyes of themselves and those around them, absorbed into it. They are truly public men, men for whom other aspects of personhood - individual character, birth order, kinship relations, procreative status, and prestige rank take, symbolically at least, a secondary position. We, focusing upon psychological traits as the heart of personal identity, would say they have sacrificed their true selves to their role; they, focusing on social position, say that their role is of the essence of their true selves. ${ }^{200}$

A few pages on, we find much the same idea:

The nearly faceless, thoroughly conventionalized, never-changing icons by which nameless gods known only by their public titles are, year after year, represented in the thousands of temple festivals across the island comprise the purest expression of the Balinese concept of personhood. Genuflecting to them (or, more precisely, to the gods for the moment resident in them) the Balinese are not just acknowledging divine power. They are also confronting the image of what they consider themselves at bottom to be; an image which the biological, 
psychological, and sociological concomitants of being alive, the mere materialities of historical time, tend only to obscure from site. ${ }^{201}$

Geertz sums up his interpretation with the terse assertion: "The illuminating paradox of Balinese formulations of personhood is that they are in our terms anyway - depersonalizing". ${ }^{202}$

According to Spiro, Wikan's work shows that the Balinese, pace Geertz, are not merely or even primarily concerned with a cultural conception of the person or in the public personae the cultural conception extracts from them in their self-presentation, but instead are centrally occupied with their individual emotional states in a way that indicates they experience their inner lives as every bit as much of a bounded, unique, more or less integrated motivational and cognitive universe as does the typical Westerner. Spiro claims that Wikan's more psychologically focused investigations reveal that

the Balinese have a constant concern with health, which is hardly surprising given that half of all deaths are attributed either to black magic perpetrated by "intimate others," or to poison administered by them. Moreover, for the Balinese, she writes, the self is experienced as "steadily exposed to myriad health-endangering forces. ... . Fellow beings, deities, demons, sundry (super) natural spirits, and the souls of the dead can strike a person sick or dead". Again, "the Balinese live in a world where murder or attempted murder resulting in sickness from sorcery is the order of the day". ${ }^{203}$

He adds later,

Thus, Balinese actors fear their own anger, according to Wikan, because of their belief that should they offend others, the latter will use sorcery and poison to make them ill, and they will suffer supernatural punishment, as well. ${ }^{204}$

According to Spiro, these considerations show that the Balinese are as individualistic in their self-presentation as the supposedly peculiar Westerner. In fact, in a twist towards the end of his paper, Spiro contends that not only is the allegedly peculiar Western self not peculiar within the context of world cultures, it is nothing but a mere "straw man" even within the context of the West itself: "No major Western student of the self, none at any rate that I am aware of, holds the view that the self, Western or otherwise, is not interdependent. ${ }^{205}$ Spiro's conclusion is thus that

there is evidence for the proposition that many putative characteristics of the Western self, which allegedly make it "peculiar," are to a greater or lesser degree also found in the non-Western self; conversely, 
many putative characteristics of the non-Western self, which allegedly are its distinguishing features, are to a greater or lesser degree also found in the Western self. ${ }^{206}$

In response to Spiro's claim that a failure to respect conceptual distinctions accounts for a large part of the error he attributes to Geertz and others, I would argue that while it is doubtless a mistake to think that one can simply read off what Spiro calls "self-presentation" and "self-representation" from cultural conceptions, it is also dubious in the extreme to believe that these three categorizations can be somehow understood in conceptual isolation from one another. For example, the very idea that self-representation can be made intelligible in logical isolation from the shared concepts of language, and so the cultural conception, in which each individual partakes, is a fantasy. Presumably even a psychologically focused investigation into an individual's sense of herself, her self-representation, one that aims to bypass what she might be inclined to share, her self-presentation, is going to have to make use of concepts drawn from a shared language. And it's hard to see how this will not involve relying on concepts connected to the cultural conception of the person. Without being isomorphic, concepts taken from the language of the culture, the concepts I rely on in my conscious modes of self-interpretation (my self-presentation), and my own sense of myself (my self-representation) are bound to interpenetrate each other. What is the alternative? Is it the idea that we can somehow make sense of a language of thought, a private language as it were, that each individual speaks to herself and that exists in logical isolation from the public language she shares with others? Is the suggestion that anthropologists practice mind reading?

As for Spiro's assertion that the experience of a kind of non-buffered interpenetration of self and other ascribed to various non-Western peoples by some social scientists is better described as an implausible inadvertent ascription of mass psychopathology, this is contested by Willerslev's and Viveiros de Castro's descriptions of a central aspect of Yukaghir and Amerindian animism respectively, namely, the persistently felt need to distinguish oneself from the animal world so that one does not simply vanish into a fusion of selves. Neither Willerslev nor Viveiros de Castro feel tempted to offer a psychiatric interpretation of their informants. Spiro reports that he finds such things difficult to understand; I can certainly agree with that. Yet I would have thought that such a sense of difficulty would be a place for anthropological reflection to begin rather than a place for it to stop. ${ }^{207}$

Next, Spiro's employment of Wikan's work in Bali fails badly as a critique of Geertz. The cited examples, far from exhibiting an inner sense of individual independence, actually illustrate how the cultural conception of a person in Bali, including the idea that "intimate others" are capable of inflicting evil on one's self, actually interpenetrates people's 


\section{0}

inner self-representation of who they are. Indeed, it does so in a way that flatly contradicts the idea that self-representation and cultural conception are sharply differentiated in this case. If Wikan's descriptions are reliable, the "others" seem to reach right to the core of the self. Rather than providing a non-Western example of a bounded, buffered self, the examples show precisely the opposite. The Javanese fear of the effects of both black magic from without and the effects of negative emotions on others from within read to me like textbook descriptions of porosity. The specific ideational content of such fears reveals a subject's sense of himself as non-buffered, not bounded, and dependent. ${ }^{208}$

Finally, there is Spiro's assertion that no major Western student of the self ever held the view that the self is not interdependent. Except for William James and A.I. Hallowell, I am not certain whom Spiro counts as a major student of the self. Presumably Spiro would exclude Luther, Calvin, Descartes, Pascal, and Kant, who despite their substantial contributions to our present self-understanding chose to disregard the obvious empirical facts of human development, viz. that each of us is born biologically and psychologically helpless and must receive enough care in our earliest years to make responsible adulthood possible. What their contributions to the peculiar modern view stem from, however, is precisely, for better or worse, their not stopping at these facts, but instead offering their articulations of an individualistic conception of the self that is shaped by the requirements of a philosophical view of human agency and cognition. However much this view sits in tension with a more interactionist perspective, it has clearly had enormous historical significance for how people have regarded themselves in the modern West.

In the end, whether Geertz is correct to declare the Western conception of the self to be a "peculiar thing" is largely an empirical matter. So far as I know, the buffered self as it is designated in modern Western epistemology has only found mass instantiation once. ${ }^{209}$ The key elements of that conception, as one sees perhaps most clearly in Descartes, are that of a morally independent integrated motivational and cognitive universe. Crucially, they entail a view of the self as normatively and logically distinct from the "external world". Secondary qualities, moral "properties", and rationality itself are collapsed into the self, which thus gazes out on a completely disenchanted world of objects. While what Hume said of skepticism may also be true of this sense of isolation from the world, that no sooner does one leave one's room and engage in practical activity than it becomes psychologically remote, the sense of the world as epistemologically remote and disenchanted is still educated common sense in much of the contemporary West. (In certain circles, even to question the subject/object divide is to run the risk being accused of trafficking in hocus pocus.)

Far from aligning with the depiction of the Western conception offered by Geertz and others, the Balinese examples Spiro cites against 
it serve instead to reveal people who understand themselves as living in direct epistemological, semantic, moral, and causal contact with a "normatively structured" world. If Taylor is roughly right, then not long after the Protestant Reformation and the rise of capitalism not only the lifeworld of intellectuals, but much of everyday life in Europe was undergoing systematic disenchantment in a manner that would have rendered it nearly impossible to understand in the terms Wikan finds apt in modern Bali. The kind of pietism described by Weber was not just for the scientifically or philosophically educated, but characterizes a worldview inhabited by the more broadly educated public. For the educated classes in Europe and North America, the scientific revolution followed by the Enlightenment put the final touches on the process of banishing both God and human mental life from nature. This is what I take Geertz to be referring to in the quotation at issue; I suspect it is pretty peculiar.

\section{IX}

The main reason for my extended discussions of historical and ethnographic material was to make it more plausible that Cavell's view of our essential human condition as one of separateness is in effect an ethnocentric dogma, albeit perhaps a tacit one. In addition, however, my discussion also touches indirectly on a closely related issue that goes to the heart of Cavell's vision of language. I will briefly take this up now.

As we saw earlier, Cavell treats the possibility of skepticism as essentially tied to his insight that criteria are not self-applying, that they need to be projected into a context of use. This point is at the center of his argument that the skeptic's procedure, which is launched by claims such as "here is a hand" or "here is a piece of wax", involves the assumption that these utterances have specific significance despite their being uttered in a "non-claim" context. In other words, the criteria guiding the use of these expressions are taken by the skeptic to be magically self-applying, an idea Cavell rightly finds unintelligible. In order to be projected into a context, language thus requires the correlative concept of a language user, a particular kind of agent. This requirement for projection in a context, moreover, is internal to the contingency of language, in particular to its teaching and learning, but also to the inevitable failures and mistakes in our projections. It is the intrinsic difficulty we humans experience living with this essential contingency that generates skepticism. The very idea of the consequences of such failures, let alone their actual occasions, exacerbate our latent sense of being locked out that these failures make manifest. Given that the criteria we project are our distinctly human way of reaching the world and reaching each other, it seems understandable that the naked isolation that such failure reveals, especially in a best-case scenario, could prove terrifying. 


\section{Skepticism and the Human Condition}

But this issue of linguistic agency may appear to raise a serious problem for my claims that there are no compelling reasons for thinking that Cavell's understanding of the self is universally valid. If his specific ontology is actually necessary for the very concept of linguistic agency, we would be faced with some unattractive options in light of the anthropological material I have discussed. In other words, we would be faced with a question as to how, given what many ethnographers report, their informants' statements could be the expressions of language users at all. "Logically", I suppose, we could infer that, lacking the required agency, these people are not language users at all. But not only is this option absurd, it is belied by the fact that self-descriptions indicating a non-buffered self pervade the historical and anthropological record. One could perhaps hold that ethnographic and historical data on the self might be highly misleading for thinking about the nature of informants' actual relationship to language use. That is, if the notion of "self" that Cavell takes for granted is taken to be identical with the underlying essential nature of language users, then it looks like from the Cavellian perspective the cultures I have described previously must be massively deluded about their language and lives. In effect, they are not the kind of creatures with language they think they are. I will return to this idea later. For now, I want to explore another possibility.

Putting what I just called the "absurd" option schematically might be useful.

1. If there is language, then there must be a Cavellian agent.

2. Certain cultural contexts lack such an agent.

3. Therefore, there is no language in those contexts.

But why should we accept the identification in premise 1) of a language user with Cavell's understanding of the self? If the requirement is only that there be an agent in some sense, and it is far from obvious that we have any pre-given notion of just what that sense is, then 3 ) does not necessarily follow. No doubt the very idea of a language having no conception of linguistic agency at all, a language that lacked usages we would most naturally translate as "I said it", "She said it", etc. is difficult to make sense of. But this is a long way from entailing the specific characteristics we find Cavell attributing to the self in his rendering of skepticism. Cavell apparently regards ordinary empirical bodily and psychological individuatedness, that I am I and you are you, as facts that inevitably should lead us to interpret ourselves as metaphysically separate, and so as intrinsically threatened by the catastrophic possibility of skepticism. However, this view is precisely what I think the historical and ethnographic record contests. Addressing this very issue Taylor writes,

When moderns read of, say, shamanistic cultures where they are alleged to believe that the human person has three souls and that one 
of them can travel outside and even remain there for a time, they find it hard to know what to make of this information. Does it mean that these people don't share our sense of the unity of the person or the link/identity of a person with his or her body, that they don't count persons in the same way as we do? We can probably be confident that on one level human beings of all times and places have shared a very similar sense of 'me' and 'mine'. In those days when a Palaeolithic hunting group was closing in on a mammoth, when the plan went awry and the beast was lunging towards hunter A, something similar to the thought 'Now I'm for it' crossed A's mind. And when at the last moment, the terrifying animal lurched to the left and crushed B's head instead, a sense of relief mingled with grief for poor B was what A experienced. In other words, the members of the group must have had very much the same sense that we would in their place: here is one person, and there is another, and which one survives/flourished depends on which person/body is run over by that mammoth. ${ }^{210}$

Nevertheless, Taylor also rightly objects to the common sense equivalence between psycho-biological integrity and metaphysical agency.

But ... as solid as this localization may seem, and anchored in the very nature of the human agent, it is in large part a feature of our world, the world of modern, Western people. The localization is not a universal one, which human beings recognize as a matter of course, as they do for instance that their heads are above their torsos. Rather, it is a function of a historically limited mode of self-interpretation, one which has become dominant in the modern West and which may indeed spread thence to other parts of the globe, but which had a beginning in time and space and may have an end. ${ }^{211}$

That there must be some sort of linguistic agent is one thing; whether we have to construe the language user in the manner in which Cavell does, taking for granted the metaphysical picture of an isolated self that we have seen is far from universal, is quite another.

Naturally, Cavell never denies the "social embeddedness" of language. But for all that his picture of language and language users is a highly individualistic one. In fact, there is something Sartrean about Cavell's understanding of our individual responsibility for the application of criteria. It is reminiscent of Sartre's description of the responsibility one constantly exercises for "choosing not to jump" from a steep precipice as one traverses a narrow mountain path. One wants to say, "Okay okay, I get the point, I'm choosing with every step not to jump". But just because you may succeed in convincing me of this sort of intentionalistic story after the fact doesn't mean that this reveals the true nature of agency. ${ }^{212}$ To say "I use the word blindly", leaving in place as it does the fact that my 


\section{Skepticism and the Human Condition}

training into a practice can in many cases just do its work transparently, in no way detracts from the fact that it is still a case of $m y$ speaking. That meaning doesn't just "take care of itself", doesn't imply that I am (or even could be) consciously or unconsciously obsessively involved with my every act of meaning. Indeed, the Cavellian self may appear to be a requirement for language use exactly because of the skeptical contexts that emerge in his depictions, where the horror of isolation resulting from the possible failure of criteria is at the forefront. Yet what if the selfinterpretation precedes, and even precipitates, the horror, rather than the horror revealing the true nature of the self?

Cavell writes in the The Claim of Reason

What we take to be necessary in a given period may alter. It is not logically impossible that painters should now paint in ways which outwardly resemble paintings of the Renaissance, nor logically necessary that they now paint in the ways they do. What is necessary is that, in order for us to have the form of experience we count as an experience of a painting, we accept something as a painting. And we do not know a priori what we will accept as such a thing. But only someone outside such an enterprise could think of it as a manipulation or exploration of mere convention. ${ }^{213}$

The combination here of a historical sensibility with the rejection of social constructivism in the last sentence is admirable. Unfortunately, Cavell extends a line of reasoning here to matters of aesthetic ontology that he withholds when it comes to the ontology of skepticism. ${ }^{214}$ Yet the more we admit historical understanding into our philosophical view of what we mean by the self, the more we must also admit it into our view of the everyday world to which the self constantly relates. If there is no good reason to think of either of these as "natural kinds", then the relation between them cannot simply be taken as given. This idea opens up the possibility that while "I am I" and "you are you" and each of us is an individual language user, how we respond to the failure of criteria or the betrayal of others will not be necessarily characterizable in the fraught self-world (and self-other) terms in which Cavell understands them. Rather, the empirical language user's response to this or that failure will only be intelligible in terms of how he or she already understands that relation. And we have seen that there are strong reasons for regarding such understanding as heterogeneous.

\section{$\mathbf{X}$}

$A$

It is now time for me to make good on a promise I made in Part II C, namely, that I would eventually address some of Cavell's remarks that 
concern the historical context of modern skepticism, remarks which prima facie may not seem to fit comfortably with my claim that his story is fundamentally ahistorical. First, it is worth pointing out that there are places throughout his corpus where Cavell not only shows sensitivity to historical context, but actually exhibits historicist sensibilities. For example, in the early essay "A Matter of Meaning It", Cavell expresses clear opposition to the idea that modernism simply revealed essential facts about the nature of art that were waiting fully intact to be discovered.

To say that the modern "lays bare" may suggest that there was something concealed in traditional art which hadn't, for some reason, been noticed, or that what the modern throws over-tonality, perspective, narration, the absent fourth wall, etc.-was something inessential to music, painting, poetry, and theater in earlier periods. These would be false suggestions. For it is not that now we finally know the true condition of art; it is only that someone who does not question that condition has nothing, or not the essential thing, to go on in addressing the art of our period. ${ }^{215}$

In similar fashion, I have already cited passages where Cavell could easily be interpreted as holding that he actually believes skepticism's conceptual connection with modernity to be closer than my subsequent discussion would suggest. ${ }^{216}$ Remarks with an historical bent that touch on skepticism are scattered throughout Cavell's work. In The Claim of Reason we read that "It should be considered also that an initiating form for the achievement of privacy would be the convulsion of sensibility we call the rise of Protestantism". ${ }^{217}$ In the introduction to Disowning Knowledge from 1987, Cavell writes of "the historical trauma that sets the scene for skepticism (or for which skepticism sets the place), the scene in which modern philosophy finds itself". ${ }^{218}$ In "The Uncanniness of the Ordinary" from 1986, he refers to the acknowledgement of otherness in certain works of film and literature as a "datable event in the unfolding of philosophical skepticism in the West" ${ }^{219}$ Finally, in "Something Out of the Ordinary" from 1997 he asks "can the great literature of the West not have responded to whatever in history has caused this convulsion in the conditions of human existence?"220

Cavell says what he says about modernism presumably because he understands that an attempt to account for the changes in the ontology of art that is conceptually divorced from the practices through which we articulate our understanding of those changes is tantamount to metaphysical realism about "the real nature of art". It is incoherent because it requires that we strip ourselves of the very resources we rely on to articulate what it is we want to say and think. Unfortunately, he does not extend the same consideration to the modern understanding of the self. While Cavell acknowledges a relation between modernity and his understanding of skepticism, the nature of this relation is seriously 


\section{Skepticism and the Human Condition}

underdeveloped in his writings. Interpreted charitably, one could say that there is simply a fundamental tension in Cavell's thought as to whether the possibility of skepticism is an essential part of the human condition or more historical in nature. But in the end, not only in terms of the sheer numbers of countervailing remarks, but more importantly in terms of their trenchant rhetoric and logical role in his overall presentations, the weight of the textual evidence strongly mitigates against anything on Cavell's part like a consistent and robust historical understanding of the nature of skepticism.

I find little indication of an appreciation in Cavell's work of the historical horizon of skepticism, as a phenomenon caught up in a dialectic between, on the one hand, circumstances beyond human control, and on the other, historically particular forms of agency and articulations of valuations, which together shaped social reality. Lacking an acknowledgement of the logical depth of practices for making sense of what it means to be a self, talk of our fundamental condition as being one of separateness and isolation is naïve at best, dogmatic at worst. While Cavell frequently mentions modernity as the period during which the Western understanding of selfhood underwent a fundamental shift, he seems to construe that shift as a case where certain budding intellectual and psychological techniques for uncovering an entity already lying beneath the veil of traditional culture dovetailed with the social conditions that permitted those techniques' successive refinement and application. The reception of the "results" were registered with approval (by the right people) in a way that reinforced the idea of a sharp separation between the contexts of discovery and justification, if you will, of what had been "found". We thus read in The World Viewed:

So far as photography satisfied a wish, it satisfied a wish not confined to painters, but the human wish, intensifying in the West since the Reformation, to escape subjectivity and metaphysical isolation - a wish for the power to reach this world, having for so long tried, at last hopelessly, to manifest fidelity to another. ${ }^{221}$

We saw previously in the case of modernism that Cavell sometimes envisages historical change without his invoking a need for such change to be underwritten or guided by something like a constant referential substrate (the nature of art). But when it comes to the self, for all his sophistication, he seems to imagine the matter as though one could speak of some brute bare particular underlying our mental life, with no accounting for how that ostensive trick is supposed to be pulled off. I am emphatically not saying that the modern self is a "social construct", or that it was "created" by language. I am saying, however, that to regard its historical emergence on the model of a quasi-empirical discovery of an entity, independently intelligible as already there apart from the broader cultural 
context of moral and other social practices within which we speak and think of the self at all, is a profoundly dubious business.

\section{$B$}

We have seen not only that the ethnographic record reveals peoples for whom Cavell's understanding of the self is alien, but also that there is no compelling philosophical reason for thinking that they are (or were) somehow wrong about the facts. In particular, in my analysis of Spiro's criticisms of Geertz, I tried to undercut the idea that there was any obvious basis for believing that a Cavellian-like take on metaphysical separateness could be grounded in the facts of our bodily separation. ${ }^{222}$ Moreover, it is actually very far from obvious that a conceptual or interpretative system with that particular self-understanding is somehow "truer to the facts" than are other systems that embody a different selfunderstanding. In dealing with Cavell's occasional references to history, I have also touched on the possibility that he regards a certain constellation of modern cultural institutions such as Protestantism, science, and liberalism which emerged coevally with the modern self-understanding, as somehow most revealing and expressive of the human condition. Now Cavell would certainly be right to resist the suggestion that we could simply shrug off our modern understanding of the self (whether precisely his own or some related iteration), even if there were weighty considerations for wanting to do so. It might be held, for instance, that once the historicity of our concept of the self (or any concept, for that matter) becomes known, then merely by agreeing to speak differently we could loosen its grip. This is naïve and unrealistic. The centrality in our thought of our concept what it is to be a self runs much deeper than can be accounted for by any mere agreements we could drop or adopt. Nevertheless, we are only required to regard skepticism as rooted in our biological nature if our conception of the role that historical ideas and practices, especially linguistic practices, play in shaping our self-understanding is a superficial and passive one. According to one such thin interpretation, before modernity took hold in the West, and still to this day in many societies, a metaphysically separate subject labors under the weight of arbitrary cultural baggage.

I mean to press hard here on a very real, even if implicit, difficulty at the heart of Cavell's work, a difficulty which I can put in two questions: Should our modern understanding of the self be taken to represent a kind of uncovering of something already there? Or is it better understood as a historical phenomenon that inevitably developed out of the very logic of human thought? This is not a dilemma in the sense that these two questions comprise two mutually exclusive logical possibilities. (There is at least one even less plausible option remaining with which I will deal at the end of this part.) I believe, however, that the respective metaphysical 


\section{Skepticism and the Human Condition}

and epistemological thrusts of these two questions are most likely to capture the philosophical space in which Cavell operates. Consequently, negative answers to both questions reveal that there is a profound problem with Cavell's view of skepticism. I will first address the ontologically inflected notion of the modern self as discovery because that expresses the assumption to which I suspect Cavell is actually committed.

What should we say about peoples for whom skepticism, as Cavell understands it, simply does not manifest, whether in art, music, philosophy, or literature? We could reject the premise of the question, dig in our heels, and simply insist that the basis for skepticism must be found in all peoples in all times: separateness is, after all, supposed to be the human condition. On the other hand, we might accept that while it appears as though skepticism as Cavell understands it is not a ubiquitous anthropological phenomenon, all language users have a relation to the possibility of skepticism. The right response to this is to say, "yes and no". In a purely formal sense, of course, all language users can be said to have such a relation, if only because, as I have already maintained in agreement with Cavell, no incommensurability thesis is forthcoming that would show that it is theoretically "impossible" to formulate skepticism within some mode of thought in which, as of yet, skepticism does not presently arise. There is, moreover, no logical guarantee that given enough time, we might also get them to be troubled by philosophical skepticism, in particular through arguing for (or "persuading" them of) the correctness of the modern model of our epistemological predicament, and of the generally Cartesian understanding of selfhood implicit in that model. But what should we say about the fact that, as of now, many people do not seem to fall into epistemological quandaries of the sort characteristic of skepticism? Do we want to rest our whole case for universality on such a thin notion, that they have a relation to skepticism as a merely formal possibility (which really amounts to a lack of a formal impossibility)? Should we say that "their" possibility of skepticism is just like "ours", but that we really do succumb to it on occasion, whereas it just so happens, as a matter of fact, that they don't? Isn't this difference significant? We could try to explain this difference by saying that the reason they don't worry about the catastrophic failure of knowledge is that knowledge is not important to them. That seems wrong to me. Maybe it would be better to say that their relationship to knowledge is a very different one from ours. But then how might we try to account for this? By viewing them as primitive, child-like, superstitious, or repressed because they do not act like we do and have difficulty understanding how and why someone could worry about such things? Strathern writes aptly here that

[A] disjunction between the ideal and the real or between ideology and practice is in the first place a disjunction between different types of data within the anthropological narrative. This differentiation is 
taken as evidence for what might be judged as concealed or revealed in the culture. But again we have to be clear that we are talking about what the outsider would regard as concealed, and not about the relationships and structures that the actors deliberately conceal from themselves. To repeat on observation made earlier, people cannot conceal from themselves what they do not know. ${ }^{223}$

But I can already hear the objection: "Fair enough, but whether they know it (and repress it, or not) the human condition is as it is: separate". Such a dogmatic response would come close to maintaining that, the historical and ethnographic work be damned, the human self is just "there" like a natural kind, and our use of "I" has always referred to it, rigidly, as it were; as a group, we moderns just happened to be the first to catch on to this fact. How exactly we pulled off this miraculous feat of insight de novo, where others before and after had failed (or fled), is, well, pretty miraculous. Yet if we allow that historically specific practices were constitutive of what we are talking about when we speak of a self as we have commonly come to do, as a psychological entity logically walled off from the world, if, that is, we allow in the present case that ontological categories track cultural ones, ${ }^{224}$ then this self starts to look like a historically emergent entity (my avoidance of "socially constructed" is intentional).

Cavell's thought seems merely to recapitulate the idea that there is an inevitable connection between the arrangements of modernity and human nature itself. For all of his brilliance and originality, he seems to be another in a long line of adherents to the implausible outlook that Taylor calls a "subtraction story", whereby "we naturally come to think that we have selves the way we have heads or arms, and inner depths the way we have hearts or livers, as a matter of hard, interpretationfree, fact". ${ }^{225}$ Anticipating Taylor by several years, Geertz remarks on this widespread tendency to take for granted a common denominator of self-understanding:

In the Enlightenment case, the elements of this essential type were to be uncovered by stripping the trappings of culture away from actual men and seeing what then was left - natural man. In classical anthropology, it was to be uncovered by factoring out the commonalities in culture and seeing what then appeared - consensual man. In either case, the result is the same as that which tends to emerge in all typological approaches to scientific problems generally: the differences among individuals and among groups of individuals are rendered secondary. Individuality comes to be seen as eccentricity, distinctiveness as accidental deviation from the only legitimate object of study for the true scientist: the underlying, unchanging, normative type. ${ }^{226}$ 
Although it would he highly misleading to attribute a standard Enlightenment subtraction story to Cavell, according to which the stripping away of the conventional accretions of culture reveals us to be a disengaged Lockean shopkeeper, his corpus remains a subtraction story in the end, even if a labyrinthian one: it's just that what was there all along waiting to be liberated from the oppressive bonds of tradition was not a rational soul, but a compulsive neurotic. The story that most philosophers have told themselves amounts to a final Victorian cover up of the awful truth: that deep down the whole time we were all Alvy Singer. So much for eschewing with explanations in philosophy.

\section{C}

Given the stark contrast between Taylor's historical sensibility and what I take to be Cavell's basically ahistorical attitude, it may be surprising to note that in one respect at least, Cavell's view of the self may in fact be close to a position that Taylor has advocated in some of his earlier work on relativism in the social sciences. Taylor has criticized Peter Winch's argument that the religious and magical practices of cultures such as that of the Azande are immune to external criticism, especially modern scientific criticism. Winch accused those who would make such external critiques of committing a logical blunder rooted in ethnocentricity, by which he meant in part that religious and magical practices and scientific practices are conceptually heterogeneous. ${ }^{227}$

It should be clear by now that I have little sympathy for this sort of maneuver. Yet Taylor points out that Winch's attempt to avoid ethnocentricity betrays its own type of ahistorical thinking. Taylor contends that Winch's taking for granted a purely expressivist symbolic view of religion and magic is in fact alien to the very cultures whose traditions he seeks to shield from scientific criticism. Winch's point was that because religion and magic are purely expressive activities on the one hand, while science is in the business of getting things right about nature on the other, to attack the former by employing standards taken from the latter is to commit a category mistake. ${ }^{228}$ Taylor rightly objects to this move on the grounds that Winch's own position actually depends on the anachronistic imposition of a modern sharp fact-value distinction onto systems of thought where the factual and expressive were not clearly distinguished. ${ }^{229}$

Taylor does not stop there, however. He goes on to claim that modern science can score "objective points" against the Azande or the Renaissance magus, since the modern scientist can clearly provide a superior account of disenchanted nature. I find it strange for Taylor to make this argument just here, since it involves a move that at least looks structurally identical to the one for which he criticizes Winch. This is because making the judgement that the modern scientific descriptions of nature are better simpliciter involves a prior commitment to the overall legitimacy of a fact 
value distinction. Obviously, once that prior distinction is accepted, then certainly modern science can be judged to be superior to the enchanted understanding. In general, if one wishes to compare two substantially different conceptual systems in some respect, the more discontinuity that one can disregard, the easier it becomes to imagine the comparison between them as being truth apt; it is easier to articulate continuity and commensurability if there already is some taken-for-granted continuity and commensurability. ${ }^{230}$ Yet as Taylor himself argues, fact and value were not understood as sharply separated before the modern period, and so his claim that modern science explains the world more successfully than could the Renaissance magician, while true, seems to presume that we can already see the disenchanted understanding of nature as implicit in and continuous with the renaissance worldview. And this in turn requires that we are able to see the two aspects for ourselves as already factored even before they became factorized for us. But this is in essence precisely what Taylor rejects in his criticism of Winch's argument from incommensurability. More peculiar still, Taylor explicitly denies the very idea of the overall "global superiority" of the modern fact/value distinction over the pre-modern integrated view, which is precisely what assuming the objective superiority of the results of disenchantment would seem to require. ${ }^{231}$ The upshot is that connecting Taylor's articulation of realism in thinking about natural kinds across conceptual and historical differences won't make the case for realism about the self in Cavell's work any stronger.

Someone might object that my criticisms of Taylor on this point serve only to bring out that I am neglecting a relevant difference between the kind of cases he is addressing, which concern natural kinds in the "external world", and the present case of the emergence of the understanding of the modern punctual self. That is, someone might feel that the question of continuity vs. discontinuity in our thinking about the modern self is somehow of a different order from the intelligibility of a purported natural kind claim made before and after a conceptual change, and that the significance of this difference in turn might undermine my problematizing the presumption of continuity. After all, it might be argued, we are not merely discussing how to understand the conceptual relations between systems of statements made before and after Copernicus that refer to the heavens. Rather, we are discussing an indispensable condition of the possibility of modern scientific discourse at all: the punctual self of modern epistemology. Well, maybe. But I hardly think an indispensability argument will help with this debate over the historical emergence of the modern self in a way that will aid a Cavellian articulation for realism here. Perhaps it's true that the unity (separateness) of the Kantian (Cavellian) self is a condition of the possibility for our scientific talk about natural kinds. (After all, "what is more obvious than that a [metaphysically separate] subject is related to [a scientifically intelligible] object and vice versa?" $)^{232}$ Yet since realism of the type defended by Taylor against 


\section{2}

Winch already depends on the inherently precarious status of modal claims about "what we would say or think" about some object in contexts like the one described in Hilary Putman's "Twin Earth" thought experiment, I think we should be doubly careful if instead we are discussing something akin to an epistemological condition of the possibility of making statements about such natural kinds. ${ }^{233}$ Employing an indispensability argument for maintaining realism about the self of (scientific) epistemology, involves trying to bolster one sort of modal claim, what we should say about the nature of the self, with the purported fact that it allows us to make another sort of modal claim, what we would say about natural kinds in science. It seems to me that the right response here is call for more caution, not less. ${ }^{234}$

I have been focusing thus far on a metaphysical interpretation of the modern self, as something understood on the order of a natural kind that was eventually uncovered. However implausible I believe this view is, it is the one that I think best captures Cavell's actual commitments based on what he writes. Nevertheless, there are alternatives, which, though they actually have less textual basis, need to be addressed, particularly as they represent interpretations that I suspect many of Cavell's sympathizers draw from his writings. That is, someone might take me to task and assert that my treatment of Cavell's numerous pronouncements about separateness is ham-fisted. What look like Cavell's conclusions are not really intended as full-throated quasi-empirical statements about what is the case with regard to our concept of the self, but are instead meant to change our perspective, to advocate for a certain grammar for talking about the human. This advocacy depends not so much on our apprehending the changeover from the porous self to the buffered self as a smoothly continuous and perhaps even inevitable process, so much as it relies on our coming to regard it as such. In this vein, consider this passage from the introduction to the Claim of Reason,

In reaching his decision, the judge is obliged, in faithfulness to his office, to be open to and to provide arguments of an institutionally recognizable character; and the point of such argument is to allow, if possible, a natural extension of the body of law, which is neither merely applying existent law nor simply making new law. The guiding myth must be that it is not the judge but the case itself which extends the law. 235

Given the centrality in his thought of the idea that criteria are never selfapplying, it's unclear to me to what exactly Cavell means with "merely applying existent law". Setting that issue aside, however, this passage might suggest that I have narrowed the possible space for articulation far too drastically. That is, Cavell's description of the dynamics of a judge's decision could be taken to indicate a way of seeing the change from 
porous to buffered as neither a determinate process ("merely applying existent law"), nor as an arbitrary exercise of will ("simply making new law"). The point would be that with the right articulation we might come to regard the emergence of the modern separate self of skepticism as, in some sense at least, always having been part of the human condition (the "guiding myth"), and not as a fundamentally contingent, historical, and discontinuous phenomenon.

I see two ways that one might try to defend this view. Neither are convincing. First, Cavell (or Cavellians) may readily grant that the metaphysical realist picture of the modern self as involving a type of discovery is indeed far-fetched. That is, they could try to persuade critics that, while it is true that we lose our grip on the very idea of there being a separate self if we insist on regarding it as a practice independent ontological matter of fact, the cultural development that has made talk of the emergence of the modern self comprehensible for us was itself somehow inevitable, and was not an historical turn that things happened to take in the modern West. The evolution of the idea of the self as buffered is built into the grammar of our language. Presumably this view also requires us to believe that the same is true, or will be true, if we just wait long enough for other societies who appear to be lagging behind us in interiority. There are familiar and insurmountable epistemological problems with this Whiggish idea of inevitable development. Of course there was a change in the Western conception of the self. This is not in dispute. What is in dispute is what basis there could be for claiming we can discern an inevitable law of historical development from porous to buffered (or any other supposedly necessary historical development, for that matter).

The second interpretation is that Cavell's real purpose is to shift our moral and aesthetic perspective; reasonable people simply should come to regard the emergence of the modern self as continuous with their more porous past (and perhaps to see that conception of the self as implicit in the non-buffered present of other present-day societies). In this case, there would be no pretense that Cavell provides an articulation such that, as some kind of independent matter of fact, it is continuous. Unfortunately, this charitable interpretation, a narrative in which Cavell attempts to foster a Gestalt-switch, is belied by most of his actual rhetoric. When he speaks about the genuine human predicament being one of metaphysical isolation, he doesn't hedge his bets on subtle issues of "seeing-as". One finds many more flat-out assertions in his corpus about separateness being the human condition per se, than one finds pleas for seeing this condition in one way rather than another. Now someone could propose that the explanation for why Cavell never makes his real strategy explicit is that his goal is to change his readers' perspectives, not to announce that he is trying to do so; being open about this might be ineffective in convincing the recalcitrantly porous in the West and elsewhere, those many millions who still haven't gotten the message that secular liberalism 


\section{Skepticism and the Human Condition}

née New England Unitarianism just obviously is the view of the human condition acceptable in polite company. But since most of these great unwashed are probably beyond hope anyway, it may also be the case that Cavell is neither trying to nor needs to change their perspective. What then? Well, I assume there will always be enough right-minded folks in respectable humanities departments who never tire of hearing their common sense views repeated back to them, even when, or perhaps, precisely when, the recounting takes the often convoluted guise of Cavell's prose. Traversing these circuitous pathways may serve to reinforce the impression in the reader that he has actually discovered something (all over again). There is no harm in this per se, I suppose, but it could suggest an unflattering picture of Cavell as a kind of clever propagandist. ${ }^{236}$ When I imagine someone confidently asserting, "We can thus come to see that the modern self was, so to speak, continuous with the pre-modern past, even if not as a self-evident matter of fact", I want to ask: Who is this "we"? What if some of us, me, don't quite manage to see this continuity? What should we say then? Perhaps my inability to see the punctual self as continuous with the porous past could be taken as evidence of poor intellectual pedigree. I guess I should have held on to my 66' Mustang and Aerosmith tapes after all. (Is this a Weltanschauung?)

\section{XI}

On Cavell's picture, most of the ontological stage-setting for the tragedy of skepticism is already in place long before the philosopher, or actually any human agent, steps onto the scene of conscious life. The epistemologist's elaborate theories are merely one intellectual form of evasion or diversion from the real problem, which is our finitude. As we have seen, moreover, Cavell believes that our finitude is coextensive with our intolerable separateness, our human condition of "metaphysical isolation". Since I have gone to great lengths to undermine the universality of Cavell's portrait of the human self, it might therefore seem as though I were denying that there is anything like a human condition at all or that there are genuine problems of human finitude. In truth, I am merely questioning whether a certain subset of these problems ought to be ascribed to the human condition. Although many modern Westerners and others whose formation has been substantially marked by Western modernity may respond to finitude by fleeing into skepticisms of various stripes, there is more than one manner of responding to human finitude. This, in fact, is one of the most important and fascinating lessons that studying the world's cultures, especially their religions, teaches. It is simply not given that this includes living with a relationship to skepticism in anything but the thinnest of senses. Human finitude, I want to say, reaches deeper into the human than the possibility of skepticism. As I see it, it's better to think of "finitude" as working more like a proper name, whereas 
"separateness" works only like a contingently associated description that indicates one mode of presentation for how finitude gets worked out or experienced, i.e. in the modern West and its cultural satellites.

If reflection on history and ethnography supports the idea that the self of skepticism is not part of our facticity, but rather one relatively recent interpretation of the human condition, then we are faced with a normative question about how we should relate to this interpretation. Yet this way of putting the matter makes it sound as though the key issue is whether we want to choose another such relation. Some no doubt would assume that if the self of epistemology is not necessary, then it must be a merely arbitrary social construct, which we can simply dispense with through an act of will, for example, by changing our vocabulary. But framing things in terms of choice makes our predicament appear far simpler than it is. Bringing to light that our modern self-understanding is fundamentally historical, and so in a certain sense conventional, certainly implies that we are not locked into this interpretation as a fact of nature, but it in no way implies that we collectively or individually could easily dispense with this interpretation. It lies too deep in our mode of thought for any philosophical or psychological act of cosmetic surgery to be credible.

But if it's premature to talk about realizing concrete possibilities for change, it is still important to ask whether our assumed condition of necessary isolation comes at a price. Since I am enough of a traditionalist to believe that there is an inherent value in being clear about the truth of one's predicament, whether or not there is anything obvious that can or should be done about it (and no, nothing I have said deprives me of the right to use "truth" here), anything that obstructs such clarity is already too high a price to pay. I believe the widespread uncritical acceptance of an interpretation of ourselves as metaphysically separate certainly satisfies that criterion. When it comes to professional philosophy, moreover, the sad fact is that the epistemological present remains so colonized by a buffered picture of the mind-world relationship, a sophisticated variant of which lies at the heart of Cavell's work, that the effect of encountering an alternative articulation even remotely smacking of its rejection tends to elicit at best a polite smile of the sort one gives to a crazy person on the bus. Maybe one ought not be surprised if attempts to explicate the meaning of a pronouncement such as "being-in-the-world is a unitary phenomenon" are met with a certain amount of amused condescension..$^{237}$ But such reactions are not limited to the likes of Heidegger. Consider the following passage from the introduction to Mind and World:

Conceptual capacities, whose interrelations belong in the sui generis logical space of reasons, can be operative not only in judgements results of a subject's actively making up her mind about something but already in the transactions in nature that are constituted by the 
world's impacts on the receptive capacities of a suitable subject; that is, one who possesses the relevant concepts. ${ }^{238}$

Given how entrenched the picture of the buffered self is in the intellectual life of the West, it's hardly surprising when words like these are met with a suspicion like that which modern philosophers once reserved for medieval obfuscation. There is also no doubt that some of the details of McDowell's view as laid out in in Mind and World are disputable. But if we resist naturalist dogma while granting some demands for revisions in his story, what is the principled reason for excluding out of hand the idea that nature is not radically heterogeneous with the mind? I think the tenacity of the traditional picture at our stage of intellectual history ought to be at least as questionable, given that it has led to one intellectual cul-de-sac after another.

The next downside of our general lack of historical perspective on the modern understanding of the self relates to the socio-political plane. I complained previously that Cavell, in practice at least, endorses the validity of a subtraction story according to which the modern buffered self was always (and still is) there, if only we could strip away the inconvenient and usually illiberal camouflage of culture, religion, and history that smother it. Another way I put this view is to say that he takes secularity for the human condition. By now it should be clear that I consider such a position to be blatantly ahistorical and without any adequate backing. Against this, the historian and anthropologist Louis Dumont argued that Western secular modernity is uniquely characterized by the collapsing of an ancient distinction. Up through much of the Middle Ages, a person was understood in terms of two distinct hierarchies, or levels, of value: the divine and the mundane. At the divine level, all persons were equal individuals in the eyes of God. Dumont describes the person here as the "outwordly individual". At the social level, however, persons were understood as fundamentally defined by their worldly relations and duties. ${ }^{239}$ According to the traditional hierarchy, therefore, while in everyday life a person was unintelligible apart from his or her nexus of social relations, the outworldly individual was conceived of as a singular spiritual entity in relation to God alone.

On Dumont's account, however, what characterizes secular modernity is that, while the divine level in the two-tiered value hierarchy is abandoned for a single-level plane of everyday life, the conception of the individual that formerly was valid only at that sacred level is retained and now comes to occupy the center stage of the now disenchanted world. The older mundane view of the person as constituted by social relations either fades to the background or disappears altogether. ${ }^{240}$ Secularism is thus the view that there is only one world, consisting of "in-the-world" individuals. It is not my aim here to evaluate the relative merits of secular modernity, but I do think that the uncritical adoption 
of this picture, however commonsensical for many, is not only intellectually dubious, but practically disastrous when it gets unconsciously (or at this point is it willfully?) imposed on people who are not quite the buffered in-the-world individuals one takes them for. This confusion often ends up either in self-flagellation on the one hand, blaming ourselves when "they" don't display the common sense habits of good buffered moderns, or demonization on the other, viewing "them" as somehow inherently defective. It seems to me that no small amount of our current political strife is due to the inability or refusal to take culture seriously.

I have been using Taylor's expressions "buffered self" or "punctual self" in ways that are meant to encompass Cavell's conception of "separateness". In one way this could be misleading if only because Taylor usually has in mind perspectives inspired by rationalists like Descartes, Locke, and Kant and not those embodied by figures like Tracy Lord or Nora Helmer. Yet however different in complexity and motivational structure these dramatic characters are from the wooden notions of human agency on offer from the philosophers, the metaphysical-epistemological predicaments of these two groupings remain fundamentally comparable. I mention this because undoubtedly much of the difficulty with seriously contemplating the possibility of allowing a loosening of the grip that the buffered, separate picture exerts on our lives stems more from lived ethical rather than abstract metaphysical concerns; anyone who has read extensively in Cavell's works recognizes in them a constant worry about the possibility of social and political oppression. He often seems less concerned with private language than with privacy. But while any fair assessment of what I have been arguing will conclude that its sole logical implications are the deflation of the metaphysical individualism we've inherited from our tradition, the usual intertwining of the ethicopolitico with the ontological may leave some readers with an uneasy feeling that I've paved a short path from release from metaphysical isolation to denying village atheists their rights. Well, perhaps there is a noticeable tendency toward intolerance and oppression among peoples where the dominant self-understanding is decidedly non-porous. But can we be so certain that any way of coming to terms with human finitude that does not foster a genuine relation to the possibility of skepticism is a recipe for oppression? What do we really know here? If it seems obvious that history suggests we should err on the side of caution, we should at least ask if that caution comes at a price. Refusing even to ask is the ethics of resignation.

Many years ago, I described the idea for this essay in a long e-mail to an acquaintance who is both philosopher and anthropologist. As I recall, she wrote back that the basic conception struck her as generally coherent, but she finished her response with a remark that made me uncertain. It ran something along the lines of, "It's important to 
remember, though, that the individual is very important for intimacy in relationships". I think one reason for my uncertainty was that the remark jumped ahead of anything I had actually said when I described the plan of the essay. In particular, nothing in my outline directly entailed any normative conclusion to the effect that the modern (Cavellian) understanding of the self ought to be jettisoned once its contingency had been uncovered. It is entirely possible that I had expressed my conclusions with such enthusiasm that it was natural for her infer that I thought that the historical contingency of the self of skepticism somehow entailed that we should dispense with that conception. People do sometimes argue that way. However it was that my acquaintance came to ascribe such a view to me, if indeed that is what she did, I hope that I have made it clear both that dispensing with the modern conception of the self is not something that can be achieved by an act of willpower and that the normative questions surrounding how we ought to relate to its contingency are complex.

But undoubtedly what took me most by surprise in my acquaintance's remark was its confident declaration of a positive correlation between separateness and intimacy. It struck me as counterintuitive that intimacy and separateness should be complementary or mutually supporting phenomena, since on the surface at least the two seemed to be opposing forces. How can you be intimate with a metaphysically separate other? Yet, at the same time, part of me (the buried Romantic?) also had a vague sense that there was something correct in the suggestion that intimacy and isolation were mutually reinforcing vectors. It is only recently, when writing this essay, that I believe I grasped the significance of what my acquaintance wrote. If isolation is typical for our modern condition, then intimacy typically arises against a certain social imaginary, where separate souls sometimes find themselves drawn across an abyss to share their isolation. This Romantic pre-understanding allows for the emotional tectonics many have come to see as essential for genuine intimacy. In other words, I regard "The individual is important for intimacy in relationships" as a grammatical remark characteristic of the culture of Western modernity. The remark simply recounts (for many at least) part of what is meant by "intimacy". I suspect there are still others, people whose sensibilities resonate with the likes of Young Werther or Holden Caulfield, who might insist that one can only be intimate with a metaphysically separate other. However that may be, I am confident that I have shown that the Cavellian view of the human condition is only conditionally valid. I have not, however, addressed the more important question as to whether our quasi-addiction to its charms has become corrosive of other relations. Am I gesturing at a culture with no romantics? Heaven forbid. But better that than a culture dominated by politicized neurotics. I guess that is a Weltanschaunng. 


\section{Notes}

1. Franz Boas, Race, Language, and Culture (Chicago: University of Chicago Press, 1940), 636.

2. See Thomas Kuhn, The Structure of Scientific Revolutions, 3rd ed. (Chicago: University of Chicago Press, 1996); Paul Feyerabend, Against Method, 3rd ed. (London: Verso, 1993). See also C. B. MacPherson, The Political Theory of Possessive Individualism (Oxford: Oxford University Press, 1964).

3. See for example, Charles Taylor, Modern Social Imaginaries (Durham: Duke University Press, 2004), 18, 62, 147.

4. I see the distinction between conceptual and cultural change as an important one to make, both because I see conceptual change as one form of cultural change, and because I want to hold open the possibility of cultural change at a level that can give rise to conceptual change.

5. Michael Williams, Unnatural Doubts: Epistemological Realism and the Basis of Skepticism (Cambridge: Blackwell, 1996).

6. Two of the main defenders of the epistemological tradition, whom Williams called the "New Humeans", are Barry Stroud and Thomas Nagel. See Williams, Unnatural Doubts, xiii-xiv. Stroud in particular, defended the cogency of the traditional epistemological requirement for a justification in general for our knowledge. See Barry Stroud, "Understanding Human Knowledge in General," in Knowledge and Skepticism, ed. Marjorie Clay and Keith Lehrer (Boulder: Westview Press, 1989), 31-50; Thomas Nagel, The View from Nowhere (Oxford: Oxford University Press, 1986).

7. Williams, Unnatural Doubts, 73-79, 218.

8. Ibid., 31-32, 40-45, 108.

9. Ibid.

10. A small irony here is that Williams does not realize that Cavell's discussion of the sort of context-free claim that Descartes wants to enter about a generic object, a piece of wax, comes very close to attributing epistemological realism to Descartes. This is because on Cavell's view, the idea that there is such a context for a knowledge claim about the existence of the piece of wax relies on the idea of self-applying criteria, and this, it seems to me, comes very close to Williams' description of the conditions of epistemological realism, viz. that knowledge is a natural kind, and thus the kind of thing with a structure whose description presupposes nothing about us. Barry Stroud, The Significance of Philosophical Scepticism (Oxford: Clarendon Press, 1984), 262 makes a claim against Cavell similar to Williams' objection, but I think the same thing can be said regarding epistemological realism and self-applying criteria in relation to Stroud. See Williams, Unnatural Doubts, 151-55.

11. Williams, Unnatural Doubts, 32. See Stanley Cavell, The Claim of Reason (Oxford: Oxford University Press, 1979), 45-46. Henceforth "CR". See also Stanley Cavell, This New Yet Unapproachable America: Lectures After Emerson After Wittgenstein (Albuquerque: Living Batch Press, 1989), 43; Stanley Cavell, Conditions Handsome and Unhandsome: The Constitution of Emersonian Perfectionism (Chicago: University of Chicago Press, 1990), 35.

12. CR, 241.

13. Ibid., 45. Later in the essay I will give this "truth" a different formulation.

14. CR, 46. See also Cavell, Conditions Handsome and Unhandsome, 77.

15. $C R, 45$.

16. Immanuel Kant, Critique of Pure Reason, trans. Norman Kemp Smith (New York: St. Martin's Press, 1965), 34.

17. Martin Heidegger, Being and Time, trans. John Macquarrie and Edward Robinson (New York: Harper and Row, 1962), 249. 
18. $C R, 456$.

19. Stanley Cavell, Disowning Knowledge: In Six Plays of Shakespeare (Cambridge: Cambridge University Press, 1987), 3. I share some of Anthony Palmer's suspicion that Cavell's bold claim here is somewhat anachronistic, but that is not a point I will explore. See Denis McManus, ed., "Scepticism and Tragedy: Crossing Shakespeare with Descartes," in Wittgenstein and Scepticism (London: Routledge, 2004), 260-77. Cavell responds to Palmer in the same volume. See Stanley Cavell, "Reply to Four Chapters," in Wittgenstein and Scepticism, ed. Denis McManus, 278-91 (London: Routledge, 2004).

20. Stanley Cavell, Pursuits of Happiness: The Hollywood Comedy of Remarriage (Cambridge: Harvard University Press, 1981), 109.

21. Cavell, This New Yet Unapproachable America, 54.

22. Ibid.

23. Ibid., 57.

24. Kant, Critique of Pure Reason, 7.

25 . I should say at the outset that I while I clearly take issue with Cavell's diagnosis of what underlies skepticism, for the purposes of this essay I am assuming the basic correctness of his identification of the phenomenon of skepticism itself, which in his hands takes on a distinctively Cartesian tenor. This is not something, however, that one ought simply to accept uncritically in all contexts. On this, see James Conant, "Two Varieties of Skepticism," in Rethinking Epistemology, ed. Guenter Abel and James Conant, vol. 2 (Berlin: Walter De Gruyter, 2012), 1-73.

26. Cavell sometimes mockingly refers to "external world" skepticism, preferring instead the term "material object" skepticism. I have no preference one way or the other and will use them interchangeably.

27. See for example, Stanley Cavell, In Quest of the Ordinary: Lines of Skepticism and Romanticism (Chicago: University of Chicago Press, 1988); Cavell, This New Yet Unapproachable America; Cavell, Conditions Handsome and Unhandsome.

28. Cavell's, Must We Mean What We Say? A Book of Essays (Reference Chapter 1, note 50), Pursuits of Happiness, Disowning Knowledge; Stanley Cavell, Contesting Tears: The Hollywood Melodrama of the Unknown Woman (Chicago: University of Chicago Press, 1996).

29. CR, 133-35.

30. Ibid. See also Cavell, Wittgenstein and Scepticism, 279.

31. $C R, 439$.

32. Ibid., 353.

33. Stanley Cavell, "What Is the Scandal of Skepticism?," in Philosophy the Day After Tomorrow (Cambridge: Belknap Press, 2006), 149-50.

34. CR, 439.

35. Ibid., 432 (emphasis in original).

36. Ibid., 437. See also CR, 453, Cavell, Wittgenstein and Scepticism, 287 and In Quest of the Ordinary, 127. In the same work (cf. 55) Cavell also briefly raises the question about the relation between the two kinds of skepticism and whether one of them is perhaps more fundamental than the other. Based on various statements he has made over many years, I am frankly uncertain whether Cavell believes there is something like a best case for knowledge (or acknowledgement) of others' minds. But my uncertainty could merely reflect Cavell's own ambivalence about the question. (Cf. Stephen Mulhall, ed., The Cavell Reader (Cambridge: Blackwell, 1996), 137) And this alone may be his way of conveying that the concept of a best case of acknowledging another (generic?) mind is so unclear as to be unusable in a diagnosis of other-minds 
skepticism. Perhaps the line of reasoning runs as follows: We are normally interested in individual mental states (e.g. love, anger, resentment) of individuals and not in some general issue of mentality (although Cavell's occasional talk of automata suggests we might be interested in that too). Since it is unclear what the best case of a generic mental object might even be with regard to a phenomenon that seems to be inherently particular, I can coherently live my skepticism about individuals without it generalizing to everyone. So, while I find it hard to discern what his position would be regarding the livability of a global other-minds skepticism, Cavell evidently does believe that in individual cases we find it quite possible, even easy in many instances, to behave towards other individuals as if the obscurity of their particular mindedness were of no great matter to us. At any rate, the kind of skepticism of other minds I can or do live presumably is not one of a world of zombies but of individual cases.

37. $C R$, xxi. See also $C R, 144$.

38. I have the term "punctual self" from Charles Taylor. See his Sources of the Self: The Making of the Modern Identity (Cambridge: Harvard University Press, 1989), 49, 171.

39. Cavell, Pursuits of Happiness, 58-59. At the risk of wading into current rancorous debates about the relations between sex and gender, for my brief discussion here I will retain the two concept pairs of male/female and feminine/ masculine. It seems to me that Cavell's own discussion often navigates a bit ambiguously between these two pairs of concepts, one of the pair being more biological the other being more social. Although he certainly gives the social its due, in other places a more biological emphasis is apparent. See for example Contesting Tears, 98 where he writes of the possible "role of the human body in the sceptical so-called problem of other minds".

40. Cavell, Disowning Knowledge, 15-16. This passage reflects well the ambiguity I mention in footnote 39. See also Conditions Handsome and Unhandsome, 119 where Cavell reiterates the consideration that skepticism may be inflected by gender. See also Contesting Tears, 100.

41. Cavell, In Quest of the Ordinary, $\mathrm{x}$.

42. Cavell, Disowning Knowledge, 16. See also Cavell, Contesting Tears, 101.

43. Cavell, Disowning Knowledge, 17.

44. Ibid., 29 (emphasis in original).

45. Ibid., 230.

46. Ibid., iii.

47. Ibid., 224. Later in the same essay Cavell ponders his "general sense of these plays as history plays about a break in history, as turns in the history of privacy, or say skepticism, hence in the history of marriage, hence in the history of legitimacy and succession" Disowning Knowledge, 245.

48. Cavell, In Quest of the Ordinary, 128.

49. Stanley Cavell, Appropriating Heidegger, eds. James E. Faulconer and Mark A. Wrathall (Cambridge: Cambridge University Press, 2000), 34.

50. Cavell, Wittgenstein and Scepticism, 281. In 2006 while considering the possible postmodern disappearance of skepticism, Cavell recalls "an older question of mine, namely whether skepticism requires historical conditions or whether the fate of possessing language, pursuing the life form of talkers ... is condition enough". Stanley Cavell, "What Is the Scandal of Skepticism?" in Philosophy the Day After Tomorrow (Cambridge: Belknap Press, 2006), 140.

51. In contrast to Taylor, a "Cavellian" subtraction story will not be one which terminates with some kind of Chicago School economist. The self in Cavell's writing is always less Game Theorist, more Lear, more Gregor Samsa. 


\section{Skepticism and the Human Condition}

52. Most of my summary here draws on the first two parts of the Claim of Reason, where the main topic is material object (external world) skepticism. I do not discuss Cavell's criticisms of the kind of view represented by Rogers Albritton or Norman Malcolm, but focus instead on Cavell's criticisms of J. L. Austin. For a nice overview of this material see Chapters 1-2 in Espen Hammer, Stanley Cavell: Skepticism, Subjectivity, and the Ordinary (Cambridge: Polity, 2002).

53. Cavell is responding to Austin's paper "Other Minds". See Philosophical Papers (Oxford: Oxford University Press, 1970), 76-116. For Cavell's critique, See CR, especially 65-77, 132-37.

54. The instrument clusters on the dashboard were also quite different and the gas caps were slightly different as well.

55. CR, 52-53.

56. Of course, it is not unthinkable, either, that someone has fitted a ' 66 Mustang with the grille and quarter panels of a ' 65 .

57. $C R, 133,135$. Elsewhere he writes, "The logic of skepticism requires two things chiefly: that knowledge be discovered to fail in the best cases - in knowing, for example, that I am seated before my fire, or that two plus three is five; and that this failure be discovered in ways open to any normal human being, not something knowable only by experts." Stanley Cavell, "What Becomes of Things on Film?" Philosophy and Literature 2, no. 2 (Fall 1978): 251.

58. CR, 45. This passage comes from Cavell's arguments against Albritton and Malcolm, but I think they are entirely appropriate in the present context as well (emphasis in original).

59. This is adapted from the schema provided by Cavell on CR, 132. There, of course, he is discussing Austin's goldfinch example. The references to the senses and the dream/hallucination possibility are mentioned at CR, 135 .

60. $C R, 135$.

61. Ibid., 84. The original context for this phrase concerns other-minds, but I take it to hold generally for Cavell.

62. CR, 94. This point is utterly central to Cavell's entire project. Here I can only present it in its barest aspect.

63. CR, 205.

64. Ibid., 211.

65. Ibid., 206.

66. Ibid., 215.

67. Ibid., 217.

68. Ibid., 220.

69. Ibid., 239 (emphasis in original). Compare this passage with the following one from a decade earlier: "One wants to say: What it envisions is unintelligible. But what is envisioned which is unintelligible? It looks as if to make out that it is unintelligible you have to do exactly what the person who claims to envision it has to do - say what is envisioned. But it is exactly your point that this cannot be done." "Knowing and Acknowledging" in Cavell, Must We Mean, 249. In each of these passages one can hear clear anticipations of what has come to be known commonly as the "resolute" reading of Wittgenstein.

70. See Stanley Cavell, "Declining Decline," in This New Yet Unapproachable America: Lectures After Emerson After Wittgenstein (Albuquerque: Living Batch Press, 1989), 41. In this essay, Cavell broaches two ways of taking Wittgenstein's term of art "form of life" (Lebensform) as that term is employed in the Philosophical Investigations. What he says there about "ethnological" and "biological" senses of Lebensform suggests to me that he would resist a clean factorization of what I refer to here as the linguistic and the creaturely. 
At the same time, I think Cavell's description of the ethnological dimension of form of life in this essay as "conventionalistic" and so merely "horizontal", as opposed to the "biological" and so "vertical" dimension of that unified whole is deeply misleading. In fact, it was my encounter many years ago with the claims made by Cavell in that essay that set me on the course to write the present work. My point here, however, is merely that there is some textual basis for believing Cavell would not object to my handling of the neologism "creature-with-language".

71. CR, 493. A decade prior to The Claim of Reason we see the same sentiment expressed: “(M)y powerlessness presents itself as ignorance - a metaphysical finitude as an intellectual lack." Knowledge and Acknowledging in Cavell, Must We Mean, 263.

72. The Availability of the Later Wittgenstein in Cavell, Must We Mean, 61-62.

73. CR, 47.

74. The Skeptical and the Metaphorical. Cavell, In Quest of the Ordinary, 148.

75. Stanley Cavell, "Something Out of the Ordinary," Proceedings and Addresses of the American Philosophical Association 71, no. 2 (1997): 28.

76. Stanley Cavell, "Benjamin and Wittgenstein: Signals and Affinities," Critical Inquiry 25, no. 2 (1999): 237.

77. Cavell, "What Is the Scandal of Skepticism?," 133 (emphasis in original).

78. Stanley Cavell, The Senses of Walden (Chicago: University of Chicago Press, 1992), 146-47.

79. $C R, 109$.

80. Cavell, Disowning Knowledge, 11, See also Cavell, Disowning Knowledge, 242.

81. Cavell, In Quest of the Ordinary, 88. See also Cavell, In Quest of the Ordinary, 4, 138.

82. Cavell, This New Yet Unapproachable America, 38.

83. Cavell, Contesting Tears, 94. In 2004 we read "it is human to wish to reject the human." Cavell, Wittgenstein and Scepticism, 283.

84. Cavell, This New Yet Unapproachable America, 54.

85. Ibid., 57.

86. Cavell, In Quest of the Ordinary, 138.

87. The Argument from the Ordinary in Cavell, Conditions Handsome and Unhandsome, 92.

88. Of course, Cavell doesn't just think we will suffer sudden onsets of skeptical insanity. He also believes that skepticism might teach us some lessons about better ways to relate to the world and to each other. He writes that "Whereas skepticism suggests that since we cannot know the world exists, its presentness to us cannot be a function of knowing. The world is to be accepted; as the presentness of other minds is not to be known, but acknowledged." "The Avoidance of Love" in Stanley Cavell, Must We Mean What We Say? A Book of Essays (New York: Scribner, 1969), 324. This passage touches on ideas that are central to Cavell's views on how we might accommodate and cope with the threat of skepticism. But as they are posterior to the underlying ontology of skepticism that I want to examine here, they are not my focus.

89. “The Availability of the Later Wittgenstein" in Cavell, Must We Mean, 52.

90. CR, 45 .

91. On the unending problem of first coming to grips with the reality of this truth Cavell writes elsewhere that, "The answer does not consist in denying the conclusion of skepticism but in reconceiving its truth." Cavell, The Senses of Walden, 133.

92. CR, 140. 
93. Ibid., 141-42.

94. At the time he wrote The Claim of Reason, Cavell quite possibly interpreted his experience of "being sealed off" from the world as close to Heidegger's descriptions of anxiety in Being and Time. Later in the book we read, "It is as though the philosopher, having begun in wonder, a modern wonder I characterized as a feeling of being sealed off from the world . . . is left only with his eyes, or generally, the ability to sense." $C R, 224$. And still later, "Why Is There Anything at All? " - the recording, again, of an experience I confess having had, and which seems to me related to, even to express, the sense of the philosopher's question "How do we know at all that anything exists?" $C R$, 241. Now it is true that Heidegger connects anxiety and wonder in Being and Time and in the 1929 lecture "What Is Metaphysics" he explicitly connects both of these to the question "Why is there something instead of nothing?" But to insinuate any connection with Heidegger in the way I suspect Cavell is doing in these passages is just wrongheaded (or worse). Heidegger may say such things as that anxiety "individualizes" Dasein and thus reveals the world as offering nothing to Dasein, but this is precisely his way of bringing out how in anxiety what he calls the "worldhood-of-the-world" obtrudes itself. That is to say, in anxiety Dasein sees that it is in a world of publicly interpreted equipment and practices and that none of these can provide it with meaning for its own life. There is no question there of being "sealed in" or "sealed off": "drowning” is perhaps more apt. Giving a Cartesian inflection to "anxiety" by speaking of "modern wonder" as Cavell does may elicit genuine affinities with early Sartre, but connecting it to Heidegger (or Wittgenstein for that matter) borders on philosophical malpractice. See Heidegger, Being and Time, 231. See also Martin Heidegger, "What Is Metaphysics," in Heidegger: Basic Writings, ed. David Farrell Krell (New York: Harper \& Row, 1977), esp. 104-12.

95. Cavell, Disowning Knowledge, 5-6.

96. Stanley Cavell, The World Viewed: Reflections on the Ontology of Film (New York: Viking, 1971), 117. Although Cavell's perennial interest in modernism is not a major topic for me here, the following groupings of quotationcouplings also display that for him separateness is not merely a function of the content of the art forms on which he wrote, but also a subject of their very form. In The World Viewed, Cavell writes not only of "the ontological facts of our separateness" as themes for film, but also directs our attention to the way the very viewing of a film brings to light our separation: "the condition of privacy, of unknownness, of being viewed - the human condition - is itself the condition of martyrdom" (World Viewed, 144, 205-6). In his early essay on Beckett's Endgame, we read how the play teaches not only that "the uniqueness of the human soul, held to be its greatest value, is its greatest curse. We are alone, separate", but also that this message is conveyed by the very act of watching the play: "Theater becomes the brute metaphysical fact of separateness" ("Ending the Waiting Game" in Cavell, Must We Mean, 154, 160). Finally, in his breathtaking essay on King Lear, Cavell reveals the same sort of modernist sensibilities regarding form and content: "Lear and Gloucester are not tragic because they are isolated, singled out for suffering, but because they had covered their true isolation (the identity of their condition with the condition of other men) within hiddenness, silence, and position; the way people do." "The Avoidance of Love" in Cavell, Must We Mean, 351. In another work, "what is revealed (in Shakespearean tragedy) is my separateness from what is happening to them; that I am I, and here, It is only in this perception of them as separate from 
me that I make them present." “The Avoidance of Love” in Cavell, Must We Mean, 338. Naturally, these points about separateness are sometimes made independently of one another. In the Senses of Walden (54) Cavell writes that "the realization of our 'infinite relations,' our kinships, is an endless realization of our separateness", while this next passage, taken from an essay on aesthetics from the late 1960s, makes no reference to the content of any particular work of art: a modern work of art "asks of us, not exactly more in the way of response, but one which is more personal. It promises us, not the re-assembly of community, but personal relationship unsponsored by that community; not the overcoming of our isolation, but the sharing of that isolation" "A Matter of Meaning It" in Cavell, Must We Mean, 229.

97. Cavell, In Quest of the Ordinary, 5.

98. CR, 369 (emphasis in original).

99. Ibid.

100. Although I am trying hard to avoid vexed issues in Wittgenstein interpretation, because I am on the subject of nonsense, I will say that while Cavell's words are surely in some sense "elucidatory", there is no hint as far as I can gather that we are to "throw away his sentences", or those of Hamlet or Spencer Tracy for that matter, once we see that they have instructed us by drawing us into an utter illusion. And while there may be no claim context for Cavell to assert that he "knows" he (we) is (are) separate, he certainly asserts it often enough: Perhaps it "stands fast" for him.

101. Clifford Geertz, "From the Native's Point of View': On the Nature of Anthropological Understanding," Bulletin of the American Academy of Arts and Sciences 28, no. 1 (October 1974): 30-31.

102. Geertz writes of the concept of the person here, whereas I speak primarily of the concept of the self. If by "person" we think mainly of a social identity as reflected in social status or in social roles, then my use here of the Geertz quote might seem questionable. I think, however, that the context of the quotation makes clear that in contemporary parlance what is at issue is the self, considered as an entity and not as a nexus of social factors. Whatever the case, I would be suspicious of any claim that "person" and "self" can be understood in sharp separation from each other.

103. See Taylor, Sources of the Self (Reference note 38). I should also mention here the ground-breaking work of Louis Dumont. See his Essays on Individualism (Chicago: University of Chicago Press, 1983).

104. Charles Taylor, A Secular Age (Cambridge: Harvard University Press, 2007). See also his The Ethics of Authenticity (Cambridge: Harvard University Press, 1991); Taylor, Modern Social Imaginaries (Reference note 3).

105. More properties could be added on each side of the divide.

106. Taylor, A Secular Age, 38.

107. Charles Taylor, "Lichtung or Lebensform," in Philosophical Arguments (Cambridge: Harvard University Press, 1995), 63.

108. This does not entail, naturally, that such conceptions are immune to revision brought about in part by theoretical considerations.

109. Taylor, Sources of the Self, 111.

110. Taylor, A Secular Age, 38.

111. Ibid., 39.

112. Ibid., 36 .

113. Ibid., 27.

114. Ibid., 42.

115. Ibid., 149. See also Taylor, Modern Social Imaginaries, 55. 


\section{Skepticism and the Human Condition}

116. Taylor, A Secular Age, 135. Taylor adds, "This agent is in a sense superbuffered. He is not only not 'got at' by demons and spirits: he is also utterly unmoved by the aura of desire. In a mechanistic universe, and in a field of functionally understood passions, there is no more ontological room for such an aura." Taylor, A Secular Age, 136. This may be true of what Taylor calls Locke's "punctual self", but it hardly fits Cavell's modern neurotic. The difference is of course that for Cavell the demons are in us. See also Taylor, Sources of the Self, 171.

117. See Taylor, Modern Social Imaginaries, 65.

118. Taylor, A Secular Age, 136-37. Taylor mentions the work of Norbert Elias in this regard.

119. Taylor, A Secular Age, 539.

120. Ibid., 301.

121. Taylor, Modern Social Imaginaries, 49.

122. Taylor, A Secular Age, 26.

123. Ibid.

124. Ibid., 22. See also Taylor, Modern Social Imaginaries, 64.

125. Taylor, Sources of the Self, 106.

126. Ibid., 3.

127. Taylor, A Secular Age, 105.

128. Ibid., 262.

129. This is of course a reference to Philosophical Investigations $\$ 122$, a remark that Wittgenstein carried over from his Remarks on Frazer's Golden Bough in which he attacks Sir James Frazer's vulgar descriptions of magic as nothing more than poor science.

130. I am aware that I employ terms like "Western" and "modern" in ways that might offend certain sensibilities, in part because I have not circumscribed them with an essence by providing a definition. We all can admit that definitions are of course sometimes useful. But I have in mind here a much more juvenile demand (arising from an equally juvenile political agenda) whereby failure to provide an essence-giving definition is thought to produce the "Gotcha!" moment in which the benighted writer, me in this case, is revealed as having missed something "complex" or "problematic" with (his?) use of the terms themselves. I suppose this strategy is preparatory for some sort of demonstration of "undecidability", "play of signifiers", or more likely in our current confusion, hidden "power relations" that the undefined terms are suspected to cloak. In response, I would first remark that Taylor is well aware of the dangers of an uncritical use of blanket terms such as "modernity" as shown in passages like this one: "Modern social imaginaries have been differently refracted in the divergent media of the respective national histories, even in the West. This warns us against expecting a simple repetition of Western forms when these imaginaries are imposed on or adopted in other civilizations." He also insists on our being open to the idea of "multiple modernities". See Taylor, Modern Social Imaginaries, 154, 195. But second, and more importantly, as long as one is aware of what one is doing, there is no harm in using a term at one stage of a discourse in a way that can, if needed, be made more precise at a later stage. If one insists on defining everything at the outset of speech (or on defining everything at any stage, actually) one is reduced to either silence or jibberish, which I take to be a reductio ad absurdum of the demand itself.

131. Rane Willerslev, Soul Hunters: Hunting, Animism, and Personhood Among the Siberian Yukaghirs (Berkeley: University of California Press, 2007).

132. Willerslev, Soul Hunters, 2, 8. 
133. Ibid., 3.

134. Ibid., 2.

135. Ibid., 9.

136. Ibid.

137. Ibid., 19-20. This theme is familiar in the work of Evans-Pritchard, Witchcraft, 222; Bourdieu, Outline, 9, 37, 171. See Chapter 2, notes 3, 7 for references.

138. Willerslev, Soul Hunters, 11.

139. Ibid. He adds later, "the very nature of hunting requires that the hunter identify with his prey and attempt to ascertain its mode of perception and action by imitating its bodily movements and smell". Willerslev, Soul Hunters, 84.

140. Willerslev, Soul Hunters, 26.

141. Ibid., 50.

142. Ibid., 55.

143. Ibid., 55.

144. Ibid., 57.

145. Ibid., 57.

146. Ibid., 58.

147. Ibid., 60 .

148. Ibid., 58.

149. This is reminiscent of something Evans-Pritchard claims about the Azande, namely that he found they had little or no theoretical interest in the question whether the traveling "soul of witchcraft", the "fireflies" that are the actual agents that afflict the victim, are emanations of, or identical with, the soul of the witch, or whether they are emanations from the witchcraft substance that inheres in the witch's body. On this and related questions, Evans-Pritchard wrote "Zande have no theoretical interest in the subject, and those situations in which they express their beliefs in witchcraft do not force the problem upon them." See Evans-Pritchard, Witchcraft, Oracles, and Magic Among the Azande (Oxford: Oxford University Press, 1937), 4.

150. Willerslev, Soul Hunters, 25.

151. Ibid., 53-54.

152. Ibid., 87. See Eduardo Viveiros de Castro, "Cosmological Deixis and Amerindian Perspectivism," The Journal of the Royal Anthropological Institute 4, no. 3 (September 1998): 469.

153. Eduardo Viveiros de Castro, "Exchanging Perspectives: The Transformation of Objects into Subjects in Amerindian Ontologies," Common Knowledge 10, no. 3 (Fall 2004): 468-69.

154. Ibid.

155. Ibid., 466, 474.

156. Willerslev, Soul Hunters, 12.

157. Viveiros de Castro, "The Transformation of Objects," 476.

158. Willerslev, Soul Hunters, 63. See Marilyn Strathern, The Gender of the Gift (Berkeley: University of California Press, 1988). Strathern's main focus here is on the Hagen in the Western Highlands Province of Papua New Guinea.

159. Strathern, Gender of the Gift, 13.

160. Ibid., 122.

161. Ibid., 157.

162. Ibid., 141. She adds later, "The Western concept of exploitation rests ultimately on the idea that violence can be done to a supposed intrinsic relation between the self as subject and its realization in the objects of its activities. I have stressed that this entails a view of agents as single entities, as singular 


\section{Skepticism and the Human Condition}

authors of what they make and do. The partibility of persons under the regime of a gift economy is very different from the positive or negative, but either way "unnatural", dividing of the "whole" self in a commodity regime." Strathern, Gender of the Gift, 162.

163. Strathern, Gender of the Gift, 131.

164. Ibid., 165.

165. Ibid., 273.

166. Ibid.

167. Ibid., 294.

168. Ibid., 269.

169. For an interesting comparison with Strathern, see Alan Rumsey, "The Personification of Social Totalities in the Pacific," Journal of Pacific Studies 23, no. 1 (1999): 48-70. What Rumsey terms the "segmentary person" of the $\mathrm{Ku}$ Waru region of the New Guinea Highlands resembles Strathern's “dividual" in some respects, yet designates multiple identities across long spans of history. Nor is it restricted for use only by chiefs, as in Sahlins' account of "heroic history" among Maori and Hawaiians.

170. Perhaps Evans-Pritchard's descriptions of the Azande encompass both aspects of the non-buffered self. On the one hand, witchcraft substance activated by evil thoughts harbored by the witch seems to be able to discreetly impact at a distance the soul of the victim with some malady. On the other hand, Evans-Pritchard also writes that witchcraft substance, like the ayibii, has a certain kind of independent physicality in that it can travel at night to attack its victims directly. Evans-Pritchard also notes in this regard that there is a lack of theoretical clarity as to whether this evil force, "the soul of witchcraft", is the essence of the substance or the essence of the witch himself, in whom the substance resides. See Evans-Pritchard, Witchcraft, 10-11 and note 149 (see Chapter 2, note 3 for reference). Some of the conceptual relations between Taylor's "porous self” and Strathern's "dividual” are discussed in Karl Smith, "From Dividual and Individual Selves to Porous Subjects," The Australian Journal of Anthropology 23 (2012): 50-64.

171. Willerslev, Soul Hunters, 2. This was in essence the heart of the dispute several years ago between Gananath Obeyeskere and Marshall Sahlins. In effect, Obeyesekere claimed that Sahlins' interpretation of the events leading up to the death of Captain James Cook, an account which relied on reading Cook's death as unfolding out of the internal logic of Hawaiian culture and religion, as amounting both to a denial of rationality to the Hawaiians and as based on a Western fetish for exoticism. See Gananath Obeyesekere, The Apotheosis of Captain Cook (Princeton: Princeton University Press, 1992). Sahlins completely dismantled Obeyeskere's charge in his How "Natives" Think: About Captain Cook, for Example (Chicago: University of Chicago Press, 1996).

172. Sahlins, How "Natives" Think, 118.

173. $C R, 144$.

174. "Incommensurability" is Thomas Kuhn's term. See his The Structures of Scientific Revolutions (Chicago: University of Chicago Press, 1962), 14849. Peter Winch employs the term "category mistake" in his argument. See "Understanding a Primitive Society," American Philosophical Quarterly 1 (1964): 314-15.

175. Some readers will at once recognize that my discussion here touches on the so-called "New Wittgenstein Debate" that has taken place over the last few decades While I have some fairly strong ideas about that debate, they are not relevant in the present context. My discussion should not be taken as a 
contribution to that debate, but rather as an application of the philosophy I believe to have learned from engaging in it. If such philosophy is not true to what Wittgenstein actually thought, that should have no consequence for my arguments here. For references, see Chapter 1, note 65 .

176. I will address the issue of repression next.

177. Strathern, Gender of the Gift, 12.

178. Ibid., 143.

179. J. Prytz Johansen, The Maori and His Religion in Its Non-Ritualistic Aspects (Munksgaard: Copenhagen, 1954), 36. Quoted in Rumsey, "The Personification of Social Totalities," 49 and in Marshall Sahlins, Historical Metaphors and Mythical Realities (Ann Arbor: University of Michigan Press, 1981), 13-14.

180. Ibid.

181. While some of the considerations advanced in this last paragraph derive from my way of reading Wittgenstein's famous remarks on the "woodsellers", it is not my intention to enter into a scholarly debate here. See Ludwig Wittgenstein, Remarks on the Foundations of Mathematics, ed. G. H. von Wright, R. Rhees and G. E. M. Anscombe, trans. G. E. M. Anscombe (Oxford: B. Blackwell, 1956), \$147-\$50. Cavell discusses this example from Wittgenstein on CR, 115.

182. I would like to thank Kristin Boyce for bringing this issue to my attention.

183. Clifford Geertz, "The Impact of the Concept of Culture on the Concept of Man," in The Interpretation of Cultures (New York: Basic Books, 1973), 44.

184. Willerslev, Soul Hunters, 70.

185. Melford E. Spiro, "Is the Western Conception of the Self 'Peculiar' Within the Context of the World Cultures?," Ethos 21, no. 2 (1993): 107-53. Interestingly, we just saw Willerslev, publishing in 2007, speaking of the literature being "crammed" with such typologies, whereas Spiro writing in 1993, writes that little work has been done on the anthropology of the person or self outside of a few societies. Perhaps this discrepancy can be explained if much work was done on the subject in the intervening period.

186. See Hazel Rose Markus and Shinobu Kitayama, "Culture and the Self: Implications for Cognition, Emotion, and Motivation," Psychological Review 98, no. 2 (1991): 224-53. Spiro also criticizes similar work by interpretivist social scientists Shweder and Bourne. See Richard Shweder and Edmund J. Bourne, "Does the Concept of a Person Vary Cross-Culturally," in Culture Theory, ed. Richard A. Shweder and Robert A. Levine (Cambridge: Cambridge University Press, 1984), 158-95.

187. Spiro, "Is the Western Conception of the Self 'Peculiar'?," 107.

188. Ibid., 108.

189. But see Willerslev's previous assertion that the literature is "crammed with typologies of this kind".

190. Spiro, "Is the Western Conception of the Self 'Peculiar'?," 117.

191. Ibid., 114.

192. Ibid., 117.

193. Ibid.

194. Ibid., 118-19.

195. Ibid., 120.

196. Ibid., 109.

197. Ibid., 10.

198. Ibid., 122.

199. Geertz, "From the Native's Point of View," 35. Quoted in Spiro, "Is the Western Conception of the Self 'Peculiar'?,"121. 
200. Clifford Geertz, "Person, Time, and Conduct in Bali," in The Interpretation of Cultures (New York: Basic Books, 1973), 386.

201. Ibid., 388-89.

202. Ibid., 390.

203. Spiro, "Is the Western Conception of the Self 'Peculiar'?," 127-28. See Unni Wikan, "Managing the Heart to Brighten Face and Soul: Emotions in Balinese Morality and Health Care," American Ethnologist 16 (1989): 294, 298, 300. See also Unni Wikan, "Public Grace and Private Fears: Gaiety, Offense, and Sorcery in Northern Bali," Ethos 15 (1987): 337-65.

204. Spiro, "Is the Western Conception of the Self 'Peculiar'?," 130.

205. Ibid., 136.

206. Ibid., 144-45.

207. Sahlins writes, “'Strange' should be the beginning of anthropological wisdom rather than a way of putting an end to it." How "Natives" Think, 62.

208. Willerslev hints (Soul Hunters, 71) that many modern Westerners might in fact sense themselves as being less buffered than can be gleaned from the "ideal type" or cultural conception. He claims that the way in which we often speak of pain or stress as "getting" to us is an example that gives the lie to a universal commitment to a buffered self-understanding. In support of this one might add that many Westerners still fully embrace various selfunderstandings where the "buffered self" seems remote. These are people who embrace various forms of traditional Christianity and more recently those embracing some Eastern forms of spirituality or New Age religions.

209. I set aside here its partial diffusion since the colonial period.

210. Taylor, Sources of the Self, 112.

211. Ibid., 111. Taylor addresses this issue both more generally and in the context of Bruno Snell's writing on the Homeric understanding of agency. See Sources of the Self, 118.

212. See Jean-Paul Sartre, Being and Nothingness, trans. Hazel E. Barnes (New York: Washington Square Press, 1956), 66-69.

213. CR, 119.

214. Elsewhere, Cavell writes, "It is perfectly true that English might have developed differently than it has and therefore have imposed different categories on the world than it does; and if so, it would have enabled us to assert, describe, question, define, promise, appeal, etc., in ways other than we do." Cavell, Must We Mean, 33. Apparently, these considerations do not apply to the cogito.

215. Cavell, Must We Mean, 219-20. Cavell explains in the Acknowledgements to Must We Mean that this essay is a rejoinder to comments he received to "Music Discomposed". See especially 188-89, where Cavell states that "modernism only makes explicit and bare what has always been true of art". The passage from "A Matter of Meaning It" quoted previous is, I take it, intended precisely to clarify the earlier confusing statement.

216. See Part II, C, pp. 122-124 for references.

217. CR, 470.

218. Cavell, Disowning Knowledge, 11.

219. Cavell, In Quest of the Ordinary, 158.

220. Cavell, "Something Out of the Ordinary," 26.

221. Cavell, World Viewed, 21 (emphasis added).

222. One could say that Cavell and Spiro have ignored the difference between beings (in this case our embodiment) and Being (our ability to make sense of that fact).

223. Strathern, Gender of the Gift, 326. 
224. I am paraphrasing something claimed many years ago by Thomas Ricketts said about Frege: "Frege's ontological categories track his logical ones I believe that this is the import of his context principle".

225. Taylor, Sources of the Self, 112.

226. Geertz, "The Impact of the Concept of Culture," 51. See also p. 38. Dumont also invokes the idea of subtraction. See Dumont, Essays on Individualism, 87.

227. Winch, "Understanding a Primitive Society." See Introduction, note 15 for reference.

228. Winch, "Understanding a Primitive Society," 314-15.

229. Charles Taylor, "Understanding and Ethnocentricity," in Philosophy and the Human Sciences (Cambridge: Cambridge University Press, 1985), 128. Stanley J. Tambiah has an interesting discussion of Wittgenstein's trenchant criticisms of Frazer that touches on many of the same questions as I am addressing here. See his Magic, Science, Religion, and the Scope of Rationality (Cambridge: Cambridge University Press, 1990).

230. In "How Old Are These Bones?" Diamond argues that the overall development of a culture's scientific practices are relevant for assessing the meaning of assertions made by members of that culture who may not yet have the actual ability to investigate their truth. See Chapter 2, note 2 for reference.

231. Charles Taylor, "Rationality," in Philosophy and the Human Sciences (Cambridge: Cambridge University Press, 1985), 149.

232. Cf. Heidegger, Being and Time, 59. Full reference in note 17.

233. Hilary Putnam, "Meaning and Reference," Journal of Philosophy 70 (1973): 699-711.

234. In fact, rather than accepting the Cartesian cogito of (scientific) epistemology as an indication of the nature of the "real self" underlying such activity, there are reasons for regarding it as a phenomenological modification brought about in us by reflection.

235. CR, 13.

236. Wittgenstein, by contrast, does not seem to have concealed this aspect of his work. Lecture notes taken in 1938 record him as stating openly that he was in a certain sense "making propaganda for one style of thinking as opposed to another." Perhaps another crucial difference is that whereas Cavell may be making propaganda for the adoption of a specific, modern grammar of the self, the style of thinking for which Wittgenstein seems to be "making propaganda" is one wherein we acknowledge the possibility of grammatical differences, so as to resist the pull of particular grammars, such as those of natural science, that may blind us to important alternatives. Seen this way, Cavell and Wittgenstein would be making propaganda with two entirely different purposes. See Ludwig Wittgenstein, Lectures \& Conversations on Aesthetics, Psychology, and Religious Belief, ed. Cyril Barrett (Berkeley: University of California Press, 1966), 28. In Philosophical Investigations, he speaks of getting someone to "regard a case differently". See $P I, \mathbb{S} 144$.

237. Heidegger, Being and Time, 78.

238. John McDowell, Mind and World (Cambridge: Harvard University Press, 1994), XX. Unfortunately, McDowell himself exhibits the untoward influence of Cavell on his thinking when he maintains that we know there will be recurrences of the philosophical impulse. There is an enormous difference between correctly pointing out that no final theoretical refutation of metaphysics is forthcoming and claiming that we are inevitably subject to fits of metaphysical confusion. The latter is a philosophical claim about human 


\section{Skepticism and the Human Condition}

nature. It has been one of the main aims of this entire essay to question how in the world such a thing could be known.

239. This is a summary of Dumont's essay "The Christian Beginnings: From the Outwordly Individual to the Individual-in-the-World," in his Essays on Individualism (Chicago: University of Chicago Press, 1983), 23-59. Dumont connects his ideas in this essay to his earlier work on the caste system of India. See his Homo Hierarchicus (Chicago: University of Chicago Press, 1981).

240. One of Dumont's other arguments is that the social view returns every so often in the monstrous guise of totalitarianism. 


\title{
Appendix \\ Wittgenstein's Paganism
}

\author{
Kevin M. Cabill
}

\begin{abstract}
"Our form of government has no sense unless it is founded in a deeply felt religious faith, and I don't care what it is." Dwight Eisenhower, Address at the Freedoms Foundation, New York City, 12/22/52
\end{abstract}

\section{I}

Religion was a subject of great philosophical and personal significance for Wittgenstein, yet his relation to it is difficult to pin down. The ambiguity of the place of religion in Wittgenstein's thought and his ambivalent attitude towards it comes out nowhere more succinctly than in Maurice O'Connor Drury's oft discussed recounting of Wittgenstein's telling him that "I am not a religious man but I cannot help seeing every problem from a religious point of view". This appendix concerns Wittgenstein's well-known respect for and tolerance of different religious traditions as well as his reticence, even revulsion, to render judgments of religious systems.

In her essay "Putnam and Wittgensteinian Baby-Throwing: Variations on a Theme,"2 Cora Diamond discusses a 1931 passage from Wittgenstein's "Remarks on Frazer's Golden Bough," where his idea seems to be that the very idea of criticizing religions as containing errors at all is basically irrelevant or confused since they are not a theory.

Frazer's account of the magical and religious views of mankind is unsatisfactory: it makes these views look like errors.

Was Augustine in error, then, when he called upon God on every page of the Confessions?

But - one might say - if he was not in error, surely the Buddhist holy man was - or anyone else - whose religion gives expression to completely different views. But none of them was in error, except when he set forth a theory. ${ }^{3}$ 


\section{Appendix}

Diamond goes on to describe Wittgenstein's view here as having strong affinities to the religiously tolerant pagan view of antiquity according to which respect was accorded to diverse forms of worship. ${ }^{4}$

We seem to find this tolerant "pagan" view displayed in other comments from around the same period of the late 1920s and early 1930s. For example, in December 1930 Friedrich Waismann recorded the following remark by Wittgenstein:

Obviously the essence of religion cannot have anything to do with the fact that there is talking, or rather: when people talk, then this itself is part of a religious act and not a theory. Thus it also does not matter at all if the words used are true or false or nonsense. ${ }^{5}$

An even more striking example of this tolerant attitude is found in Wittgenstein's recorded conversations with Drury around 1929:

The symbolisms of Catholicism are wonderful beyond words. But any attempt to make it into a philosophical system is offensive.

All the religions are wonderful, even those of the most primitive tribes. The ways in which people express their religious feelings differ enormously. ${ }^{6}$

One might wonder whether these remarks fundamentally bear the stamp of this (very turbulent) phase of Wittgenstein's philosophical development. But even after his understanding of philosophy had undergone substantial revision, when he returned to commenting on Frazer several years later (Rhees writes that this second set of remarks on Frazer are from "not earlier than 1936 and probably after 1948") we find passages that seem to strike the same chord. ${ }^{7}$

The nonsense here is that Frazer represents these people as if they had a completely false (even insane) idea of the course of nature, whereas they only possess a peculiar interpretation of the phenomena. That is, if they were to write it down, their knowledge of nature would not differ fundamentally from ours. Only their magic is different.

As simple as it sounds: the distinction between magic and science can be expressed by saying that in science there is progress, but in magic there isn't. Magic has no tendency within itself to develop. ${ }^{8}$

Diamond offers two ways of construing Wittgenstein's 1931 remark as it relates to Augustine's Manichean period, but she finds neither of them satisfactory as a way for accounting for Augustine's own self-understanding. ${ }^{9}$ On the first construal, even if Wittgenstein considered Augustine's Manichaeism to be a kind of theory, it is possible that he did not consider Augustine's act of calling upon God as essentially connected to that 
theory and so did not see the invocation itself, qua purely expressive act, as open to error. On the second construal, Wittgenstein did not consider Augustine's Manichaeism to be a theory at all, and so the issue of his being in error when he calls upon God never arises. Diamond claims, however, that unless we arbitrarily limit our concepts of truth and error to the methods of the sciences, Wittgenstein seems on either construal simply to disregard Augustine's own later ideas about what is true (what is not in error) about Christianity and what is false (in error) about Manichaeism and other pagan religions. Wittgenstein thus seems to be overlooking here the possibility that there are other ways of understanding truth than as scientific truth, and thus of understanding religious practices as embodying or leading to truth or falsehood.

Diamond stresses at one point how Wittgenstein hated Frazer's treatment of magic and religion. ${ }^{10}$ Yet I worry that her discussion of this particular remark by Wittgenstein about Augustine makes it seem as though his overall response to Frazer was merely an expression of this antipathy and so merely an expression of his "pagan" reluctance to criticize religious and magical practices. His open animus towards Frazer notwithstanding, Wittgenstein thought that Frazer was not only arrogant, but deeply confused. In the broader context of these remarks, Wittgenstein is mainly concerned with criticizing Frazer for arbitrarily, if not intentionally, imposing a misleading picture on the ethnographic record, viz., that scientific ways of relating to the world are really the only available options and so that ipso facto religion must necessarily be some crude attempt at scientific explanation. Given this context, where scientism was paramount in Wittgenstein's mind, it seems most reasonable to read his particular comment on Augustine as meaning that there is nothing more to be said about error in relation to these practices, once one drops the assumption that they are proto-scientific theories. Wittgenstein's point in this context relies, I think, on a narrow understanding of theory and error, even if these are not the only meanings these terms can have. ${ }^{11}$ Consequently, the fact that what Wittgenstein wrote in a particular remark is ambiguous between the two possibly inadequate interpretations of Augustine that Diamond points out is not really to the point because it isn't necessary to read him as concerned (and possibly failing) there to reconcile his critique of Frazer with every aspect of Augustine's selfunderstanding. He can still acknowledge that there are possibilities of error other than scientific error.

But quite apart from how one interprets this single remark, Wittgenstein was in general hostile to the idea that religions essentially involve truth claims in ways that would make them vulnerable to certain forms of criticism. Wittgenstein understood well of course that most religions involved the mixing of the expressive and the cosmological. ${ }^{12} \mathrm{He}$ was obviously aware that different religious discourses are wrapped up in different ontic views and that when religious people get into disputes over 


\section{Appendix}

different aspects of the truth of these views they often take themselves to be fighting over real claims. In On Certainty, for example, he suggests the possibility that specific religious dogmas can even play a role that is close to grammar in shaping a discourse or world view. But while there is a place in his thought for the idea that the acceptance of particular facts can be essential to religion provided they are embedded logically deeply enough in the "riverbed" of a form of life, as so understood, these are not supported with evidence and so not believed to be true (or false)..$^{13}$ Thus Wittgenstein thought that even if the religious impulse becomes wrapped up with various ontic views, for him the truth or falsity of these views was really not what is basic about the religious impulse itself. ${ }^{14}$

Whether we understand Wittgenstein's view to be that there is no such thing as a religion being true (or in error) or to be the weaker view that religion need not involve truth claims, there remains a question about whether either of these is really more than one person's view about the essence of religion that carries no special philosophical weight. For example, many traditional Christians might insist on the opposite view, that religion must be about truth, precisely because of the importance for them of the idea that only Christianity is true, and thus that all other religions are false. While the claim that religion must involve truth might have the odd consequence that certain practices ordinarily counted as religious would be excluded from that category, the assertion itself seems to be logically in order. ${ }^{15}$

Now someone could react to this claim by asking the following question: if religion concerns truth, what are its methods? After all, it isn't unreasonable to tie truth claims to some form of method, even if that is only a very informal common-sense method of confirming facts. It need not be a more formal method such as is found in medicine, the natural sciences, law, etc. It may seem that religion doesn't really have anything like a method in any of these senses and this may cast suspicion on the idea that it concerns truth. Yet Diamond, for instance, might counter by arguing that within a particular tradition, religious practices such as prayer or reflection are sometimes themselves regarded as "methods" for finding truth; there is no obvious reason why this sense should have to be explicated with reference to everyday, legal, scientific, or historical, methods for finding truth. She might add further that although there is perhaps no way of specifying a particular religion's conception of truth without reference to the very methods prescribed by that religion, this is no more damaging to that religion's claim to truth than it would be to any other kind of pursuit: the demand for an explication of the "truth directedness" of a set of religious practices that is independent of those practices already begs the question against those in the tradition who maintain the centrality of their religion's truth. ${ }^{16}$

At any rate, whether Wittgenstein thought that religion did not have to be concerned with truth and error or whether he thought that it essentially 
did not involve these ideas, Diamond believes that either option is merely one way of thinking about religion, enjoying no philosophical superiority over views insisting on robust uses of truth and error in a religious context. With her general view about the intelligibility of criticizing from outside of a system in place, Diamond can point out that however we choose to interpret Wittgenstein's remark mentioning Augustine, there is an important distinction to be made between a generally tolerant pagan attitude towards other religions and a philosophical view that tries to ban criticisms of other religions, as though, for example, anti-pagan false god criticism was logically confused. ${ }^{17}$ Diamond ascribes only the first, tolerant, pagan-like view to Wittgenstein. And she concludes that while biographically interesting, this fact about him provides no support for a general philosophical claim to the effect that the anti-pagan false god view is conceptually off limits or that Wittgenstein thought it was. How tightly connected, then, are these views of his on religion to his overall philosophical outlook? Diamond thinks the answer is not very connected: "The fact that Wittgenstein was strongly attracted to the view opposed to Augustine's is deeply interesting; but it leaves us just where we were". ${ }^{18}$

\section{II}

While Diamond is correct about the consequences of Wittgenstein's views on religion with regard to the possibility of criticism, providing a wider context for this issue will bring out that, while not exemplifying a general philosophical position concerning the possibility of such criticism, behind his views lay an intellectual and spiritual framework that I think deserves to be described as broadly philosophical. There may be nothing like a general a priori argument about what is or is not philosophically confused with criticizing forms of religious life, but there is much at stake in how we think about these questions. At the very least, a fuller picture will help to make the case for thinking that Wittgenstein's attitude towards religion formed an important part of the background for his philosophizing and so for understanding its full significance.

I have argued elsewhere that a fundamental thread running through Wittgenstein's work and thought is a critique of modernity, in particular a critique of the pretensions of modern scientism and naturalism. ${ }^{19}$ His work attempts to engage the self-understanding of a reader who is likely to come to philosophy with a certain cast of mind that includes unexamined commitments from a particular cultural context. I have argued further that at least one, perhaps the most important, intended outcome of this critique is an enabling of a sense of humility and wonder at the fit between word and world, a fostering of a sense of reverence for how deeply language is interwoven with what is special about human life. So, while Wittgenstein's views on religion were not derivable from his views on philosophy, they were of a piece with those views, as both were 


\section{Appendix}

fundamentally interwoven with his views on mind and world, on human life in the world and nature. The importance of wonder for understanding Wittgenstein's thought accounts for a great deal of what I take to be the relevance of his use of a "religious point of view" in his statement to Drury. ${ }^{20}$

This is why Wittgenstein believed that religion in its essence was not concerned with claims to historical truth or about the "furniture of reality". The religious impulse as he understood it is instead concerned with the mystery of there being an intelligible world at all, and he thought that this impulse finds its fullest expression when a religious symbol system becomes the grammar of one's experience of the world. ${ }^{21}$

It appears to me that a religious belief could only be (something like) a passionate committing oneself to a system of coordinates. Hence although it's belief, it's really a way of living, or a way of judging life. It's passionately taking up this interpretation. And so instruction in a religious faith would have to be portraying, describing that system of reference and at the same time appealing to the conscience. And these together would have to result finally in the one under instruction himself, of his own accord, passionately taking up that system of reference. It would be as though someone were on the one hand to let me see my hopeless situation, on the other depict the rescueanchor, until of my own accord, or at any rate not led by the hand of the instructor, I were to rush up and seize it. ${ }^{22}$

Apart from whether this correctly describes the way things look to participants from within a religious practice, Wittgenstein saw religions as essentially grammars of wonder, and so as holding out the promise of sustaining an openness to wonder, not least by providing a vehicle for its expression. Religions were "systems of coordinates" for giving direction to a life fundamentally characterized previously all by reverence, which Wittgenstein felt was the highest kind of human life to lead.

\section{III}

On the question of the possibility of criticism of other religions, we are in one way still "just where we were," as Diamond put it. But with the discussion of the prior section as background, I can now try to bring out more fully what I think is the philosophical significance of Wittgenstein's attitude towards religion. I want to do this by discussing a particular case which Diamond mentions, that of a statement by Elizabeth Anscombe in a letter to Rush Rhees. Anscombe wrote,

An irreligious man rejects certain conceptions; he is not innocent of them. Don't misunderstand me: there are forms which such 
misconceptions can take, such that a man is better off if he rejects them than if he retains them in these forms. I would rather a man were like Bertrand Russell than that he were a worshipper of Durga. (I rather believe that Wittgenstein would not: he'd certainly have me up for thinking I could say anything about a worshipper of Durga. $)^{23}$

There are two issues that the context of this letter does not make clear; I will take up each of them in turn.

First, the letter does not make clear in what capacity or from what standpoint Anscombe is stating her preference for Russell over Durga worship. In an earlier paper, "Wittgenstein on Religious Belief: The Gulfs Between Us," Diamond discusses a remark made by Wittgenstein in the third lecture on religious belief in the notes published as Lectures and Conversations on Aesthetics, Psychology, and Religious Belief. ${ }^{24}$ Wittgenstein said there that in a given case of religious belief, a person may place the whole weight of his belief in a particular picture, for example in certain phrases expressing the idea of resurrection after death. ${ }^{25}$ Given certain well-known remarks Wittgenstein makes elsewhere about pictures in philosophy, it is perhaps easy to read him making a pejorative remark in the lecture about the relation between the use of a picture and the nature of religious belief. ${ }^{26}$ But Diamond makes clear that Wittgenstein isn't using the idea of a picture pejoratively here at all. If I read her correctly, she thinks Wittgenstein's point in the lecture is not that the use of a picture in this or that situation is automatically a reason for suspicion; it may in fact be essential. His point is simply that we need to be clear about different ways in which such pictures are used. Ignoring these differences might lead, for example to our assuming that the sense of a form of words used in a religious context can simply be read off of the logic of everyday non-religious uses of the same form, without our paying attention to these particular contexts. Diamond suggests that Wittgenstein is trying to avoid an "overly strong" sense of the essentiality of a picture in which the sense and the context must go together, while at the same time he is trying to make space for a kind of essentiality that is robust enough to do justice to religious (and presumably other) contexts. ${ }^{27}$

Diamond discusses in some detail different ways in which there can be "detachable" or purportedly inessential uses of a picture in religious thinking as well as "non-detachable" uses..$^{28}$ In the case of a detachable use, the picture may be thought to serve an important heuristic function for conveying a religious idea, but the same idea could at least in theory be paraphrased or conveyed without the picture. One of her main points is that although philosophers might assume that the use of a religious picture is in order only if it is used in the detachable sense, there is in fact no compelling reason for thinking this. According to Diamond (and on her interpretation of Wittgenstein here), there is nothing philosophically fishy if a person lets a religious picture be at the "bottom of all of her 


\section{Appendix}

thought" without being able to paraphrase her thought in a manner that is detachable, that is independently characterizable, of that very same picture. The demand for such a non-circular description of a religious picture simply begs the question about the legitimacy of its use.

At the same time, Diamond contends that there is no automatically given logical compartmentalization or "walling off" of language games irrespective of particular cases. What someone means with a particular expression drawn from religion might be shown in how she allows it to shape her thought and speech in certain contexts, but not in others. How someone else understands the same given expression might be shown in how it shapes her thought in a much more global sense. In this vein, Diamond claims that, for example, the idea of God intervening in history may be at the bottom of a person's thought when she is engaged in more ostensibly secular activities, such as political philosophy, and not only when thinking about or discussing religion per se. ${ }^{29}$ This seems to make room for the idea of being a religious philosopher in a particularly strong sort of way. So as I understand her, Diamond could argue that the fact that a particular religious picture may lay at the basis of Anscombe's judgment about Russell and Durga, a picture, furthermore the use of which as we just saw does not require any non-circular defense, provides no automatic philosophical argument for doubting that such a judgment is a perfectly intelligible example of religious criticism.

Assuming, then, that Anscombe was speaking as a Catholic philosopher in the letter to Rhees, the second issue that the context of her remark does not make clear is what she means when she writes that she is sure that Wittgenstein would "have me up" for criticizing Durga worship. She may be indicating that Wittgenstein would think she is making a philosophical error in rendering her judgment. Alternatively, she may imagine that Wittgenstein would simply disagree with her because of his "pagan" tolerant attitude. Since, as I have already said, I basically agree with Diamond's reading of Wittgenstein, according to which he did not find any philosophical arguments available that would ban such judgments, I assume here that Anscombe too imagines him to be reacting out of a pagan responsiveness to religiosity. In this event, does Wittgenstein's statement that all the world's religions are wonderful simply gainsay a position like Anscombe's? ${ }^{30}$ Is all of the weight being in a particular religious picture compatible with seeing all the world's religions as wonderful ${ }^{31}$ Or are we still just where we were? This leads to my final question.

Even if there is no argument showing how Anscombe's criticism of Durga worship can be rejected on some kind of "supergrammatical" grounds that demonstrates its logical confusion, Wittgenstein could have regarded her remark to Rhees as having missed something important anyway. ${ }^{32}$ A response to Anscombe's statement about Russell being better than Durga worship is that she might have been right in one way and wrong in another. To explain what I mean, I want to bring in an idea of 
anthropologist Louis Dumont's to which I have already referred to in Chapter 3 (see p. 146). This is the idea of "hierarchical encompassment". Dumont employs this idea to make sense of certain binary oppositions found in ethnographic and historical data that at first glance might appear to occupy the kind of simple one-dimensional horizontal opposition in relation to one another such as that of odd and even natural numbers. Dumont argues that this flattened out picture obscures how such binaries are sometimes not simply opposed to one another, but rather are often opposed along different hierarchical axes, which are crucial for understanding the different contexts where certain judgments are made.

Recall Dumont's way of analyzing a binary aspect of medieval culture, the relationship between the sacred and the secular. In the sacred dimension, what Dumont calls the "outwordly individual" is equal to all others in his or her standing before God. The "individual-in-the-world" on the other hand is bound up in a network of hierarchical social roles and identities. Yet a simple binary opposition between "equal" and "unequal" conceals the social fact that a sacred axis of comparison was itself regarded as superior in value to the secular one. This is shown by the relative positions of priest to king. "Priests are superior, for they are only inferior on an inferior level".33

It will help to bring out an important point if we now consider Anscombe's remark about Russell and Durga worship in terms of the schema provided by Dumont. Although I take it to be pretty unlikely, consider first the possibility that was Anscombe's intention merely to compare Russell's thought to Durga worship along an axis we could perhaps describe as modern common sense secular ethics. I don't see any reason for Wittgenstein to have thought that this judgement would have posed any special philosophical difficulties. Things become more interesting, however, if we consider the possibility that Anscombe intended to compare Russell and Durga worship as two religious systems. It may strike us as odd to even consider Russell's thought on the religious plane. However that might be, it may seem fair to assume that this comparison too would strike Wittgenstein as posing no special logical problems, just as was the case with the comparison of Russell and Durga on the secular axis. After all, Wittgenstein never says anything to the effect that all religions are equally wonderful, only that they are all wonderful. But reading Anscombe's remark this way would imply that she herself believed that Durga worship was so spiritually depraved that even the thought of a selfconsciously irreligious man like Russell was religiously superior. I think Wittgenstein would take Anscombe to have missed something important here, but before I elaborate what that is, someone might preempt me by observing that whatever trouble I may imagine with Anscombe's remark is probably just an artifact of my having imposed Dumont's hierarchical schema on it in the first place. I have in fact provided no 


\section{Appendix}

reason for thinking that she would accept the conceptual regimentation that that schema imposes. It is moreover entirely plausible that even had Anscombe been made aware of the Dumontian schema, she would have insisted on the legitimacy of making her comparison across the two axes of the sacred and the secular anyway, which in effect demolishes the point of the schema itself. And there would be nothing logically preventing her from doing that. But in fact what I just described as Anscombe's arriving at the judgement that Russell is superior to Durga worship by her crossing of the secular and sacred evaluative axes, or what I described previously as her judging Russell to be superior to Durga worship on the religious axis alone, really amount to the same thing. The first is asserting that Durga worship is so evil or depraved that even a system pertaining to a self-consciously non-religious order of value is preferable. The second amounts to claiming that Durga worship is so awful that Russell's ethical thought defeats Durga worship as a religion, i.e. on Durga worship's own home turf, so to speak. These two distinct claims are not really different.

Interestingly, after recounting Anscombe's letter, Rhees' recollection continues:

When I said [Wittgenstein's] view could lead to consequences that are hard to take, I meant that a form of worship like the worship of Durga should have the respect due to a form of worship, and should not be judged as though it were a depraved practice in our own community. ${ }^{34}$

I think Rhees' reaction here is on the right track. I will now try to explain why and what it is I think Anscombe has failed to recognize. As I just described, along an axis of what I termed "secular common sense ethics" Wittgenstein might have regarded men like Russell as superior to Durga worshipers (although given his assessments of Russell, one wonders). But along a religious axis of comparison, I believe he would have regarded Durga worship as superior to Russell precisely because of a connection between significance itself and the phenomenon of wonder. What is this connection? I said previously that one intended outcome of Wittgenstein's work was a (re)enabling of a sense of humility and wonder at the fit between word and world, a fostering of a sense of reverence for this uniqueness that typifies the human being. (Here I think is the connection between logic and ethics.) The element of humility implicit in wonder is a way of acknowledging that our being minded creatures is not a feature of life that we can fully objectify or control. We must rather accept that we are not only agents of the world's intelligibility and significance, we are its creations.

With this goes the idea that for there to be an experience of something genuinely and authoritatively important, there must be some acknowledgement of this affective dimension to experience. People and actions 
must show up for us as significant, and not merely as made intelligible by us or as grasped by us as objects for manipulation. What I am trying to get at here concerns the hierarchical distinction between there being significance per se and the relative worth of different systems. Wonder is important because it is a psychological "condition of the possibility" of there being an experience of genuine significance at all. And so Durga worship, though not necessarily equal or better than any other religion in particular, is, qua grammar of wonder, better than none at all. Culture and Value contains the following brief remark from 1929: "What is good is also divine. Queer as it sounds, that sums up my ethics. Only something supernatural can express the Supernatural". ${ }^{35}$ As much as many of us may insist today on hearing this remark as a paean to what is independently identifiable by us as good, something which only then deserves our reverence, this idea was alien to Wittgenstein. ${ }^{36}$ Durga worship is better than Russell because, at a higher level, something is better than nothing. Views like Russell's are ultimately nihilistic, destructive of significance itself.

I think a strong case can be made that a genuine understanding of what it means to be committed to one's own particular religious picture requires a high degree of respect and tolerance for other traditions. Suppose, however, that someone insisted that the only genuine value can be found in her specific tradition, and, moreover, that this value is essentially located in the exclusively true character of the claims made in this tradition. She might claim, then, that the particular features of Durga worship, even though it is a religion, make it crucially at odds with the kind of truth claims of her picture, in fact even more at odds with these truths than Russell's wholly anti-religious attitude. She might think this because she regards Durga worship and systems like it as blocking the spiritual routes to the truths of her own religious tradition, and doing so in ways that Russell's outlook does not undermine, or at least does not undermine as badly. At any rate, there would be no violation of any supposed conditions of meaningful speech in standing by such a comparative claim. "Paganism" as I've been calling it here cannot claim superiority as a general critical position over this dogmatic view. But I am suggesting nevertheless that we see the difference between the dogmatic view just described and Wittgenstein's view as constituting a deep issue. The meaning of our words is bound up with the point we want to make with them. And so, the meaning of Wittgenstein's teaching should be a point beyond the purely diagnostic and critical tools he employs to dismantle metaphysics. Quite possibly part of that point was intellectual clarity for its own sake. But that alone doesn't seem to me to be an adequate motivation for his work, the philosophy behind the philosophizing as it were. Wittgenstein thought that our culture's obsession with progress left in its wake nothing more than an "unimposing spectacle" where "the strength of the individual is wasted through overcoming of opposing forces and 


\section{Appendix}

frictional resistances" ${ }^{38}$ His views on religion ran along similar tracks. He was certainly neither the first nor the only thinker to regard a particular kind of obsession with truth, whether in religion or philosophy, as ultimately inimical to significance (including perhaps the significance of truth). This observation alone does not definitively answer whether he was right. But does it leave us just where we were?

\section{Notes}

1. Rush Rhees, ed., Recollections of Wittgenstein (Totowa, NJ: Rowman and Littlefield, 1981), 94. This ambivalence is noted by many who knew Wittgenstein well. See for example G. H. von Wright in Norman Malcolm, Ludwig Wittgenstein, a Memoir (London: Oxford University Press, 1962), 19, 72.

2. Cora Diamond, "Putnam and Wittgensteinian Baby-Throwing: Variations on a Theme," in The Philosophy of Hilary Putnam, ed. R. E. Auxier, D. R. Anderson, and L. E. Hahn (LaSalle: Open Court, 2015), 603-39. See Introduction, note 10 for reference.

3. Ludwig Wittgenstein, Philosophical Occasions, 1912-1951, ed. J. C. Klagge and A. Normann (Indianapolis: Hackett, 1993), 119.

4. Diamond, "Putnam and Wittgensteinian Baby-Throwing," 632.

5. Friedrich Waismann, Wittgenstein and the Vienna Circle, ed. B. McGuinness, trans. J. Schulte and B. McGuinness (Oxford: Blackwell, 1979), 117. Taylor notes in Sources of the Self that the idea that the religious language of socalled primitive religions was a kind of ritual had wide currency in modernist circles. See Charles Taylor, Sources of the Self: The Making of the Modern Identity, 493. See Chapter 3, note 38 for reference.

6. Rush Rhees, ed., Recollections of Wittgenstein (Totowa, NJ: Rowman and Littlefield, 1981), 117.

7. Wittgenstein, Philosophical Occasions, 115.

8. Ibid., 141. In fact, one finds remarks expressing these and similar ideas over the span of many years. See for example Ludwig Wittgenstein, Culture and Value, ed. G. H. von Wright, trans. Peter Winch, rev. 2nd ed. (Oxford: Blackwell, 1998), 37-38, 96-97.

9. Diamond, "Putnam and Wittgensteinian Baby-Throwing," 630-31. What she says about respecting Augustine's self-understanding strikes me as somewhat at odds with her own interpretative practice in the paper when other cases of self-understanding are at issue. But perhaps there is a principled difference between different cases that I'm missing.

10. Diamond, "Putnam and Wittgensteinian Baby-Throwing," 632.

11. Diamond acknowledges this way of taking this remark as a possibility, but I don't believe she gives it its proper weight.

12. What often appear to be his anti-Western, anti-modern sentiments concern his repulsion at the near complete taking over of the cosmological at the expense of the expressive dimension.

13. See Ludwig Wittgenstein, On Certainty, ed. G. E. M. Anscombe and G. H. von Wright (New York: Harper, 1972), \$239. See also Wittgenstein, Culture and Value, 32-33.

14. A journal entry from 1937 suggests that Wittgenstein may have been open to a sense of truth (and error) in religion that was detached from the nature of things and centered instead on the experience of happiness or courage in the religious participant. See Wittgenstein, Culture and Value, 32. 
15. I am thinking here particularly of certain interpretations of Zen Buddhism.

16. Of course, this by no means implies that one can never say that these practices lead to falsehood unless we are "moving on the inside of them". That would be to accept the very kind of Winch-Dilman view that Diamond is at pains to reject. See Cora Diamond, "Wittgenstein on Religious Belief: The Gulfs Between Us," in Religion and Wittgenstein's Legacy, eds. D. Z. Phillips, M. Von Der Ruhr, and R. Rhees (Aldershot: Ashgate, 2005), 99-137 for her discussion of Ludwig Wittgenstein's, Lectures and Conversations on Aesthetics, Psychology, and Religious Belief (Los Angeles: University of California Press, 1966).

17. Diamond, "Putnam and Wittgensteinian Baby-Throwing," 627.

18. Ibid., 23.

19. See Kevin M. Cahill, The Fate of Wonder: Wittgenstein's Critique of Metaphysics and Modernity (New York: Columbia University Press, 2011).

20. Norman Malcolm reports his belief that "that a certain feeling of amazement that anything should exist at all, was sometimes experienced by Wittgenstein, not only during the Tractatus period, but also when I knew him". Norman Malcolm, Ludwig Wittgenstein, a Memoir (London: Oxford University Press, 1962), 70-71. Malcolm stresses that the sense of wonder he means to ascribe to Wittgenstein was strictly separate from cosmological questions about a first cause and that "any cosmological conception of a Deity, derived from the notions of cause or of infinity, would be repugnant to him". I take Wittgenstein to be making this very point in the following remark from 1950: "If the believer in God looks around \& asks 'Where does everything I see come from?' 'Where does all that come from?', what he hankers after is not a (causal) explanation; and the point of his question is that it is the expression of this hankering. $\mathrm{He}$ is expressing, then, a stance towards all explanations”. Wittgenstein, Culture and Value, 96-97.

21. "The way you use the word 'God' does not show whom you mean, but what you mean". Wittgenstein, Culture and Value, 58. See also Culture and Value, 97.

22. Wittgenstein, Culture and Value, 73. See also Culture and Value, 61, where Wittgenstein writes of being seized by a symbol system.

23. Rush Rhees, "Picking and Choosing," in Religion and Philosophy, ed. D. Z. Phillips (Cambridge: Cambridge University Press, 1997), 309. Quoted in Diamond, "Baby-Throwing: Variations on a Theme," 633. Here and throughout I use "Durga" instead of "Dourga".

24. See Chapter 3, note 236 for reference.

25. Wittgenstein, Lectures and Conversations, 72. "Picture" here is being used in a very general way. It may refer literally to something like a painting. But it can just as easily refer to certain language forms or rituals.

26. Cf. Wittgenstein, Philosophical Investigations, $\mathbb{1 1 1 5 .}$

27. It is this overly strong, or perhaps better "naively strong" sense of essentiality that Diamond suggests may lie at the heart of Wittgenstein's disagreement with Yorick Smythies in the lecture. The "Smythies" position strikes me as a core feature of fundamentalism.

28. See especially Diamond, "The Gulfs Between Us," 118-23.

29. Ibid., 130.

30. I see no inherent conflict between Wittgenstein's pointing in the lecture to the irreplaceability of a religious picture in a given case and my claim that he saw wonder as the essence of religion. To think that wonder forms the psychological basis of religion does not imply that it must be detachable or abstractable from any or all particular constellations of pictures. This point concerns what 


\section{Appendix}

I said previously about how ontic views can form the riverbed of a religious form of life.

31. Cf. John Paul II, "Redemptor Hominis," paragraphs 11-12, accessed July 21, 2020. www.vatican.va/holy_father/john_paul_ii/encyclicals/documents/ hf_jp-ii_enc_04031979_redemptor-hominis_en.html.

32. I am borrowing the expression "supergrammatical" from an early draft of Diamond's paper "Criticising from 'Outside" ".

33. Dumont, "The Christian Beginnings: From Outwordly Individual to the Individual-in-the-World," in his Essays on Individualism (Chicago: University of Chicago Press, 1983), especially 31 and 46. See Chapter 3, note 239 for reference.

34. Rush Rhees, Religion and Philosophy, ed. D. Z. Phillips (Cambridge: Cambridge University Press, 1997), 309.

35. Wittgenstein, Culture and Value, 5.

36. We find the following entry in Waismann's notes for Wednesday, 17 December 1930: "Schlick says that in theological ethics there used to be two conceptions of the essence of the good: according to the shallower interpretation the good is good because it is what God wants; according to the profounder interpretation God wants the good because it is good. I think that the first interpretation is the profounder one: what God commands, that is good. For it cuts off the way to any explanation 'why' it is good, while the second interpretation is the shallow, rationalist one, which proceeds 'as if' you could give reasons for what is good". "The first conception says clearly that the essence of the good has nothing to do with facts and hence cannot be explained by any proposition. If there is any proposition expressing precisely what I think, it is the proposition 'What God commands, that is good' ". Friedrich Waismann, Wittgenstein and the Vienna Circle, ed. B. McGuinness, trans. J. Schulte and B. McGuinness (Oxford: Blackwell, 1979), 115. See also TLP 6.372 .

37. I am doubtful, however, that merely exercising one's conceptual right to make religious claims deserves to be called a philosophical speech-act. If philosophizing out of a particular religious perspective is to be more than mere phenomenological description, apologetics, or proselytizing, then the point of this philosophizing, its value, should reach beyond the ethical and doctrinal confines of the particular position. The picture or pictures don't play exactly the same overt role in philosophy as they do in other more overtly confessional contexts. This is why the hierarchical distinction between value per se (and thus wonder) and the relative ethical worth of positions such as Durga and Russell must be kept in view. Taylor's work is exemplary in this regard.

38. Wittgenstein, Culture and Value, 8-9. 


\section{Bibliography}

Bourdieu, Pierre. Outline of a Theory of Practice. Cambridge: Cambridge University Press, 1977.

Cahill, Kevin. The Fate of Wonder: Wittgenstein's Critique of Metaphysics and Modernity. New York: Columbia University Press, 2011.

- "The Habitus, Coping Practices and the Search for the Ground of Action." Philosophy of the Social Sciences 46, no. 5 (2016): 498-524.

- "Naturalism and the Friends of Understanding." Philosophy of the Social Sciences 44, no. 4 (2014): 460-77.

Cavell, Stanley. "Benjamin and Wittgenstein: Signals and Affinities." Critical Inquiry 25, no. 2 (1999): 235-46.

. The Claim of Reason: Wittgenstein, Skepticism, Morality and Tragedy. Oxford: Clarendon Press, 1979.

- Conditions Handsome and Unhandsome: The Constitution of Emersonian Perfectionism. Chicago: University of Chicago Press, 1990.

- Contesting Tears: The Hollywood Melodrama of the Unknown Woman. Chicago: University of Chicago Press, 1996.

. Disowning Knowledge: In Six Plays of Shakespeare. Cambridge: Cambridge University Press, 1987.

- In Quest of the Ordinary: Lines of Skepticism and Romanticism. Chicago: University of Chicago Press, 1988. 1969.

. Must We Mean What We Say? A Book of Essays. New York: Scribner,

. "Night and Day: Heidegger and Thoreau." In Appropriating Heidegger, edited by James E. Faulconer and Mark A. Wrathall, 30-49. Cambridge: Cambridge University Press, 2000.

- "Notes and Afterthoughts on the Opening of Wittgenstein's 'Investigations'." In The Cambridge Companion to Wittgenstein, edited by Hans Sluga and David Stern, 245-80. Cambridge: Cambridge University Press, 2018.

- "Old and New in Emerson and Nietzsche." International Studies in Philosophy 35, no. 3 (2003): 53-62.

—. "On Wittgenstein." Philosophical Investigations 24, no. 2 (2001): 89-96. Philosophy the Day After Tomorrow. Cambridge: Belknap Press, 2006.

Pursuits of Happiness: The Hollywood Comedy of Remarriage. Cambridge: Harvard University Press, 1981.

(1999): 19-28. 


\section{Bibliography}

"Reply to Four Chapters." In Wittgenstein and Scepticism, edited by Denis McManus, 278-91. London: Routledge, 2004.

- The Senses of Walden. Chicago: University of Chicago Press, 1992.

- "Something Out of the Ordinary." Proceedings and Addresses of the American Philosophical Association 71, no. 2 (1997): 23-37.

- This New Yet Unapproachable America: Lectures After Emerson After Wittgenstein. Albuquerque: Living Batch Press, 1989.

- "What Becomes of Things on Film?." Philosophy and Literature 2, no. 2 (Fall 1978): 249-57.

—. "Who Disappoints Whom?.” Critical Inquiry 15 (Spring 1989): 606-10.

. The World Viewed: Reflections on the Ontology of Film. New York: Viking, 1971.

Conant, James. "The Method of the Tractatus." In From Frege to Wittgenstein: Perspectives on Early Analytic Philosophy, edited by Erich Reck, 374-462. Oxford: Oxford University Press, 2002.

—. "The Search for Logically Alien Thought: Descartes, Kant, Frege, and the Tractatus.” Philosophical Topics 20 (1991): 115-80.

—. "Two Conceptions of Die Überwindung der Metaphysik." In Wittgenstein in America, edited by Timothy McCarthy and Sean C. Stidd, 13-61. Oxford: Oxford University Press, 2001.

- "Two Varieties of Skepticism." In Rethinking Epistemology, edited by Guenter Abel and James Conant, 1-72. Berlin: Walter De Gruyter, 2012.

- "Varieties of Scepticism." In Wittgenstein and Scepticism, edited by Denis McManus, 97-136. London: Routledge, 2004.

Davidson, Donald. Inquiries into Truth and Interpretation. Oxford: Oxford University Press, 2001.

- "Meaning, Truth, and Evidence." In Truth, Language, and History, 47-62. New York: Oxford University Press, 1990.

Diamond, Cora. "Criss-Cross Philosophy." In Wittgenstein at Work: Method in the Philosophical Investigations, edited by Erich Ammereller and Eugen Fisher, 201-20. London: Routledge, 2004.

- "Criticising from 'Outside'." Philosophical Investigations 36 (2013): 114-32.

- "Ethics, Imagination and the Method of Wittgenstein's Tractatus." In The New Wittgenstein, edited by Alice Crary and Rupert Read, 149-73. London: Routledge, 2000.

. "How Long Is the Standard Metre in Paris." In Wittgenstein in America, edited by Timothy G. McCarthy and Sean C. Stidd, 104-39. Oxford: Clarendon Press, 2001.

- "How Old Are These Bones? Wittgenstein, Putnam and Verification." Proceedings of the Aristotelian Society 73 (1999): 99-134.

- "Putnam and Wittgensteinian Baby-Throwing: Variations on a Theme." In The Philosophy of Hilary Putnam, edited by R. E. Auxier, D. R. Anderson, and L. E. Hahn, 603-39. LaSalle: Open Court, 2015.

- The Realistic Spirit: Wittgenstein, Philosophy, and the Mind. Cambridge: MIT Press, 1991.

- "Rules: Looking in the Right Place." In Attention to Particulars: Essays in Honor of Rush Rhees, edited by D. Z. Phillips and Peter Winch, 12-34. New York: St. Martin's Press, 1989. 
. "The Skies of Dante and Our Skies: A Response to Ilham Dilman.” Philosophical Investigations 35 (2012): 187-204.

—. "Truth: Defenders, Debunkers, Despisers." In Commitment in Reflection, edited by Leona Toker, 195-222. New York: Garland, 1994.

_. "Unfolding Truth and Reading Wittgenstein." Sats - Nordic Journal of Philosophy 4, no. 1 (2003): 24-58.

- "Wittgenstein on Religious Belief: The Gulfs Between Us." In Religion and Wittgenstein's Legacy, edited by D. Z. Phillips, Mario Von Der Ruhr, and Rush Rhees, 99-137. Aldershot: Ashgate, 2005.

Dilman, Ilham. Wittgenstein's Copernican Revolution: The Question of Linguistic Idealism. Basingstoke: Palgrave, 2002.

Dreyfus, Hubert. "Holism and Hermeneutics." The Review of Metaphysics 34, no. 1 (September 1980): 3-23.

- "Overcoming the Myth of the Mental: How Philosophers Can Profit from the Phenomenology of Everyday Expertise (APA Pacific Division Presidential Address 2005)." Proceedings and Addresses of the American Philosophical Association 79, no. 2 (November 2005). 352-65.

Dumont, Louis. Essays on Individualism. Chicago: University of Chicago Press, 1983.

Dupré, John. "From Molecules to Systems: The Importance of Looking Both Ways." Studies in History and Philosophy of Biological and Biomedical Sciences 40, no. 1 (March 2009): 54-64.

- "How to Be Naturalistic without Being Simplistic in the Study of Human Nature." In Naturalism and Normativity, edited by Mario de Caro and David Macarthur, 289-303. New York: Columbia University Press, 2010.

- Human Nature and the Limits of Science. Oxford: Oxford University Press, 2001.

—. "It Is Not Possible to Reduce Biological Explanations to Explanations in Chemistry and/or Physics." In Contemporary Debates in Philosophy of Biology, edited by Francisco J. Ayala and Robert Arp, 32-47. Oxford: Blackwell, 2010.

-. "Social Science: City Center or Leafy Suburb." Philosophy of the Social Sciences 46, no. 6 (2016): 548-64.

Evans-Pritchard, E. E. Witchcraft, Oracles, and Magic Among the Azande. Oxford: Oxford University Press, 1937.

Føllesdal, Dagfinn. "Hermeneutics and the Hypothetical-Deductive Method." In Readings in the Philosophy of Social Science, edited by Michael Martin and Lee McIntyre, 233-45. Cambridge: MIT Press, 1994.

Geertz, Clifford. Available Light: Anthropological Reflections on Philosophical Topics. Princeton: Princeton University Press, 2000.

- " 'From the Native's Point of View': On the Nature of Anthropological Understanding." Bulletin of the American Academy of Arts and Sciences 28, no. 1 (October 1974): 26-45.

- The Interpretation of Cultures. New York: Basic Books, 1973.

Goldfarb, Warren. "Kripke on Wittgenstein on Rules.” Journal of Philosophy 82, no. 9 (September 1985): 471-88.

-. "Semantics in Carnap: A Rejoinder to Alberto Coffa." Philosophical Topics 25, no. 3 (1997): 51-66. 
Hammer, Espen. Stanley Cavell: Skepticism, Subjectivity, and the Ordinary. Cambridge: Polity, 2002.

Heidegger, Martin. Being and Time. Translated by John Macquarrie and Edward Robinson. New York: Harper and Row, 1962.

Kripke, Saul A. Wittgenstein on Rules and Private Language: An Elementary Exposition. Oxford: Blackwell, 1982.

Kuhn, Thomas. The Structure of Scientific Revolutions, 3rd ed. Chicago: University of Chicago Press, 1996.

Lovibond, Sabina. Realism and Imagination in Ethics. Oxford: Blackwell, 1983.

Luria, A. R. Cognitive Development: Its Cultural and Social Foundations. Edited by Michael Cole. Translated by Martin Lopez-Morillas and Lynn Solotaroff. Cambridge: Harvard University Press, 1976.

MacIntyre, Alasdair. After Virtue: A Study in Moral Theory. London: Duckworth, 1985.

Maddy, Penelope. The Logical Must: Wittgenstein on Logic. Oxford: Oxford University Press, 2014.

Malcolm, Norman. Ludwig Wittgenstein, a Memoir. London: Oxford University Press, 1962.

McDowell, John. "Meaning and Intentionality in Wittgenstein's Later Philosophy." In The Wittgenstein Legacy, edited by Peter A. French, Theodore E. Uehling, and Howard K. Wettstein, 40-52. Notre Dame: University of Notre Dame Press, 1992.

—. Mind and World. Cambridge: Harvard University Press, 1994.

- "Wittgenstein on Following a Rule." In Essays on Wittgenstein's Later Philosophy, edited by Crispin Wright, 324-63. Dordrecht: Reidel, 1984.

McGinn, Marie. "The Real Problem of Others: Cavell, Merleau-Ponty, and Wittgenstein on Scepticism About Other Minds." European Journal of Philosophy 6, no. 1 (1998): 45-58.

Mulhall, Stephen, ed. The Cavell Reader. Cambridge: Blackwell, 1996.

- Stanley Cavell: Philosophy's Recounting of the Ordinary. Oxford: Clarendon Press, 1994.

Prytz-Johanesen, J. The Maori and His Religion in Its Non-Ritualistic Aspects. København: I Commission hos E. Munksgaard, 1954.

Putnam, Hilary. "Philosophers and Human Understanding." In Realism and Reason: Philosophical Papers, vol. 3, 184-204. Cambridge: Cambridge University Press, 1983.

Quine, W. V. O. "Epistemology Naturalized.” In Ontological Relativity and Other Essays, 69-90. New York: Columbia University Press, 1969.

- "Two Dogmas of Empiricism.” In From a Logical Point of View, 20-46. Cambridge: Harvard University Press, 1953.

- The Ways of Paradox and Other Essays. Cambridge: Harvard University Press, 1976.

Quine, W. V. O., and J. S. Ullian. The Web of Belief. New York: Random House, 1970.

Rhees, Rush, ed. Recollections of Wittgenstein. Totowa, NJ: Rowman and Littlefield, 1981.

- Rush Rhees on Religion and Philosophy. Edited by D. Z. Phillips and Mario von der Ruhr. Cambridge: Cambridge University Press, 1997. 
Risjord, Mark. Philosophy of Social Science: A Contemporary Introduction. New York: Routledge, 2014.

Rorty, Richard. Philosophy and the Mirror of Nature. Princeton: Princeton University Press, 1979.

Roth, Paul A. "Beyond Understanding: The Career of the Concept of Understanding in the Human Sciences." In The Blackwell Guide to the Philosophy of the Social Sciences, edited by Stephen P. Turner and Paul A. Roth, 311-33. Oxford: Blackwell, 2003.

- "The Philosophy of Social Science in the Twentieth Century: Analytic Traditions: Reflections on the Rationalitätstreit." In The Sage Handbook of the Philosophy of Social Sciences, edited by Ian Jarvie and Jesus Zamora-Bonilla, 103-18. London: Sage, 2011.

Rumsey, Alan. "The Personification of Social Totalities in the Pacific." Journal of Pacific Studies 23, no. 1 (1999): 48-70.

Sahlins, Marshall. How "Natives” Think: About Captain Cook, for Example. Chicago: University of Chicago Press, 1996.

—. Islands of History. Chicago: University of Chicago Press, 1987.

- "The Return of the Event, Again: With Reflections on the Beginnings of the Great Fijian War of 1843-1855 Between the Kingdoms of Bau and Rewa.” In Clio in Oceania: Toward a Historical Anthropology, edited by Aletta Biersack, 37-99. London and Washington, DC: Smithsonian Institution Press, 1991.

Spiro, Melford E. "Is the Western Conception of the Self 'Peculiar' Within the Context of the World Cultures?.” Ethos 21, no. 2 (1993): 107-53.

Stern, David. "The Practical Turn." In The Blackwell Guide to the Philosophy of the Social Sciences, edited by Stephen P. Turner and Paul Roth, 185-206. Oxford: Blackwell, 2003.

- "Practices, Practical Holism, and Background Practices." In Heidegger, Coping, and Cognitive Science: Essays in Honor of Hubert L. Dreyfus, edited by Mark Wrathall and Jeff Malpas, 53-69. Cambridge: MIT Press, 2000.

Strathern, Marilyn. The Gender of the Gift. Berkeley: University of California Press, 1988.

Stroud, Barry. “The Significance of Naturalized Epistemology.” Midwest Studies in Philosophy 6, no. 1 (1981): 455-72. 1984.

. The Significance of Philosophical Scepticism. Oxford: Clarendon Press,

- "Understanding Human Knowledge in General." In Knowledge and Skepticism, edited by Marjorie Clay and Keith Lehrer, 33-50. Boulder: Westview Press, 1989.

Tambiah, Stanley J. Magic, Science, Religion, and the Scope of Rationality. Cambridge: Cambridge University Press, 1990.

Taylor, Charles. The Ethics of Authenticity. Cambridge: Harvard University Press, 1991.

—. Modern Social Imaginaries. Durham: Duke University Press, 2003.

- Philosophical Arguments. Cambridge: Harvard University Press, 1995.

- Philosophy and the Human Sciences. Cambridge: Cambridge University Press, 1985.

—. A Secular Age. Cambridge: Harvard University Press, 2007. 


\section{Bibliography}

Sources of the Self: The Making of the Modern Identity. Cambridge: Harvard University Press, 1989.

Viveiros de Castro, Eduardo. "Exchanging Perspectives: The Transformation of Objects into Subjects in Amerindian Ontologies." Common Knowledge 10, no. 3 (Fall 2004): 463-84.

Waismann, Friedrich. Wittgenstein and the Vienna Circle. Edited by B. McGuinness and J. Schulte. Oxford: Blackwell, 1979.

Willerslev, Rane. Soul Hunters: Hunting, Animism, and Personhood Among the Siberian Yukaghirs. Berkeley: University of California Press, 2007.

Williams, Michael. Unnatural Doubts: Epistemological Realism and the Basis of Skepticism. Cambridge: Blackwell, 1996.

Winch, Peter. The Idea of a Social Science and Its Relation to Philosophy. London: Routledge, 1958.

. "Understanding a Primitive Society." American Philosophical Quarterly 1 (1964): 307-24.

Wittgenstein, Ludwig. Blue and Brown Books, 2nd ed. Oxford: Blackwell, 1969.

- Culture and Value. Edited by G. H. von Wright. Oxford: Blackwell, 1998.

. Lectures \& Conversations on Aesthetics, Psychology, and Religious Belief. Edited by Cyril Barrett. Berkeley: University of California Press, 1966. . On Certainty. Edited by G. E. M. Anscombe and G. H. von Wright. New York: Harper, 1972.

- Philosophical Investigations. Translated by G. E. M. Anscombe. Oxford: Blackwell, 1997.

. Philosophical Occasions, 1912-1951. Edited by James C. Klagge and

Alfred Normann. Indianapolis: Hackett, 1993.
. Tractatus Logico-philosophicus. Translated by D. F. Pears and B. F. McGuinness. London: Routledge \& Kegan Paul, 1974.

Zahle, Julie. "Methodological Anti-Naturalism, Norms, and Participant Observation." In Normativity and Naturalism in the Philosophy of the Social Sciences, edited by Mark Risjord, 78-95. New York: Routledge, 2016. 


\section{Index}

animism: Amerindian 112-13;

Yukaghir 108-11

Anscombe, G.E.M. 168-72

anthropology, cultural (social)

$2-3,42$

a priori 4, 6, 7, 26, 29, 35, 37, 58, 167

Aristotle 10

Augustine, St. 163-5, 167

Austin, J.L. 87-8

Azande 53-5

bald naturalism 36

\section{Bildung 36}

Bourdieu, Pierre 70n7

Calvin, John 130

Carnap, Rudolf 23, 59-61

Cavell, Stanley 1-2, 7, 29, 31, 62-4, 75-80; on external world (material object) vs. other minds skepticism 80-3; on human relation to skepticism 137-40; on origin of skepticism 91-9; on possible refutation of skepticism $75-7$, 87-92, 97-8; on truth of skepticism $75,77-8,95-9,100$; see also skepticism

Colbert, Claudette 76

Conant, James 4, 48n52

criteria 87-9; projectability of $62-4$

culture: concept of 8-11

Davidson, Donald 23, 35, 46n36, 59

Descartes, René 63, 116, 130

Diamond, Cora 4, 6, 47n51, 51n86, 56-63, 66-8, 71n $28,72 \mathrm{n} 32$, 72n33, 161n231, 163-70, 174n9, $175 \mathrm{n} 16,175 \mathrm{n} 27,176 \mathrm{n} 32$ disenchantment 104-5, 131, 141

dividual 113-15

Dreyfus, Hubert L. 23-8, 32-4, 46n37, 49n65

Dumont, Louis 146, 171

Dupré, John 13-23, 25-8, 46n34

Durga 169-73

Evans-Pritchard, E.E. 53-6, 70n5, 157n149, 158n170

finitude 77, 83-4, 93, 144-5, 147

Føllesdal, Dagfinn 36n46

Frazer, Sir James 163-5

Gable, Clark 76

Geertz, Clifford 3, 8-10, 11n6, 41, 101, 121-31, 139, 155n102

Goldfarb, Warren 60-1

grammar 61-2, 63-6

Grant, Cary 99

Heidegger, Martin 14, 24, 25, 32, 33, 43, 50n71, 52n89, 75-7, 145, $154 \mathrm{n} 94$

Hepburn, Katherine 99

holism: practical 24-8; theoretical 23-4, 39

human condition $1,76,78$

Hume, David 80, 130

Humean predicament $48 \mathrm{n} 52$

interpretivism 11, 11n6

intimacy 148

Johansen, J. Prytz 119

John Paul II (Karol Józef Wojtyła) 176n31 


\section{Index}

Kant, Immanuel 34, 75, 76, 77, 84, $130,141,147$

Kincaid, Harold 47n52

Kitayama, Shinobu 122, 123, 126

knowledge 20-1

Kripke, Saul 30

Kuhn, Thomas 59, 118

Levi, Primo 72n33

limits (bounds) of sense 32, 34, 58-9

linguistic frameworks 59-60

Lovibond, Sabina 64

Luther, Martin 130

MacIntyre, Alasdair 40

Maddy, Penelope 50n75

Malcolm, Norman 60, 175n20

Markus, Hazel Rose 122, 123, 126

Marx, Karl 40

McDowell, John 10, 15, 33, 35-7, 43, 49n65, 50n71, 50n72, 50n75, 50n76, 51n80, 146

Melanesia 113-15

Merleau-Ponty, Maurice 24, 33, 34

mimesis 109-10, 113

modernity $1,73,103,105-6$

Moore, G.E. 22

myth of the given 29

Nagel, Thomas 77

naturalism: in the philosophy of the social sciences 3-4, 15-17; pluralist naturalism 16

Newton, Isaac 39

New Wittgenstein 4-6

Nietzsche, Friedrich 77, 94

ordinary language $14,16-17,19,39$

paganism 164-5, 167

Palmer, Anthony 150n19

parochialism: empirical $v s$. transcendental 64-6

Pascal, Blaise 130

pictures: use of in religion $168-70$

principle of tolerance 60

Protestant Reformation 102, 107

Putnam, Hilary 60-1, 67, 71n21, 72 n32

Quine, W.V.O. 9, 23, 25, 32, 37, 40, $46 \mathrm{n} 28,48 \mathrm{n} 52,51 \mathrm{n} 82$ relativism see linguistic frameworks religion $163-8$

Rhees, Rush 164, 168, 170, 172

Ricketts, Thomas 161n225

Rorty, Richard 70n2, 71n21, 72n33

Roth, Paul 41, 45n21, 51n86, 52n87

rules 17-19

Russell, Bertrand 169-73

Sahlins, Marshall 158n169, 158n171, 160n207

Sartre, Jean Paul 133, 154n94

Schlick, Moritz 176n36

Searle, John 47n47

second nature $35-7$

self: buffered 102-3, 104-5, 106-8; and ethics 146-7; historicity of 139, 145; modern development of 142-4; porous $103-4,107-8$

Sellars, Wilfrid 29

separateness 98-100, 116-17, 131, 136-8, 141-5, 147-8; repression of $138-9$

skepticism: and gender (sex) 83-5; about meaning 28-31; and modernity $85-7,134-7$; theoretical diagnosis of 74,78 ; therapeutic diagnosis of $74,78,87$

skeptic's procedure 87-90; Cavell's diagnosis of 90-1

space of reasons $35-6$

Spiro, Melford 122-30

Strathern, Marilyn 113-15, 119, $157 \mathrm{n} 162$

Stroud, Barry 47n52, 77, 149n6, 149n10

subtraction story 105-6, 139-40; and politics 146

system of thought $56-8,59,61,69$; see also linguistic frameworks; universe of discourse

Taylor, Charles 1, 2, 50n71, 51n87, 73, 102-8, 131-3, 139-41, 147, 156n116, 156n130, 158n170, $160 \mathrm{n} 211,174 \mathrm{n} 5,176 \mathrm{n} 37$

thick description 2, 3, 41, 42, 43

Tractatus Logico-Philosophicus 4-6, 58-9

truth 72 n $33,164-7,168,173-4$

universe of discourse 79,85 
Viveieros de Castro, Eduardo 112-13, 115, 129

Von Wright, G.H 1-2

Waismann, Friedrich 164, 176n36

Weber, Max 9, 41, 104, 124, 131

Wiggins, David 71n28

Wikan, Unni 127-31

Willerslev, Rane 108-16, 119, 121, 122-4, 129, 159n185, 160n208

Williams, Bernard 71n28

Williams, Michael 74-5, 78, 87, 149n6, 149n10

Winch, Peter 4, 6, 12n17, 14, 18-19, 27-8, 45n20, 46n $37,53-62,140-1$ witchcraft see Azande

Wittgenstein, Ludwig 1-8, 12n15, 13-17, 30, 44n8, 44n11, 45n14, 45n17, 49n66, 50n75, 51n87, 58-9, 65-6, 92, 95, 154n94, 155n100, 156n129, 158n175, 161n237, 163-74, 174n14, 175n20, 175n27, 175n 30 ; interpretation of his work 4-8; on religion 163-9

wonder 167-8, 172-3

Yukaghir people 108-12; hunting 109-12; and reincarnation 110; and soul (ayibi) 110-11 


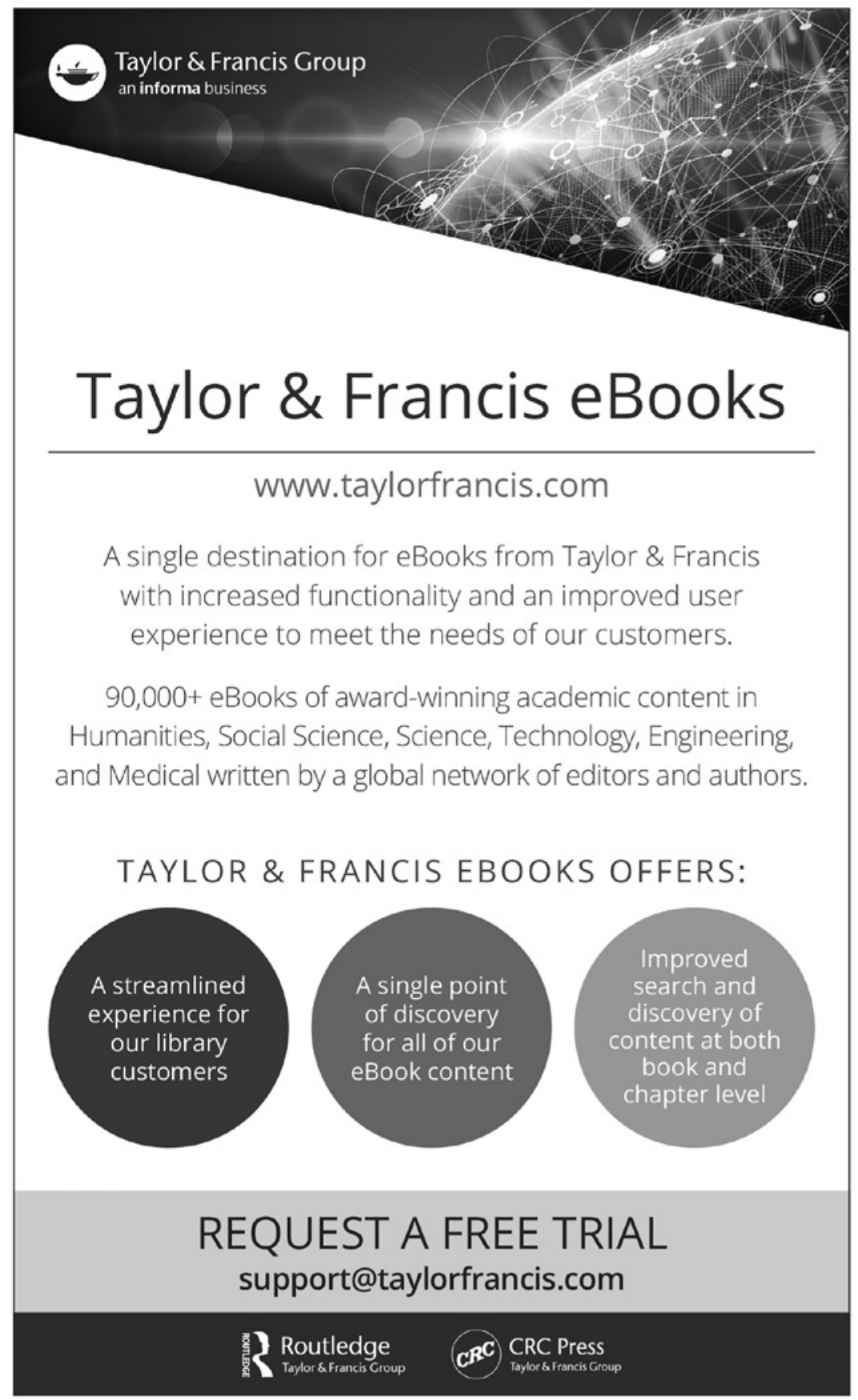

